Portland State University

PDXScholar

$5-19-2000$

\title{
Asiatic Cholera and Dysentery on the Oregon Trail: A Historical Medical Geography Study
}

\author{
Brian Lee Altonen \\ Portland State University
}

Follow this and additional works at: https://pdxscholar.library.pdx.edu/open_access_etds

Part of the Geography Commons, and the United States History Commons Let us know how access to this document benefits you.

\section{Recommended Citation}

Altonen, Brian Lee, "Asiatic Cholera and Dysentery on the Oregon Trail: A Historical Medical Geography Study" (2000). Dissertations and Theses. Paper 4305.

https://doi.org/10.15760/etd.6189

This Thesis is brought to you for free and open access. It has been accepted for inclusion in Dissertations and Theses by an authorized administrator of PDXScholar. Please contact us if we can make this document more accessible: pdxscholar@pdx.edu. 


\section{THESIS APPROVAL}

The abstract and thesis of Brian Lee Altonen for the Master of Science in Geography were presented May 19, 2000, and accepted by the thesis committee and the department.

COMMITTEE APPROVALS:

Martha Works, Chair
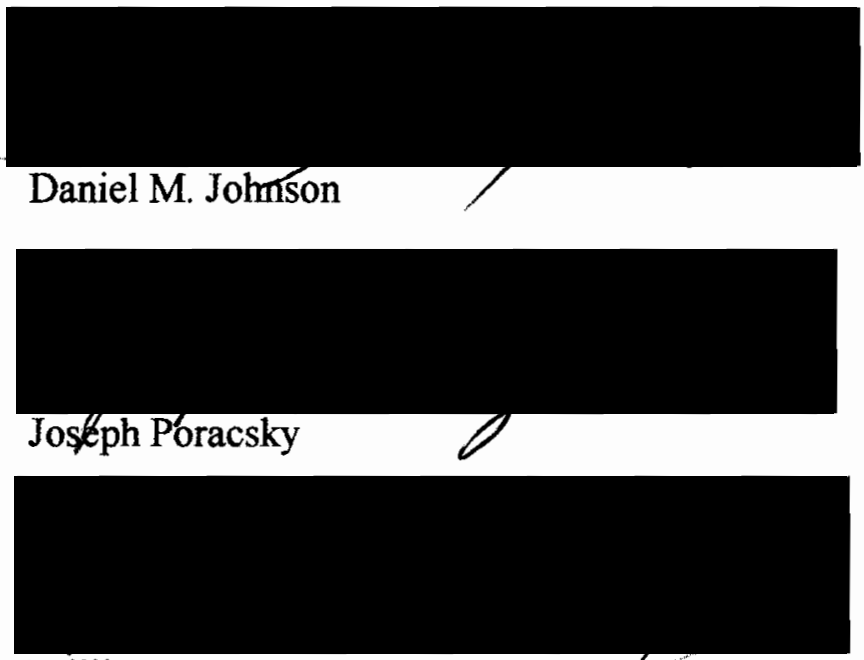

William L. Lang

Representative of the Office of Graduate Studies

DEPARTMENT APPROVAL:

Teresa Bulman, Chair

Department of Geography 


\section{ABSTRACT}

An abstract of the thesis of Brian Lee Altonen for the Master of Science in Geography presented May 19, 2000.

Title: Asiatic Cholera and Dysentery on the Oregon Trail: a Historical Medical Geography Study.

Two disease regions existed on the Oregon Trail. Asiatic cholera impacted the Platte River flood plain from 1849 to 1852 . Dysentery developed two endemic foci due to the decay of buffalo carcasses in eastern and middle Nebraska between 1844 and 1848, but later developed a much larger endemic region west of this Great Plains due to the infection of livestock carcasses by opportunistic bacteria.

This study demonstrates that whereas Asiatic cholera diffusion along the Trail was defined primarily by human population features, topography, and regional climate along the Platte River flood plain, the distribution of opportunistic dysentery along the Trail was defined primarily by human and animal fitness in relation to local topography features. By utilizing a geographic interpretation of disease spread, the Asiatic cholera epidemic caused by Vibrio cholerae could be distinguished from the dysentery epidemic caused by one or more species of Salmonella or Campylobacter. In addition, this study also clarifies an important discrepancy popular to the Oregon Trail history literature. "Mountain fever," a disease typically associated with Rocky Mountain Spotted Fever, was demonstrated 
to be cases of fever induced by the same bacteria responsible for opportunistic dysentery.

In addition, several important geographic methods of disease interpretations were used for this study. By relating the epidemiological transition model of disease patterns to the early twentieth century sequent occupance models described in numerous geography journals, a spatially- and temporally-oriented disease model was produced applicable to reviews of disease history, a method of analysis which has important applications to current studies of disease patterns in rapidly changing rural and urban population settings. 
ASIATIC CHOLERA AND DYSENTERY ON THE OREGON TRAIL:

A HISTORICAL MEDICAL GEOGRAPHY STUDY

\author{
by \\ BRIAN LEE ALTONEN
}

A thesis submitted in partial fulfillment of the requirements for the degree of

\author{
MASTER OF SCIENCE \\ in \\ GEOGRAPHY
}

Portland State University

2000 


\section{ACKNOWLEDGEMENTS}

I would like to thank the following geography professors: Larry Price for introducing me to the field of geography and providing me the encouragement needed to research historical medical geography; Gil Latz for his teachings on Pacific Rim geography, which helped me to draw some important conclusions about disease behaviors along the West Coast during the 1800s; Rick Vrana for his help with the GIS; and Barbara Brower and Martha Works for encouraging me to explore the geographical journals, research which led to my writings on sequent occupance.

My reviews of the history of medicine and medical geography came with the help and support of numerous librarians at several local history, history of medicine and biomedicine libraries. Librarians at Oregon Health Sciences University in particular brought to my attention a number of important resources which enabled me to review important nineteenth century documents relevant to the American cholera epidemics and medical geography history. The History of Medicine Collection at the New York Academy of Medicine, New York City, New York, provided me with access to many of these early nineteenth century medical climatology and medical topography publications, not to mention several history of medicine book dealers. 
Librarians at the Oregon Historical Society brought to my attention important documents relevant to Oregon Trail history. Assisting me greatly during this part of my research was Kris White (now residing in New Mexico), Sieglinde Smith, Elizabeth Winroth, Steven Halberg, Todd Welch, John Mead, and James Strassmaier. Deborah Confer of the Lane County Historical Society in Oregon informed me of a diary most important for this study, in which "water cure" was practiced by a female hydropath.

I am most thankful to the National College of Naturopathic Medicine and their librarian Friedhelm Kirchfeld for allowing me to handle and borrow a number of fragile historical medical documents.

Several graduate students and close friends deserve mention as well, in particular Laura Waggoner who assisted me in some of the technical aspects of my work, Michaela Seeger for pointing out the application of Christaller's writings to my work, and Terri Adams who helped me through my many writings, their final proofreadings, and critiquing the numerous figures and illustrations I developed for this work.

Finally, I am most grateful to the staff of the Interlibrary Loan Department at Portland State University Library and Oregon Historical Society for spending innumerable hours handling my requests for scarce medical publications over the years. 
TABLE OF CONTENTS

PAGE

ACKNOWLEDGEMENTS

LIST OF TABLES $\ldots \ldots \ldots \ldots \ldots \ldots \ldots$ vi

LIST OF FIGURES $\ldots \ldots \ldots \ldots \ldots \ldots$. . . . . . . . . . . .

CHAPTER

I INTRODUCTION $\ldots \ldots \ldots \ldots \ldots \ldots \ldots \ldots$

Defining "Cholera" . . . . . . . . . . . . . 2

A Review of the Literature. . . . . . . . . . . . . 4

Methodology . . . . . . . . . . . . . . 9

II DISEASE GEOGRAPHY $\ldots \ldots \ldots \ldots \ldots \ldots \ldots$

Disease Ecology . . . . . . . . . . . . . . 18

Sequent Occupance and Disease Patterns . . . . . . . 23

Disease Diffusion . . . . . . . . . . . . . . 29

Conclusion . . . . . . . . . . . . . 41 
PAGE

III ASIATIC CHOLERA AND DYSENTERY ECOLOGY . . . . . 43

Vibrio Biology . . . . . . . . . . . . . 45

Dysentery Ecology . . . . . . . . . . . . . 56 56

Salmonella . . . . . . . . . . . . . . 5 57

Campylobacter . . . . . . . . . . . . 59

Summary . . . . . . . . . . . . 61

IV ASIATIC CHOLERA AND DYSENTERY GEOGRAPHY . . . . 63

Asiatic Cholera Geography. . . . . . . . . . . . 64

Biogeography . . . . . . . . . . . . . . 67

Physical Geography . . . . . . . . . . . . . . 70

Human Geography and Hierarchical Diffusion. . . . 80

Summary . . . . . . . . . . . 83

Dysentery Geography . . . . . . . . . . . . . . . 85

Two Disease Regions . . . . . . . . . . . . . . . . . 87

V THE OREGON TRAIL AND ASIATIC CHOLERA . . . . . . . 91

The Asiatic Cholera Region . . . . . . . . . . . . . . 96

The Platte River Floodplain Epidemics . . . . . . . 97

Fort Laramie and the Rocky Mountains . . . . . . 99

Trail Deaths in the Diaries. . . . . . . . . . . 105

Summary . . . . . . . . . . . . . . 108 
PAGE

VI OREGON TRAIL DYSENTERY 109

Dysentery and "Cholera" . . . . . . . . . . . . . 109

The Eastern Nebraska Epidemic . . . . . . . . . . 110

The Platte River Fork Epidemic . . . . . . . . . 112

The Wyoming Epidemic . . . . . . . . . . . 114

Trading Post- and Fort-generated Epidemics . . . . 117

Martha Read's Diary Notes . . . . . . . . . . . 121

The Snake River Epidemic . . . . . . . . . . . . . 123

The Dalles-Umatilla Epidemic . . . . . . . . . . . 124

Dysentery and Mountain Fever . . . . . . . . . . . 126

"Cholera" in Portland . . . . . . . . . . . . . . . . 129

Summary ..................... 130

VII CONCLUSION ................... 132

BIBLIOGRAPHY $\ldots \ldots \ldots \ldots \ldots \ldots$

APPENDICES

A Glossary . . . . . . . . . . . . . . 157

B Vibrio Cholerae, Food Stuffs and Other Growing Surfaces 163

C A Historical Review of Asiatic Cholera Epidemiology . . 168

D The Geography of Other Forms of Diarrhea . . . . . . 177

E Oregon Trail Demography . . . . . . . . . . . . 188

F Rocky Mountain Spotted Fever . . . . . . . . . . . 211

G Oregon Trail Maps . . . . . . . . . . . . 218 


\section{LIST OF TABLES}

TABLE

PAGE

I. Epidemiological Transitions Based on Meyer's Sequent

Occupance Model . . . . . . . . . . . . . . . . . . 26

II. Epidemiological Transitions Based on Meyer's Sequent

Occupance Model, Updated to Include Contemporary

Disease Patterns . . . . . . . . . . . . . . . . . . . . . . . . . . 28

III. Environmental Preferences of Vibrio cholerae . . . . . . . 47

IV. Principle Reservoirs for Vibrio species associated with

Food-Borne Diseases in the United States . . . . . . . . 49

V. Foods Associated with Vibrio Cholerae Cases in the United States, 1972 to Present . . . . . . . . . . . . . . .52

VI. The Human Ecology and Geography of "Cholera" . . . . . . 90

VII. Oregon Trail Deaths . . . . . . . . . . . . . . . . . . . . 98 


\section{LIST OF FIGURES}

FIGURE

PAGE

1. Chains of Disease Transmission . . . . . . . . . . . . 20

2. The Sequent Occupance of a Developing Tract of Land . . . 24

3. Innovation and Hierarchical Diffusion . . . . . . 30

4. Type I or "Pioneer" Disease Diffusion Model: the Migration of Asiatic Cholera into the United States in 1832 and 1833 . . 32

5. Type II or "Mixed" Disease Diffusion Model: the Migration of Asiatic Cholera into the United States in 1848 and 1849 . . 33

6. The Mixed Contagious and Hierarchical Diffusion Behavior of an Iceland Measles Epidemic . . . . . . . . . . . . . 35

7. The Diffusion of Asiatic Cholera and Dysentery Between Various Population Settings $\quad$. . . . . . . . . . . . . . . . . . 38

8. The Asiatic Cholera Niduses in India and Southeast Asia . . . 65

9. Vibrio cholerae in the Natural and Human Ecological Settings . . . . . . . . . . . . . . . 68

10. Cholera Deaths in Trinity, England in 1848, Relative to Proximity to Stream, Number of People per Acre, and Average Mortality per Year of Areas Defined by Elevation above Stream . . . . . . . . . . . . . . . . . 73

11. The Cholera Pandemic of 1842 to 1862 . . . . . . . . . 81

12. Opportunistic Dysentery Ecology in the Human-Environment Setting 
13. Cholera and Dysentery Trail Deaths Relative to Forts, Trading Posts and Missions, ca. 1850-1853 . . . . . . . . . 88

14. Possible Cholera Routes to the West Coast, ca. 1850-1853 . . . 89

15. The Oregon Trail . . . . . . . . . . . . . . . . 92

16. The Overland Migration Populations from 1836 to 1860 . . . . 93

17. Migrations to each State by Overland Routes, by Year . . . . . 94

18. Fremont's Exploration of the Far West, 1842 and 1843 . . . . . 101

19. Changes in Sunrise Temperature Relative to Elevation as Recorded by Fremont in 1842 and 1843 . . . . . . . . . . . 102

20. Changes in Sunset Temperature Relative to Elevation as Recorded by Fremont in 1842 and 1843 . . . . . . . . . . . 103

21. Number of Human Graves passed each day along the Oregon Trail by Cecelia Adams and Parthenia Blank in 1852 . . 107

22. Graves and Animal Carcasses per mile traveled along the Oregon Trail, Martha Read, 1852 . . . . . . . . . . . . . 122

23. Trail Sickness Relative to Graves and Carcasses, Martha Read, 1852 . . . . . . . . . . . . . . . 125 


\section{CHAPTER I}

\section{INTRODUCTION}

Two epidemics developed on the Oregon Trail between 1844 and 1852. A severe form of diarrhea known as dysentery took its toll on pioneers making their way to Oregon in 1844 and remained an Oregon Trail problem until the arrival of Asiatic cholera in 1849. From 1849 to 1852, Asiatic cholera turned Platte River flood plain into an epidemic region. Beginning in 1850, a new dysentery epidemic developed west of the Great Plains due to the decaying animal carcasses produced the year before.

From 1850 to 1852 , those fortunate enough to avoid the Asiatic cholera epidemic to the Great Plains were in turn exposed to dysentery as they began their final ascent into the Rocky Mountains. By 1853, the last of the immigrants to arrive in Portland, Oregon, brought this disease with them. Both the Asiatic cholera and dysentery epidemics of the Oregon Trail are referred to as "cholera" in the historical documents. This thesis details the differences between these two epidemics, providing geographic reasons underlying the development of two distinctly different epidemic regions between 1845 and 1852 . 


\section{DEFINING "CHOLERA"}

The problem of distinguishing Asiatic cholera from dysentery and other forms of diarrhea is a recurring problem in medical history. According to Celsus Aurelianus (ca. 160 A.D.), the Latin term cholera refers to "bile-flow", a condition in which excessive amounts of fluids, often bile-colored (yellow or black), are discharged from the body (Drabkin 1950, 417). This definition for "cholera" changed little over the next 1500 years.

By the mid-1600s, certain forms of diarrhea were often referred to as "cholera morbus" or "biliary disease" (Swan 1753, 22), due to the suspected cause for their more deadly nature. In 1669 and 1676, this "cholera morbus" took on an "extremely rare" form when it struck London. Described by seventeenth century physician Thomas Sydenham as "a discharge of vitiated humours by stool, with great difficulty and pain ... a small and irregular pulse ... coldness of the extremities, and other like symptoms, which greatly terrify the attendants, and often destroy the patient in twenty four hours" (ibid 147), this epidemic is interpreted by medical historians as one the first introductions of Asiatic cholera to Western Europe (Chamber 1938, 17; Pollitzer 1959, 14).

Attempts to distinguish the more fatal Asiatic cholera from various less fatal forms of diarrhea led to the use of the terms "Cholera Maligna" to refer to the epidemic of India and its surrounding countries and "English cholera" to refer to the cholera morbus typical of Europe (Leonard 1850,429). With the publication of Diseases of India by Curtis in 1807, attention was drawn to the important geographic differences that existed between these two diarrhea diseases. As a 
result, the cholera of India became known as a "spasmodic" form of a diarrhea considered unique to its region.

During the early nineteenth century, this geographical distinction drawn between the fatal and non-fatal forms of cholera changed as Asiatic cholera made its way to Western Europe and became highly fatal. By the late 1820 s, this cholera spread throughout much of the rest of Western Europe and parts of the Soviet Union, reaching the United States in 1832. By the mid 1800s, this Asiatic form of cholera became the first rapidly spreading pandemic disease (Hirsch 1883-6, 394, Pollitzer 1959).

Unable to distinguish "English Cholera" from Asiatic cholera, doctors often referred to these and other deadly forms of diarrhea simply as "cholera," relying on terms like "cholera morbus," "cholera spasmodica," "cholera maligna," and "cholera infantum" to differentiate them from each other. In the United States "cholera morbus" was the name popularized for the Asiatic cholera which made its way into this country in 1832 (Sherrill 1835). Due to the fatality of this epidemic, the second epidemic of Asiatic cholera which arrived in 1848 was known as "malignant cholera" (Anonymous 1855). With the identification of the bacterium Vibrio cholerae as the cause for Asiatic cholera by Robert Koch in 1883 (Koch 1884), this confusion between Asiatic cholera and the various forms of severe diarrhea and dysentery subsided, becoming a forgotten part of medical and medical geography history. 


\section{A REVIEW OF THE LITERATURE}

The need for a study of the "cholera" regions of the Oregon Trail emerged several decades ago when a number of confusing statements were published about "Plains cholera" and other forms of Oregon Trail "cholera" in the historical writings. Both Asiatic cholera and dysentery were typically referred to as "cholera" in popular medical writings and their different geographic behaviors often ignored, making it difficult to distinguish them from each other during the course of a review of these writings. For example, in an extensive review of Oregon Trail history by F. G. Young (1900), confusing statements were made in regard to 1849 Trail pioneer Chenoweth's reflections (1883) about his overland experience. During his overland migration, Chenoweth noted the deadly form of cholera to be primarily a disease of "the flat prairie east of and about Fort Laramie, [Wyoming]." A later review of the same by Young led him to conclude that "the dreadful scourge of cholera" occurred during the years of 1849,1850 and 1852 , followed by mention of another deadly Trail epidemic which occurred in 1847 and the following conclusion: "[e]xcepting in these cholera years there were only infrequent cases of mountain fever and forms of dysentery that were developed in the alkali regions of the mountains" (ibid 364).

A quarter of a century later, Oregon historian Leslie Scott's review of the Trail diaries and related history writings, which included a review of Young's article, led Scott to conclude "[t]he worst years of the cholera were 1847, 1849, 1850 , and 1852. Sickness lasts usually but a day," a conclusion followed by mention of George Himes's writings about the 1849 "plains cholera" experience (Himes 1909, 259) and a listing of trail fatalities published in the local newspaper, 
the Oregon Statesman, in December 1852. These observations led Scott to conclude "[m]ost of the deaths are from "plains cholera"” (Scott 1924, vol. 3, 258). Unable to differentiate between the deadly Asiatic form of this disease and the more prevalent endemic form of diarrhea common to the Trail known as dysentery, the question about whether or not "cholera" did or could spread to Oregon remained an unanswered question.

Still, historians are not solely to blame for this confusion between Asiatic cholera and the other "cholera" diseases. Another reason for this misinterpretation of these various forms of "cholera" behavior relates to the changing definition of the disease by mid-nineteenth century epidemiologists and physicians. Without knowledge of the bacterial cause for disease, medical professionals interpreted these various forms of diarrhea as the same disease manifesting differently from region to region due to changes in local climatic and physical geographic features. Such reasoning had in fact been the primary reason for the growing popularity of California physician and climatologist Thomas Logan's claim that Asiatic cholera could not strike California due to its healthy climate (Logan 1851, 1852), the debates about which published in the medical literature led to strong support for both sides of this argument about the healthiness of California life (Leonard 1850; Stillman 1851; Hatch 1855; for more on this history see Thompson 1971). Ten years later, another misunderstanding about the differences between dysentery and Asiatic cholera history led San Francisco physician and medical journal editor Henry Gibbons to mention ' 1847 ' as a "malignant cholera" year in his note about the epidemics of "the Atlantic cities" in "1847, 1849 and 1850" (Gibbons 1865), a 
reading most likely interpreted by later researchers as a possible Asiatic cholera year.

By 1900 , effective quarantine practices and the changing nature of the organism enabled the United States to experience its last official Asiatic cholera epidemic years (Blake 1994). No attempts have since been made to clarify earlier misconceptions published about these underlying differences between the Asiatic cholera and other diarrhea or "cholera" epidemics in regard to Oregon State and the Oregon Trail experience. As Asiatic cholera became a disease of the past to much of North American history, its distinction from other forms of deadly diarrhea was equally forgotten.

Between 1945 and 1946, issues related to these confusing statements about "cholera" resurfaced once again when Oregon physician Olof Larsell began his review of the State's medical history (Larsell 1946). Relating the eastern Oregon "cholera" epidemic of 1852 to the Asiatic cholera epidemics, Larsell concluded that any inferences of a possible introduction of Asiatic cholera to the Oregon Trail in 1852 were made in error and that these references to "cholera" more likely pertained to one or more severe forms of dysentery (Larsell 1947, 589).

In spite of Larsell's attempt to clarify the history of the Asiatic cholera epidemic along the Oregon Trail and in eastern Oregon for the mid-nineteenth century, subsequent writers continued to refer to these two diseases as a single epidemic in the re-telling of the Oregon trail story. In a post-script for the transcribed diary of twenty-two year old emigrant John Callison, for example, it is noted that Callison died from an undefined form of "cholera" just prior to reaching La Grande in northeastern Oregon in 1852 (Callison 1959), a statement republished 
one year later by Briggs (1960). In a more recent article about Asiatic cholera, both forms of "cholera" were inadvertently inferred by the inclusion of the term "Bloody Flux" in its title, a term more reflective of dysentery (Milikien 1996).

To some historians, these writings left open the possibility that Asiatic cholera made its way to the Pacific Northwest by the Oregon Trail during the early 1850s, a belief that conflicts with the writings of most Trail historians who consider Oregon Trail Asiatic cholera to be a disease primarily of the Platte River valley. For example, noted Trail historian Merrill Mattes wrote "this virulent plague raged intermittently along the Platte River Road and its approaches during the climax years of the Gold Rush" (Mattes 1969, 83-84), making no further mention of Asiatic cholera as a disease west of the Rocky Mountains. In a more focused review of trail medical history and geography, Rieck noted the possibility that the "cholera" noted along the western half of the Trail were possibly "incorrect diagnoses, diseases with symptoms similar to cholera or possibly cases caused by east bound travelers" (Rieck 1991, 14).

So what form of "cholera" was this Trail disease? Other historians have suggested that this diffusion of Asiatic cholera was not limited to the Platte River flood plain, but able to make its way to the West Coast by way of the much warmer southern and southwestern routes through Utah, Texas, New Mexico, and Nevada (May 1950, Rosenberg 1962), an interpretation of the disease migration history matched by earlier physicians (Peters 1871; Peters and McClellan 1875; Stille 1885; Chambers 1938). A brief passage by Rieck suggested these scattered cases of cholera west of the Platte River to be "diseases similar to cholera or possibly cases caused by eastbound travelers" (Rieck 1991, 14). However, Asiatic cholera 
was unlikely to migrate to the Oregon Trail west of Fort Laramie by east-bound travelers since the disease had not struck the west coast until its arrival by way of the southern California Trail route to Sacramento and San Francisco during the mid-Winter of 1851 to 1852 (Logan 1851,1852 ). Therefore, except for the writings of several historians, the general impression about Asiatic cholera and Oregon Trail history has been that this disease failed to penetrate the Pacific Northwest, but instead made its way to California by way of one or more of the numerous overland trail routes as well as heavily traveled routes through Mexico, Panama, and by boats traveling around South America and along the eastern half of the Pacific Rim, where it remained throughout the remaining epidemic years.

In spite of numerous attempts to put to rest the notion that Asiatic cholera could have made its way to Oregon on the Oregon Trail during the 1850 s, questions about the "cholera" which struck the west coast during the nineteenth century remain unanswered as do the different meanings of the word "cholera" in the Oregon Trail literature. Such an uncertainty about the different Midwest, Far West, and Northwest "cholera" epidemics is best demonstrated by a comment made by editor Bert Webber in his forward to Reverend Edward Evans Parrish's Oregon Trail diary. Parrish diagnosed his own "cholera" condition while crossing the Great Plains in 1844, nearly five years before the return of Asiatic cholera to the United States and its subsequent introduction to the Oregon Trail. Parrish's self-diagnosis led Webber to ask "we wonder if Parrish's own illness, that dragged on for many weeks, might have been cholera? He mentions being so weak he could hardly keep his daily notes. He does not mention riding in the wagon thus we presumed he 'toughed it out' and walked. Cholera killed thousands" (Webber 
1988, 8). This research demonstrates that through a geographic interpretation of these diseases and their diffusion processes, two distinct epidemic regions can be defined for the Oregon Trail where either Asiatic cholera or an opportunistic form of dysentery was the fatal form of diarrhea.

\section{METHODOLOGY}

This study of Oregon Trail disease geography begins with a review of disease geography. The disease ecology model defined by medical geographer Jacques May is covered, along with several biogeographic interpretations of endemic and epidemic disease patterns based on the ecological and migration behaviors of animal hosts and vectors. This same chapter then applies Whittlesey's sequent occupance model to how particular disease patterns change over time within a given region and why specific diseases fail to erupt in a region until the right human geographic conditions exist. Finally, several of the more commonly employed disease diffusion models are discussed, emphasizing their applicability to researching epidemic activity within different population settings.

The review of disease geography is followed by a chapter describing the microbiology of disease-causing organisms or pathogens relevant to the Oregon Trail epidemics. The Vibrio cholerae Classical responsible for Asiatic cholera is described, followed by brief discussions of the several opportunistic microorganisms responsible for Oregon Trail dysentery epidemics.

The diffusion processes of Asiatic cholera and opportunistic dysentery are then reviewed in detail, with a significant part of this chapter based largely on the historical and modern epidemic studies published about the ecology of Vibrio 
cholerae Classical, the organism responsible for Asiatic cholera, and the geographic conditions underlying its ability to manifest in endemic and epidemic disease forms. Such a review of how diseases like Asiatic cholera were interpreted geographically during the nineteenth century provides important insights into some of the more modern epidemiological approaches to disease interpretation, since early studies of disease often focused on the spatial diffusion of the disease itself, rather than just on the disease-causing organism or pathogen and its victims. This work begins with the assumption that past Asiatic cholera and dysentery diffusion behaviors were similar to those of their modern epidemics, in turn allowing a number of physical and human geographic conclusions to be drawn about how each of these diseases diffused along the Oregon Trail.

In the next two chapters of this thesis, the different ecological and geographic interpretations of these diseases are then applied to the "cholera" reports of the Oregon Trail. First detailing the behavior of Asiatic cholera, followed by a review of the two bacteria suspected to be the cause for Oregon Trail dysentery. Other potential causes for the dysentery and/or diarrhea experience of the Trail are reviewed in the Appendices.

Some of the most important historical contributions to this aspect of Trail medicine reviewed for this work include the work of Olch (1985) and Mattes (1969; see esp. "Chapter III. Elephants of the Platte"). To put this work into perspective with studies already published about epidemics in the Far West, Boyd's - writings are important to note in that they portrayed the Oregon setting and its disease patterns in the years just prior to and during the peak Oregon migration years, especially with regard to Fort and Native American disease history (Boyd 
1975a, 1975b, 1999). One of the most comprehensive reviews of Oregon medical history used for this study was that of Medical historian and physician Olof Larsell (1947).

Reviewing the Trail diaries was the most important part of this research. Locating Trail-related materials for this study began with Overland Passages, a bibliographic review of Trail diaries, letters, reminiscences, and assorted other Trail-related documents in possession of the Oregon Historical Society (OHS) (White and Cuthill 1993). Two other bibliographies on Trail diaries important to this work were Platte River Road Narratives by Trail historian Merrill Mattes (1988) and John Townley's The Town West ... (1988).

Important to note about this phase of the research process is the value of reviewing historical writings about the Trail. At times it was difficult to differentiate trail diaries from reminiscences or recollections. The information provided by each about similar events along the trail varied greatly, including their statistical representations of what happened. Therefore, the trail diaries and reminiscences perused for this work were quite numerous (ca. 180-200), and those considered most important to this work detailed at great lengths in this thesis (about 30). The major requirement for selecting trail diaries for this work was that the writing had to be the actual diary, or appear to be transcribed or published from the actual work, basing this qualifier on the method by which the Trail story was presented (i.e. short succinct stories penned on the Trail versus lengthier, often modified stories told in much longer form, with numerous adjectives and artistic prose in the months to years that followed). 
Diaries written by doctors were first reviewed in search for medical authenticity and detailed observations, for example the notes penned by Dr. Reuben Knox for 1849 (Turner 1974), McKinstry for 1850 (McKinstry 1975), and Dr. John Hudson Wayman for 1852 (Todd 1971). Other useful trail diaries were transcribed from original copies and footnoted by historian Bert Webber, several of which were most valuable to this study $(1988,1994,1997)$.

Many trail diaries available for review are revisions of actual diaries, often edited during the initial writing process (a recollection) and a second time by the publisher before publication. For example, Charles Glass Gray, a well-educated writer and later editor of numerous diaries, had his own diary published post-humously, which due to his educated background provides excellent details about the California Trail experience (Gray 1976). A similar review of the Oregon Trail experience is that of Reverend William Thornton (1849), which was reliable in its detail but still perhaps edited or retold for final publication. One of the more popular writings of the Trail experience often cited is Life on the Plains and Among the Diggings by Alonzo Delano. Intended for sale as a popular book, Delano's book seems fairly reliable but has is limitations due to the lengthy narratives and periods of story-telling he interspersed throughout his writings, a condition atypical of the more succinct trail diaries penned solely on the trail.

Important reminiscences or recalls of the trail experience were published in the Transactions of the ... Oregon Pioneer Association, Portland, an annual report published from 1873 to 1925 . These reports typically included transcripts of the speeches given each year. Many are reminiscences instead of actual observation-based notes. In a few cases these Transactions included what appear 
to be transcripts of actual trail diaries, some of which may have been re-composed from a particular family's diary or the like, and may or may not consist of actual recollections of the Trail experience.

It is also important to note that certain reviews and reminiscences published long after the trail experience should be avoided for this type of study, due to the rapid changes in medical history and disease interpretation which took place between the early Trail years covered by this thesis and the years following the Civil War when a number of diaries were actually penned. Recollections of the trail experience penned by people during the late nineteenth century were produced at a time when the bacterial theory for disease was finally accepted, and so may contain some text related to the more "modern" view for disease and its related sanitation issues, impressions less likely to have been existed along the trail. For many of the writings in Transactions, for example, the bacterial theory for disease had not yet been documented during the first publication years of this series. For this reason, we find a change in the interpretation of the two forms of Trail "cholera" (and thus the confusion about the definition for this disease as detailed throughout this writing). This suggests that with the acceptance of the bacterial theory for disease by 1885 , any Transactions articles or reminiscences thereafter published may leave the reader with some interpretation problems to contend with. Aside from diaries, a number of the articles appearing in Overland Journal are important to this study. Those most relevant to this work have been extensively reviewed in this thesis. In general, these Overland Journal writings were reliable, but were not used to draw any final conclusions without supporting evidence. 
Finally, the Oregon Historical Society's collection of Trail-related writings were useful, a number of which are: 1) in manuscript form as actual diaries, 2) published as trail diaries, and/or 3) collections of notes and records apparently transcribed by hand, photocopied, photographed or typed from family records reviewed by their producer (i.e. trail diaries, letters and genealogical notes). In general, genealogically-produced writings have been considered less reliable than academically- or historical society-supported historical writings; this interpretation is less the case for some of the more recently published genealogy-related Trail writings.

Local historical society writings were reliable but once again questionable at times. They were useful for supporting evidence, so long as their claims were not based on other references reiterating any possible historical misconceptions that might have existed (i.e. the re-telling John Callison's death due to "cholera" (Briggs 1960) as noted in the first chapter of this thesis. A highly reliable set of trail diary transcripts used for this study were transcribed and republished in typographic form by the Lane County Historical Society between 1955 and 1965 (i.e. see Pengra 1853, Callison 1959). These often included brief biographical endnotes about the writer, with diary text unchanged in terms of misspellings, spacing between words, and even crossed-out notes.

Major sources for this work aside from the previously mentioned OHS bibliography include the numerous women's diaries transcribed, compiled and published by Kenneth Holmes (1983-1993). Holmes did perhaps omit some of the unnecessary penmanship (i.e. crossed out words) from his published forms, but produced the best diaries for developing a statistical profile of the Trail experience. 
Most importantly, the observational notes used in this thesis to produce the morbidity and mortality graphs in the trail disease chapters came from Holme's series.

Holmes's diaries are also significant is that they depict an important part of the Oregon trail life experience. Upon reviewing these diaries, it became apparent to me that a review of women's diaries was most important to this work for several reasons. In the years immediately preceding the Oregon Trail experience, the transcendental, temperance and home missionary movements were strengthened by a number of early women's rights activists (i.e. Narcissa Whitman). One outcome of this movement was the establishment of the first medical institutions designed for the education of women only in medicine. The earliest of these institutions (which preceded the admission of women to the Harvard school of medicine) were devoted to a combination of teachings in nutrition, personal hygiene and domestic medical practices (i.e. the Sylvester Graham dietary "graham bread" movement), and midwifery accompanied by water cure and safe living practices based on sanitation and prevention (a belief which developed as possible extension of the water-based miasma theory of disease) (Weiss and Campbell 1967).

The best evidence for the impact of this movement on medicine and public health is by several medical historians (Morantz 1985; Murphy 1991; Leavitt 1973, $1977,1999)$. In regard to Overland history, we see the impact of this movement in particular women's diaries (i.e. Parsons 1850). The first evidence linking the observational skills of certain women writers to the water cure movement was found in a diary which mentions "water cure" (Pengra 1853), supporting evidence 
for which later surfaced in Allyn's 1853 Trail diary (Allyn 1924, 429-430), a diary which may in fact be a reminiscence.

With regard to Oregon Trail medical history, the observations of women trained in water cure and "grahamism" (a lacto-ova vegetarian-"graham bread" diet) were very focused on sanitation, for which reason they kept detailed notes about weather, water quality, air quality, the presence of animal carcasses, and the development of particular maladies. A review of the history of this influence of women along the Trail was produced by Ellet (1973), Faragher (1979) and Lockley (1981). A review of the women's water cure/Sylvester Graham diet movement is well-documented (Weiss and Campbell 1967, Cayleff 1988) and exemplified by the writings of Mary S. Gove Nichols (1852) of New York and the lives of home missionaries Mary Walker and Narcissa Whitman of the Oregon missions (McKee 1945).

In sum, this method of analysis involved made use of the primary and secondary historical literature published about geography, medicine and Oregon Trail history to define the two disease regions reviewed in this thesis. Two disease regions existed along the Trail, where either Asiatic cholera or opportunistic dysentery prevailed during the migration years of 1845 to 1852 . By producing a complete description of two diseases common to the Oregon Trail, this work serves as a contribution to Trail medical history, and demonstrates the value of medical geography research techniques to historical epidemiology research. 


\section{CHAPTER II}

\section{DISEASE GEOGRAPHY}

The behavior of disease is geographically definable both spatially and temporally. The spatial features for a disease relate to the physical and human geography of the region infected relative to the ecology of the organism responsible for the disease and/or the environment in which the disease erupts. The temporal features of a disease define how its behaviors change over time.

Biogeography plays a role in the diffusion process whenever an organism such as a bacterium or an insect is responsible for disease and/or is an important part of the disease-causing organism's ecology. Physical geography is important due to the impact of climate and physiography on people, the disease causing organism, and the disease hosts and vectors. Human geography is important because local population and demographic features can have important impacts on disease behavior, especially for diseases spread through contact with prior disease victims or materials contaminated by them.

In general, the study of disease ecology and temporal behaviors takes each of these spatial features into account to determine whether or not a region is susceptible to a disease. By studying historical disease patterns, we not only learn about the possible root causes for diseases, but also uncover important differences between local and regional disease behaviors. Under the best conditions, these 
discoveries can even result in the implementation of effective prevention and prognostication programs.

\section{DISEASE ECOLOGY}

The ecology of the disease-causing organism within its environment is often what defines the underlying causes for a given disease pattern. This ecological basis for interpreting disease is the result of numerous studies of microbial, vector and animal studies by American and Soviet medical geographers. Jacques May's disease ecology model describes how a particular pathogenic organism develops and behaves both in and out of the human environmental setting (May 1958, 1961). The biogeography of disease models proposed by Pavlovsky and Voronov categorize diseases based on their environmental and zoonotic behaviors (Pavlovsky 1966; Voronov 1967, 1977). Recent reviews of disease geography combine the ecological and biogeographic interpretations of disease patterns with physical geography features to produce the current models in use focused on human ecology, the culturally-defined living space, environmentalism, and landscape epidemiology (Stamp 1964a, 1964b, McGlashan 1972, 1983, Howe 1977, Pacione 1986, Learmonth 1988, Meade, Florin and Gesler 1988, Gesler 1991).

\section{The Disease Ecology Model}

The interactions between a pathogen and its natural environment define the ecology of disease. More importantly, these interactions identify the vector and host interactions responsible for disease onset. In diseases which are 
anthroponotic, no vectors are involved and disease is passed primarily from person to person.

Diseases for which the organism survives by interacting with animals within a given environment are termed zoonotic. Whenever this organism begins to infect humans it becomes anthropo-zoonotic. Physioanthropic diseases develop because of changes in the environmental setting caused by people (Voronov 1977, Meade, Florin and Gesler 1988). Whereas xenotic diseases are foreign to their natural environment, axenotic diseases naturally exist in a region and typically require no intervening animal or vector to spread from their source to a potential human victim; the pathogen may be a biological product (biocenotic) or non-biological product (abiocenotic). Animal hosts can harbor biocenotic organisms for long periods of time, serving as storage receptacles or reservoirs for the disease-producing organism (Voronov 1967, 1977). These behaviors, referred to as chains of disease transmission, define the infectious disease routes produced by natural and human ecological means (Meade, Florin and Gesler 1988, 63; for more, see Appendix A for Glossary ) (Figure 1).

Unique examples of disease transmission take place whenever zoonotic organisms typically unable to infect humans suddenly become infectious. Termed opportunistic, these infections which result involve common microbial organisms taking advantage of individuals who suffer from a reduced immune system induced by personal behavior within a given social setting. Non-infectious and often zoonotic in nature, these organisms become anthropo-zoonotic because the right conditions develop to produce a permanent disease site or focus (Voronov 1967, 1977). 


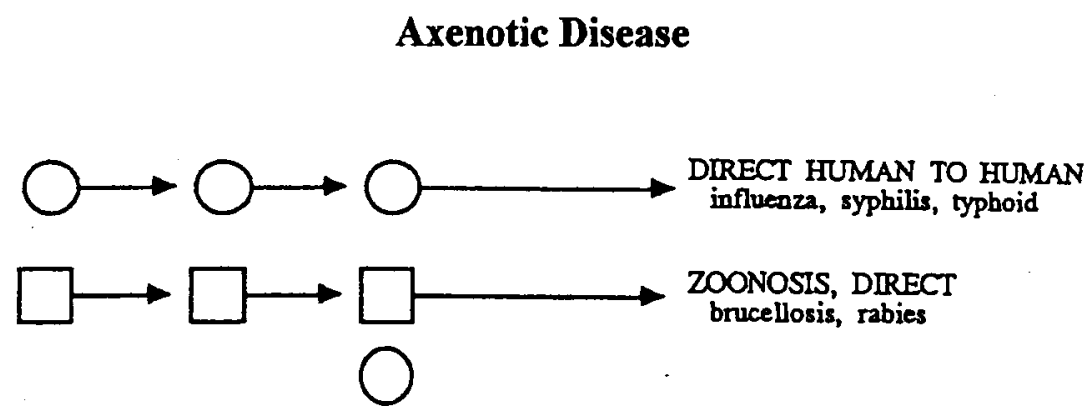

Metaxenotic Disease

$\mathrm{O} \rightarrow \mathrm{X} \rightarrow \mathrm{O} \rightarrow \mathrm{X}$

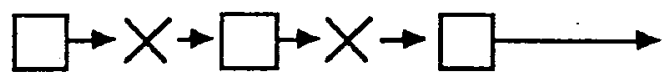

(1)
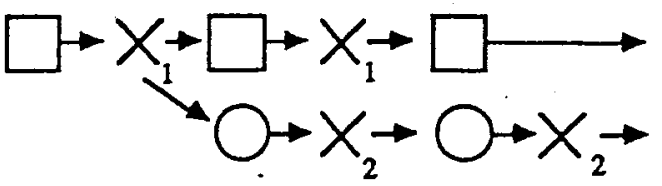

VECTORED HUMAN DISEASES malaria, onchocerciasis

VECTORED ZOONOSIS

Rocky Moumtain spotted fever, encephalitis

\section{ANTHROPO - ZOONOSIS}

filariasis, typanosomiasis, yellow fever, plague $\bigcirc$ human being as host

cycle transmission $\underset{\text { transmission }}{\text { incidental, dead-end }}$

vector

amimal host; most often reservoir

Figure 1. Chains of Disease Transmission (modified from Meade, Florin and Gesler 1988, 64) 
The organism responsible for a disease typically resides naturally within this disease nidus or focus without need for human interaction. Depending on the behavior of people within this environment, the organism may or may not become pathogenic. The behavior of an opportunistic bacteria is physioanthropic and anthroponomic in that it relies on human-induced environmental changes and how these changes in the local ecology affect how it will react to human presence as a potential pathogen. Most commonly, opportunistic diseases develop due to human contact with a fomite (i.e. a carcass or contaminated food source) or vehicle (i.e. insects) within or upon which the pathogen resides. For example, whereas a decaying animal carcass may naturally not be infectious in spite of numerous bacteria residing on it, given the right circumstances it might suddenly become capable of infecting humans due to a reduction in immunity in people brought on by some sort of environmental stress. This axenotic (non-vectored), zoonotic (animal-borne) disease behavior differs greatly from a metaxenotic (vectored), anthropo-zoonotic disease behavior in which not only is an animal host required, but also a vector in which the pathogen spends a significant portion of its life before infecting people (Voronov 1977).

Since metaxenotic, anthropo-zoonotic diseases require animal hosts or reservoirs, vectors and people, this implies a spatial relationship for the disease defined as the space shared by each of the organisms involved in the disease process. In some cases, the space shared by the host, the vector and the human victim is where the disease exists, resulting in a disease pattern defined by the vector's ecology in relation to separate animal host and human ecologies. In other cases, a disease region is shared just by the vectors and humans which are involved. 
An example of a vectored disease, Rocky Mountain Spotted Fever, provides us with one of the more classical examples of an anthroponotic-zoonotic behavior. It develops wherever the living pathogen, Rickettsia ricketsii is spread from deer to humans by way of a tick bite. This makes the disease common to regions where the ecologies of each of the organisms overlap (Voronov 1967, 1977).

Asiatic cholera is currently viewed as a disease dependent on fomites and vehicles. The organism responsible for Asiatic cholera, Vibrio cholerae, is naturally zoonotic and attaches to various forms of marine life. This vibrio and its carriers play an important role in local natural ecology and are capable of becoming a part of human ecology by entering the food chain. If it survives as an infectious agent on the surface of edible marine animals, it can be spread by way of a fomite (i.e. contaminated cookware or water), a vehicle (i.e. a fly, although very rarely), or in a possible vector-like fashion (i.e. from within the animal environment of an imbibed copepod into the human intestinal environment). Each of these zoogeographic and physioanthropic features of disease transmission have to be taken into account to determine the spatial requirements for a given Asiatic cholera epidemic pattern and identifying the nidus from where it originates.

According to mid-nineteenth century medical geographer George Hall, the "nidus" is where "the poison on which it depends, could germinate, so to speak, ... and it prevailed in no other places" (Hall 1855). More recently this definition for a disease nidus has come to recognize the importance of the various ecological requirements for the pathogen's survival, both naturally and due to specific human geographic features (Pavlovsky 1966, 249, Meade, Florin and Gesler 1988, 62). Whereas the spatial distribution of axenotic and metaxenotic diseases has been 
viewed by epidemiologists as a disease distribution pattern defined primarily by the behaviors of the pathogenic organism, its vector, and its animal reservoirs, more recent disease ecology models have led to a deeper understanding of disease as both a naturally and or human-induced phenomenon.

\section{SEQUENT OCCUPANCE AND DISEASE PATTERNS}

Whittlesey believed that "[ $\mathrm{h}]$ uman occupance of area, like other biotic phenomena, carries within itself the seed of its own transformation" (Whittlesey $1929,162)$. For each transformation or succession in land use for a given living space, Whittlesey concluded that the geographic features definitive of that space undergo important changes as well which are dictated by the development of human occupied living spaces over time and how this development influences victuals and water use, community and personal space use, and the various occupational habits, transportation methods, and local business behaviors within that living space. Examples of the sequent occupance method of analysis are published by Thomas (1931), Trewartha (1940), Meyer $(1954,1956,1959)$, Gentilcore (1957, Meyer and Strietelmeier (1963, 778-795) and Peplies (1965). In Meyer and Strietelmeier's interpretation (1963, 788-789, see also Meyers 1959), typical changes in land use progress from unoccupied or occasionally occupied "Indigen/Explorer" regions (termed aboriginal regions engaged in fur trade by Meyers), to "Pioneer" regions where more stationary, self-sustaining homesteads are built, followed by "Commercial Agricultural/Early Industrial" and finally "Late Industrial/Early Tourism" settings where a variety of agricultural, industrial and urban activities are engaged in between different regions (Figure 2). 

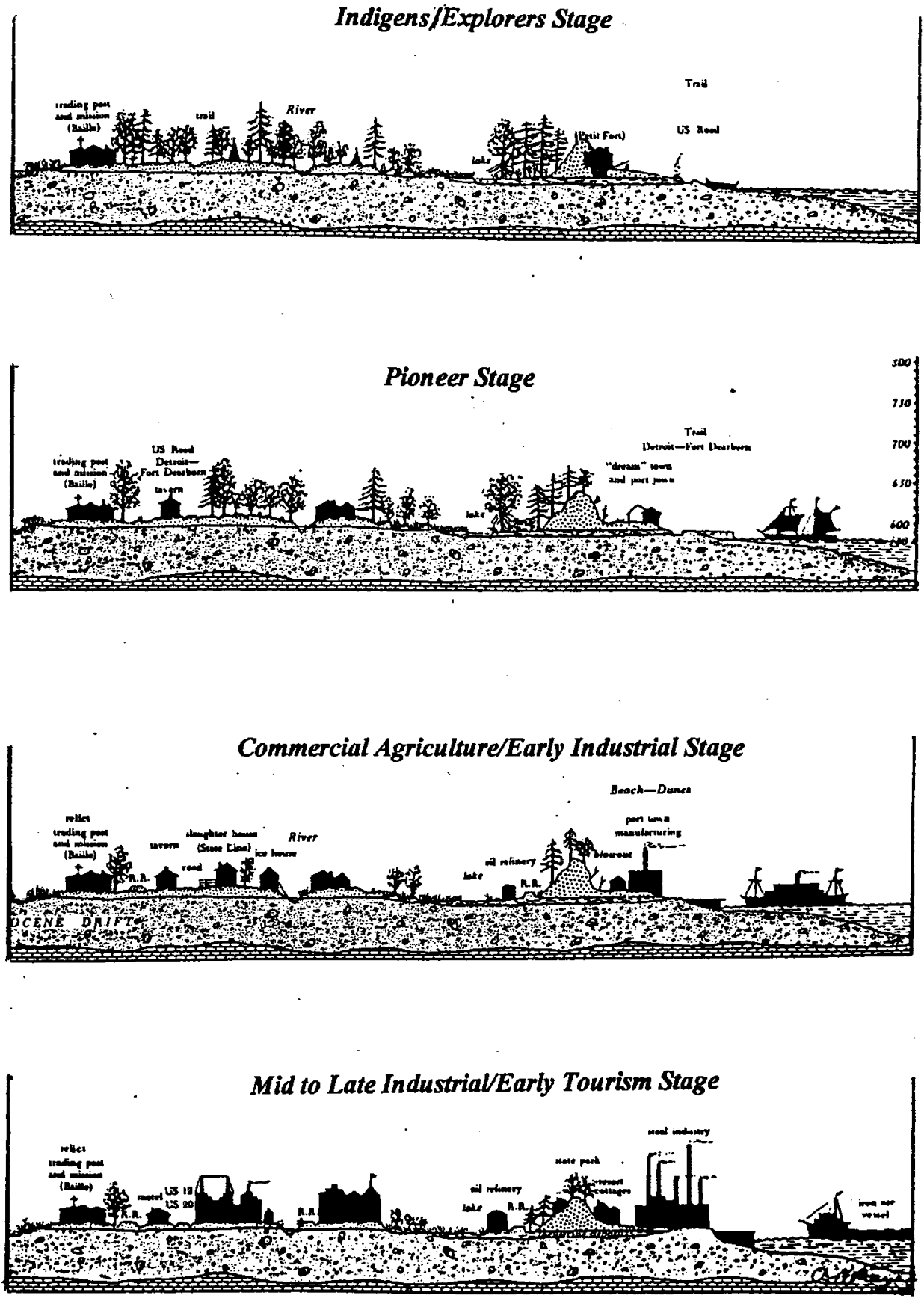

Figure 2. The Sequent Occupance of a Developing Tract of Land (Meyer and Strietelmeier 1963, 789) 
Whereas Whittlesey's model has traditionally been used to understand the changes which result due to the economic development of a region, recent epidemiological studies suggest that the sequent occupance model can also be used to understand a region's temporal disease patterns. The geographically defined sequent occupance model combines well with the epidemiological transition model defined by McKeown, Record and Turner (1975), which states that temporal changes in disease patterns occur due to the sociologic changes experienced by growing societies. This suggests that once an epidemic disease is introduced into a population, its incidence increases until large numbers of cases develop, after which its impact on the population is greatly reduced (Table I).

Recent support for McKeown's theory of epidemiological transition has been published by numerous epidemiologists, sociologists and anthropologists (Marmot 1984, 1986, Rose 1985, Koskinen 1988, Rogers and Ginzberg 1993, Wilkinson 1994, 1996, Trafzer 1977, Adler et al. 1999), as well as geographers (Learmonth 1978, Eyles and Woods 1983, Jones and Moon 1987, Schneider and Greenberg 1992, Meade 1992). Sociological interpretations of these changes in disease pattern blame what has been called a "loss of social cohesion" or the development of some form of inequity within the given population setting, an "inequity" accompanied by what social epidemiologists term "social disintegration" and a heightened mortality and development of new disease patterns within the demographic setting. Within low income communities these diseases develop due to increasingly unsanitary living conditions, changes in personal and social habits, and numerous problems linked to poor nutrition and/or a weakened immune system (Table II). 


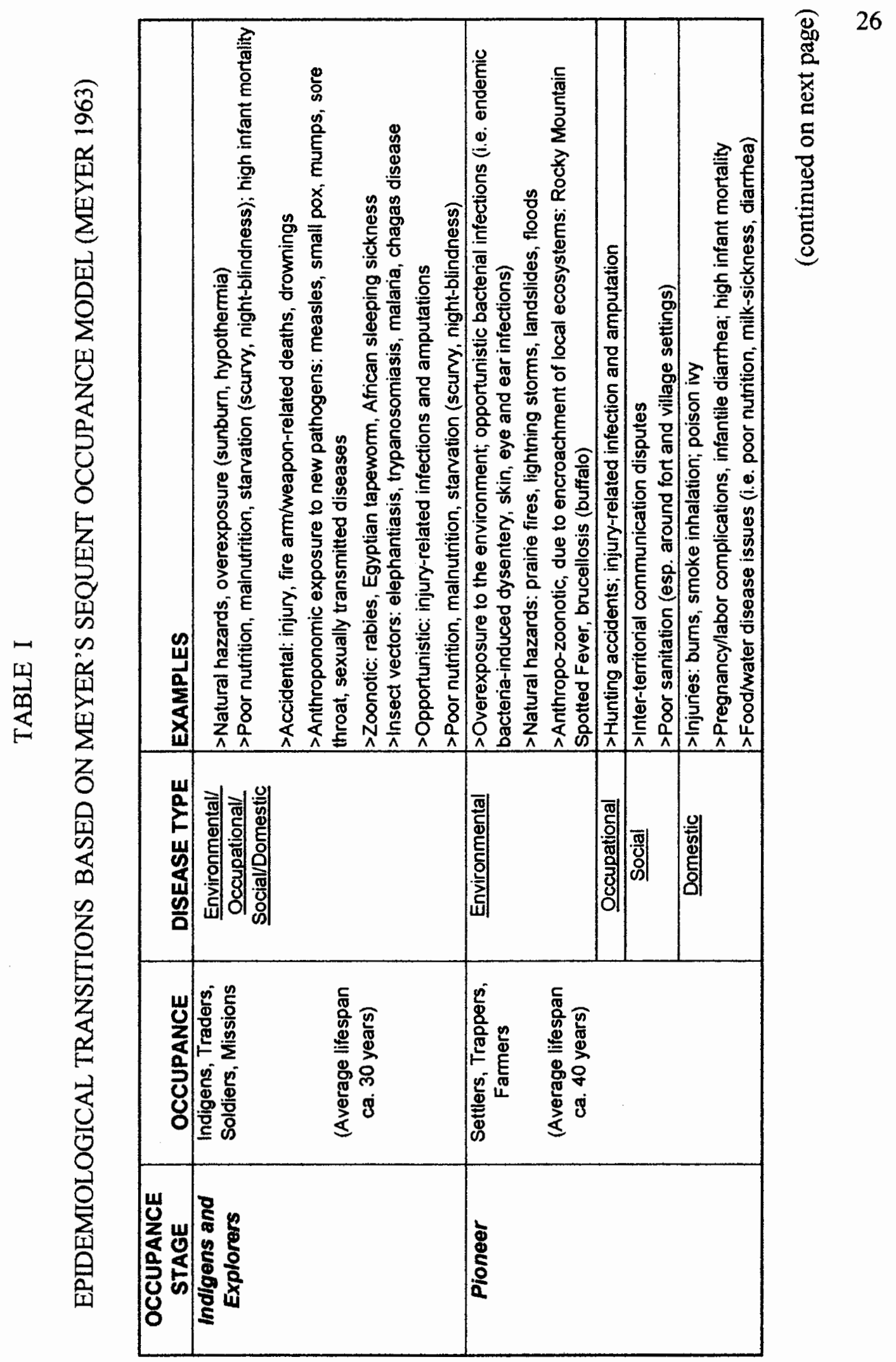




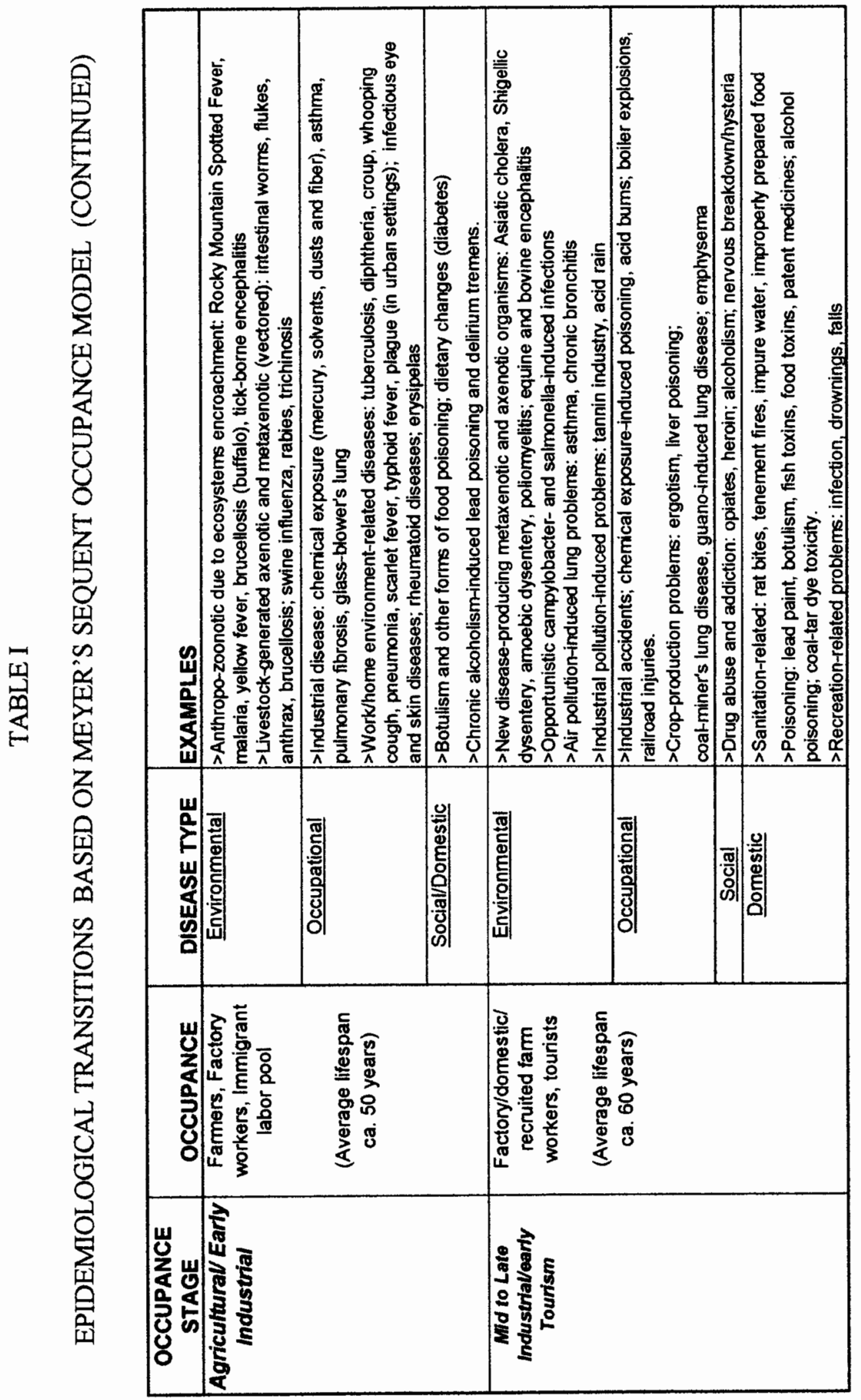




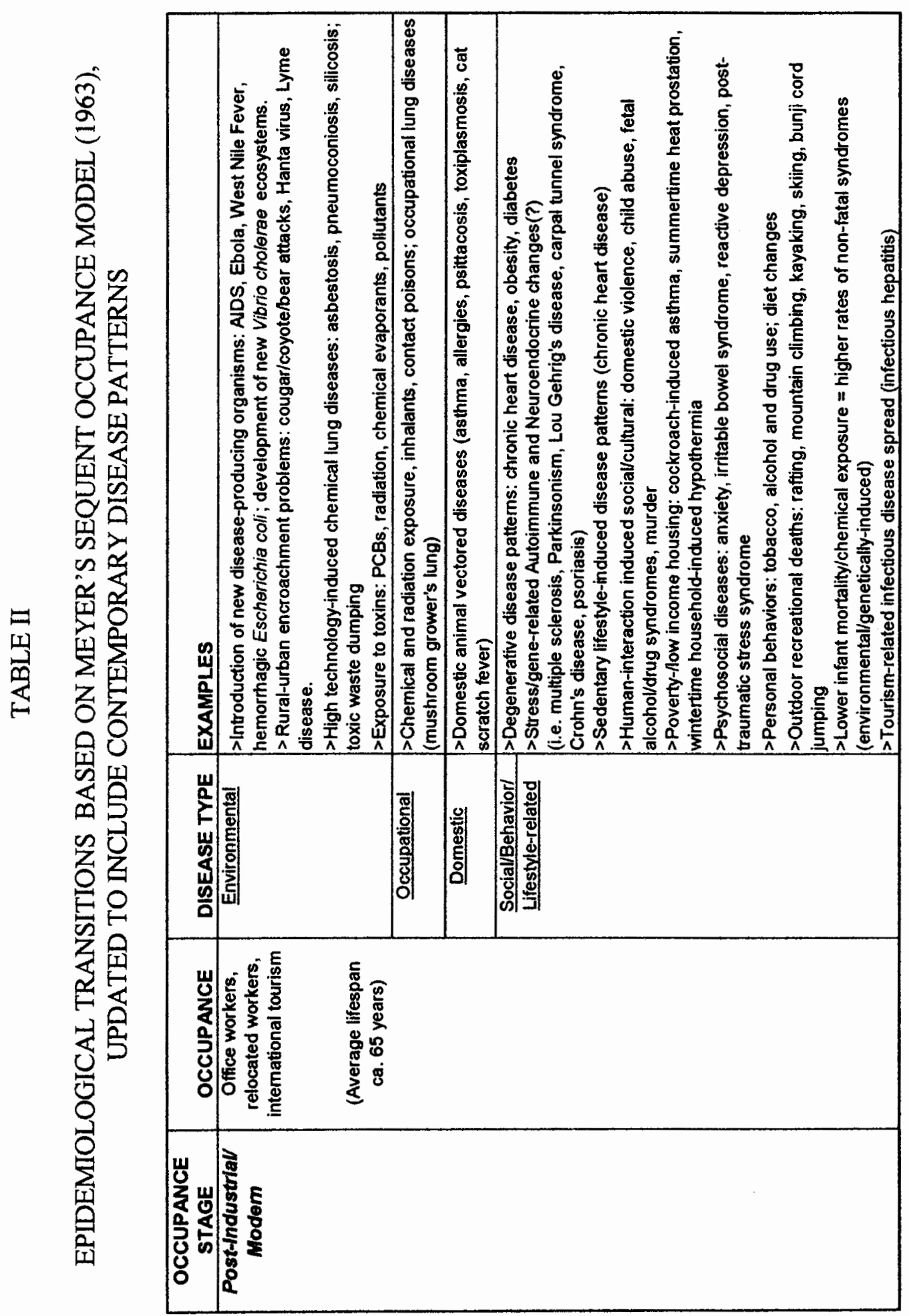


Whittlesey's sequent occupance model has direct applications to McKeown's epidemiological transition model in that it helps define which kinds of disease may infect specific temporally-defined human population settings. The more developed a given population is, the more differentiated it becomes. This differentiation in turn implies an ability for a more diverse population to experience new disease patterns. During each of the stages of regional development, different diseases exist due to changes in people, living patterns and occupations. By understanding the impacts various living conditions have on pathogens, disease carriers and disease vectors at each level of the sequent occupance/epidemiological transition model, some diseases might be better understood and even predictable temporally and spatially within the given physical and human-generated environmental setting.

\section{DISEASE DIFFUSION}

\section{The Macrogeography of Disease Diffusion}

Conclusions drawn from Whittlesey's sequent occupance model may be related to Pyle's diffusion model theory of epidemic diseases (Pyle 1969). Whereas Whittlesey's model defines disease patterns for a single human-occupied region, Pyle's model covers the ways in which these diseases diffuse from one region to the next. Unlike Whittlesey's model, which is based upon changes in numerous human geographic features over time such as population size and density, methods of transportation used, occupational settings and common living patterns, the diffusion model produced by Pyle relies simply on transportation, 
regional economy and urban density features to define the diffusion pattern. More importantly, Pyle's model is a direct extension of Christaller's diffusion of innovation model (Christaller 1935) and its sequels defined by Hagerstrand (1952, 1967), Cliff et al. (1981) and Haggett (1994).

Christaller's model states that innovations and new products (for Pyle, new infectious diseases) diffuse hierarchically by way of transportation routes between economically important urban areas, and then from highly important economic centers into smaller communities (Figure 3). Applying this diffusion behavior to epidemics, Pyle's hierarchical diffusion model suggests that Asiatic cholera typically makes its way from one country to the next by way of major shipping ports, reasoning useful for explaining why Asiatic cholera initially entered the United States by way of shipping ports along the Atlantic coastline in 1832 rather than transoceanic Pacific Ocean and Pacific Rim ports (Pyle 1969).

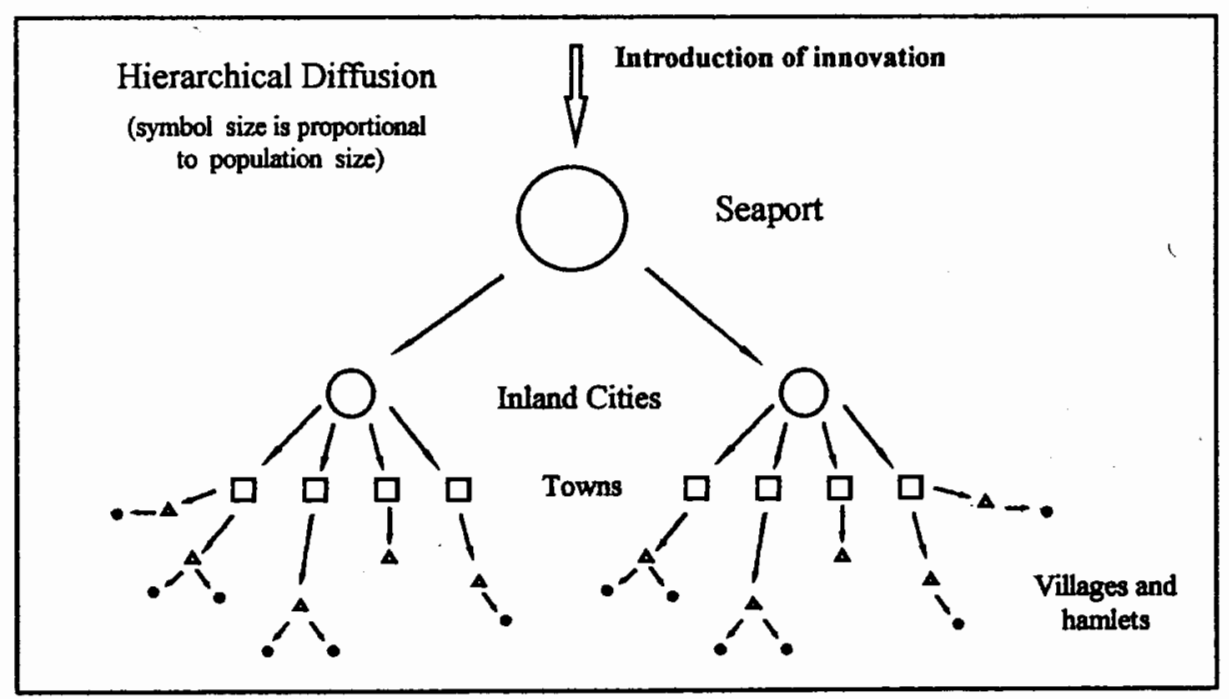

Figure 3. Innovation and Hierarchical Diffusion 
Pyle's models also define the order in which specific regions will be infected as the disease diffuses along a given route. A non-hierarchical diffusion pattern will cause a disease to follow river ways and infect one inland community after another located along this transportation route. This linear diffusion pattern Pyle called the "Pioneer" or Type I method disease diffusion, noting that whenever developing regions are impacted by a disease for the first time, they tend to limit their diffusion to this predictable pattern (Figure 4).

When Asiatic cholera made its way in the United States a second time in 1849 , it quickly passed through the port cities to infect previously infected regions in very short time. Regions previously impacted by cholera and which served as important transportation hubs behaved as "Developed" regions (Type III), diffusing in a hierarchical fashion from one hub to the next. As this hierarchical diffusion led to the infection of a large urban area, the disease then diffused outward from each of these urban centers to infect smaller communities. Once previously uninfected parts of the country were reached, this diffusion process returned to its much slower linear (Pioneer or Type I) diffusion pattern. Pyle termed this a "Mixed" or Type II model of disease diffusion (Figure 5).

Several important limitations need to be taken into account regarding Pyle's cholera diffusion maps. First and foremost, they are based primarily on United States cholera statistics, and do not mention a number of important diffusion routes by way of Mexico and the Caribbean into Middle America. This diffusion pattern enabled Asiatic cholera to cross the Panama isthmus and begin infecting various Mexican west coast cities before diffusing northward to San Francisco (Wendt 1885; see first inserted map page in this text). 


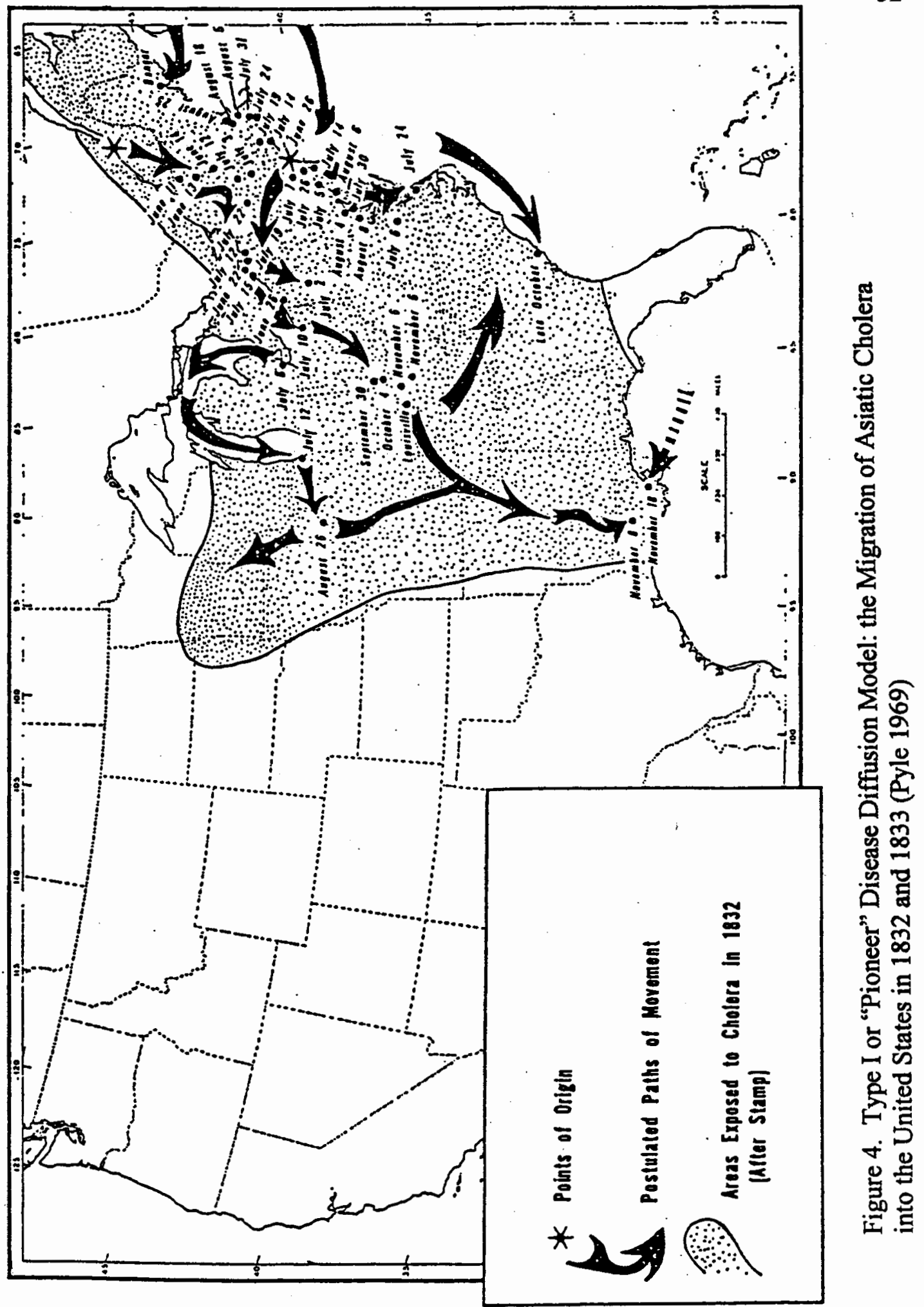




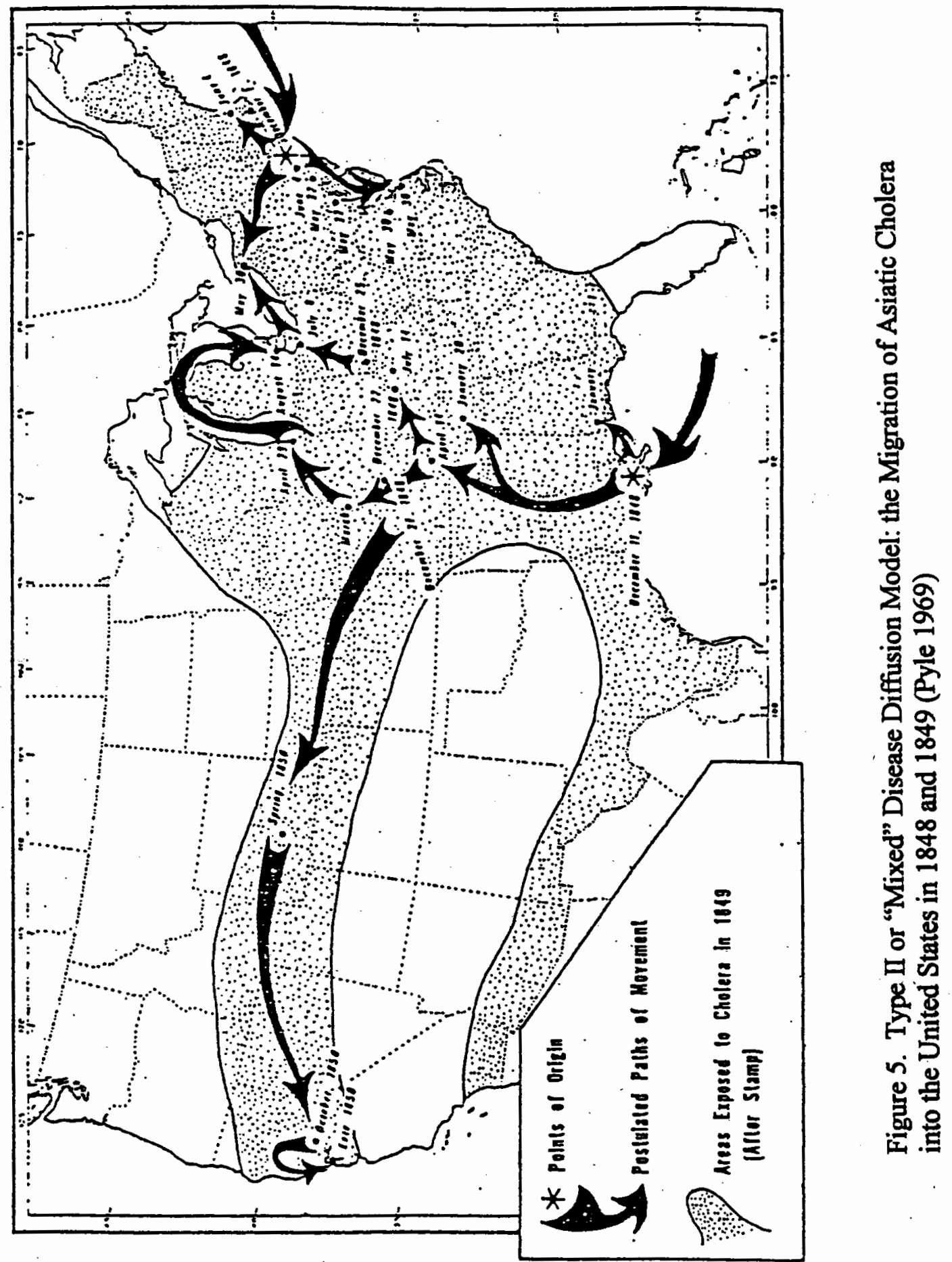


Pyle's model also depicts the diffusion process for Asiatic cholera in the Far West at a rather macrogeographic scale. It depicts a Platte River-California Trail diffusion process which departs the trail for a considerable distance in both northward and southward directions. Due to lack of human populations in these regions, this route might have been more appropriately depicted as adhering primarily to the river routes which defined these trails. This same feature holds for the San Antonio River route taken by Asiatic cholera, which in actuality made its way primarily along a narrowly-defined route along the United States Territory-Mexico border (Peters and McClellan 1875).

Recent interpreters of Pyle's models have modified them to include some of the more contemporary biomedical views of infectious disease diffusion patterns. Pyle's Type I model has been renamed a "contagious" pattern for disease diffusion. The Type II model is termed a "mixed contagious-hierarchical" pattern.

A popular example of this interpretation of disease diffusion depicts the hierarchical diffusion of measles from Bergen, Norway to Reykjavik, Iceland between 1946 and 1947. By avoiding quarantine, people previously infected by measles within the past five years made their way to nearby towns and communities, spreading the epidemic contagiously into nearby communities and the homesteads of school children. In turn, these children diffused the epidemic even further by way of school environments (Cliff et al. 1981, 27-32). (Figure 6). 


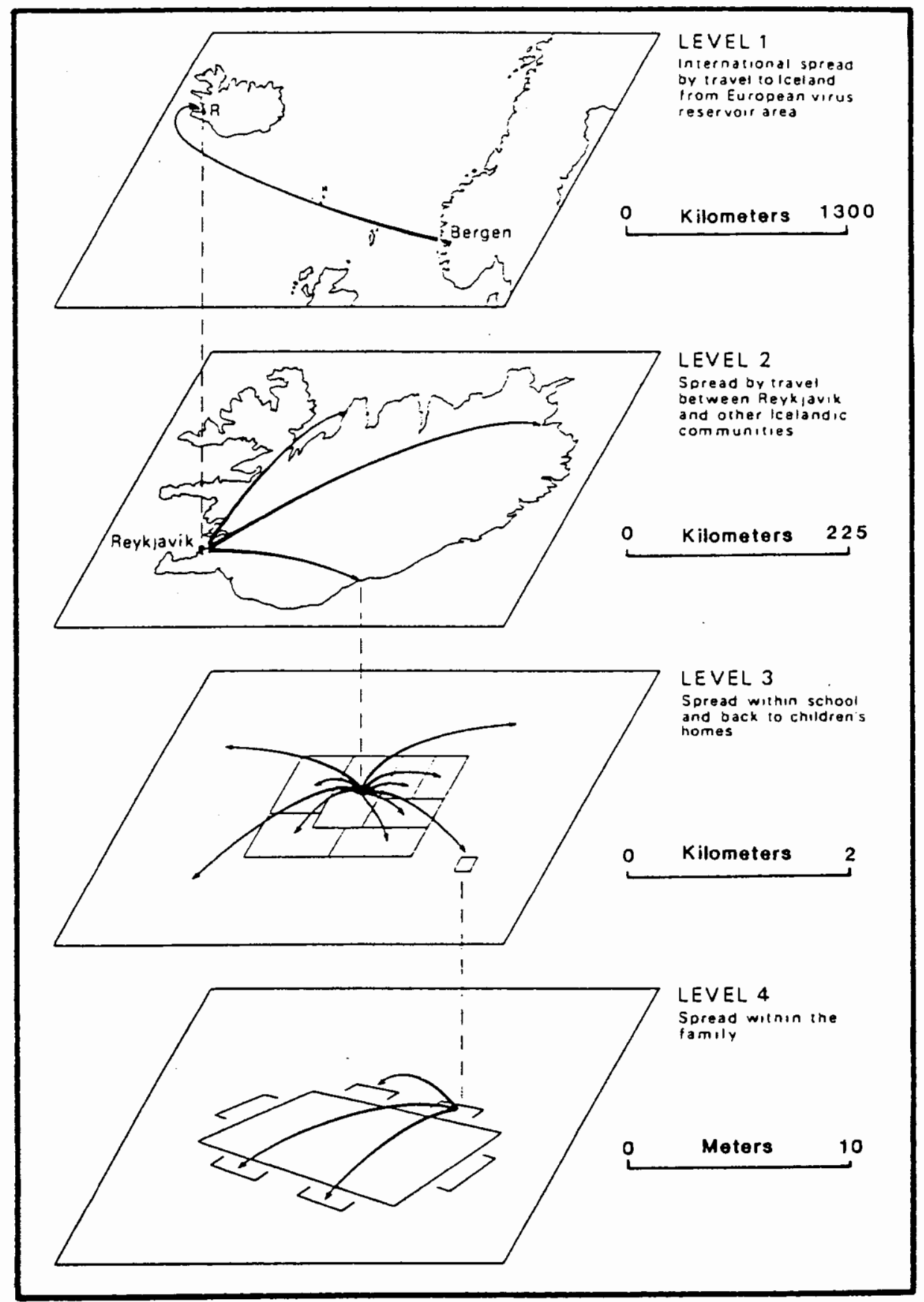

Figure 6. The Mixed Contagious and Hierarchical Diffusion Pattern of an Iceland Measles Epidemic (Gould 1985, 235) 
As derivations of Christaller's hierarchical theory, Pyle's diffusion models have traditionally been used to explain and predict the diffusion of new diseases from one region to the next by way of popular transportation routes. They relate human migration patterns to infectious disease diffusion patterns at a global and international scale. They also suggest that as an infectious disease carrier travels from one region to the next, he/she will most likely infect places of higher economic and/or political status such as a large seaport cities before spreading to places of lower status (the smaller villages).

This hierarchical diffusion pattern therefore assigns smaller, more inland communities adjacent to the much larger urban region lesser status regarding concern or worry about the potential for early disease onset. In theory, this "innovation" (the disease) must first arise in the more economically-important section of the urban setting before diffusing to other regions. Based on this economic geographical reasoning, the highest risk regions are expected to be located high up within this given hierarchical setting, implying that should a disease be introduced to this region by way of international trade routes, it will infect the more important social settings close to seaports before diffusing into other localities well distanced from this urban center. This hierarchical diffusion pattern depicts well the diffusion of highly infectious contagious diseases anthroponotically from person to person. For diseases induced by other sociological causes, a microgeographic interpretation of the disease patterns may be needed to identify the specific reasons for this diffusion process. In some cases, socioeconomic status has to be taken into account when diseases like Asiatic cholera and dysentery are prone to eruption in urban-based low income settings. 
The Microgeography of Disease Diffusion

Hierarchical theories are traditionally based on political and economic status. They may be used to define disease spread along international trade routes and human migration patterns. In some cases however, even though a disease spreads hierarchically from one economically successful urban region to the next, once this disease begins to infect these urban regions, its activities often need to be interpreted at a much smaller microgeographic scale. With Asiatic cholera, not only are large urban settings required for the disease to spread effectively, but also regions of lower socioeconomic status adjacent to or within the boundaries of an economically prospering urban region.

Improvements in Pyle's disease models by Cliff et al. (1981) and Haggett (1994) partially take such human geographic features into account by detailing the non-hierarchical diffusion behavior for disease. However, further improvements of this model can be made by focusing on diffusion patterns relative to socioeconomic conditions such as income and poverty status. Once these demographic features are taken into account, new interpretations of the disease diffusion process may be produced. For this reason, two renderings of the disease diffusion process may be envisioned as reasons for urban-centered epidemic behaviors. The first process involves an infection of low income suburban communities and rural settings, followed by a reversed hierarchical diffusion pattern contained within a much larger hierarchical diffusion process. The second process begins with the development of a disease within the urban ghetto environment, a low income urban community situated in the center of a potential epidemic region, followed by a hierarchical diffusion process (Figure 7). 

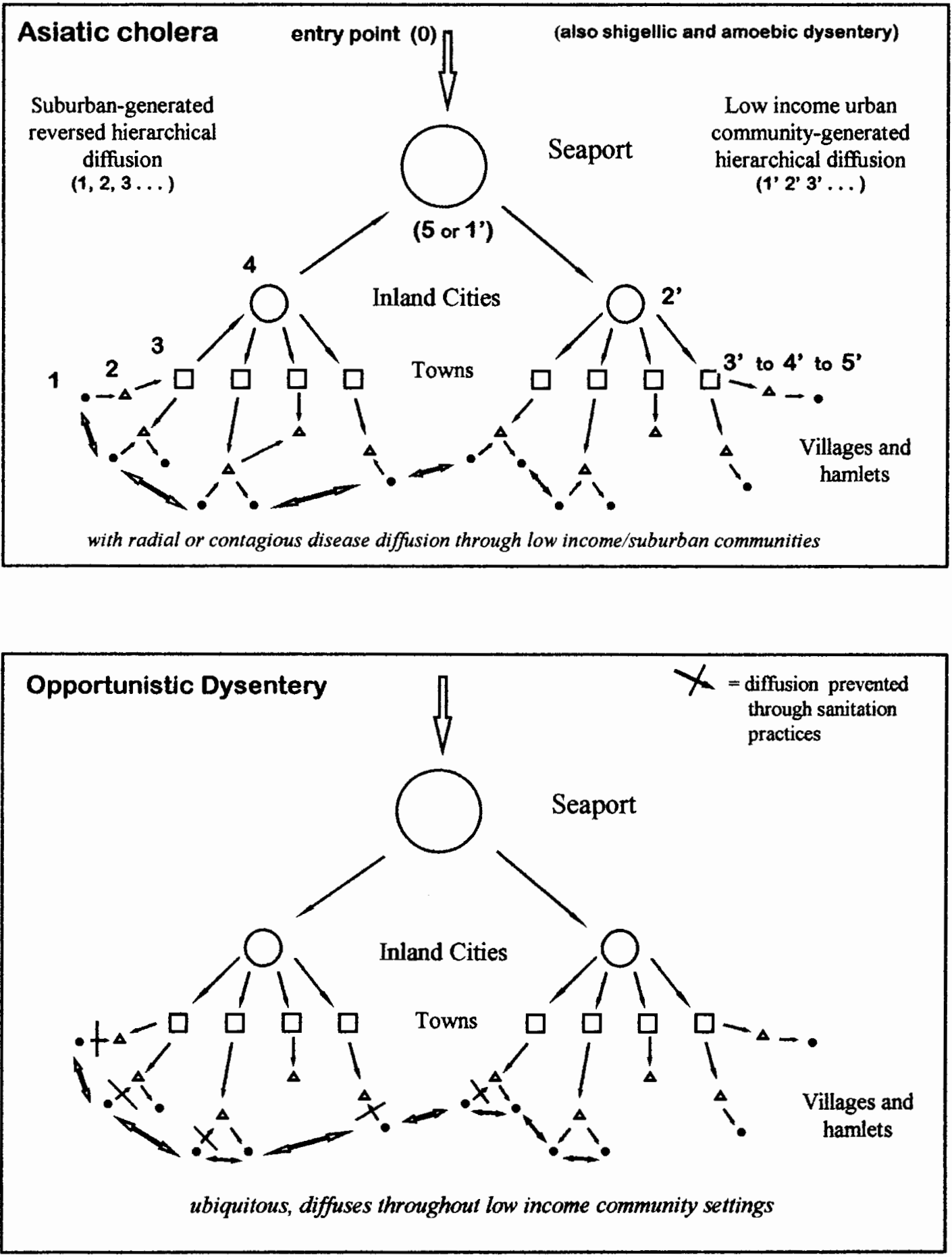

Figure 7. The Diffusion of Asiatic Cholera and Dysentery

Between Various Population Settings 
The socioeconomically-related disease transmission theory linking social inequality to increased epidemic activity within the large population setting suggests that low income generated diffusion patterns for cholera have their own implications involving a given region's medical concerns. It implies that once a disease infects a region of lower hierarchy, it may begin its ascent to the center of a region in a reverse hierarchical fashion before disseminating further into other previous uninfected regions hierarchically. In this way, this disease infects even higher urban settings, which in turn infect previously uninfected regions of lower or matching status due to a hierarchical descent of the disease. Since this hierarchical diffusion of epidemics is often linked to human movement and migration patterns in relation to socioeconomic status and regionalization within an urban area, important geographic features to be considered when researching this diffusion process include population density, income status, what forms of transportation are engaged in by the most susceptible groups, and what personal and social behaviors exist in the most highly susceptible populations.

For both Asiatic cholera and dysentery, an important sociological and human geographical interpretation of disease models has paid particular attention to income status as one of the most important role in understanding the disease diffusion process (Eyles and Woods 1983, Meade, Florin, and Gesler 1988, Earickson et al. 1989, Jones and Moon 1991, Gesler and Ricketts 1992, Kearns 1993, Kearns and Gesler 1998). A higher incidence of disease onset for both Asiatic cholera and dysentery may be directly linked to socioeconomic conditions within the developing or developed region. This reversed hierarchical model also implies that whereas the cause for disease diffusion may be interpreted as a result 
of the economic success of a region as demonstrated by its more effective transportation methods, this development of a fairly stable, sizable heterogeneous population is what makes a region vulnerable to disease. This also implies that the development of low income communities and the lack of social cohesion of a population may be in large part responsible for the growth and development of certain epidemic disease patterns within urban centers.

This link between social cohesion and epidemic disease behaviors is not new and has been heavily promoted during the past decades by Wilkinson (1973, $1986,1994,1996)$. Although Wilkinson's writings focus on diseases typical to developing countries (i.e. their transition from malnutrition to developing heart disease), his theories are equally applicable to other social settings in developed countries where various sub-populations co-exist. In such regions, how a population segregates into regions of low and high socioeconomic status defines how its people interact with each other and where certain types of diseases and epidemics will evolve within that social setting. In addition, since the hierarchical theory suggests that initial infections are more likely to ensue within densely populated regions of economic importance, Wilkinson's social cohesion/social disintegration model suggests social reasons for why these given urban-dependent disease diffusion patterns evolve, i.e. by infecting the most susceptible people, the disease organism in turn adapts to this human environment setting.

This latter feature helps to differentiate Asiatic cholera-prone regions from dysentery regions. Highly populated urban regions with low income living conditions and families of low income status predispose people elsewhere to the greater likelihood for a successful infections developing. Opportunistic dysentery 
on the other hand follows a diffusion process which tends to remain in low income communities where poor sanitation, poor nutrition and compromised immune systems prevail, features typically lacking in the higher socioeconomic setting ( $c f$. in Figure 7).

\section{CONCLUSION}

Based on Whittlesey's sequent occupance model, the requirements for an Asiatic cholera region are the development of an urban space where population aggregates facilitate the transmission of a disease. The disease ecology model states that these urban regions need to be positioned close to important international shipping routes where both the ecological (estuarine or deltaic environment) and human population requirements of vibrio are met in order for disease onset to begin. Once infected, the disease spreads throughout the rest of this urban space from highly susceptible sub-populations, namely low socioeconomic and in some cases higher socioeconomic individuals engaged in particular behaviors exposing them to the disease organism, then along hierarchical routes to other economically active regions.

Regions engaged in earlier stages of development may not be capable of supporting large scale Asiatic cholera epidemics. Instead, due to the stage of growth they are going through, distinctly different disease patterns arise and include common infectious diseases like dysentery brought on by poor sanitation practices and the prevalence of anthropo-zoonotic opportunistic bacteria infections within these younger pioneer regions. In the case of a more human-dependent form of bacteria-like shigellic or amoebic dysentery, human behaviors are most 
important due to the direct person-to-person transmission of the pathogen involved in the transmission process. A densely packed urban region where stable domestic environments exist is therefore an important spatial requirement for this infectious process to continue.

By combining these different interpretations of disease behavior introduced by May, Whittlesey, McKeown, Pyle and Wilkinson, a disease model may be produced which has several advantages over the contemporary interpretations of the behavior of the disease and its pathogen. This model can be interpreted at a more microgeographic scale, differentiating regions within a heavily populated urban area where communities exist that are highly disease prone for illnesses like Asiatic cholera versus others more prone to opportunistic dysentery. This method of disease interpretation may also explain why new disease niduses may develop in some regions but not in others. In the best of circumstances, this socioeconomic interpretation of epidemic behavior might even lead to the development of more effective ways of determining where new niduses and disease foci may form. 


\section{CHAPTER III}

\section{ASIATIC CHOLERA AND DYSENTERY ECOLOGY}

\section{Introduction}

Asiatic cholera recurs frequently in areas where Vibrio cholerae (common name vibrio) infects people who are interacting with the local ecology. Known as endemic regions, the result of an initial infection from these regions is often the spread of the disease to other individuals, either through direct contact or indirectly by way of contaminated personal belongings, food and water supplies, and numerous reinfections induced by interacting with the local ecology. In areas where the natural ecology required by vibrio is missing, epidemic regions exist where vibrio maintains itself by infecting one individual after another and/or by surviving in the local environment (i.e. a contaminated water well) for brief periods of time between disease victims.

Modern dysentery commonly occurs due to two predominantly tropical microorganisms--Shigella dysenteriae (shigella bacteria) or Entamoeba histolytica (amoeba). These organisms cause diarrhea by entering the intestinal tract and inflaming the inner surface of the intestines and/or the secretion of fluids into these intestines. The spread of these two dysentery organisms is typically from one person to the next through direct contact or indirectly by way of infecting waters, foods, clothing and personal belongings. Once the natural ecology of these 
organisms characteristic of endemic regions is no longer involved, epidemic regions develop where direct person to person contact becomes necessary for the disease to continue to be spread.

These three bacterial agents responsible for Asiatic cholera and modern dysentery epidemics are similar in how they are spread from person to person. Individuals infected by each of these organisms typically have similar reasons for why they were successfully infected. Intestinal tract infections in general are facilitated by low stomach acidity. Therefore, each of these organisms have similar human physiology and geographic requirements in order for single cases and epidemics to erupt. Since the spread of these diseases is primarily anthroponotic in nature, the prevention of these epidemics comes by preventing its further spread from person to person. Therefore, by changing a given human population setting, such as by killing off disease susceptible individuals or by dispersing the population at risk thereby reducing the chance for spread by contact, an epidemic becomes less likely to continue. Should a second disease with similar diffusion requirements infect the now-modified population, it is less capable of diffusing through the population setting.

Throughout history, a number of ubiquitous bacteria have also been linked to the various diarrhea epidemics often confused with shigellic and amoebic dysentery. These microorganisms are less dependent on human population features to form their endemic or epidemic regions. They cause disease whenever people interact with them as a natural part of the surrounding environment. Many of these microorganisms are opportunistic in nature in that they typically infect people whose immune systems have been weakened by poor nutrition, fatigue, alcoholism, 
or severe illness. The diseases these organisms produce are axenotic-zoonotic in nature in that they are spread from animal hosts or reservoirs to people. Due to the littering of the Oregon Trail by animal carcasses, one or more opportunistic bacteria-induced several dysentery epidemics along the Oregon Trail between 1844 and 1852.

To differentiate the Asiatic cholera region of the Trail from opportunistic dysentery regions, the biology and ecology of each have to be considered. Whereas the vibrio responsible for Asiatic cholera epidemic infects people as a direct consequence of the human and natural ecological activities, the bacteria responsible for dysentery along the Oregon Trail tend to be more ubiquitous in nature and less selective in producing epidemic regions. With the organisms responsible for opportunistic dysentery readily available as early as the first trail migrations, the introduction of Vibrio cholerae onto the Great Plains in 1849 caused these dysentery regions to diffuse westward, forming new disease regions further west by 1850 .

\section{VIBRIO BIOLOGY}

\section{Microbiology}

The bacterium responsible for Asiatic cholera, Vibrio cholerae, exists in numerous genetically-identified forms referred to in the medical writings as serogroups and biotypes. The serogroup of Vibrio linked to most modern Asiatic cholera epidemics, Vibrio cholerae $\mathrm{O} 1$, presumably identical to the past epidemic strains, is referred to throughout this thesis unless otherwise noted. The biotypes of 
Vibrio cholerae $\mathrm{O} 1$ noted in this study are the nineteenth century Vibrio cholerae Classical and its early twentieth century replacement Vibrio cholerae El Tor. As of this date, the El Tor biotype is the most common Asiatic cholera pathogen, although several new genetic variations of a potentially more virile nature have surfaced in recent years, including several Vibrio cholerae non-O1 strains and Vibrio cholerae O139 (Kay, Bopp, and Wells 1994, Morris and the Cholera Laboratory Task Force 1994, Wachsmuth et al. 1994).

In spite of these differences, the various serotypes and biotypes of vibrio have similar behaviors as disease-causing organisms. Each induces significant amounts of diarrhea while residing in the human intestinal tract, leading to death due to dehydration. Both also prefer similar ecosystems outside the human body, and tend to reside in similar nesting places or niduses from where new cases and epidemics erupt due to human-environment interactions. Understanding the ecology of Vibrio cholerae is useful for differentiating endemic regions where the bacterium survives naturally in close proximity to human populations, from epidemic regions where its persistence is due to non-ecological reasons related to human populations. For this reason the behavior of the modern Vibrio cholerae El Tor provides us with important insight into the $V$. cholerae Classical.

\section{The Environment}

As detailed by studies of the ecology of Vibrio cholerae El Tor, a number of zooic and geographic features define where the best niduses occur (Table III). Due to its environmental requirements, vibrio survives well in regions which are replenished each spring with nutrient-rich detritus being discharged into deltas and 
estuaries due to snow melt and spring rainwater run-off. These water-based environments also provide vibrio with several mechanisms for migration, namely:

(1) the flow of oceanic water along coastlines which carry vibrio from one ecosystem to the next, (2) the modification of water-based transportation by way of climatic and weather changes; and (3) periodic changes in water flow related to tidal activity. The ability of vibrio to migrate into and out of estuaries not only causes it to come in contact with nutrient rich discharges produced by urban settings but also in some cases to infect people engaged in outdoor activities within this same environment.

\section{TABLE III}

ENVIRONMENTAL PREFERENCES OF VIBRIO CHOLERAE

(ADAPTED IN PART FROM KAYSNER AND HILL $(1994,32)$ AND FROM CONCLUSIONS DRAWN BY THIS STUDY)

\begin{tabular}{|r|l|}
\hline $\begin{array}{c}\text { Environmental } \\
\text { Features }\end{array}$ & \multicolumn{1}{c|}{ Vibrio Preferences } \\
\hline Temperature & $\begin{array}{r}\text { refrigeration increases vibrio lifespan, see growth at } \\
\text { Temperatures }>10 \mathrm{C}(50 \mathrm{~F})\end{array}$ \\
\hline Humidity & survival is better with higher humidity \\
\hline $\mathrm{pH}$ & range of 6.0 to $10.0,7.0$ to 8.5 is favored \\
\hline Salinity & $\begin{array}{l}0.25 \% \text { to } 3 \% ; \text { optimum conditions at } 2 \% \text { with } \\
\text { adequate sodium ions }\end{array}$ \\
\hline Organic Debris & serves as nutrient, extending vibrio survival \\
\hline Sunlight & reduces lifespan of vibrio \\
\hline Osmotic Pressure & high osmotic pressure reduces vibrio vitality \\
\hline Geography & favors estuarine and deltaic environments \\
\hline Ecology & favors ecosystems with crustacea, some fish, some \\
& algae, and some aquatic vascular plants \\
\hline
\end{tabular}


In a study of United States coastline settings by Seidler and Evans (1984), the most important features for a stable vibrio environment were found to be $\mathrm{pH}$, salinity and dissolved Oxygen stores. Since the ocean water environment is often too saline for vibrio, the estuary creates more stable growing conditions due to a mixing of fresh water river effluence with naturally flowing ocean water cross-currents. This mixing of waters also replenishes its environment with dissolved oxygen stores and helps to stabilize the $\mathrm{pH}$ and alkalinity that exists in this environment, making it more supportive of vibrio survival.

One of the more important human ecological features for vibrio survival is the discharge of human-generated sewage containing well-digested organic materials enriched by a significant amount of nutrients. This human ecological interpretation of vibrio behavior can be used to define several ecosystems where several of the more common Vibrio species survive. The natural reservoirs noted for these Vibrio species are primarily coastal (deltaic) in nature but also include some fresh, brackish and estuarine water environments. When these natural environments are combined with human-generated (physioanthropic) sewage outflow environments, a particular species, Vibrio cholerae, has the ability to survive as a suspended or free-floating organism capable of infecting people exposed to these contaminated waters (Table IV). 


\section{TABLE IV}

PRINCIPLE RESERVOIRS FOR VIBRIO SPECIES ASSOCIATED WITH FOOD-BORNE DISEASES IN THE UNITED STATES (BLAKE 1984, 580)

\begin{tabular}{|l|l|l|l|}
\cline { 2 - 4 } \multicolumn{1}{c|}{} & \multicolumn{2}{c|}{ Water-based Environments } \\
\hline Species & reservair & sewage & free-living? \\
\hline V. cholerae 01 & fresh and coastal water & sewage & free living \\
\hline V. cholerae non-01 & unclear & sewage & probably free living \\
\hline V. hollisae & probably coastal water & unknown & unknown \\
\hline V. mimicus & probably coastal water & unknown & unknown \\
\hline V. parahaemolyticus & $\begin{array}{l}\text { estuarine and coastal } \\
\text { water }\end{array}$ & $\begin{array}{l}\text { possible sewage- } \\
\text { borne strains }\end{array}$ & free-living \\
\hline V. vulnificus & $\begin{array}{l}\text { coastal and brackish } \\
\text { water }\end{array}$ & unknown? & free-living \\
\hline
\end{tabular}

\section{Vibrio Ecology}

Due to the tendency for vibrio to utilize organic debris and other forms of organic waste for nutrition, vibrio often likes to bind to the chitinous exoskeleton of living animals which are detritus feeders. In Colwell's studies of the natural ecology of vibrio, a close symbiotic-like relationship was show to exist with the copepod, a microscopic animal which periodically migrates into estuaries for feeding and reproductive purposes (Colwell 1984). By adhering next to the oral cavity of the copepod, Vibrio cholerae maximizes its exposure to incoming organic debris consumed by the copepod, and is thought to enter the copepod's gut at times in order to initiate reproductive processes (Oppenheimer 1978, West and Colwell 1984, Colwell and Huq 1994). This vibrio may also be carried into and out of the estuary by this mobile organism, or be moved from nutrient-poor environments into nutrient-rich environments. In a study related to this migration behavior, vibrio has also been shown to attach to egg sacs of copepods, a process which facilitates its 
dispersal into new ecosystems by way of egg releasal into new environments sought out by the copepod during periods of environmental stress (Huq et al. 1984, 521, 529).

Other organisms important to vibrio ecology include prawns (Kundu and How 1938), shrimp (Roberts, Bradford Jr., and Barbay 1984) and oysters (Ronchetti, 1911-1912, Pollitzer 1959, 877, Colwell and Liston, 1960, 1961, Baross and Liston 1970). In freshwater environments, the crayfish is suspected to support vibrio growth (Pollitzer 1959, 860). Like the copepod, a number of these shellfish provide vibrio with a chitinous shell to adhere to for protection and assist it in migrating to new ecosystems during periods of ecological stress (Kane, Culver, and Mathieu 1994). Another advantage to this relationship with marine organisms is that it improves vibrio's chance of becoming a part of the local human ecology and infecting people to cause Asiatic cholera outbreaks.

\section{Vibrio Human Ecology}

Since both animal and plant ecology play important roles in vibrio survival, possible axenotic zoonotic associations exist between vibrio, marine animals and people. Marine animals are involved in the passage of vibrio to humans due to its ability to survive on edible fish and shellfish. It may also be passed to human by way of a number of environmental causes, including contact with vibrio-contaminated animal parts, contact with ocean water in which vibrio remains suspended, and/or particular surfaces on which vibrio continues to exist ecologically or as a simple contaminant produced by other cholera victims. 
The shells of crabs in particular support vibrio activity in both its natural and human environments. In the natural setting, the chitinous shell protects vibrio from possible environmentally-induced chemical damage, including changes in the $\mathrm{pH}$, alkalinity, and salinity of the water. Likewise, this adherence to crab shells has been shown to prevent the destruction of vibrio during its pass through the normally acidic stomach environment following consumption (Dietrich, Hackney and Grodner 1984).

Due to this link between the consumption of crabs and cholera epidemic onset, a number of studies have been carried out detailing the ability for vibrio to reside on foods and other domestic items. Preliminary studies focused on its ability to spread by way of foreign and food surfaces (Pollitzer 1959) (Appendix B). In more recent studies, Blake (1984) suggested that the various forms of vibrio were spread primarily by undercooked crabs (particularly for Vibrio cholerae $\mathrm{O} 1$ and $V$. parahaemolyticus), lobsters ( $V$. mimicus), crawfish ( $V$. mimicus), raw oysters $(V$. cholerae non-O1, $V$. hollissae, and $V$. vulnifucus), and possibly turtle ( $V$. cholerae 01). In a more detailed study focusing on culturally-defined causes for the disease, Mintz, Popovic and Blake (1994) demonstrated certain food preparation techniques involving various seafood and other tropical food stuffs to be linked to Asiatic cholera incidence in United States citizens returning from international travel (Table V). 


\section{TABLE V}

\section{FOODS ASSOCIATED WITH VIBRIO CHOLERAE CASES \\ IN THE UNITED STATES, 1972 TO PRESENT \\ (MINTZ, POPOVIC AND BLAKE 1994, 350)}

\begin{tabular}{|l|l|l|}
\hline Country & Year & Food \\
\hline Australia & 1972 & Hors' d'oeuvres \\
\hline Italy & 1973 & raw mussels \\
\hline Portugal & 1974 & raw/undercooked mussels \\
\hline Guam & 1974 & lome-preserved pada (salted raw fish) \\
\hline Gilbert Islands & 1977 & raw and salt fish and clams \\
\hline Singapore & 1982 & cooked squid \\
\hline Truk & 1982 & ill food handlers infection \\
\hline Mali & 1984 & millet gruel \\
\hline Guinea & 1986 & leftover cooked rice \\
\hline Thailand & 1987 & raw pork \\
\hline Guinea-Bissau & 1987 & cooked crabs \\
\hline Malawi & 1990 & cooked pigeon peas \\
\hline Chuuk & 1990 & raw fish \\
\hline Maryland (Thailand) & 1991 & frozen coconut milk \\
\hline Ecuador & 1991 & seafood \\
\hline Peru & 1991 & cooked rice \\
\hline Peru & 1991 & raw vegetables and fruit \\
\hline Peru & 1991 & street vendor food \\
\hline New Jersey (Ecuador) & 1991 & cooked crabs in cold salad \\
\hline New York (Ecuador) & 1991 & cooked crabs in cold salad \\
\hline California (Peru) & 1992 & shrimp and fish in cold salad \\
\hline Louisiana & 1978 & cooked crabs \\
\hline Texas & 1981 & cooked rice \\
\hline Louisiana & 1986 & cooked crab, cooked or raw shrimp \\
\hline Colorado & 1988 & raw oysters \\
\hline
\end{tabular}

These relationships between vibrio, shellfish, and fish play an important role in the spread of vibrio to human populations residing near Asiatic cholera endemic and epidemic regions. Once consumed, vibrio can pass through the stomach environment unaffected by stomach acidity if it attaches to the right food 
substances, after which it thrives in the human intestinal tract about 3 days, but may last as long as 26 days in a "healthy," non-convalescent victims, and 42 days in convalescent victims (Greig 1914, Pollitzer 1959, 867).

\section{Vibrio Behavior and Demographics}

This human ecology of vibrio in relation to demography and human behavior provides important insights into how Vibrio cholerae behaves in the human body. Once this organism is placed in close proximity to a population of people, one or more disease-related behaviors may result in the development of disease. In endemic regions, Asiatic cholera recurs regularly causing a temporary immunity to develop in that population over time due to recurring exposure and infection by the bacterium. In epidemic regions, large numbers of cases develop in densely populated settings in very short time due to a lack of immunity and a disease which does not recur periodically or regularly due to a lack of local natural ecological features. Therefore epidemics often have a greater impact on populations in which large numbers of people are susceptible to the disease. This implies an ecological relationship between Asiatic cholera and large human population settings close to the nidus where various human behaviors make it more likely for vibrio to connect with and infect the right people. Therefore, by surviving in regions close to large human populations, vibrio not only benefits from the human waste discharged into the estuary or delta, but also increases its likelihood of surviving as a disease-producing organism (Cash et al. 1974, Blake 1984).

To infect people, vibrio has to first avoid exposure to stomach acids and enter the intestinal tract environment where it then begins to engage in its normal 
biological activities. Vibrio enters the intestines by either adhering to the chitin surfaces of certain food items, being ingested with alkaline food substances and beverages, or entering individuals with low stomach acidity (Greenberg et al. 1984). This low stomach acidity requirement is important to note since it typically occurs in people who either inherit this condition (achlorhydric people) or are engaged in personal and social behaviors related to poor nutrition, alcoholism and physical stress (hypochlorhydric people). In the case of the hypochlorhydric individual, personal and sociological reasons often exist for this condition, suggesting that large populations are more likely to be infected by the disease due to the greater number of people per unit area potentially predisposed to becoming infected by Vibrio cholerae. Since each of these human genetic and personal behavioral causes for Asiatic cholera development is common in certain large population settings, such settings placed close to deltas and estuaries become some of the first to be impacted by the global diffusion process.

\section{Vibrio and the Human Intestinal Environment}

By passing into the intestines, the threat of stomach acids is greatly reduced by the secretion of highly alkaline bicarbonates by the pancreas. This changes the $\mathrm{pH}$ of the intestine tract and makes it more useful as a growing medium by vibrio. To improve this environment vibrio secretes a toxin which causes sodium ions to enter the gut followed by the osmosis of water, in the end creating a more hospitable estuary-like environment similar to the copepod gut in which vibrio is suspected of reproducing (Kaper, Fasano, and Trucksis 1994, 150-151). 
According to Huq et al. (1984), the probability interactions between vibrio and people increases with each stage vibrio passes through in the food web. An early introduction into the food web increases the size of its population within the infected organism and improves its chance for infecting people. Vibrio may also be introduced into a population by way of contaminated drinking water or water used in recreational activities.

\section{Incidence}

For Vibrio cholerae Classical, the morbidity and mortality behaviors have been demonstrated quite well statistically by past medical geographers and epidemiologists (Appendix C). The age groups of people most susceptible to the disease are both children and elders, although a greater number of cases and associated fatalities tend to occur in middle age groups (ca. 40-60) due to the day to day living activities they engage in which expose them to either other Asiatic cholera carriers and victims, possessions contaminated by these victims, and the various naturally-formed ecological settings common to outdoor human recreation activities. The result of this pathogenic activity is the production of large amounts of vibrio, followed by its elimination from the body in the form of "rice water stools," a whitish, cloudy fluid diarrhea discharge resembling the water poured off of rice in which numerous small white particulates are seen (Kaper, Fasano, and Trucksis 1994, 150-151). 
Summary

Since both the human gut and the natural estuary provide vibrio with the chemical and physical features needed for its survival, the potential for preventing the transmission of Asiatic cholera to other people seems identical from culture to culture. Proper sanitation practices reduce or prevent human contact with whatever vibrio is surviving in the local environment. The modification of certain living practices common to low socioeconomic status also impacts the likelihood for contacting this disease and becoming fatally dehydrated. Therefore, the best way to avoid Asiatic cholera is to engage in clean and healthy living practices.

\section{DYSENTERY ECOLOGY}

Dysentery is a severe form of diarrhea accompanied by bleeding and mucus. It is typically induced by the ingestion of specific microbial organisms. The most common modern forms of dysentery produced by Entamoeba histolytica (amoebic dysentery) and Shigella dysenteriae (bacillary dysentery) rely heavily upon human population features to be transmitted from one person to the next. Both were probably uncommon to the Oregon Trail, except perhaps during its first few weeks of travel. In addition, changes in trail population brought on by a constantly dividing trail and the impact of the Asiatic cholera epidemic made the more western parts of the migration through the Great Plains less populated and therefore less likely to support these two primarily human-dependent anthroponotic forms of dysentery (for reviews of each, and additional geographic reasons for their exclusion, see Appendix D). The more common form of dysentery to the Trail environment was induced by opportunistic infections like Salmonella and 
Campylobacter. Several other possible bacterial causes like Escherichia and Yersinia are reviewed in the appendix as well.

Salmonella

Salmonellosis is produced by various members of the genus Salmonella. A strain of Salmonella enterica was the first to be identified as a cause for diarrhea following the ingestion of raw meat from an infected cow during the late 1800 s. Then known as Gaertner's bacillus, this organism has since proved capable of producing numerous forms of food-generated non-typhoidal Salmonella infections.

The most famous bacteria of this genus, Salmonella enterica Typhi, is responsible for Typhoid fever (Tauxe and Pavia 1994, 613). Salmonella paratyphi and the $S$. schottmulleri have been associated with paratyphoid fevers. Two other strains of Salmonella, sometimes referred to as distinct species, S. enterica Cholerae-suis and S. enterica Enteritidis, resemble Asiatic cholera in their epidemic behavior.

The zoonotic behavior of salmonella most often takes the form of an infection of living animal tissues, most commonly involving wild animals and livestock (May 1958; Waterman, Juarez and Carr 1990; Tauxe and Pavia 1994; Miller, Hohmann, and Pegues 1995). Dairy cattle are known to carry S. dublin and S. typhimurium (Tauxe and Pavia 1994). Salmonella enterica Bovis-morbificans relies on cattle for its reservoir ( ibid). In each of these zoonotic disease cases, the various forms of Salmonella may be spread through human contact with decaying animal parts and carcasses (Clarenburg 1964, 150; Banatula et al. 1999). 
The geographic distribution of salmonella is global, with epidemics known to occur in sub-arctic regions like Saskatchewan as well as the tropical climates of Southeast Asia. Soil chemistry is important to determining whether or not salmonella will remain in a region. Ground water activity can spread it from one place to the next. Salmonella tends to survive longer in the outdoors during cold temperatures, becoming more infectious as the natural thaw-water flow reach its peak (May 1958 177).

For the typhoid and paratyphoid strains of Salmonella, pollution of water is often a precursor for many epidemics. The flow of human waste from sewers into local waterways following a period of heavy rain is a common cause for epidemics. Camp settings make for highly contagious disease settings.

The most common vehicle linked to the spread of Salmonella is contaminated food, especially poorly processed fish, shellfish, meats and dairy products. The meats of wild fowl are known to carry several species of this organism. Oysters may carry Salmonella when they are grown in beds in sewage contaminated water.

Most of the current salmonella-induced epidemics occur in industrialized agriculture settings and are often linked to improper meat processing techniques. For this reason, many salmonella epidemics are considered anthropogenic in nature, their incidence increasing in direct relationship with the region's population density and economic development. Food handlers who deal with raw milk, fruit, poultry, unprocessed raw meats, and wild animal meats are often linked to these epidemics. Historically, the salmonella epidemics have been linked to well-developed portions of the Eastern United States, more so than the Pacific 
Northwestern States. Within a single human population setting, the infection of cattle and beef products is the most common cause for the rapid passage of this disease to large numbers of people (Tauxe and Pavia 1994, 620).

Salmonella outbreaks are characterized by the rapid development of numerous cases from a common source of exposure. This disease impacts mostly children under 15 years of age, followed by rapid decline in fatality experienced by middle age groups until 65 years of age or greater is reached. As with Asiatic cholera and shigellic dysentery, those most susceptible to Salmonella infections suffer from hypochlorhydria (ibid 621).

Symptoms of this diarrhea include mucus- and blood-streaked stools, prolonged diarrhea, vomiting and fever (ibid 624). The fever onset may differentiate this disease from the more severe bloody diarrhea or dysentery due to shigella. In many cases, the fever resolves itself in 48 to 72 hours, making cases that last more than ten days unusual and suggestive of another bacterial cause (Miller, Hohmann and Pegues 1995, 2020). When deaths do occur, they often result in fatalities due to the septic shock and an arrest of heart functions associated with the development of a massive blood-based infection (Tauxe and Pavia 1994, 614).

\section{Campylobacter}

Campylobacter is a zoonotic disease associated with cattle and sheep. Campylobacter jejuni, C. fetus, C. coli, C. laridis, and C. pylori are the most noted species in this genus, of which, the first two are considered opportunist organisms which are capable of infecting people with compromised immune systems. 
Common causes for this susceptibility include chronic alcoholism, cancer, diabetes, heart disease, and old age. A number of farm animals and domestic pets often serve as common hosts for these bacteria. Given the right living conditions, these organisms may survive for outside of the human body for several weeks as contaminants of a number of food products, milk, fecal material and water (Allos and Taylor 1994, Blaser 1995).

Broadly dispersed throughout the world, campylobacter is capable of infecting both developed and developing countries and has its greatest impact on children under five years of age, and adults who are 20 to 30 years of age or 60 to 80 years of age, who often demonstrate a high incidence of mortality due to diarrhea.

Seasonally, campylobacter is most active during the warm summer months. Within an environment bearing a neutral to alkaline $\mathrm{pH}$, it may survive as long as three months, even at temperatures approaching 100 degrees Fahrenheit. Recent reviews suggest it favors a warm climate to initiate its resurgence in the form of dysentery in the United States setting (Taylor, McDermott and Little 1983, Allos and Taylor 1994).

Hyperendemic regions are noted to exist for campylobacter, places where new-comers become easily infected whereas regular residents experience infrequent dysentery outbreaks due to a temporary immunity they have developed (Bolton et al. 1999). During the mid-nineteenth century the rapidly developing United States could have experienced this hyperepidemic behavior permanent settlement like to early fort settlements where stable local populations existed, a 
behavior which enables new epidemics to develop each time migrating populations pass through.

Another feature favoring campylobacter-induced dysentery in pioneer regions is the very low cell count needed for the bacterium to successfully infect individuals. As few as 500 cells have been shown to initiate an epidemic. Undercooked foods can harbor the bacteria and spread the infection to unsuspecting victims. People who come in direct contact with cattle, sheep, beef, horses, swine, and chickens may pick up and carry this disease to other animals and people. As with salmonella-induced dysentery, unpasteurized milk is a common cause for the campylobacter cases where bovine udder mastitis is common in dairy cows. Campylobacter has also been associated with diarrhea epidemics in the Rocky Mountains due to the contamination of drinking water (ibid).

According to Allos and Taylor (1994) campylobacter-induced dysentery is twice as likely to occur in humans as salmonella and 4.5 times more likely than shigella. Some species are capable of eliciting a severe, dehydrating form of diarrhea. Campylobacter jejuni in particular, like Vibrio cholerae and Shigella dysenterica, produces a toxin with diarrhea-inducing effects. In current epidemic strains, this diarrhea lasts from two to three weeks and is accompanied by abdominal pain and fever.

\section{Summary}

In cases of dysentery when the continuation of the epidemic is dependent primarily upon human interactions, Shigella-induced dysentery may have occurred but is not included in this study of the dysentery noted along the higher altitude 
regions of the Oregon Trail. Of the most likely opportunistic bacteria associated with dysentery, Salmonella and Campylobacter are the most likely causes along the Oregon Trail due to their association with both live animals and decaying carcasses and their possibility of spreading by way of various fomites and vehicles (for further coverage on other causes for diarrhea on the Oregon Trail, see Appendix D). 


\section{CHAPTER IV}

\section{ASIATIC CHOLERA AND DYSENTERY GEOGRAPHY}

The geographic features underlying the Asiatic cholera and dysentery epidemic diffusion processes are useful in differentiating between the two. For Asiatic cholera, once the ecosystem of its pathogen, Vibrio cholerae, is departed, the resulting inland migration has attached to it specific biogeographic and physical geographic features responsible for how the pathogen may or may not continue to behave in epidemic form. Furthermore, as these biogeographic and physical geographic requirements for vibrio survival are reduced due to the inland migration, the behavior of its attached disease becomes defined more so by the human population features, making human geography the most important determinant as to whether or not Asiatic cholera will continue to diffuse inland away from its natural ecological setting and the attached tropical climatic setting.

Unlike Asiatic cholera, opportunistic dysentery has numerous bacterial causes. In the case of the epidemics which infect the Oregon Trail, one or more species of opportunistic bacteria are responsible. For this reason, whereas Asiatic cholera has a well-defined history with both endemic and epidemic regions defined by the ecology and geography of vibrio, the numerous bacterial causes for dysentery are often endemic and ubiquitous in nature, and behave according to a number of physical geographic, zoogeographic, and human geographic causes. 
Aside from these ecological interpretations of the disease patterns, human geographic requirements play important roles in differentiating Oregon Trail dysentery from Asiatic cholera regions once the disease has diffused inland, which for vibrio is away from its natural ecological setting. Since Asiatic cholera is spread primarily through person-to-person contact once it leaves its original nidus, a method of disease transmission greatly reduced by the human fatalities it causes. With respect to a typical migration route like the Oregon Trail, numerous forks and cut-offs further diminishes the impact of this diffusion process might have by further reducing population density.

The organisms responsible for dysentery, however, are not solely reliant on human geographic features for their continued survival. As opportunistic bacteria, they are dependent on the behavior of animals and are of axenotic, zoonotic origin. They rely primarily on the location of decaying carcasses along the Oregon Trail and the ability of these carcasses to infect people without need for a direct transmission process. The geography of these organisms and animal hosts not only helps to explain why Asiatic cholera ceased its northwestward migration along the Trail whereas dysentery continued this diffusion westward.

\section{ASIATIC CHOLERA GEOGRAPHY}

The nidus or nest for Asiatic cholera is where endemics erupt repeatedly and where global epidemics or pandemics are born. The original nidus for Vibrio cholerae is suspected to be the Bay of Bengal situated off the coast of India and Bangladesh, where detritus discharged of the Ganges river provides it with valuable nutrients supplemented by human waste (May 1951a, 1951b) (Figure 8). 

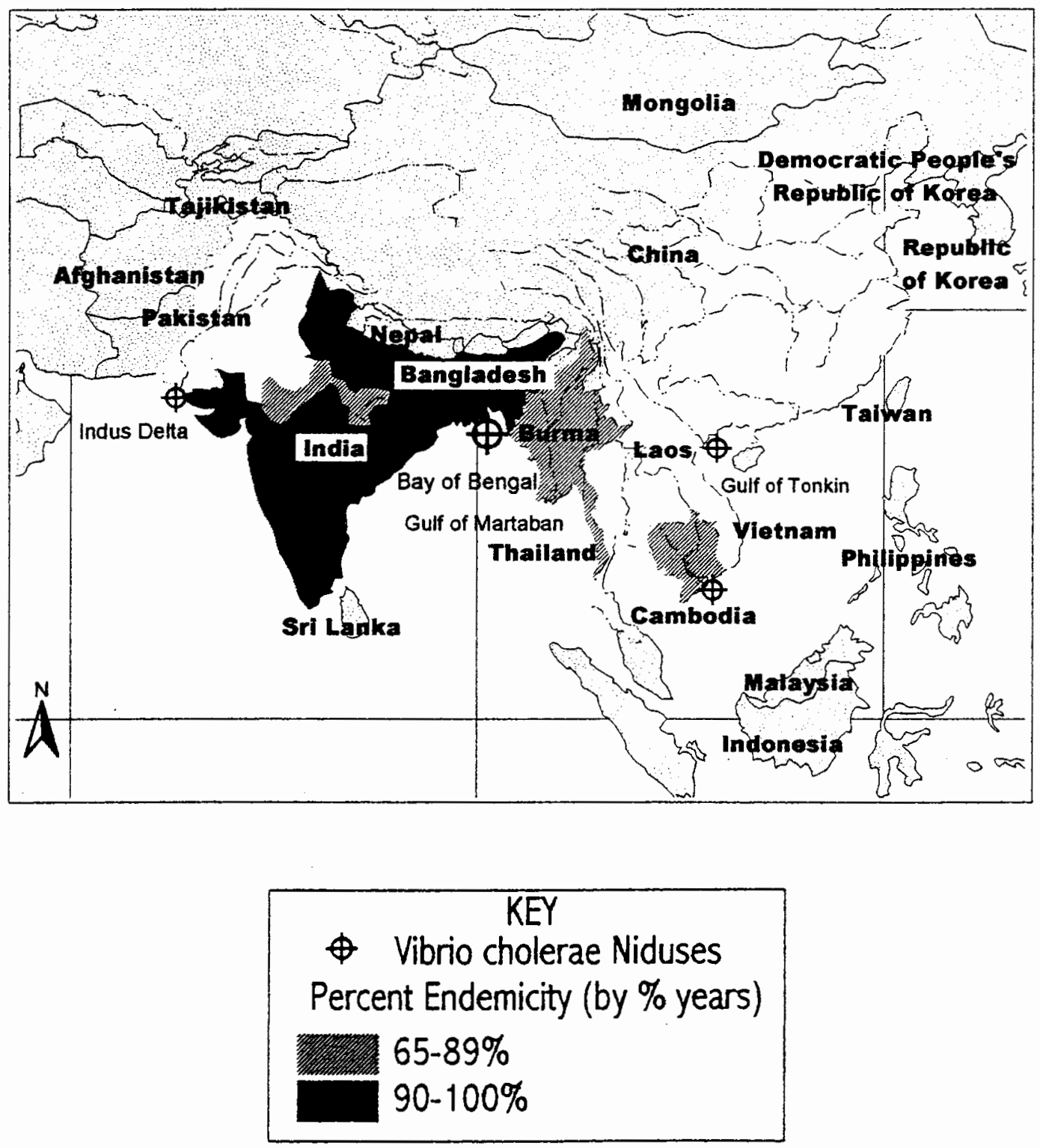

Figure 8. The Asiatic Cholera Niduses in India and Southeast Asia (May 1951b) 
This placement of the nidus allows vibrio to survive within an active ecosystem close to a sizable human population, two features responsible as well for the more recent development of niduses within the delta and estuary environments of Chesapeake Bay, the Gulf of Mexico, and the coastlines of parts of Africa and Latin America (Blake 1994a, 1994b, Swerdlow and Isaacson 1994, Tauxe et al. 1994). According to Haggett, the original nidus for Vibrio cholerae in the Ganges River Delta (about 20 degrees north, 70 degrees west) developed as a long term consequence of the local ecology and human geography of this region. Haggett suggests endemic cholera first developed in this nidus about 5000 years ago due to the human population growth. As human population density increased, the ability of vibrio to successfully infect new victims quite regularly allowed for the development and maintenance of infections chains followed by the formation of an endemic nidus (Haggett 1994). Therefore, both ecologically and demographically, the spatial requirements for a vibrio nidus and the development of an Asiatic cholera endemic region can be more accurately defined.

By understanding the biogeography, physical geography and human geography of Vibrio cholerae as a potential pathogen, we are provided with insights into why the disease develops elsewhere in the world and well-distanced from the original nidus. This interpretation of Vibrio cholerae Classical, the evidence for which is provided by nineteenth century medical journals, helps to define how and why certain endemic and epidemic regions for Asiatic cholera exist as well as how vibrio tends to behave before and during the infection process within particular population settings. Such nidal and ecological environments for vibrio may in turn be related to the Oregon Trail. 


\section{Biogeography}

Biogeography plays a key role in defining the different ecosystems, niduses and potential endemic and epidemic regions for Asiatic cholera (Figure 9). By residing naturally within an ecosystem formed by warm salt water mixed with detritus-rich fresh water river discharges, Vibrio cholerae remains biologically active and stable within this environment regardless of its irregular and often unpredictable contact with nearby human populations. Between human infection periods, vibrio develops important ecological connections with various animals in the regions. Colwell (1984) suggests that these commensal relationships between vibrio and the various animal populations are due to their shared need for decaying organic matter or other organisms closely associated with that organic matter.

Studies supporting Colwell's conclusion include several classical ecological studies in which bottom feeding fish were found to be capable of carrying vibrio inland along estuaries and large rivers, for example Hilsa (Hilsa ilisha), Climbing Perch (Anabus testudineus) and Murrel (Opiocephalus punctatus) of India and Bangladesh (Pandit and Hora 1951, 861-862). By residing mostly in the bottoms of murky waters of estuarine and deltaic environments, these fish are capable of carrying vibrio to new ecosystems, swimming well below the surface and therefore protecting vibrio from excess exposure to fatal solar radiation.

Vibrio also has been shown to have numerous associations with algae and plants. As early as the mid-nineteenth century, an association of Asiatic cholera to aquatic river plants was made by several medical geographers who related Asiatic cholera incidence to stagnant waterways due to ongoing plant decomposition (Hall 1855, Buel 1856, Stillman 1851, Estrauzlas 1873). More recent studies on this 


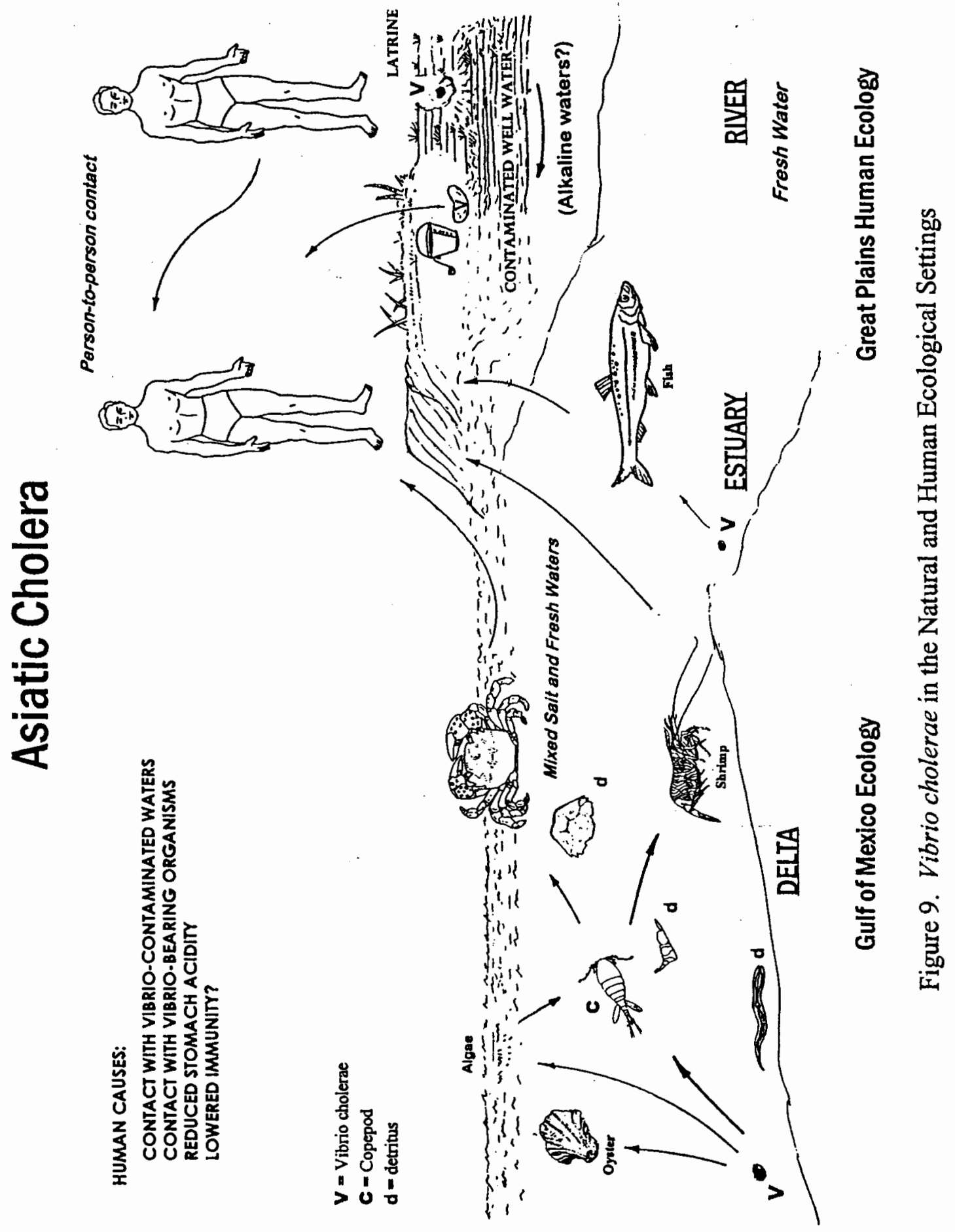


particular aspect of vibrio ecology behavior demonstrate similar relationships between disease incidence and local vegetation patterns involving duckweed (Lemna minor), water lilies (Nuphar and Nymphaea spp.), sedges (Cyperus and Carex spp.), reeds (Arundinaria gigantea), rush (Juncus and Scirpus spp.) and water hyacinth (Eichhornia spp.) (Islam, Draser and Bradley 1990, Islam, Alam and Neogi 1992, Spira et al. 1981). Within brackish water and fresh water environments, vascular plants are suspected of being supportive of vibrio due to the nutrients they provide as well as a growing surface to attach to and another means of protection from harmful solar radiation (Huq et al. 1984, 521).

The most recent methods used to study disease behavior focus on vibrio ecology. Since Vibrio cholerae has also been associated with rapidly dispersing Rhizoclonium fonatanum blue-green algal populations, a food source for copepods (Islam, Draser and Bradley 1989, Islam 1990), remote sensing has become an important tool for monitoring algal blooms and copepod activity related to vibrio activity, a disease surveillance technique potentially applicable Asiatic cholera endemic prediction (Epstein 1998). Similarly, a number of early twentieth century studies focusing on Asiatic cholera prediction by way of tidal and weather monitoring processes (Rogers 1928, Russell and Sundararajan 1928), have more recently been matched by similar studies about disease behavior based on El Nino activity and how these long term and short term changes in climate, lunar (tidal) activities, and solar-generated seasonal activities might impact the copepod which vibrio survives on (Arbona and Crum 1996, Dold 1999; CHAART 2000). 


\section{Physical Geography}

In the United States, a number of physical geographic features define cholera-prone regions outside of the typical nidal or endemic region for Vibrio cholerae. Local fluvial features, the elevation of land above local water levels, and topography or landscape provide the means for a transitory nidal-like region to develop under the right climatic conditions. These nidal-like regions in turn enable vibrio to remain viable outside the human body between victims, increasing its likelihood of finding new victims well after the last infected person has passed away. In warmer regions, for example, as vibrio migrates inland along estuarine rivers and makes contact with inland populated regions, new cases often erupt due to highly susceptible people residing within a town or city. As this vibrio migrates further inland and further away from its estuary environment, it becomes more detached from its natural ecological setting and begins to depend more upon features present in the local physical and human geographic settings to remain alive. The most important of the physical geographic determinants for vibrio behavior inland are local hydrology and flood plain geography.

During its residency in the deltas and estuaries just off the coast, Vibrio cholerae was provided with ample amounts of dissolved sodium ion stores in water and proper alkalinity typical of this natural setting (Tison and Kelly 1984). By diffusing inland, changes in water chemistry reduce its ability to maintain itself ecologically outside the human body for long periods of time, thereby increasing its dependence on the process of repeatedly infecting human victims. For this reason, vibrio tends to follow heavily traveled rivers, an observation which led Benjamin to coin the term "Riverine cholera" for this form of diffusion (Pollitzer 1959, 876). 
Well-distanced from the estuarine environment, hydrochemical features become more important to the survival of vibrio in regions devoid of adequate human populations (Jusatz 1977). As certain river reaches or channel segments are passed, some may suddenly become capable of serving as important transitory niduses for vibrio during its more stressful periods of inland activity due to their salinity and large amounts of natural and human generated detritus. One of the best examples of these rivers in North America is perhaps the Platte River of the Midwest, a braided river surrounded by broad flood plains through which fairly alkaline, moderately warm saline waters flow.

Latitude. Asiatic cholera often changes its latitude and thereby experiences a climate change as it migrates inland along rivers. Such regional climate patterns in relation to latitude and disease often played an important role in understanding the disease diffusion process during the mid-nineteenth century, an important part of medical geography first described in detail by two British doctors, Johnston (1856) and Little (1874). Johnston considered certain diseases to be endemic to tropical or "Torrid disease realms" because of the warmer climates, which he defined as having a mean annual temperature of 72 degrees Fahrenheit or more (Johnston 1856). Johnston termed the cooler regions "Inflammatory disease realms" due to the nature of the epidemics they produced, and "Catarrh disease realms" for the more colder portions then traveled. During the later part of the nineteenth century, these regions were renamed "Tropical," "Temperate," and “Arctic" disease realms (Little 1874).

Since Asiatic cholera was born in and behaved more aggressively within the tropical environment, Johnston and Little expected it to become less fatal once it 
left this latitude-defined climatic region. The further away from the tropical setting progressed, the less active it became until it ceased its diffusion process due to significant climatic changes. This climate-regulated behavior of Asiatic cholera has historically been matched by two other forms of "tropical dysentery" brought on by shigella and amoeba, each of which, according to Johnston's and Little's arguments demonstrated reduced activity in developing countries located in the much cooler climates of the northern and southern temperate zones. This dysentery could in turn be differentiated from the more opportunistic forms of dysentery already present in the much cooler climates experienced by still other developing countries, like the United States.

Topography. This climate-generated model for disease behavior also has its matching elevation-related component, particularly for regions where mountain climates prevail. The higher up a mountain one ascends in these regions, the less virulent the epidemic is expected to become and the more it dependent it is on direct person-to-person transfer to continue its diffusion process. This topographical view of Asiatic cholera behavior is most applicable to any flood plain setting in which epidemics erupt. Whereas along coastlines elevation is typically measured as a vertical distance above local sea level, along inland rivers and large water bodies, this elevation may be measured as a vertical distance above the local water level. On the oceanic shorelines, Asiatic cholera occurred most prevalently due to its close ecological association with the marine environment. In riparian flood plain environments, this behavior of cholera relative to elevation above local water surfaces was best demonstrated by William Farr of England, who in his $\mathbf{1 8 5 2}$ study of cholera in London showed that residents living close to a river 
had the greatest risk of becoming infected (Farr 1852 in Susser 1973, 53, Stolley and Lasky 1998) (Figure 10).

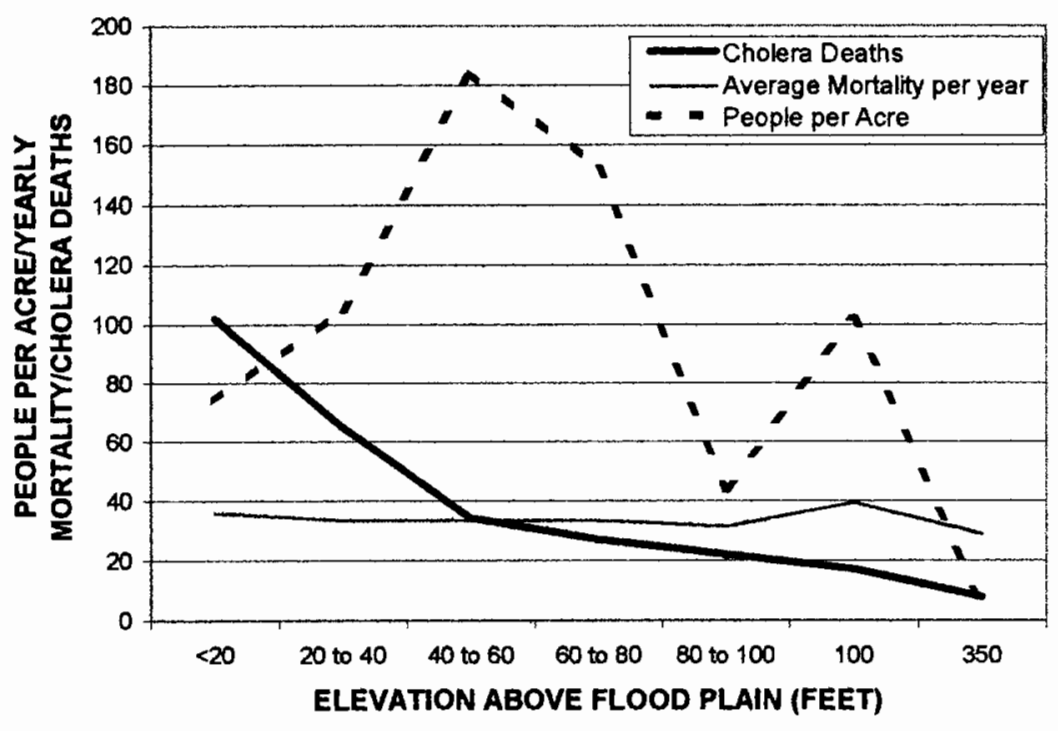

Figure 10. Cholera Deaths in Trinity, England in 1848, Relative to Proximity to Stream,, Number of People per Acre, and Average Mortality per Year of Areas Defined by Elevation above Stream (Farr 1852, in Susser 1973, 53)

This relationship between elevation and Asiatic cholera incidence existed in large part due to the way this impacts the survivability of vibrio within alluvial plain settings and aquifers between disease victims. Proximity to a local river setting implies not only proximity to a preferred environmental setting, but also proximity to disease hosts interacting with or migrating along that same environmental setting. Farr's study also demonstrated that this higher incidence of Asiatic cholera deaths did not necessarily ensue due to high population density, for 
following ascent from the stream, cholera deaths decreased considerably in spite of greater population densities at 40 to 60 and 100 feet above the local river. Similar studies by Snow and other physicians have also demonstrated proximity to river to be linked to Asiatic cholera onset due to the tendency for drinking waters to be contaminated by nearby sewage overflow and water main leaks (Snow 1849, 1936).

This association between Asiatic cholera deaths and elevation or distance above local water level formed the core of many nineteenth century medical topographers' arguments for the development of cholera in epidemic form within shoreline urban settings. Several mid-nineteenth century American physicians used this reason to explain why communities residing at low elevations in Ohio and Illinois were more heavily impacted during the 1832 and 1849 epidemics (Hall 1855, Knapp 1855a, 1855b). In 1889, British medical geographer Felkin concluded that the people most prone to cholera resided near the mouth of the Ganges in houses close to the river, adding "should the hill men descend from their mountains, or have any communication with the inhabitants of the plain, they suffer severely" (Felkin 1889, 21). Likewise, India cholera specialist Swaroop related elevation to Asiatic cholera by defining the typical birthplace for a cholera epidemic in India as a densely populated region where humid climate prevailed and where low-lying lands were placed adjacent to rivers less than 500 feet above sea level (Pollitzer 1959, 824; Swaroop, 1951).

The above topographic observations about Asiatic cholera activity by medical geographers suggest that rapid changes in elevation, such as by migrating through mountain ranges, is one of the most important topographic limitations to Asiatic cholera diffusion. Elevation not only reduces the likelihood for vibrio 
survival due to changes in landscape features and available water supplies, but also because of how these changes impact local temperature conditions. For these reasons, mountains formed an important barrier to cholera diffusion. During one of the cholera epidemics of the late nineteenth century in India, for example, cholera diffusion along the east coast was checked by the sparsely inhabited hills which stretched down to the coastline (Rogers 1928; Pollitzer 1959, 56).

Soil and Geology. Soil-based theories for Asiatic cholera began to surface during the early 1800 s, but it wasn't until the late 1840 s, when Bavarian scientist and hygienist Max von Pettenkofer speculated that air within the soil layers could be a cause, that several pedological theories for Asiatic cholera became popular (Hume 1927). A major component of Pettenkofer's theory claimed that aerated soil which bore oxygen could facilitate disease production due to its tendency to emit effluvium from its substratum (a variation of the miasma theory). Pettenkofer believed regions prone to this effluvium lacked a solid rock foundation and contained a porous soil rich in organic detritus which produced toxic substances capable of "ripening" the causative agents for the disease. Referred to as the "telluric" and "terrene" theory by other medical geographers, Pettenkofer's supporters proposed that cholera ensued whenever soils became impregnated by its contagion and bore the environmental conditions required for its causative agent to proliferate and disperse in epidemic form (Garrison 1929, 658).

By 1850 , this soil theory for disease led California physician Stillman to blame the local diarrhea epidemics on the alluvial fans situated at the base of the mountains near San Francisco, which bore gravelly soil and a nearby roaring stream (Stillman, 1851). Still other interpretations of the same two decades later 
by medical hydrologists helped in the development of another variation of the miasmatic theory of disease--the zymotic or fermentation theory (for examples, see Viele 1874/5 and Gardner 1977; for a historically important pedological interpretation of a "zymotic disease"--namely tuberculosis or consumption--see Bowditch 1866).

Another disease theory similar to the pedological theory was posed by a medical geologist who stated that tertiary and quaternary beds located close to riverways were the most susceptible landforms for disease development (Bell, 1851). In particular, the "calcareo-magnesian water" produced by these geologic formations was a theorized cause for many devastating epidemics within river and stream shore communities (Lea 1851, Bell 1851 335-337). An important extension of this geologic view of disease during the 1870 s related rock type to subterranean water flow and resulting water-borne disease distribution (Latham 1877). Latham deduced that disease was due to the lack of permeability of certain underground strata and surmised that the impact of local geology on water flow (especially underground waterflow) could be used to explain why certain epidemics were well-localized.

In 1884 (the year Koch's bacterial theory for disease was published), Bellew used similar reasoning to define the key physiographic feature for cholera epidemic regions as "a low-lying alluvial soil, which is more or less supersaturated with ground water in a state of stagnation or but comparatively very slight motion, and which is subject to periodic inundations or water-logging by the seasonal flooding of the great rivers by which those areas are traversed in deltaic formation." (Pollitzer 1959 820). 
Climate. According to Hirsch (1883-1886) the nineteenth century cholera epidemics occurred mostly in the summer. Supporting this association between temperature and the development of a nidus are several studies detailing endemicity relative to climate in India (Rogers 1928, Russell and Sundararajan 1928). Recent observations of climate behaviors in relation to Asiatic cholera suggest that a reduction in temperature to about 50 degrees Fahrenheit impeded the diffusion of Asiatic cholera across large regions, whereas 40 degrees Fahrenheit halts this diffusion process completely (Pollitzer 1959 827-828).

Supporting the view that cholera behavior is greatly influenced by climate and local weather was the observation made during the early 1800 s that vibrio tends to be non-pathogenic during the cold months, during which time it may even "hibernate" within its natural environment. Examples of this overwintering followed the introduction of vibrio to the cold estuaries of Canada and New York just prior to the 1832 and 1849 epidemics. Whereas the initial fatalities due to Asiatic cholera during the mid-winters of 1832 and 1849 in Quebec, Toronto, New York, Cincinnati and Charleston were few, a resurgence of cholera ensued with the warming of the estuarine water environments resulting in a significant number of fatalities. These observations suggest that past epidemics which have been historically interpreted as re-introductions of vibrio into a region, might have occurred due to the ability of vibrio to adapt to the new ecological setting. By developing a new nidus, a new Asiatic cholera endemic region was developed, a possibility greatly supported by studies carried out in recent years in and around the Gulf of Mexico and Chesapeake Bay (Colwell 1981, 1984), along with studies 
linking the behavioral tendencies of vibrio to seasonal changes in temperature and salinity (Singleton et al. 1982).

Rainfall. Due to the sensitivity of vibrio to water-based growing mediums, the impact of rainfall on cholera incidence has historically led to mixed opinions about the impacts of rainfall on cholera activity. McPheeters's (1850) study of cholera incidence relative to rainfall in St. Louis demonstrated that an inactivation or cessation of cholera took place soon after the initiation of a period of heavy rain. This finding, however, differed from Hall's review of cholera introduction into Illinois from 1851 to 1853 (Hall 1855), which stated that cholera activity ensued following a period of incessant rainfall, suggesting precipitation increases vibrio activity in a region due to either the introduction of new nutrient sources to the growing medium and/or the diffusion of vibrio from latrines into new water sources such as wells.

Even more perplexing is the likelihood that both an increase and decrease in cholera fatalities following heavy rainfall could occur for different hydrological reasons. An initial period of rain can result in the passage of vibrio from contaminated latrines and water wells to nearby uncontaminated water wells enabling it to infect new people. During periods of incessant rain, however, this vibrio may instead be effectively diluted so as to reduce its vitality and cell count in the local waters, followed by its discharge into local rivers and/or a reduction in its viability initiated by changes in salinity, alkalinity and nutrient suspension. This reasoning provides possible reasons for why vibrio is less viable with increased distance from flood plain settings. Such an effect in the freshwater environment contrasts greatly with effect of similar changes involving an estuarine ecosystem, 
where periods of heavy rain improve vibrio growing conditions by increasing detritus suspension in the water and changing the migration of copepods and other chitin bearing animals (Oppenheimer et al. 1978, Huq et al. 1984).

Review. Asiatic cholera has been referred to as "the archetype of geographically-related water-borne diseases" (Clemow, 1903, 25). According to Felkin, it "follows the course of rivers . . . due to the fact that the riparian areas possess soil saturated with water and decaying organic matter" (Felkin, 1889, 23). Recent studies suggest the importance of the saline environment in the development of new vibrio niduses historically may be lessening, as indicated by its discovery in brackish fresh water creeks in Australia (Bashford et al. 1979) and even some of the more common ditch environments (Desmarshelier and Reichelt 1981, West and Lee, 1984).

With the exception of these more recently evolved cholera nidal requirements, certain waterways and springs were most likely linked to the behavior of Vibrio cholerae along the Platte River portion of the Overland Trail to Oregon. The alkaline, saline waters typical of certain parts of this region have the potential of successfully harboring vibrio between human cases. Should such an endemic region develop, the physical geography of vibrio behavior suggests that whatever cholera epidemics were produced would be most aggressive in low-lying, water-soaked regions where highly susceptible groups of people resided in non-hygienic, highly popular camp grounds. The survival of Vibrio cholerae is highly dependent upon the local physiography and topographic land features and how these prevent or encourage contacts to occur between any potential disease victims and the infected local water supplies. Since many of these associations 
between vibrio, water and people are the consequences of human ecology and are often population related, human geography plays one of the more important roles in determining the diffusion behavior of this disease.

\section{Human Geography and Hierarchical Diffusion}

Human geography defines cholera diffusion by the way people behave socially as well as in their environment setting. As Vibrio cholerae diffused globally, certain transportation routes were more heavily utilized enabling it to impact important trade routes. This diffusion pattern ultimately brought Asiatic cholera to North America by 1832. Repeating this pattern from 1846 to 1856 , vibrio made its way to southern New Orleans by late 1848 , and from there to the interior valley in Spring 1849 (Figure 11).

Although less-popular than the immigration route by way of New York City, the port of New Orleans was the most important route for vibrio diffusion into the United States during the mid-nineteenth century. The primary reason for this preference on behalf of the vibrio was the warmer climate the Gulf of Mexico provided and the proximity of New Orleans to the Mississippi delta, a place where the ecological requirements for vibrio could be met. Once it left its ecological setting near New Orleans, a number of human geographic features either supported, hampered or prevented its diffusion process into North America. 


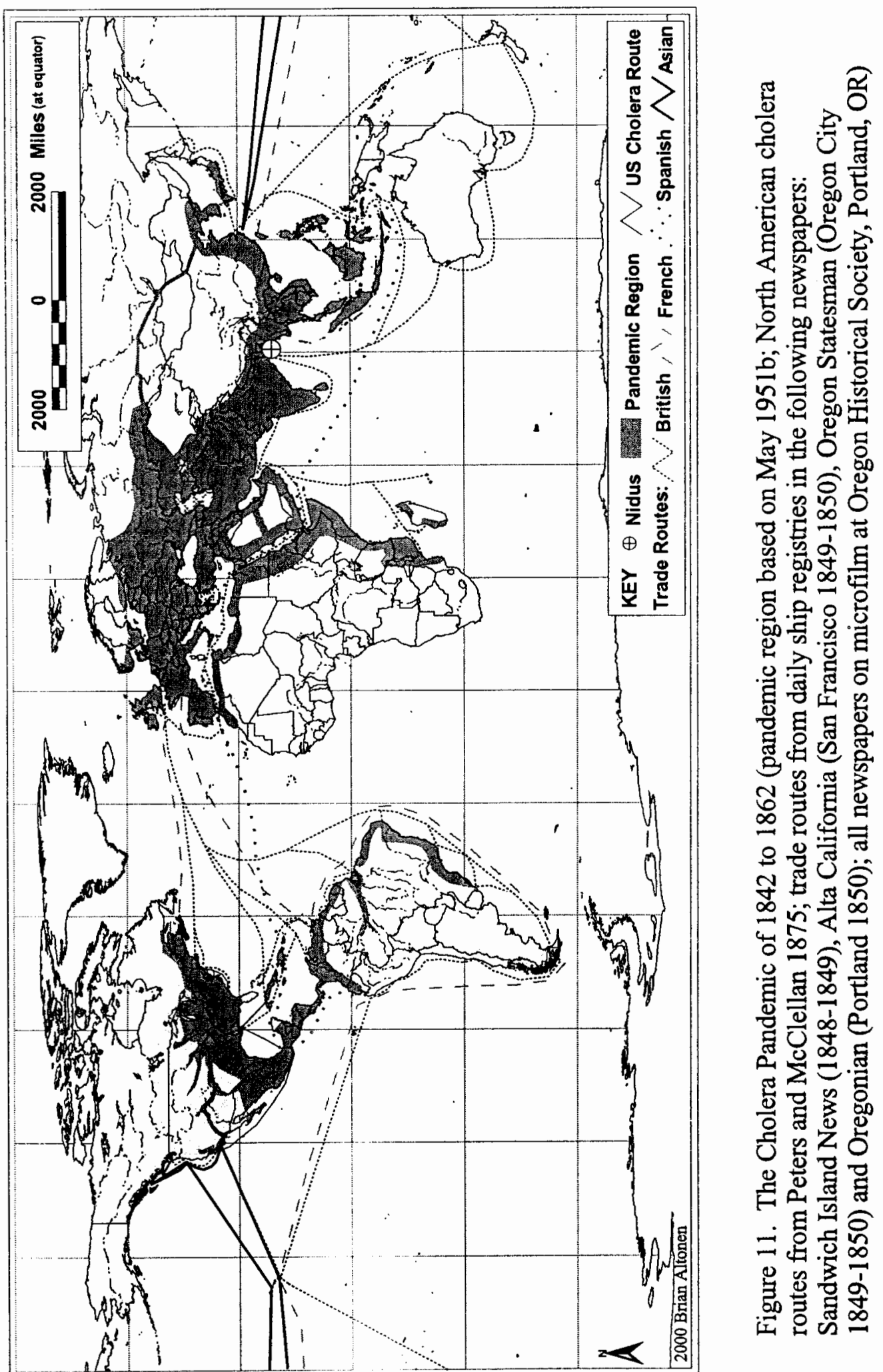


Due to its reliance on human transportation for introduction to heavily populated urban settings, Asiatic cholera is typically spread in hierarchical fashion along well established human migration routes. Whereas locally, migrating animal carriers or the flow of vibrio-containing estuarine waters inland during periods of climatic and weather change may be primarily responsible for vibrio migration areally, the pandemic diffusion of cholera across long distances between continents in very short time is due mostly to human migration along waterways.

Several methods for the transportation of vibrio by uninfected human victims are worthy to note. The contamination of stored personal belongings, such as coats and jackets locked away in trunks, or by way of a food or liquid previously infected by a deceased cholera victim has been linked to the spread of disease between continents and across oceans throughout the nineteenth century (Peters and McClellan 1875). A third method for cholera spread proposed most recently by epidemiologists is from port to port by way of ballast water tanks infected with various vibrio-ridden microorganisms, fauna, and algal products (Chen et al. 1991), a method similar to those proposed by a Havana physician (contaminated logs on board) (Anonymous 1833) and a Californian medical climatologist (contaminated ballast soil dug in Sacramento and shipped to San Francisco) (Logan 1851).

Canals and railroads have been implicated as methods of cholera spread due to their proximity to water and/or the establishment of numerous towns equally spaced from each other along the more popular canal routes. The canal routes which were more susceptible to disease tended to form important links between undeveloped rural communities and much larger port cities. During the mid-nineteenth century, the limited development of trains and canals west of Ohio 
made rivers the primary routes of migration into the Interior Valley (Peters and McClellan 1875).

An unusual case of cholera diffusion through high elevation regions is important to note since it demonstrates the ability of human behaviors to overcome this limitation. The transport of Asiatic cholera through the 6000 feet Ural mountains escarpment was accomplished by Russian soldiers in 1831 due to the rapid migration of people interacting in such a way so as to produce new disease victims in very short time (Scouttetten 1832). This suggests that in order for the Asiatic cholera to migrate through impassable mountain regions, human population features have to dominate throughout the epidemic. This reasoning is also related to the sequent occupance related behavior of disease diffusion since simple technological improvements in developing countries can make them more susceptible to the disease, such as simple improvements in transportation systems and human population density features.

Summary

A combination of human and physical geographic features suggests that rivers attached to estuaries and deltas are the most likely diffusion routes inland for Asiatic cholera. They not only provide Vibrio cholerae with supporting natural and human ecological settings but also bear a number of additional riparian features capable of supporting vibrio between disease cases, such as alluvial fans and certain topographic, alluvial, hydrologic, and plant and animal related biogeographic features. Since these rivers often serve as the most important routes of travel from seaports to higher elevation regions further inland, the climate along 
these routes of travel can either support an epidemic or impede its diffusion further. In the United States, these important deltaic or estuarine transportation routes have historically been the Saint Lawrence, Hudson, and Mississippi Rivers, with the large Ohio and Missouri serving as important branches off of these important international trade routes to further inland urban regions. As the rivers get even smaller, one geographer noted that the vibrio is more likely to travel through well-formed deep valleys or small narrow-channeled streams where numerous town and city are interlinked along a well-delineated pathway (Dunham 1904).

Relating these disease diffusion features to Oregon Trail history, the various towns and forts in the Midwest served as important way-points for the disease by providing it with new victims to infect and in turn diffuse further into the interior of the country. In addition, a number of local climatic and physiographic features assisted Asiatic cholera in this diffusion inland. Latitude and elevation changes introduces vibrio to cooler environments where, according to some geographers, it became less likely to continue inducing disastrous epidemic results. The most important physiographic features for Asiatic cholera diffusion into the Interior Valley relate to hydrology and topography. The alkaline chemistry of Platte River water and its alluvial soil and broad flood plains are features which might have improved the viability of the organism vibrio outside the human body between disease victims by residing in well and aquifers. The braided shape of Platte River made for even more accommodating physiographic changes, changes which were lost as travel progressed further westward along this the river.

With the loss of these physical geographic features along the western half of the Trail, the likelihood that Asiatic cholera would continue traveling westward 
depended greatly on the human population features. By the time Fort Laramie was reached, the diffusion of Asiatic cholera became primarily anthroponotic in nature and depended solely on person-to-person contact to continue this migration westward. As the Trail diaries show (next chapter), this diffusion was no longer possible due to the significant demographic changes taking place during the Platte river cholera epidemics.

\section{DYSENTERY GEOGRAPHY}

A dysentery epidemic may be caused by a number of bacterial and non-bacterial organisms. When interpreted by its primary symptom--bloody diarrhea--spatial interpretations often lack the specificity associated with tropical borne Asiatic cholera. Since the opportunistic bacteria responsible for the dysentery are often ubiquitous in nature, they lack a physiographically definable regional specificity related to their ecology, but may often be linked to animal carcasses.

As noted in the previous chapter, the agents responsible for dysentery were more capable of surviving the colder mountain environments than the bacterium responsible for Asiatic cholera. Therefore, their epidemic activity was unimpeded by these geographic and climate features that prevented the continued diffusion of Asiatic cholera along the Oregon Trail. Instead, their diffusion of opportunistic dysentery depended primarily on the physiographic features responsible for animal deaths and increased human susceptibility (Figure 12). 


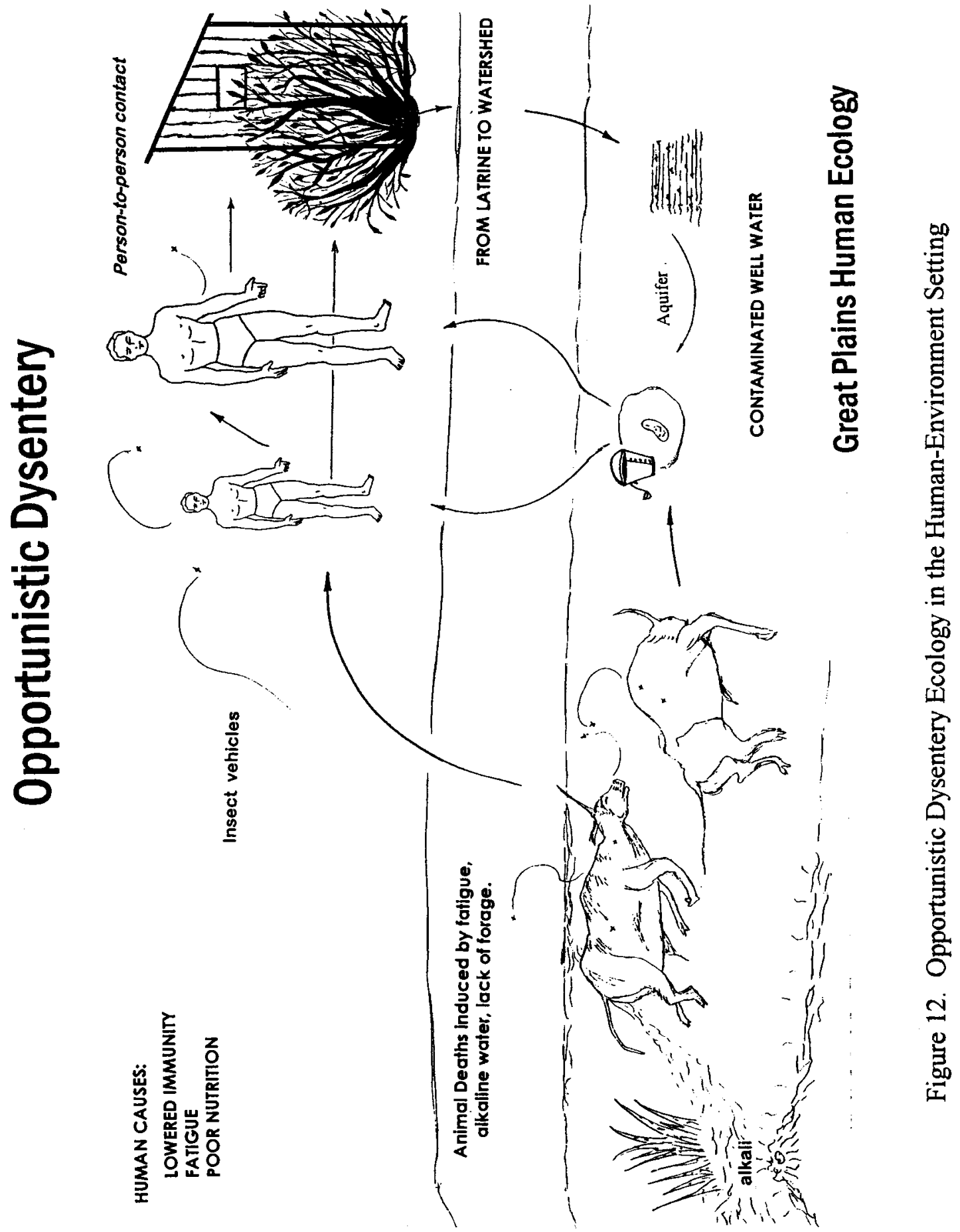




\section{THE TWO DISEASE REGIONS}

Based solely on the physiographic and climatic spatial behaviors defined in this chapter, two disease regions can be defined in the United States relative to the Oregon Trail (Figure 13). The Asiatic cholera region existed from the Gulf of Mexico and extended through much of the Platte River flood plain wherever human populations existed. The vibrio preferred places where dense population clusters supported continual epidemic activity; most likely it thrived in places where the right salinity and alkalinity also existed, such as along the Platte River aquifers. In such places, vibrio depended less on human population features, at least during the summer season. Therefore, the Asiatic cholera region of the Oregon Trail may be interpreted as an extension of a much larger epidemic region formed in the well-populated states east of the Mississippi River (Figure 14). Diffusing westward along the Oregon trail, it made its way as far west as Fort Laramie, where the last true cases were recorded. With the ascent of the Rocky Mountains, many of the living requirements for vibrio were eliminated, resulting in a rapid reduction in Asiatic cholera deaths and any subsequent "cholera" cases were actually a form of dysentery. The conditions which ceased the migration of Vibrio cholerae to Oregon west of Fort Laramie led in turn to the development of dysentery epidemics for years to come. For this reason, two distinct "cholera" regions formed along the Trail, each with its own geographic requirements (Table VI). The best evidence supporting this conclusion is the diary evidence reviewed in the next two chapters. 


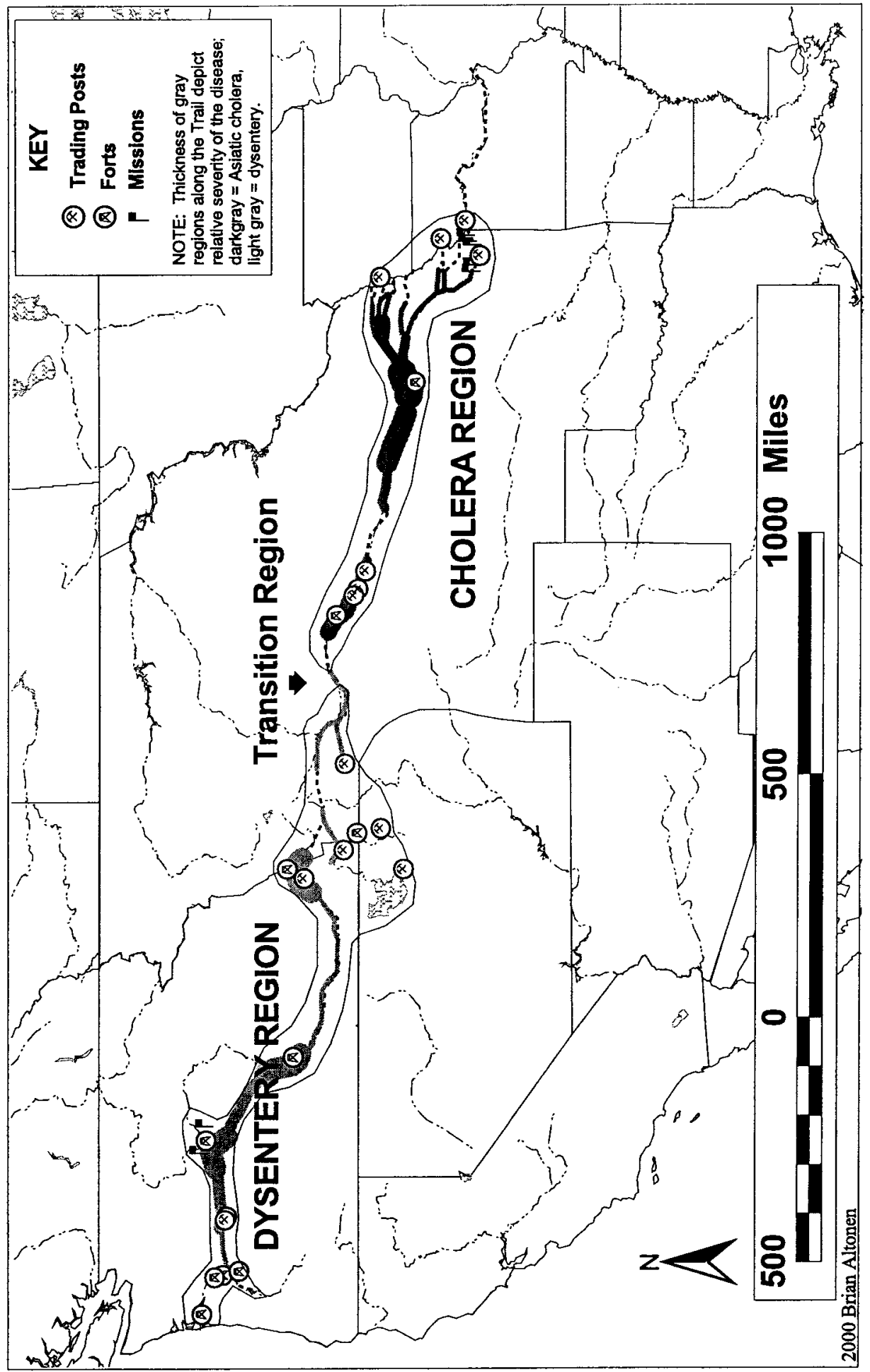

吕 

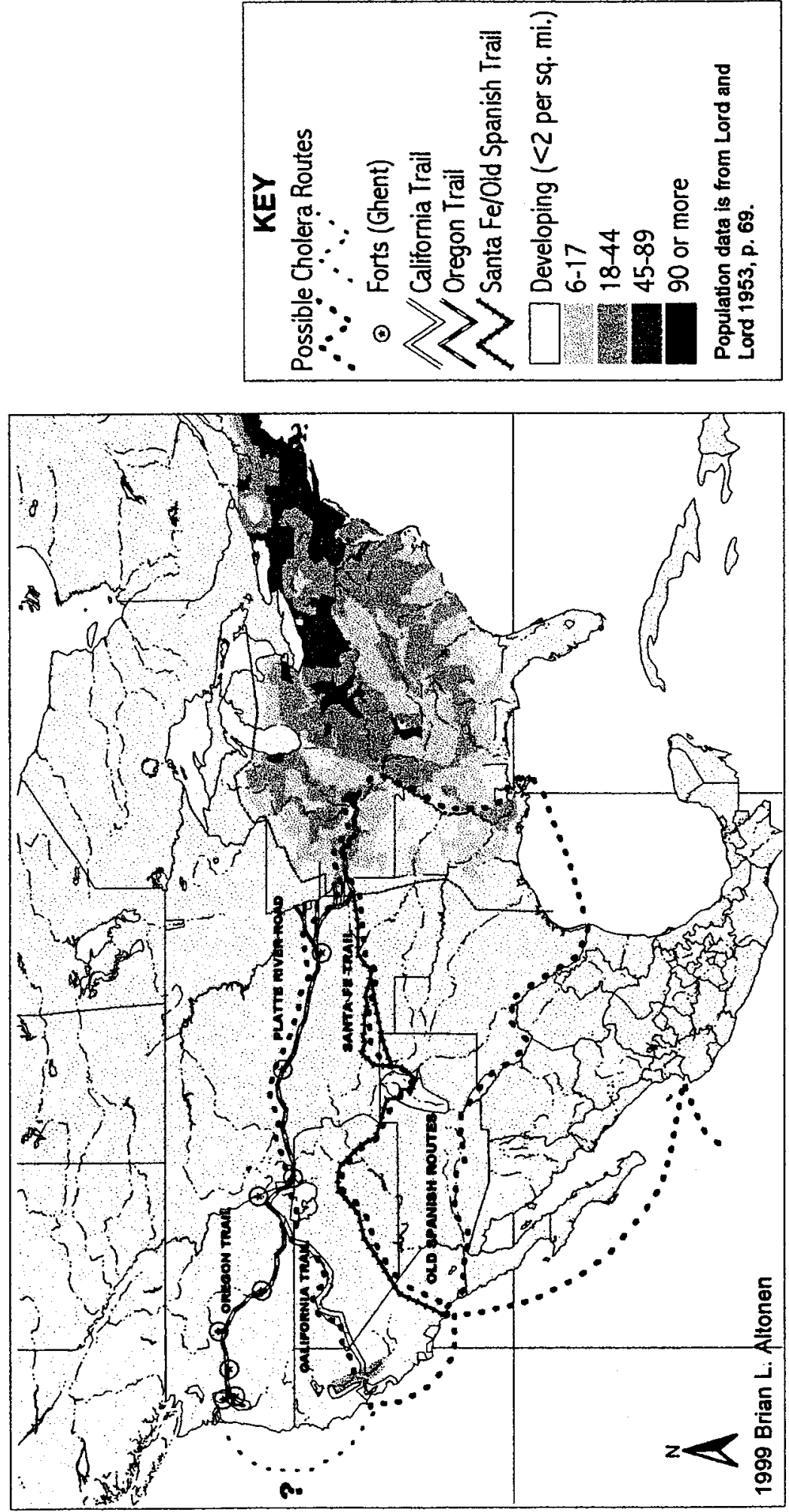

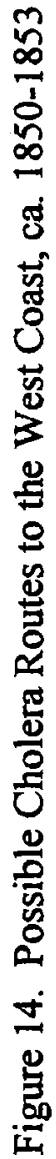




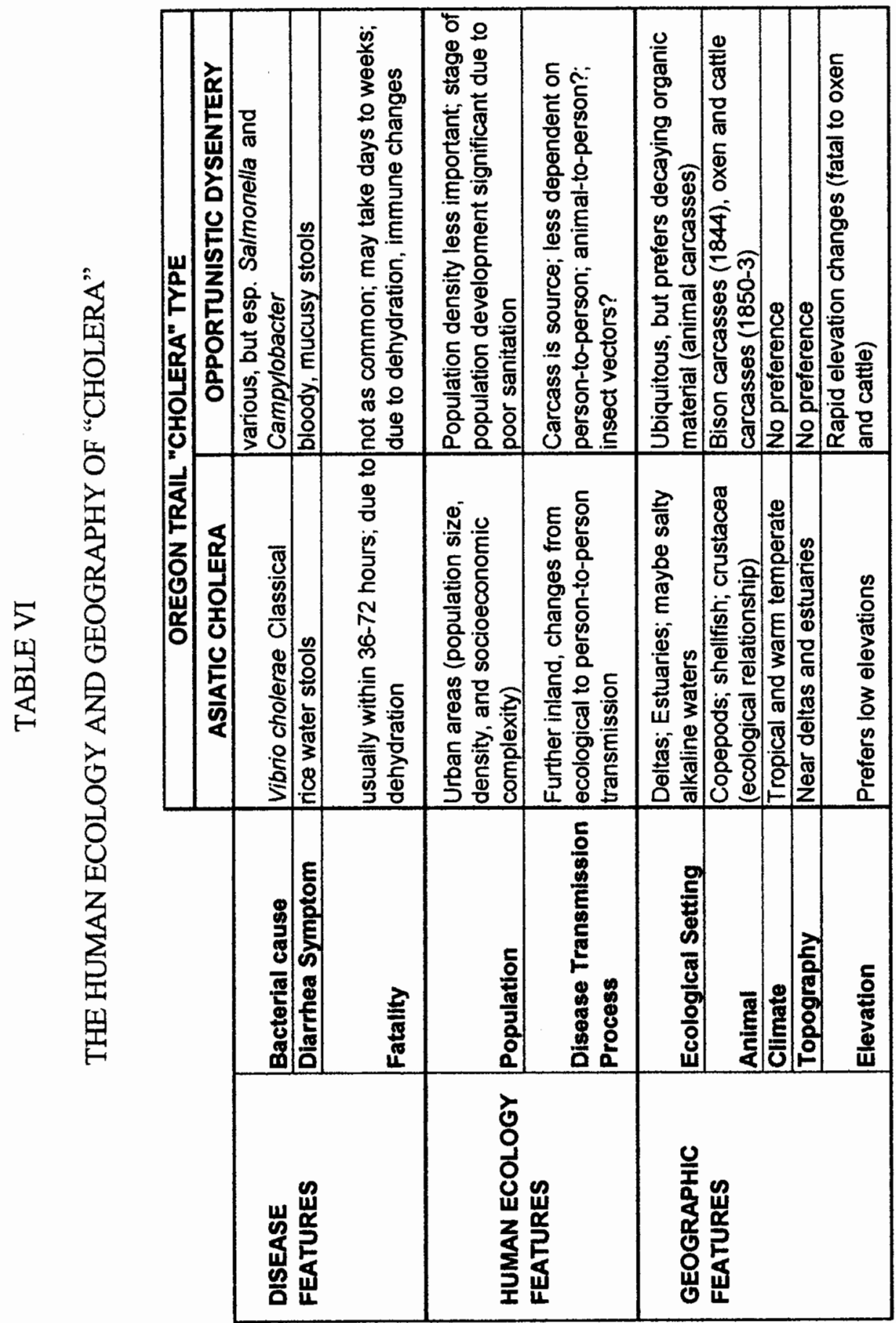




\section{CHAPTER V}

\section{THE OREGON TRAIL AND ASIATIC CHOLERA}

The Oregon Trail extends from the western border of Missouri to Oregon City, Oregon (Figure 15). Approximately 1900 miles in length, it passes through Western territory now defined as the states of Nebraska, Wyoming, Utah, and Idaho. This trail is traversed by several major geographic regions. It begins by making its way across the fairly level Great Plains, crossing and paralleling the flood plains of the Platte River and its numerous tributaries until Fort Laramie is reached. After Fort Laramie, this trail begins its ascent of the Rocky Mountains. This portion of the trail brings pioneer through rugged terrain, characterized by high altitude climates and scarce amounts of potable drinking water. Following the several week journey through what is now Wyoming, the trail descends into the Snake and Columbia River valleys of the Pacific Northwest.

The first significant populations traveling this route in 1843 ranged from a single person to several families in the form of a wagon train. The total number of wagons per train ranged from 20 to 300 , with each wagon bearing about five people (Meyers 1960). By 1846, this population grew to as many as two to three thousand heading west to Oregon. In 1849, more than 30,000 people attempted this journey, the majority of whom were Gold Rush pioneers (Mattes 1969) (Figures 16 and 17). 


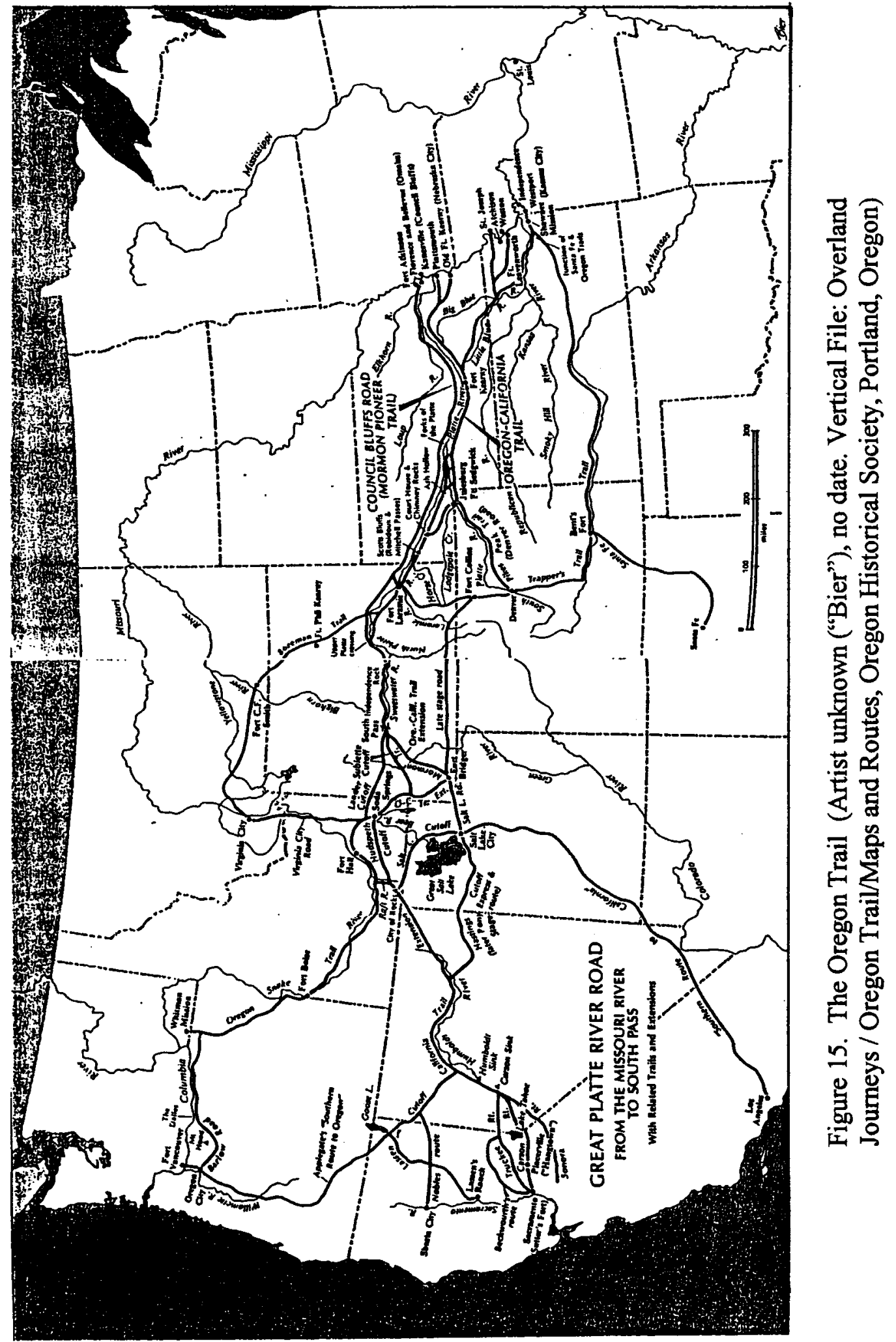




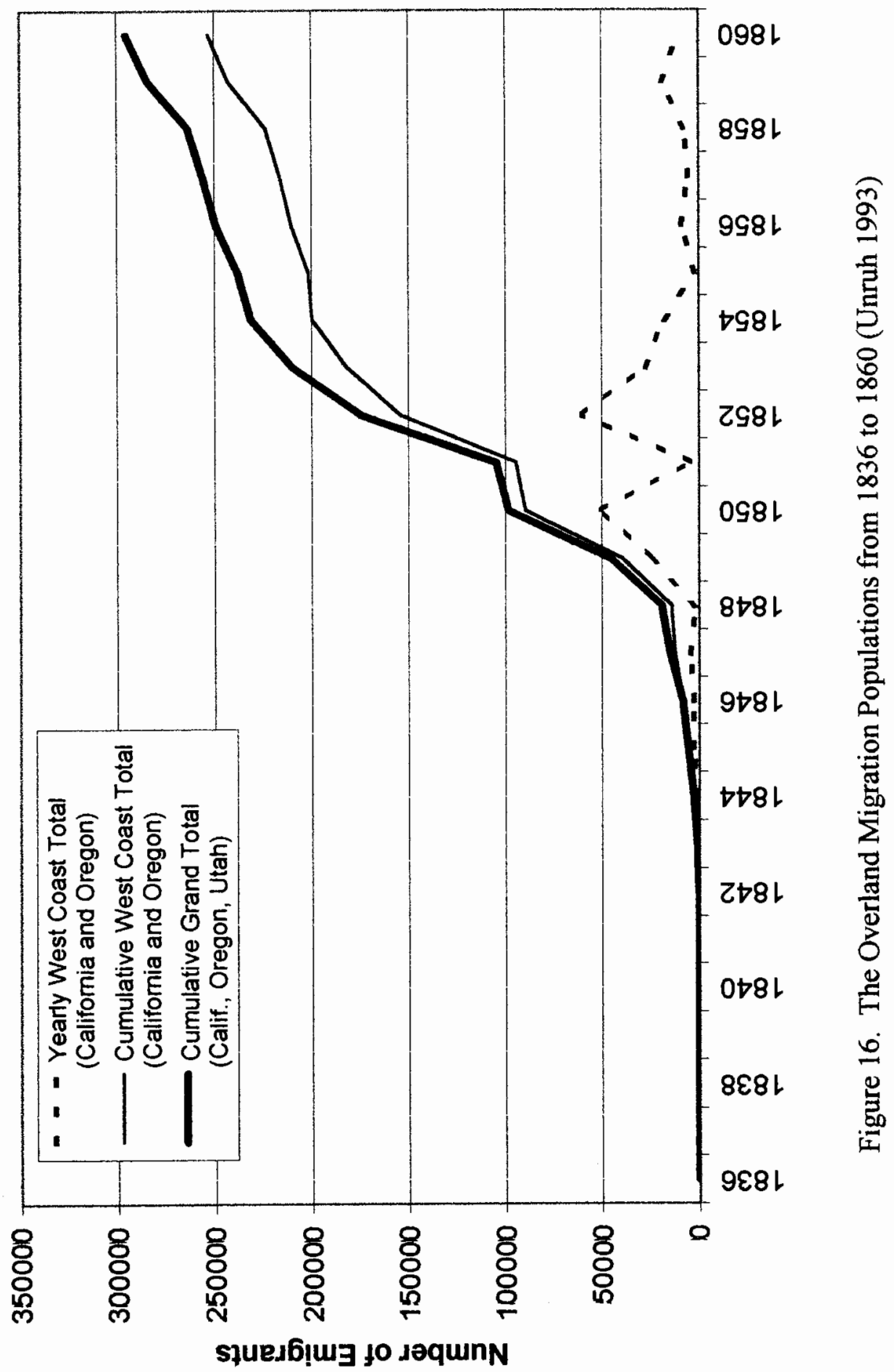




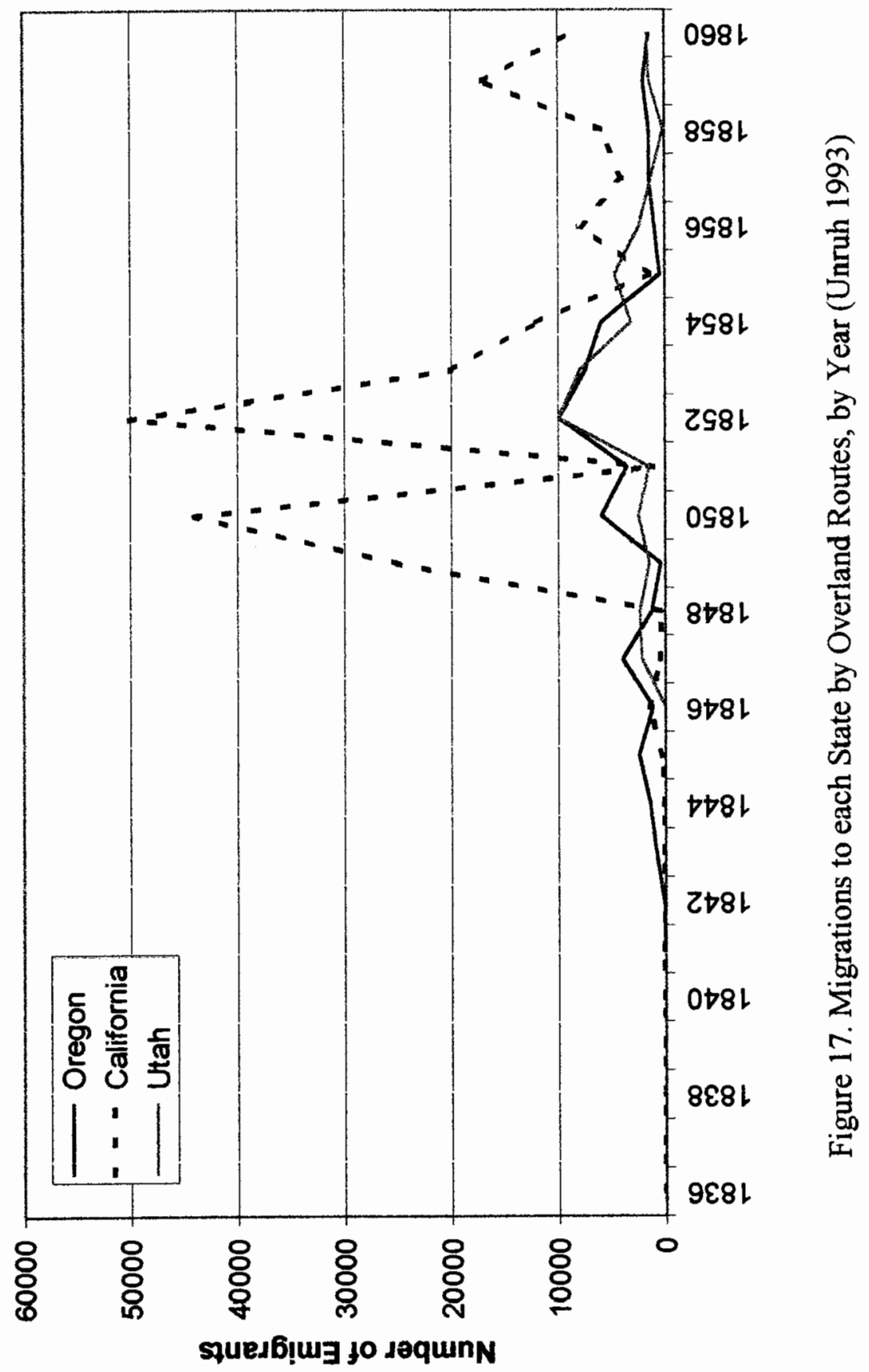


The largest wagon trains formed in 1850 and 1852 and were estimated to have as many as one thousand wagons making up a single company, each wagon averaging about four to six pioneers. As many as 55,000 emigrants made their way to the Far West per year in 1850 and 1852; one-fifth this population size migrated to the Far West in 1851. According to Trail historians Mattes (1969) and Unruh (1993), just under half of these emigrants headed to Oregon. The remaining half went to California and Utah. According to 1853 statistics kept about emigrants passing through Umatilla Pass in north central Oregon, most wagons bore just a couple and a child, but as many as twelve pioneers may have accompanied a single wagon, including children, parents, grandparents, relatives, and friends (See Appendix E for more demographic information).

Throughout the migration years, people and livestock suffered from the increasingly unhealthy living conditions of the Oregon Trail environment. In some places, unsanitary living conditions were induced by human waste disposal and numerous animal carcasses littering the Trail, a condition not new to Midwestern history. In 1844, well before any sizable migrations took place, trappers and travelers killed many of the buffalo in the Midwest, leaving their skinned carcasses to rot and setting the stage for certain diseases to erupt. Additional evidence shows that an abandoned Indian encampment may have contributed to some of the unhealthy trail conditions in eastern Nebraska. Following a battle with the Sioux, Pawnee Indians left behind animal parts in land subsequently traveled by pioneers. Evidence linking these carcasses to "cholera" appear in two 1844 trail diaries (Webber 1988, Rumer 1990). In an 1846 diary kept by another pioneer and republished along with his reminiscences about Oregon history (Thornton 1849), 
animal carcasses along Platte River fork caused another epidemic to erupt due to buffalo carcasses and/or a contaminated water supply.

In 1849 , these cholera-like diarrhea endemics suddenly worsened as Asiatic cholera penetrated the United States. As concerns for the potential for mortality due to "cholera" in the Midwest were heightened, the Oregon Trail rapidly formed into two epidemic regions with "cholera" as their chief malady. An Asiatic cholera epidemic region formed along the Platte River flood plain and extended as far west as Fort Laramie, Wyoming. The dysentery "cholera" region moved to that portion of the Trail west of Fort Laramie.

\section{The Asiatic Cholera Region}

The Asiatic cholera epidemic region of the Oregon Trail is an extension of a diffusion pattern already formed in the United States beginning in 1832 and revived from 1848 to 1854 when Vibrio cholerae returned to this country and for the first time became a part of Trail history (cf. Figure 13). By traveling slowly across the Great Plains, this epidemic ultimately reached its final destination along the Northwest Oregon trail route just west of Fort Laramie. As other emigrants attempted to reach the Far West by way of the California Trail, Asiatic cholera made its way to San Francisco and Sacramento only after two Asiatic cholera epidemic years had passed.

Relating this disease diffusion pattern to the Oregon Trail migration, Asiatic cholera began its diffusion westward from the various jump-off towns in Western Missouri. Due to its distance from the Gulf of Mexico, vibrio ecology could no longer play an important role in the disease diffusion process. Further 
west along the trail, climatic differences brought on by changes in latitude and elevation prevented vibrio from being able to survive for long periods of time between cholera victims. For a short time, this vibrio sustained itself along the Platte River Valley, by residing in specific aquifers, wells and latrines during the warmer days of the year. Further west, however, these vibrio-supporting physiographic and climatic features became less dominant making human population density important to sustaining the migration of this epidemic westward.

Two types of epidemic patterns developed along the Trail during this time. A radially spreading contagious diffusion of the disease occurred at popular campgrounds and fort locations. Along the Oregon Trail, a linear Type I diffusion pattern developed, with its peak occurring just a few days after Fort Kearney was departed or passed. Smaller epidemics then followed near popular camping areas like Ash Hollow, Chimney Rock and Independence Rock. The last deaths occurred near Fort Laramie, after which, rapid changes in topography, hydrologic features and climate prevented a further diffusion of Asiatic cholera westward.

The Platte River Flood Plain Epidemics. A summary of trail deaths by Trail geographer and historian Rieck (1991) defined nearly fifty percent of the known causes for trails deaths to be some form of "cholera" (Table VII). Of these deaths, most took place within the first week, followed by a second wave one to two weeks later. About 91 percent of these "cholera" deaths ensued by the time Fort Laramie was reached, and 96 percent by the time South Pass was reached (Rieck 1991). The remaining four percent were most likely not due to Asiatic cholera, but rather dysentery. 
TABLE VII

OREGON TRAIl DEATHS (RIECK 1991, 14)

DISEASE TYPE

INFECTIOUS

Cholera

"Fever"

Other

INDIAN

STARVATION/FREEZING

DROWNING

ACCIDENT

Gunshot

Run over

Stampede

Lightning

Other

HOMICIDE/CRIMINAL JUSTICE

Murder

hanged

Firing Squad
TOTAL CASES

468

367

60

41
PERCENT OF KNOWN

123

13.2

111

11.9

69

7.4

65

50.2

39.4

6.4

4.4

27

17

13

4

6

$\begin{array}{rrr} & 41 & 4.4 \\ 30 & & 3.2 \\ 8 & & 0.9 \\ 3 & & 0.4\end{array}$

MISCELLANEOUS

56

6

TOTAL KNOWN CAUSES

931

100

TOTAL UNKNOWN CAUSES

1609

TOTAL BOTH GROUPS

2540 
The possible reasons for these cholera deaths, especially around the forts includes (1) contact with carriers and disease victims, (2) contact with the belongings of recently deceased pioneers sold in the fort setting or by local traders, (3) contamination of the local water due to the concentration of victims in and around the Fort along with the contamination of the various water holes dug on this portion of the trail, and (4) the placement of this Fort on a flood plain enabling vibrio to travel from one water system to the next and diffuse through a highly porous alluvial flood plain setting with vibrio supporting alkaline waters nearby.

Fort Laramie and the Rocky Mountains. The region around Fort Laramie was the last to be infected by Asiatic cholera. Some evidence suggests that both dysentery and Asiatic cholera may have prevailed, leading to a significant amount of confusion about what form of diarrhea was erupting. For example, as Stout passed through an area near Fort Laramie which he called "Pine Woods," he was taken ill with "a severe attack of the cholera," but did not die suggesting instead that this illness could have been dysentery (Stout 1852).

Most of the diary evidence suggests that topographic changes west of Fort Laramie prevented the diffusion of Asiatic cholera further west due to climatic changes. One-hundred miles west of Fort Laramie, the Trail became very arid and lacked the grass needed by livestock due to its predominantly sagebrush environment and sandy soil. As noted by Stout, "we are in a miserable country now." Some contentment was probably felt by Stout though due to this changing scenery, for with it came a rapid reduction in graves.

Stout's diary also suggests that a sudden onset of cold temperatures might have greatly reduced the ability of vibrio to survive outside of the human body or 
remain virulent as he continued heading west from Laramie, for he noted the tendency for nocturnal temperatures to go below freezing, causing local swamps to form ice and unmelted snow to remain on the ground. By the time he reached Devil's Gate in early July, the air temperatures were very cold, accompanied by recurring hail storms and winds (Stout 1852).

Detailed observations about this impact of elevation change on local climate is best documented by Captain John C. Fremont, who, during his exploration of the overland routes to the Pacific Northwest in 1842 and 1843, recorded daily weather conditions and temperatures four times per day during the spring and summer months. From June 10, 1842 to August 3, 1842 Fremont traveled from Missouri to a turnaround point just west of the Sweetwater River-Cherry Creek junction, after which he returned to the East Coast. The following year, he recommenced his study of the Rocky Mountain region on August 9th, logging the same climate data until he reached Walla Walla near the Oregon-Washington-Idaho border on October 26, 1843 (Preuse 1846) (Figure 18). Fremont's temperatures were combined and then related to his published description of encampments to produce a description of the weather conditions he faced during his journey westward, information directly applicable to later migrations along the same overland route by other pioneers crossing the Rocky Mountains (Figures 19 and 20). 


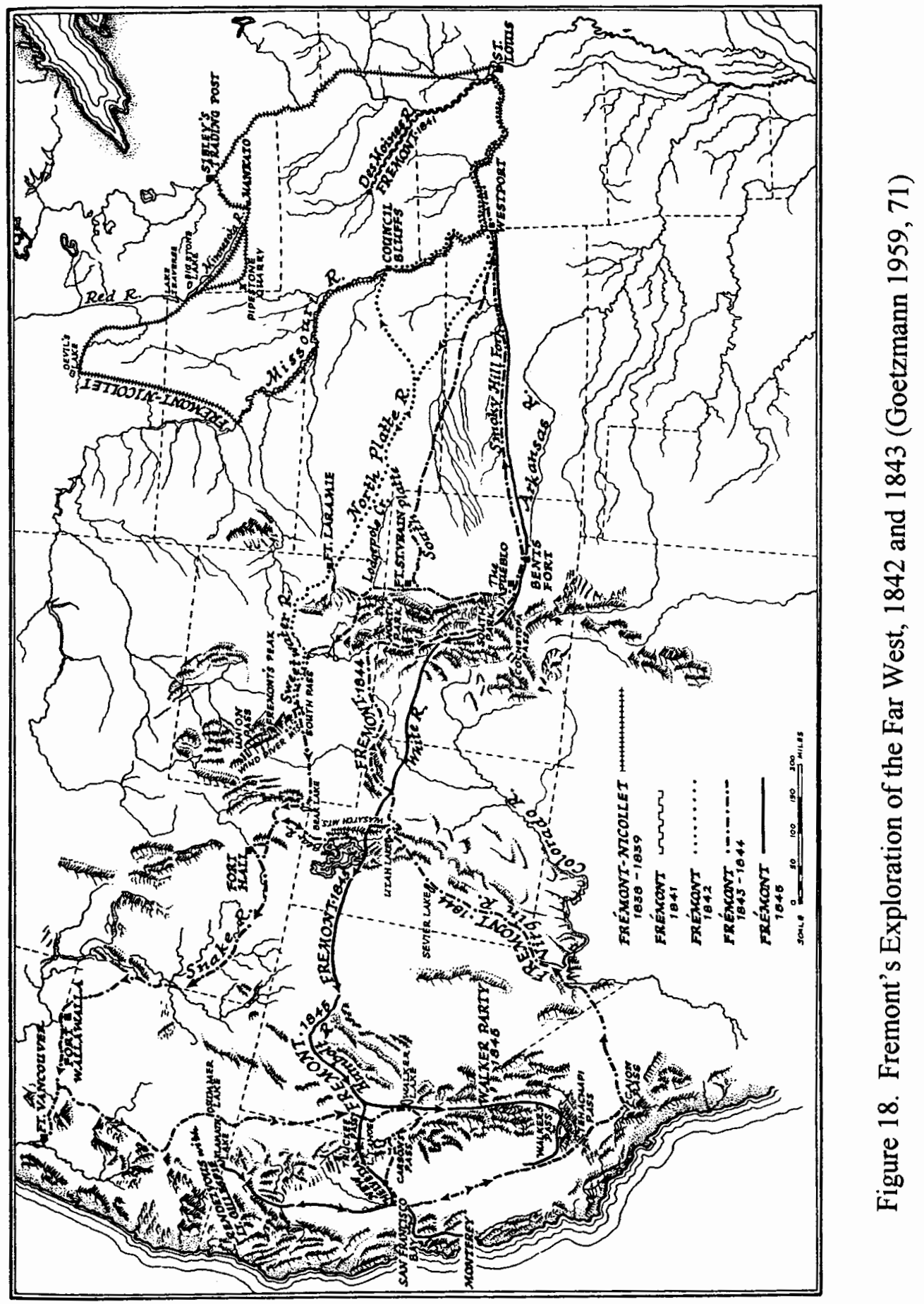


(t) anquesadur|

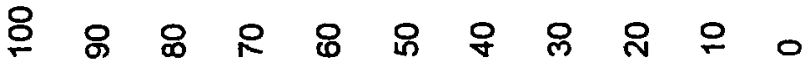

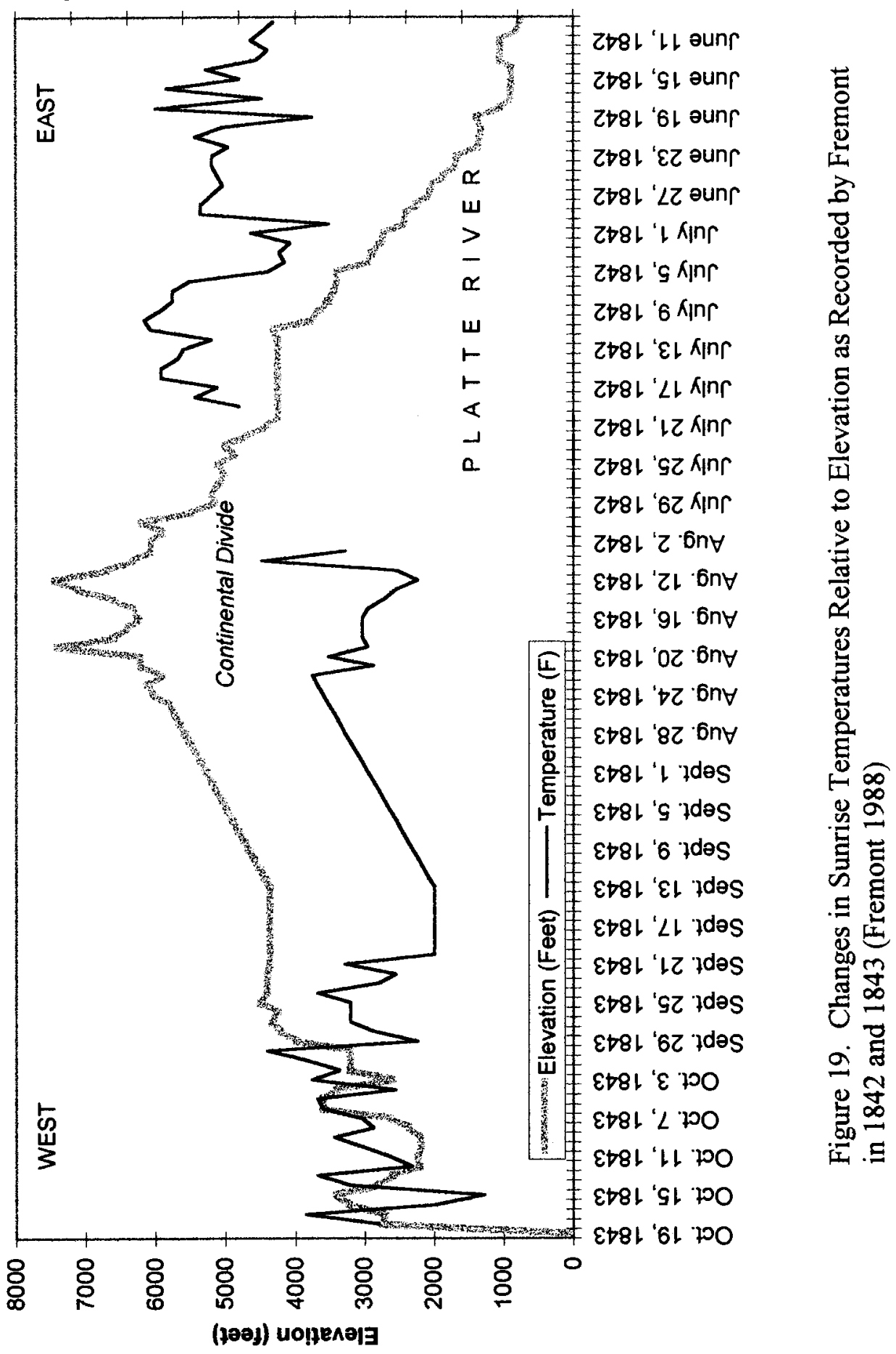


anņedodure1

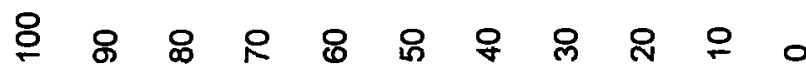

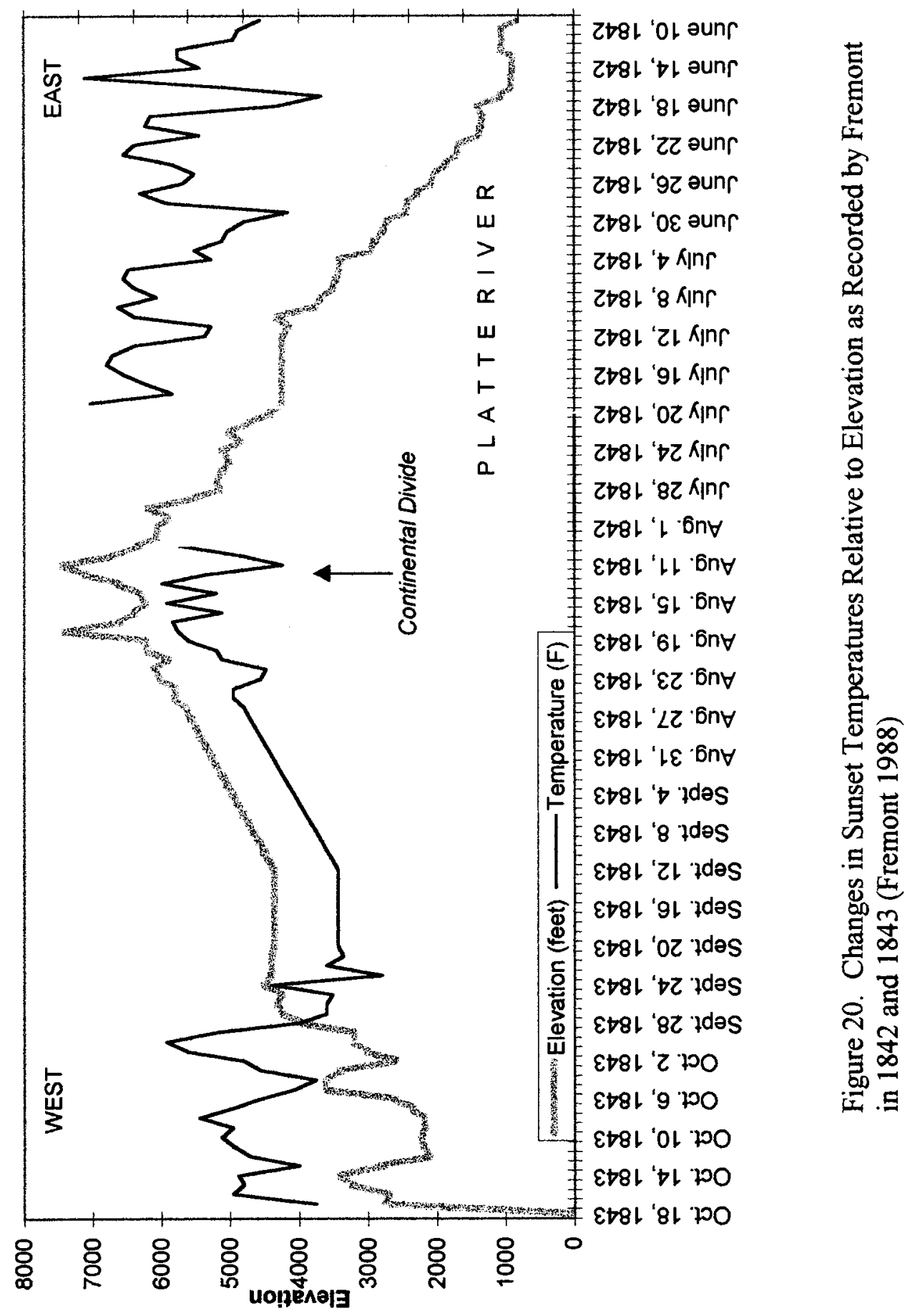


Fremont's records note a significant drop in temperature during his overnight stay in Wyoming, in spite of summer-like daytime temperatures from late July to mid-August. Whereas daytime temperatures were perhaps warm enough to favor vibrio activity outside the body, the nocturnal thermal pattern mimics the activity of a much cooler region which cause tropically-borne diseases like Asiatic cholera to lose much of their virulence (Jusatz 1977).

Interpreting this disease behavior in an ecological sense, the surrounding environment and local ecology would be non-supporting of Vibrio cholerae outside the human body. For these reasons, the climate and environment of Wyoming forced vibrio to infect one victim after another by way of direct contact if it were to successfully make its way through this region. However, due to the reduction in trail population induced by earlier deaths and the division of the trail into numerous alternative routes and cut-offs, person-to-person transmission of Asiatic cholera was unlikely to continue once the Platte River valley was departed.

An important argument against this reasoning for the prevention of cholera diffusion through the Rocky Mountains is the possibility that even though the virulence of vibrio outside of the human body was reduced by cold temperatures, these same temperatures might have also had the affect of increasing the longevity of vibrio in its inactive state, such as within soil, within an adequate water-based environment, or while residing on infected clothing and food. Furthermore, the cold climatic conditions might have also increased the likelihood that any vibrio unknowingly carried in the form of contaminated clothing and personal belongings could have infected an unsuspecting victim who used these materials to stay warm in the colder high elevation reasons, a reason the first migration of Asiatic cholera 
into the United States from Europe was successful during the early nineteenth century (Peters 1875, 635) (see Appendix B, second part for Oregon Trail food and supplies lists). Throughout the diary readings, however, no evidence for such a reason for the re-emergence of Asiatic cholera within or west of Wyoming can be found. This suggests that any contact with contaminated clothing would have been made quite early in the migration, such as where the near freezing temperatures began to force pioneers to put these belongings to good use.

Trail Deaths in the Diaries. Final support for the claim that a reduction in Asiatic cholera deaths took place near the Continental Divide of the Oregon Trail appears in trail diaries detailing the numbers of graves passed per day. This data also provides a second reason for the lack of cholera diffusion westward as well: the rapid fatality of Asiatic cholera victims leading to the cessation of this westward diffusion by killing all or most of the highly susceptible trail pioneers.

In general, when reviewing grave markers as possible Asiatic cholera death indicators, it is important to realize that Asiatic cholera wasn't the only cause for deaths along the Trail. In fact, according to Rieck's data (Rieck 1991, 1993, 1999), Asiatic cholera may have only been responsible for as little as one third to one half of the trail deaths. But if we assume the percent of graves passed per day to be proportional to the percent of all deaths induced by cholera in that region, then cholera prone regions can be identified and the various reasons for these events better understood.

In a diary kept by Cecelia Adams and Parthenia Blank in 1852 the number of human graves passed per day were noted (Webber 1997). A graphical depiction of these suggest the first peak in deaths to be near the junction of Platte River and 
its tributary, a place where various jump off trails at Platte River converge (Figure 21). This was followed by second peak near a popular camp ground at the junction of two creeks. The greatest number of graves were recorded near Fort Kearney, where the increase in fatalities was most likely due to the spread of Asiatic cholera between wagon trains as people approached others near the fort and unknowingly purchased contaminated goods once owned by emigrants, and/or made contact with vibrio-contaminated water. Other peaks in deaths occurred along Platte River flood plain, and near Ash Hollow and Independence Rock, two popular campgrounds frequented by pioneers one week prior to reaching Fort Laramie. Just west of Fort Laramie is a small number of graves, a brief resurgence in fatalities, due either to Asiatic cholera or dysentery. The cessation of this epidemic began with the ascent and passage through the Rocky Mountains, making Fort Laramie the last place where this disease could be successfully spread to new victims. The portion of the Trail between Fort Laramie and Willow Springs or Sweetwater River therefore behaved much like a disease transition region, where deaths due to Asiatic cholera decreased as deaths due to dysentery increased. 


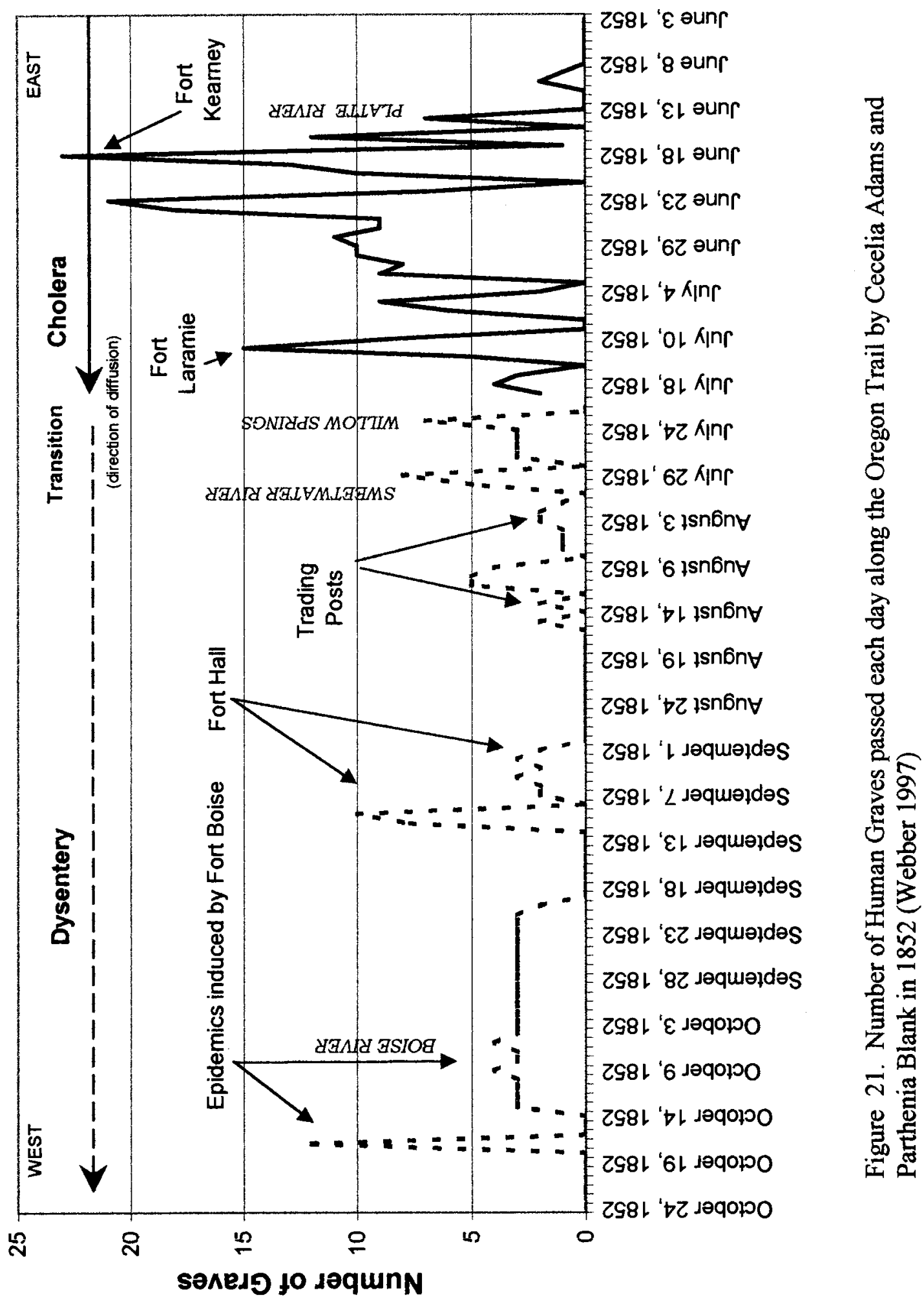


The stretch of the Oregon Trail leading from Fort Laramie to Snake River passed through some of the coldest environments and most irregular terrain that has to be traveled. According to Mattes and Unruh, this migration through the cold climates of Wyoming traversed about 375 miles of upper desert region, a distance which would normally take emigrants about three weeks to complete before descending into much drier and warmer climates along the Snake River valley in Idaho. Thus the likelihood for Vibrio cholerae survival within an infected person is greatly reduced by its inability to remain pathogenic during the two to three week migration to Snake River. Further support for the claim that Asiatic cholera didn't cross the Rocky Mountains is a lack of adequate descriptions of Asiatic cholera fecal discharges and the reduction in population density of the Overland route due to its division into numerous alternative routes. Together these changes in trail geography suggest that for the first time the Oregon Trail was free of Asiatic cholera once the Continental Divide was reached.

\section{Summary}

The most important physical geographic features supporting the diffusion of Asiatic cholera along the Great Plains portion of the Oregon Trail were: 1) climate and weather conditions, 2) the elevation of the trail on the flood plain above local river level, 3) local water chemistry, and 4) Platte River ecology. West of the Great Plains, the ability of Asiatic cholera to continue its migration westward was ceased due to the mountain climate of the trail west of Fort Laramie along with a number of physical geographic and human population features. 


\section{CHAPTER VI}

\section{OREGON TRAIL DYSENTERY}

Years before the Asiatic cholera epidemic struck the Platte River flood plain, dysentery developed along several parts of the Trail in eastern Nebraska and near the Fork of the Platte River in middle Nebraska. Pioneers who passed through the Great Plains without succumbing to disease in turn ascended the Rocky Mountains, often with the hope of leaving their fears of this "cholera" behind them. Quite soon into this part of the journey, however, a significant number of oxen succumbed to this portion of the Trail due to rapid elevation changes. In short time, this led to the development of a dysentery epidemic which ultimately spread along the entire length of this route over the next three years. Once this disease reached Portland, Oregon in January 1853, it was referred to it simply as "cholera." The geography of this "cholera" indicates it was due to one or more forms of dysentery brought on by opportunistic organisms borne by animal carcasses which in turn infected Trail emigrants. The same geographic features which prevented the diffusion of Vibrio cholerae and Asiatic cholera from the Great Plains to the Rocky Mountains, were in turn responsible for a new dysentery epidemic.

\section{Dysentery and "Cholera"}

To differentiate Asiatic cholera from the more common forms of dysentery mentioned in the trail diaries, the description of the disease, its place of eruption, and its tendency to erupt without fatality provide the best evidence for arguing 
against any possible continuation of the Asiatic cholera epidemic into the Northwest. Other supporting evidence is the atypical behavior of the dysentery epidemic which erupted along the trail. Since it often occurred a day or two after animal carcasses were passed, this suggested the disease was either related to the carcasses themselves or the unsanitary conditions their deterioration produced. In addition, recent Asiatic cholera deaths and the formation of numerous cut-offs of the trail caused a significant reduction in trail population density. This in turn greatly reduced the likelihood that any other form of dysentery dependent on person-to-person transmission, such as shigellic or amoebic dysentery, could have made its way westward instead of the population dependent Asiatic cholera. Due to the ability of opportunistic dysentery to occur in areas devoid of people for significant periods of time, such as between disease cases, a form of opportunistic dysentery primarily of environmental origin was the cause for this Trail epidemic.

The results of this study indicate that this opportunistic form of dysentery developed along the trail due to common organisms taking advantage of fatigued emigrants, a conclusion based largely on the descriptions of diarrhea in the trail diaries relative to trail geography and their forced proximity to carcasses produced by the drastic changes in trail topography. Once the infection commenced, a prolonged diarrhea problem ensued, which was rarely as fatal as the "Plains cholera" due to Vibrio cholerae.

The Eastern Nebraska Epidemic. A number of the prerequisites needed for a dysentery epidemic to develop had already taken place in eastem Nebraska just prior to the first migration of Oregon Trail pioneers in 1843. Pawnee Indians left their encampment on the North Fork of Loup River following a territorial dispute 
with Sioux Indians, leaving behind numerous animal parts strewn about in close proximity to the river bed. In addition, certain portions of the overland route served as wallowing sites for buffalo, which in some cases led to the death of these buffalo, either naturally by living out the final moments of their life or as a result of recreational hunting. As these animal parts and carcasses decayed, they infected the aquifers used by pioneers for drinking water and perhaps exposed these pioneers to insects which served as vehicles for the bacteria responsible for the development of the first severe diarrhea, dysentery or "cholera" cases.

Jacob Hammer's diary of 1844 provides some of the earliest evidence linking this unsanitary condition of the Platte River flood plain to the development of a diarrhea epidemic. Passing the North Fork of Loup River in mid-June, Hammer noted numerous buffalo parts along the trail, leading him to write on June 14th: "We camped near the old Pawnee village which is now left desolate on the account of the Sioux fighting them so much that they abandoned the place ...." (Rumer 1990, 82). After providing a detailed description of the remaining village site, he added "We have seen Buffalow bones in several places" (ibid 83).

The following day, Hammer's team crossed Loup River, passed by another Pawnee village on June 15th, and then three days later, came upon more "Buffalow bones" along the south shore of Loup River. Quite soon after, Hammer's friend John Murphy developed a fever. By the time they reached the Platte River on June 21st Hammer wrote: "Thomas Vance very sick and has been for several days." Several others in Hammer's train were also taken ill by this time. One week later, as this disease continued, this led Hammer to make an entry on June 28th 
concerning Thomas Vance's death along the north shore of the fork of North and South Platte Rivers (ibid 86).

This possible relationship between buffalo parts and carcasses and trail dysentery was again suggested, but not directly proven, by a note about the same encampment in 1846 by Virgil Pringle, who gave a more detailed account of the commonness of buffalo deaths along this part of the trail. After passing through the Pawnee encampment, he wrote on June 7th "Buffalo sign is now plenty and we see occasionally a dead one in the bottom" (Pringle 1923, 287). By June 9th, as the fork of the Platte was reached, he made the following journal entry: "Buffalo plenty, two being killed and several wounded" (ibid). It is important to note, however, that throughout Pringle's migration, no illness was noted following his pass through this region west of the old Pawnee encampment in 1846.

In 1847 , an early identification of another case of dysentery as "cholera" was made by Loren Hastings. After passing through the same abandoned encampment in eastern Nebraska, Hastings used the term "cholera" to describe the diarrhea epidemic this region was known for. A few days later, as members of Hastings' train camped along the Platte River, they apparently came in contact with the bacteria responsible for this diarrhea, for on June 7th, various members of his train experienced the onset of illness and "[a] sick many died" (Hastings 1926, 14). By the end of the summer of 1847 , Hastings noted that enough "cholera" cases had developed along the trail between North Loup River and Platte River to spread this epidemic to places further west along the trail.

The Platte River Fork Epidemic. Evidence for the development of a second dysentery epidemic region further west at Platte River Fork appears in William 
Thornton's diary penned in 1846 (1849). According to Thornton, the portion of the trail leading from South Platte River to North Platte River was a popular recreational buffalo hunting site where his friends actively engaged themselves in a buffalo hunt on the North and South Platte Rivers on June 16, 1846 (Thornton 1849, I: 80-83). Soon after this hunt, members of his train experienced their first cases of dysentery. Thornton's notes suggest that the most likely causes for the development of dysentery in this region included (1) contact made with the rotting of already dead buffalo strewn about, (2) insect vehicles, (3) the natural contamination of live buffalo just before they were slaughtered with bacteria capable of causing dysentery, or (4) by drinking river water contaminated by these carcasses.

Two days after passing through the buffalo hunt site at Platte River fork, both Thornton and his wife became ill by eating the freshly prepared buffalo meat (ibid 85). This illness continued for several days and by June 22 nd had spread to others in the train (ibid 91). Evidence that this dysentery was continuing to infect Thornton's team appeared the following week when still more people became ill without fatalities. On June 26 th, ten days into this illness, Thornton noted that he was still suffering from the diarrhea once Chimney Rock was passed 100 miles north-northwest of the fork of the Platte River (ibid 110). He made no more comments about this diarrhea spell until Fort Hall was reached, when members of his team were once again taken ill (ibid 163), this time due to their exposure to poor sanitary conditions in and around the fort.

This diary evidence indicates that several regions developed along the Trail by 1848 , one year before the return of Asiatic cholera, which were prone to a form 
of dysentery referred to as "cholera." It also suggests that certain human behavioral and human population features enabled a fairly endemic form of bacterial disease to develop within this natural setting well before emigrants arrived. With the establishment of more permanent settlements in this region such as forts, parts of the Oregon Trail became prone to this diarrhea disease due to physioanthropic changes in the environment. Between 1849 and 1850, one or more disease foci developed. According to Meyer's sequent occupance model for disease development, the development of this opportunistic form of dysentery was more likely than a shigellic and amoebic form of the disease.

The Wyoming Epidemic. Between South Pass and the Columbia River, a new dysentery epidemic developed in 1849. The rapid increase in human and animal migrations caused numerous deaths of oxen west of Fort Laramie. As this dysentery slowly diffused westward over the next three years, it developed more virulent forms with each passing of the migration season. By the time it reached the eastern edge of the current Oregon boundary in late Autumn of 1852 , this epidemic was compared with "Plains cholera" due to its highly debilitating nature.

The first significant concentration of dysentery cases in a single region west of Fort Laramie took place near Sweetwater River just east of South Pass in 1850. Until then, most of Platte River was traveled without much incidence of dysentery due to the Asiatic cholera epidemic underway. Immediately after passing Fort Laramie, the Trail began its steep ascent into the heart of the Rocky Mountains, leading in turn to the rapid death of oxen and cattle and the development of numerous dysentery niduses due to their carcasses. The remaining requirement for this potential epidemic region--disease susceptible people--was introduced to this 
part of the overland migration during the later years as trail populations increased in size and density. During the peak migrations of 1852 , the diminished supply of fort provisions for these travelers added further to the malnutrition suffered by these pioneers.

Oregon Trail pioneer and naturalist Bruce McKinstry of 1850 provided some of the most detailed descriptions of the epidemic environment. Noting in his diary the possible topographic causes for the development of these unsanitary conditions, McKinstry correctly linked the intake of alkali waters and the crystallization of alkali on local forage materials as possible causes for oxen and cattle deaths near Chimney Rock and Independence Rock (McKinstry 1975, 150-157). He also correctly deduced that these carcasses were more than likely cause for the local dysentery cases.

After traveling without incidence of illness throughout the entire the month of June, McKinstry reached Willow Springs on June 30th and wrote: "We passed numerous dead cattle in the vicinity of Alkali Springs, and some left not dead" (ibid 150). The next day he passed through "Alkali Country ... [where] "the grass as well as the water was poisenous ... the dead carcasses confirming this" (ibid 151) Upon reaching Sweetwater River, he noted yet another region rich in "tons of Seleraetus." Continuing past Independence Rock through Devil's Gate, he was subsequently forced to camp on a river "strongly impregnated with alkali" (ibid 157), leading him to pen the following description of cattle deaths on July 4th: "Many cattle die from eating the grass, but there is no other chance for them. The road is well lined with carcasses and the smell anything but agreeable, we can 
scarcely find a ground clear of the stench" (ibid 157). McKinstry had yet to see or experience any dysentery or diarrhea problems.

The following day (July 5th), during their pass through Sweetwater valley, members of McKinstry's train suddenly became ill with diarrhea. McKinstry blamed this diarrhea on the dead cattle, referring to its fatality as if it were related to the more deadly Asiatic cholera:

"Hibbard continues very sick--we do not expect that he can live long. Half the wagons have sick men with them. We would lie by altogether, but $\mathrm{H}$. will not consent to it. It might be the death to us all, it is getting late and the feed is nearly gone, and every day growing worse, and thousands just behind us." (ibid 160)

The following day (July 6th), two more members from his train were taken ill as well, as Hibbard's condition slightly improved. According to McKinstry, dead cattle continued to litter the trail along with "live ones that have been left unable to proceed" (ibid 167). Soon after, Hibbard's illness once again worsened and lasted another week, by which time Bruce McKinstry himself was taken ill and wrote: "I passed a disagreeable night oweing to a severe toothache also diarrhea" (ibid 170). According to McKinstry, his people were by then traveling at about 7300 elevation above sea level near Burnt Ranch.

Once McKinstry passed Fort Bridger and Ham's Fork he came upon a French mountaineer's trading post, where he spent the night on July 19th. The following day, his train ascended a summit overlooking Ham's Fork and Bear River valleys, a portion of the trail which was highly fatal to livestock due to the rapid 
changes in elevation. During his ascent, McKinstry commented "Dead animals all the way up, the stench intolerable." As McKinstry provided detailed descriptions of the dead animals strewn about this region, he also described their bloated, rotting carcasses and the maggots and swarms of insects flying about. These observations led him to deduce that the causes for subsequent livestock deaths and the sickness his fellow pioneers were experiencing was simply due to the carcasses lying about, "strewed on every hill and in every valley, poisining the otherwise pure air" (McKinstry 1975, 194-195). The following day, members of his train again became ill and complained of colicky symptoms (ibid 199).

In the days that followed, as McKinstry's train reached the trading posts of the Far West, he engaged in several activities capable of furthering his team's problems with diarrhea. In need of food, McKinstry purchased an "Elk carcass" from Natives (ibid 218). A short while later he passed through the Bear and Green River valleys where he again noted numerous animal parts strewn about (ibid 222).

Trading Post- and Fort-generated Epidemics. McKinstry's detailed notes not only provide us with an explanation as to why dysentery epidemics continued to develop along the trail--the numerous animal deaths which occurred-it also provides us with insights into how particular human geographic features may have allowed this disease to spread from central Wyoming to rapidly growing communities further west in Oregon. Trading posts and forts bore many of the same environmental features as the "old Pawnee" settlement noted in eastern Nebraska and much older Fort Hall settlement referred to by Thornton. Along with increased population density came the increased likelihood for contact with others carrying or suffering from these and numerous other diseases, thereby increasing 
the likelihood for their further spread. In addition, many inhabitants of this region most likely suffered from poor living conditions and poor nutrition, making them more susceptible to various infectious diseases.

Finally, due to the possible infection of livestock exchanged at the trading posts for refreshed more vigorous livestock, the stage was set for the contamination of numerous foods sold at these places by bacteria. Such bacteria-contaminated livestock may have even, in some cases, become the sources for contaminated food as well. For example, at the Sioux-French Canadian trading post between Fort Kearney and Fort Laramie, jerky products were often prepared and then sold to pioneers, with poor sanitation practices and poor food preparation techniques (i.e. undersmoked, partially dried meats) as the most likely causes for food contamination.

Together, these features increased the likelihood that popular gathering places could have developed into localized epidemic regions thereby facilitating the diffusion of the opportunistic dysentery epidemic problem further westward. Since forts were places where people tended to congregate along the Oregon Trail to set up large encampments, these fort environments added to the likelihood that previously uninfected pioneers would be infected by unsanitary fort waste and other pioneers already experiencing dysentery. Older forts in particular were a problem due to their old garbage sites and outhouses built in close proximity to each other and on the same watershed as drinking wells. At Fort Laramie for example, in his letter written on June 20,1850, Dr. Reuben Knox described a non-fatal "cholera" which began soon after passing an Indian trading post: "Joseph was unwell with diarrhea and Henry and myself were on the move on horseback 
and off most of the time" A short time later he wrote: "Have had some 15 or 20 cases in my train, none of whom have proved fatal except Mason who was relying upon his favorite Hom[e]opathic remedies until [he] perfectly collapsed" to which he added: "Have had two slight attacks myself, --Joseph and Henry also, but all are well now..." (Turner 1974, 52, 53).

Another way for dysentery to spread was by the mishandling of human bodies and/or the belongings of the deceased. The re-exposure of the buried bodies of victims by wolves was a possible problem. The common practice of unloading personal belongings on the trail to improve mobility had the probability of increasing disease spread. In 1850 , for example, Dowell most likely helped to spread this disease by trading the belongings of a deceased emigrant with a merchant at Fort Hall (Dowell 1850, 35).

Since the migration of 1851 was considerably less than that of neighboring years, little diary evidence was uncovered mentioning the development of dysentery epidemics along the trail. Nevertheless, the numerous deaths of livestock the year before had already set the stage for a more serious dysentery epidemic to ensue in the years to come, Most likely the 1851 trail migration added to the growing animal carcass problem along the Oregon Trail and made the 1852 migration one of the worst in Oregon Trail history due to the two epidemic regions which had developed along the Great Plains and in the Northwest.

In 1852, dysentery infected much of the Oregon Trail between Wyoming and Oregon. As before, bacteria responsible for this epidemic survived on dead animal carcasses, but in due time passed from animal carcasses to emigrants in a state of fatigue and malnourishment in axenotic, anthropo-zoonotic fashion. The 
local geological features responsible for the deaths of oxen, cattle and horse included the fatal alkali water or alkali-contaminated forage grasses consumed by livestock. Various landform features were also linked to their deaths such as hilly or rough cobbled terrain with wide streams to cross. Likewise, as food and water scarcity continued to take its toll on the pioneers, trail topography continued to be fatal to livestock and oxen populations.

The spread of bacteria from these decaying carcasses into drinking water worsened in 1852 due to the forced encampment of people next to carcasses and the increased prevalence of each along the Trail. This problem was at its worst near Fort Hall, where human behaviors responsible for dysentery, poor sanitation, crowding, and various unsanitary trade activities were at their worst. In Reverend John McAllister's description of Fort Hall dated August 1852 he wrote: "the fort is situated on a slough of snake river a plane of many miles surrounding it a bad slough on a slough right of road is good grass Camped there" (McAllister 1925). Other gathering places where pioneers spent the night waiting to ford a stream were also, relatively speaking, densely populated, and at times so heavily contaminated with animal carcasses that camping next to them often became an inevitable cause for pioneers to be exposed to the right diarrhea-inducing conditions.

An additional problem in 1852 was the development of malnutrition problems along the western part of the trail due to inadequate food stores at the forts and trading posts. With the high Trail population of 1852, fort provisions failed to meet the needs and demands of pioneers. In a letter written by Christian Kauffman to his parents in 1852, he described the fort as a place where livestock were greatly weakened by the scarcity of grass to forage, then adding: "A great 
many had to kill their poor cattle to keep from starving, but the beef gives them the diarrhea, and that is why so many die on the latter end of the road" (Kauffman 1852, 35-36). The infection of livestock and the malnutrition suffered by pioneers increased their susceptibility to dysentery brought on by eating contaminated meats, not only by forcing pioneers to consume their own livestock, but also due to the tendency for their malnutrition to induce low stomach acidity, a condition necessary for opportunistic bacteria to successfully infect people. The effects of this more fatal form of diarrhea on trail emigrants is best demonstrated by diaries detailing animal deaths in relation to human gravesite counts and personal notes added about the dysentery experience.

Martha Read's Diary Notes. Martha Read's (1852) diary provides the most convincing evidence for the association between animal deaths and human fatality along the Northwest portion of the Oregon Trail (Figure 22). Read documented the number of animal carcasses and human graves passed each day. By converting her data into spatial-temporal graphs of graves and animal carcasses passed per mile per day on the trail, differences between the dysentery and cholera regions become apparent. In particular, Read's data shows a fairly regular wave of Asiatic cholera graves both temporally and spatially along the Great Plains, a pattern which contrasts greatly with the irregular spacing noted for the Northwest regions where trail deaths due to dysentery were recorded. Read's figures demonstrate a wave-like pattern for Asiatic cholera deaths along the Trail, i.e. the further away from the disease nest one travels, the less likely one will be infected and pass it on to new victims due to the deaths of highly susceptible people and/or ecological and environmental changes. 


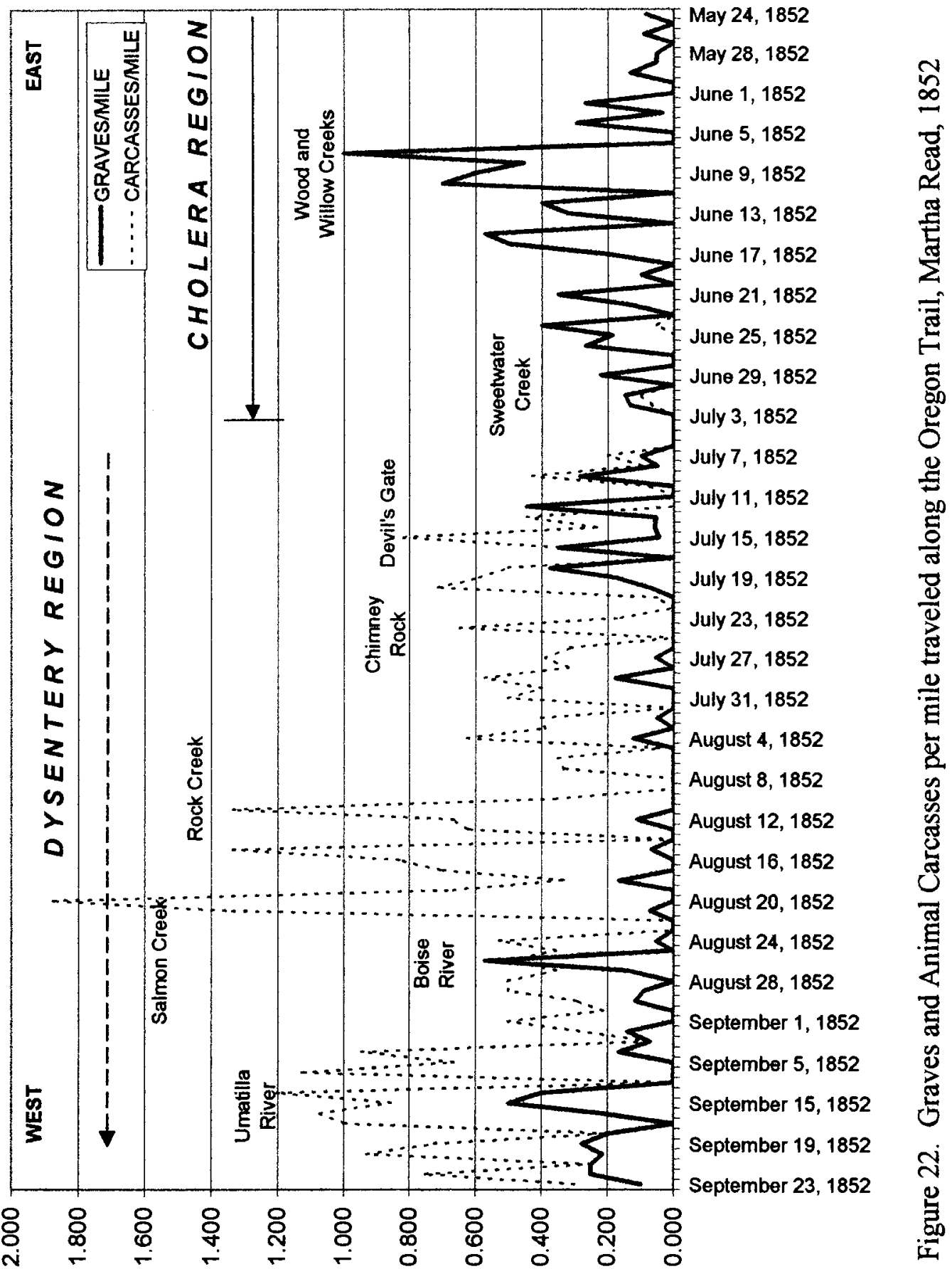

\section{ә|!W Jad sasseojeว/sə^eגอ}


Unlike Asiatic cholera, dysentery lacked the much larger temporal-spatial relationship seen with Asiatic cholera. By remaining active along the entire length of the trail, this dysentery showed a tendency to erupt at certain locations due to specific well-localized geographic features related to animal deaths. These epidemics were of multiple causes, but as the trail headed further westward, human population features became the primary feature determining how aggressive future dysentery problems might become.

The Snake River Epidemic. Along Snake River, the various geographic features which contributed to the deaths of livestock were at their worst. Alkali water caused numerous oxen deaths between American and Cascade Falls. Kerns for example noted 17 recent livestock deaths in 5 days of travel across 95 miles of trail, the chief reason he gave for these deaths was the lack of potable water (Kerns $1917,175-176)$. One week later, Kerns again noted cattle deaths accompanied by a sudden increase in human graves. Soon after, members of his train became ill, leading him to write on August 17, 1852: "Mr. Stone's wife was taken sick last evening with cholera and died this evening after camping" (ibid 177). As this illness continued, it peaked in severity just before reaching Fort Boise. Delazon Smith blamed the deaths in the fort region (including Native Americans as well) on water contamination by carcasses, noting at least 5000 of the 14,000 to 15,000 horses chancing this journey had been left dead or nearly-dead by pioneers trying hastily to complete the final miles of trail migration (Smith 1852, Letter 1, 7).

As Kerns's wagons reached this carcass-ridden region, his team camped on the Owyhee River just south of Fort Boise on August 21st, and Kerns made the following entry "we have taken several sick persons in the train this evening, 
mostly scurvy" (Kerns 1917,178 ). At this point all we can tell is their illness resembled scurvy, an illness due to Vitamin $\mathrm{C}$ deficiency, in which the chief symptoms include diarrhea and/or a reddening of the skin, two symptoms also typical of dysentery and typhoid fever. Kerns's subsequent entry suggests this condition was non-fatal, reducing the possibility that a highly fatal typhoid fever epidemic was developing. Scurvy is further ruled out by an entry made the following day by Kerns in which he described in more detail the illness his team was suffering: "Some of our train severely afflicted with a bloody diarrhea, the mountain fever, and the scurvy which begin to make us think we are treading the elephant's tail." (ibid 179).

The Dalles-Umatilla Epidemic. By the time the emigrants reached the western Blue Mountains, they were more susceptible to dysentery than ever due to malnutrition. In Mrs. L. A. Bozarth's recollection of her 1852 migration, she recalled the nutritional deficits her family suffered as they passed Fort Boise: "our provisions were running low, in fact, we were in danger of starving" (Bozarth 1852). Likewise, Sila Miller and his wife noted the same problem in a letter about the journey from Ft. Hall to Burnt River: "It is certainly one of the most God-forsaken countrys in the world. Here we suffered - - here our Cattle died - here we gave out ... here we were sick -. here we run out of provisions ..." (Miller and Miller 1852, 6).

The most concrete evidence that these diarrhea spells were linked to malnutrition and length of migration appears in Martha Read's diary. During the last weeks of her journey through Grande Ronde and Umatilla Valley, dysentery led several members of her train to experience these problems daily (Figure 23). 
GRAVES

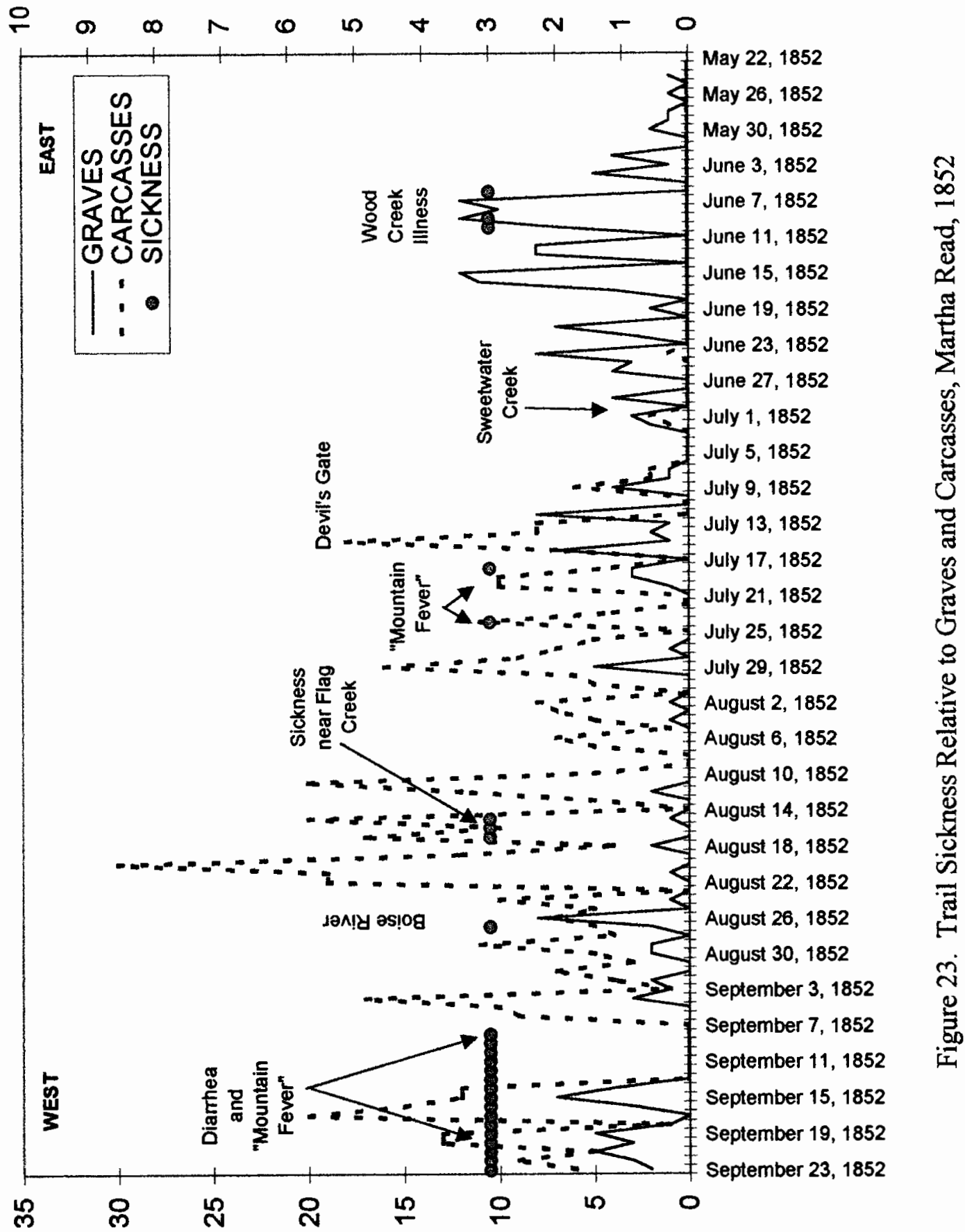




\section{Dysentery and Mountain Fever.}

The microorganisms responsible for dysentery were not only responsible for diarrhea epidemics but also the "mountain fever" common to this portion of the Trail. In some cases, this fever accompanied dysentery. In other cases it occurred as a single symptom related to an infection in which neither simple diarrhea nor the more contagious dysentery ensued. This "mountain fever" epidemic serves as the final proof that a bacterial disease of ubiquitous nature had taken hold of the Oregon Trail in 1852.

The "Mountain Fever" of Oregon Trail history is typically interpreted as Rocky Mountain Spotted Fever or Colorado Tick Fever, a metaxenotic, zoonotic disease with a disease pattern geographically-definable based on the spatial distribution of its vector, the Western Pacific Tick, and the numerous reservoirs or animal hosts for this tick. A recent cartographic impression of the Rocky Mountain Spotted Fever epidemic region shows it to be well distributed throughout Wyoming, bearing a spatial distribution pattern defined by the living environments of its vector, the tick, and the various mammals infected by this tick (Appendix F). The fact that a sizable portion of the Oregon Trail passes through this region is strongly supportive of the possibility of Rocky Mountain Spotted Fever as a possible Trail epidemic.

This association of Rocky Mountain Spotted Fever cases with many of the "mountain fever" cases noted in the diaries however seems unlikely. Supporting this argument is the ability of a typical Rocky Mountain Spotted Fever case to resolve itself fairly quickly. Had a pioneer developed this illness several weeks before reaching Oregon City, the end of the Trail, this condition should have 
lessened during the remaining days of overland migration, rather than erupt much later near the more heavily populated regions in and around The Dalles.

This review shows that many if not all of the cases of "mountain fever" experienced by pioneers in Idaho and Oregon, since they often continued throughout the remaining weeks of the migration, were induced by one or more bacteria capable of inducing cases of diarrhea, dysentery and fever as combined or as separate illnesses. The first evidence supporting this link between mountain fever and dysentery once again appears in the statistics about trail deaths tabulated by historical geographer Rieck (Rieck 1993). As already demonstrated, the "cholera" Rieck noted west of the Continental Divide and which struck Snake River was not Asiatic cholera but in fact the "cholera morbus" or dysentery defined earlier in this thesis. According to Rieck, the Asiatic cholera fatalities far outnumbered the dysentery fatalities on the Trail at least six fold. However, assuming the Trail deaths west of the Continental Divide due to dysentery could have been interpreted as either "cholera" or "fever" cases, we find that these combined fatalities are superseded only by freezing and malnutrition. In essence, the opportunistic form of dysentery responsible for the "cholera" of the Northwest was also responsible for the numerous cases of "mountain fever" noted along the same portion of the trail, rather than Rocky Mountain Spotted Fever.

Early diary evidence linking mountain fever to dysentery appeared as early as 1844 in Jacob Hammer's diary. After noting the dysentery experienced by members of his train due to the numerous buffalo carcasses along North Loup River in eastern Nebraska, he wrote "In camp today because John Murphy has the fever" (Rumer 1990, 84). 
Eight years later, this association of carcasses to mountain fever and dysentery was again made by Kerns in 1852 during his 213 mile trek from Catherine Creek to Burnt Creek when members of his team experienced diarrhea and fever, often together. On August 22nd, he noted "mountain fever" followed by the another entry just four days later: "[August 26th] Saw some very sick persons afflicted with mountain fever and flux. We saw one man taking his "last" moments in preparing for a journey to his home above" (Kerns 1917, 179).

As James Akin's team passed American Falls on Snake River on August 10th, 1852, Akin noted "Great numbers of dead cattle" two days after which his mother became ill (Webber 1994, 46). Twelve days into this illness, James Akin wrote: "mother taken worse in the morning and died about 9 o'clock in the evening." According to Webber, the researcher and publisher of this trail diary, farnily records state Akin's mother died of typhoid fever (ibid 48), a condition often confused with scurvy and dysentery. Hints that typhoid could have also been present along this portion of the trail were in fact penned by Rev. Thomas Stevens in 1852 when he, his wife, and three children suffered "a severe attack of the camp fever" (a term often used to infer typhoid fever), eventually causing the death of his 17 year old daughter (Henderson, Latourette and Latourette, 1916, 470). However, this possible "typhoid" epidemic in Umatilla Valley either never continued or resurfaced along this portion of the trail, for it was never referred to as such again by Akin or other pioneers reviewed for this study.

A similar misidentification of mountain fever as a disease distinct from dysentery was made by Jane Davies Kellogg. After passing through Snake, Grande Ronde and Umatilla River valleys, Kellogg was taken ill along with her sister 
following their stop in The Dalles (by then, a potential nidus for dysentery). This led her to write: "Sister Rachel and I were down with mountain fever, had taken sick coming down on the raft." Meanwhile, another woman on this raft, also taken ill by fever, had a young child who had just died due to this illness (Kellogg 1916, 94).

\section{"Cholera" in Portland.}

Final evidence for the spread of "cholera" in the form of dysentery-mountain fever from Wyoming to Portland, Oregon, is in the form of various recounts of the trail experience by pioneers immediately following their arrival. In late September, John Eldridge arrived in Oregon City from Illinois and claimed he witnessed about "one death a day at the Dalles," comments subsequently published in the newspaper Oregon Statesman on September 23, 1852 (Down 1926, 115). Two days later, the editor of Oregon Statesman received a copy of a newspaper listing the names of pioneers who suffered cholera deaths along the Oregon Trail, which he subsequently republished (Anonymous 1852), further heightening any local fear about the possible arrival of a more deadly form of "cholera" felt by the newly settled pioneers. Evidence for this local concern appears in a letter written one month later by Charles Stevens to "Brother Levi and Sister Emma Kelsey" dated "Portland, Oregon Territory 31 October 1852." As emigrants continued to arrive, they shared with others their "cholera" experiences, leading Stevens to write: "A great many died with the Cholera on the Snake from Salmon falls to this side of the river at Ft. Boyse, and with the diarhoea all the way to this place, and many of the emegrants (sic) have died since they have arived (sic) 
here" (Lockwood 1936, 145-146). Two months later, in a second letter from Milwaukee dated 27 December 1852 , Stevens added more to the story about the migration of "cholera" to Portland by way of the Oregon Trail: "[t]here has been some Cholera in Portland this fall. The late emigrants, or the poor people in Portland are about to starve, so we are told" (ibid 154).

\section{Summary}

An exact bacterial cause for the opportunistic dysentery epidemic along the Oregon Trail remains uncertain due to the lack of physical evidence. This Oregon Trail epidemic however appears to be directly linked to human exposure to bacteria residing on animal carcasses. Whereas some of the dysentery cases east of the Rocky Mountains could have been due to amoebic and shigellic dysentery, two diseases of tropical origin which might have tolerated Midwestern climate conditions, the limited population of the Pacific Northwest makes either of these causes for dysentery unlikely. The most likely cause for epidemics immediately west of the Great Plains is one or more species of Salmonella. Still further west into the Rocky Mountains and Pacific Northwest, a Campylobacter species could have been involved due to the inclusion of farm animals and contaminated food stuffs into this part of the epidemic history. As emigrants approached The Dalles, the development of Typhoid Fever was possible.

The recurring association of dysentery with "mountain fever" by pioneers during the final weeks of their migration is the primary support for the conclusion that most of the Oregon Trail dysentery epidemics were due to one or more species of Salmonella. Additional support for this theory comes from the mention of a 
combined fever and toothache problem by McKinstry, a complaint found in other diaries as well (Mattes 1969, 83). Since numerous Salmonella species have fever as a primary affect and Salmonella intermedia, an animal-borne opportunistic bacterium, is known to cause toothaches (a condition noted by McKinstry), one or more Salmonella species are suspected to have caused these Trail epidemics. This behavior of Salmonella in relation to people and animals suggests that this problem was probably prevalent throughout Oregon Territory as well during its earliest stages of development. 


\section{CHAPTER VII}

\section{CONCLUSION}

This study defined two epidemic regions along the Oregon Trail--the cholera region and the dysentery region. Specific physical and human geographic features were responsible for their development. Regions successfully infected by the Vibrio cholera were well-populated or linked directly to other well-populated semi-urban and urban areas where other Asiatic cholera epidemics had already taken form. Regions infected by the opportunistic organisms responsible for dysentery lacked the heavy population required of Asiatic cholera, and were typically places engaged in the early stages of development as pioneer towns and cities. The most common bacteria linked to this illness were most likely one or more species of Salmonella.

Asiatic cholera is differentiated from dysentery by its unique distribution along the Oregon Trail. Due to its dependency on a nidus located in estuarine and deltaic ecosystems, Asiatic cholera lost its ecological support once it diffused inland and its passage through the Rocky Mountains prevented by cooler temperatures brought on by the rising elevation of the trail and the changes in the topography of the river shoreline. An even more likely reason for this cessation of cholera diffusion westward into Wyoming was the ability of Vibrio cholerae to rapidly take the lives of the most susceptible people such that by the time Fort 
Laramie was reached, the possibility of infecting new people so as to continue the diffusion westward in active epidemic form was eliminated.

Since Asiatic cholera epidemic regions transmit their infection in a combined hierarchical/non-hierarchical nature, the first regions infected along the Trail were the partially developed semi-urban locations-- forts--where transportation to and from by way of rivers brought cholera carriers to places where local events of economic importance took place. By entering this dense population setting, the organism responsible for Asiatic cholera was able to infect large numbers of emigrants making their way further westward along Platte River and the Great Plains and caused radially diffusing epidemics of Asiatic cholera from the fort settings.

Once a fort was departed, this Trail epidemic followed a linear diffusion pattern from one camp ground to the next until it infected nearly all the pioneers who were susceptible. By reaching Fort Laramie, it caused a much smaller outbreak, killing off any remaining susceptible people. During the remaining portion of the overland journey through Wyoming, this Asiatic cholera epidemic dissipated due to human fatalities and topographic and climatic changes along the Oregon Trail.

The diffusion of the second diarrhea epidemic of the Trail, opportunistic dysentery commenced in the same region where Asiatic cholera ceased to cause fatalities. Less inhibited by local climatic and physiographic features, its westward diffusion was first and foremost related to livestock activities in relation to local topography, forming niduses wherever animal carcasses lie. The most infectious 
parts of the Trail were located close to late pioneer settlements with poor sanitation practices.

Perpetuating this cause for the dysentery problem were the various forts and trading posts where contaminated meats were often sold by nearby merchants. Still further west along the trail, malnutrition became a growing problem and caused many pioneers to become more susceptible to the disease. In the end, some of these victims effectively carried opportunistic dysentery to Portland, Oregon around January 1853.

In sum, the physical and human geographic features responsible for the prevention of vibrio diffusion from Wyoming to Oregon were equally responsible for the development of an opportunistic dysentery region. Whereas the geographic behavior of Asiatic cholera is due primarily to its history as both an endemic and epidemic disease in specific ecologically-definable regions, the geographic behavior of dysentery is less restricted in its diffusion pattern. This review of the historical behavior of diseases and their interpretations by mid-nineteenth century medical geographers, when used in the context of modern ecological disease approaches, demonstrates the value of utilizing historical evidence to interpret two otherwise identical disease patterns and develop new methods of evaluating spatial and temporal disease diffusion patterns. The early stage of economic development of Oregon State prevented diseases like Asiatic cholera from striking the Pacific Northwest but did little to prevent pioneer diseases like opportunistic dysentery from developing into epidemics in these communities. 


\section{BIBLIOGRAPHY}

Adler, Nancy E., Michael Marmot, Bruce S. McEwen, and Judith Stewart (eds.). 1999. Socioeconomic Status and Health in Industrial Nations. Social. Psychological and Biological Pathways. Annals of the New York Academy of Sciences volume 896. New York: New York Academy of Sciences.

Akhtar, Rais. 1991. Environment and Health. Themes in Medical Geography. New Delhi: Ashish Publishing House.

Allos, Ban Mishu, and David N. Taylor. 1994. Campylobacter Infections. In Alfred S. Evans and Philip S. Brachman (eds.) Bacterial Infections. Epidemiology and Control (New York: Plenum Medical Book Company) pages 169-190.

Anonymous. 1833. Cholera in Havana. Medical Magazine (Boston) 1: 668-674.

Anonymous. 1852. Mortality on the Plains. Oregon Statesman. September 25, 1852. p. 3.

Anonymous. 1855. The Contagiousness of Cholera--A Review. Boston Medical and Surgical Journal 52: 235-242.

Arbona, Sonia, and Shannon Crum. 1996. Medical Geography and Cholera in Peru. The Geographer's Craft Project, Department of Geography, University of Texas at Austin. April 6, 2000. http://www.utexas.edu/ $\mathrm{depts} / \mathrm{grg} / \mathrm{gcraft} /$ warmup/cholera/cholera.html.

Banatula, N., A. Cramp, I. R. Jones, and R. A. Feldman. 1999. Salmonellosis in North Thames (East), U.K.: Assocated Risk Factors. Epidemiology and Infections 122: 201-207.

Baross, J., and J. Liston. 1970. Occurrence of Vibrie parahaemolyticus and related hemolytic vibrios in marine environments of Washington State. Applied Microbiology 20: 179-186. 
Bashford, D. J., T. J. Donova, A. L. Furniss, and J. V. Lee. 1979. Vibrio cholerae in Kent. Lancet i: $436-437$.

Bell, Theodore S. 1851. Epidemic Influences, and the duties of the Medical Profession in relation to them. Western Journal of Medicine and Surgery 7: 277-344.

Bellew, H. W. 1884. The history of cholera in India from 1862 to 1881 . London.

Blake, Paul A. 1984. Prevention of Food-Borne Disease caused by Vibrio species. In Rita R. Colwell (ed.). Vibrios in the Environment (New York: John Wiley \& Sons) pages 579-591.

Blake, Paul A. 1994. Endemic Cholera in Australia and the United States. in Kaye I. Wachsmuth, Paul A. Blake, and Orjan Olsvik (eds.). Vibrio cholerae and Cholera. Molecular to Global Perspectives (Washington, D.C.: American Society for Microbiology) pages 309-319.

Blake, Paul A. 1994. Historical Perspectives on Pandemic Cholera. In Kaye I. Wachsmuth, Paul A. Blake, and Orjan Olsvik (eds.). Vibrio cholerae and Cholera. Molecular to Global Perspectives (Washington, D.C.: American Society for Microbiology) pages 293-295.

Blaser, Martin. 1995. Campylobacter \& related species. In Gerald C. Mandell, John E, Bennett, and Raphael Dolin (eds.). Principles and Practice of Infectious Diseases.4ed. (New York: Churchill Livingstone) pages1948-1956.

Bolton, F. J., S. B. Surman, K. Martin, D. R. Wareing, and T. J. Humphrey. 1999. Presence of Campylobacter and Salmonella in Sand from Bathing Beaches. Epidemiology and Infections 122: 7-13.

Bowditch, Henry L. 1866. Topographical Distribution and Local Origin of Consumption in Massachusetts. Read at the annual meeting, May 28, 1862. Medical Communications of the Massachusetts Medical Society 10: 59-138.

Boyd, Robert T. 1975a. Another Look at the "Fever and Ague of Western Oregon. Ethnohistory 22: 135-154.

Boyd, Robert T. 1975b. The Introduction of Infectious Diseases among the Indians of the Pacific Northwest. Thesis. University of Washington, Seattle. 
Boyd, Robert T. 1999. The Coming of the Spirit of Pestilence: Introduced Infectious Diseases and Population Decline among Northwest Coast Indians. 1774-1784. Seattle: University of Washington Press.

Bozarth, Mrs. L. A. 1852. Narrative of Mrs. L. A. Bozarth, a Pioneer of 1852. MSS 1508 Oregon Historical Society, Portland, OR.

Briggs, Mrs. Ethel. 1960. A History and Genealogy of Gilmore Callison and his Descendents. Lebanon, OR: n.p.

Buel, William P. 1856. On "Chagras Fever" and some of the other Disease to which California Emigrants are Liable." The American Journal of the Medical Sciences 31: 319-326.

Callison, John Joseph. 1959. The Diary of John Joseph Callison, Oregon Trail-1852. Typescript, reproduced by The Lane County Pioneer-Historical Society, Eugene, OR 1959.

Cash, R. A., S. I. Music, J. P. Libonati, M. J. Snyder, R. P. Wenzel, and R. B. Hornrick. 1974. Response of man to infection with Vibrio cholerae. I. Clinical, serologic and bacteriologic responses to a known inoculum. Journal of Infectious Disease 129: 45-52.

Cayleff, Susan. 1988. Gender, Ideology, and the Water Cure Movement. In Norman Gevitz (ed.). Other Healers. Unorthodox Medicine in America (Baltimore: Johns Hopkins University Press) pages 82-98.

Chambers, J. S. 1938. The Conquest of Cholera. America's Greatest Scourge. New York: MacMillan Company.

CHAART. 2000a. Bangladesh Bay of Bengal Study. CHAART (Center for Health Applications of Aerospace Related Technologies), February 2000. April 6, 2000 at http://geo.arc/nasa.gov/sge/health/chaart.html.

CHAART. 2000b. Remote Sensing of Cholera Outbreaks: First Year Report. CHAART (Center for Health Applications of Aerospace Related Technologies), February 2000. April 6, 2000 at http://geo.arc.nasa.gov/sge/ health/projects/cholera/cholerarpt $1 . h t m l$. 
Chen, F., G. M. Evins, W.L. Cook, R. Almeida, N. Hargett-Bean, and K.

Wachsmuth. 1991. Genetic Diversity among toxigenic and nontoxigenic

Vibrio cholerae $\mathrm{O} 1$ isolated from the Western Hemisphere. Epidemiology and Infection 107: 225-233.

Chenoweth, Hon. F. A. 1883. Occasional Address. In Transactions of the Tenth Annual Re-union of the Oregon Pioneer Association for 1882 (Salem, Oregon: E. B. Waite, Steam Printer) pages 28-39.

Christaller, W. 1935. Die Zentralen Orte in Suddeutschland. Jeda: Gfischer.

Clarenburg, A. 1964. Salmonellosis. In J. Van der Hoeden (ed) Zoonoses (New York: Elsevier Publishing Company) pages 132-161.

Clemow, Frank G. 1903. The Geography of Disease. Cambridge: At the University Press.

Cliff, A. D., P. Haggett, J. K. Ord, and G. R. Versey. 1981. Spatial Diffusion. An Historical Geography of Epidemics in an Island Community. Cambridge: Cambridge University Press.

Colwell, Rita R. 1984. Vibrios in the Environment. In Rita R. Colwell (ed.). Vibrios in the Environment (New York: John Wiley \& Sons) pages 1-15.

Colwell, Rita R., and Anwarul Huq. 1994. Vibrios in the Environment: Viable but Nonculturable Vibrio cholerae. In Kaye I. Wachsmuth, Paul A. Blake, and Orjan Olsvik (eds.). Vibrio cholerae and Cholera. Molecular to Global Perspectives (Washington, D.C.: American Society for Microbiology) pages 117-133.

Colwell, Rita R., and J. Liston. 1960. Bacteriological study of the natural flora of Pacific Oysters (Crassostrea gigas). Applied Microbiology 8: 104-109.

Colwell, Rita R., and J. Liston. 1961. A bacteriological study of the natural flora of Pacific Oysters (Crassostrea gigas) when transplanted to various areas in Washington. Proceedings of the National Shellfishing Association 50: 181-188. 
Colwell, Rita R., R. J. Seidler, J. Kaper, S. W. Joseph, S. Garges, H. Lockman, D. Maneval, H. B. Bradford, N. Roberts, E. Remmers, I. Huq, and A. Huq. 1981. Occurrence of Vibrio cholerae serotype $\mathrm{O} 1$ in Maryland and Louisiana estuaries. Applied Environmental and Microbiology 41: 555-558.

Creighton, Charles. 1965. A History of Epidemics in Britain. London: Frank Cass \& Company, Limited.

Curtis, C. 1807. An account of the diseases of India as they appeared in the English fleet. and in the naval hospital at Madras in 1782 and 1783. Edinburgh.

Delano, Alonso. 1854. Life on the Pains and Among the Diggings. Auburn and Buffalo, NY: Miller, Orton, \& Mulligan. Reproduced in 1966 in Readex Microprint form by Readex Microprint Corporation.

Desmarshelier, P. and J. L. Reichelt. 1981. Phenotypic characterization of clinical and environmental isolates to Vibrio cholerae in Australia. Current Microbiology 5: 123-127.

Dietrich, M. A., C. R. Hackney, and R. M. Grodner. 1984. Factors Affecting the Adherence of Vibrio cholerae to Blue Crab (Callinectes sapidus) Shell. In Rita R. Colwell (ed.). Vibrios in the Environment (New York: John Wiley \& Sons), pp. 601-611.

Dold, Catherine. 1999. The Cholera Lesson. Discover 20: 71-75.

Dowell, Benjamin Franklin. 1850. Letter. Sacramento City, California, September, 1850. To Greensville Dowell, Come (?) Mississippi. MSS 209, Oregon Historical Society, Portland, OR.

Down, Robert Horace. 1926. A History of Silverton Country. Portland: The Berncliff Press.

Drabkin, I. E., (ed.) 1950. Caelius Aurelianus. On Acute Diseases and on Chronic Diseases. Chicago: The University of Chicago Press.

Dunham, Edward K. 1904. Asiatic Cholera. In A Reference Handbook of the Medical Sciences. (9 vols.) Albert H. Buck (ed.) (New York: William Wood \& Company.) 8: 352-370. 
Earickson, Robert J., Michael R. Greenberg, Nancy D. Lewis, Melinda S. Meade, and S. Martin S. Taylor. 1989. Medical Geography. In Gary L. Gaile and Cort J. Willmott (eds.), Geography in America, (Colombus: Merrill Publishing Company) pp. 425-450.

Ellet, Elizabeth Fries. 1973. The Pioneer Women of the West. Freeport, NY: Books for Libraries Press.

Epstein, Paul R. 1998. Health Applications of Remote Sensing and Climate Modeling. In People and Pixels. Linking Remote Sensing and Social Science. Diana Liverman, Emilio F. Moran, Ronald R. Rindfuss, and Paul C. Stern, eds. (Washington, D.C. National Research Council) pages 197-207.

Estrauzlas, Enrique M. 1873. Epidemic Cholera in South America. The American Journal of Medical Sciences 66: 74-84.

Eyles, John and Kevin J. Woods. 1983. The Social Geography of Medicine and Health. New York: St. Martin's Press.

Faragher, John Mack. 1979. Women and Men on the Overland Trail. New Haven: Yale University press.

Farr, William. 1852. Report on the Mortality of Cholera in England, 1848-9. London: Her Majesty's Statonery Office.

Felkin, R. W. 1889. On the Geographical Distribution of Some Tropical Diseases and their relation to Physical Phenomena. London: Young J. Pentland.

Fremont, Captain John Charles. 1988. The Exploring Expedition of the Rocky Mountains. Washington, D.C.: Smithsonian Institution Press. Originally published in 1845 as Report of the Exploring Expedition to the Rocky Mountains in the Year 1842, and to Oregon and North California in the Years 1843-44 (Washington, D. C.: Blair and Rivers, Printers).

Gardner, James T. 1877. Relation between Topographical Surveys and the Study of Public Health. The Sanitarian 5: 385-389.

Garrison, Fielding H. 1929. An Introduction to the History of Medicine 4ed. Philadelphia: W. B. Saunders Company. 
Gaulter, Henry. 1833. The Origin and Progress of the Malignant Cholera in Manchester, London. London.

Gentilcore, R. Louis. 1957. Vincennes and French Settlement in the Old Northwest. Annals of the American Association of Geographers 47: 285-297.

Gesler, Wilbert M., and Thomas C. Ricketts. 1992. Health in Rural America. The Geography of Care Services and Delivery. New Brunswick: Rutgers University Press.

Gibbons, Henry. 1865. Malignant Cholera in California. Pacific Medical and Surgical Journal 8: 191-197.

Goetzmann, William H. 1959. Army Exploration of the American West. 1803-1863. New Haven: Yale University Press.

Gould, Peter. 1985. The Geographer at Work. New York: Routledge.

Gray, Charles Glass. 1976. Off at Sunrise. The Overland Journal of Charles Glass Gray Thomas D. Clark (ed.). San Marino, CA: Huntington Library.

Greenberg, E. P., Heidi B. Kaplan, M. DuBoise, and B. Palhof. 1984. Persistence and Distribution of Marine Vibrios in the Hardshell Clam. In Rita R. Colwell (ed.). Vibrios in the Environment (New York: John Wiley \& Sons) pages $479-493$.

Hagerstrand, T. 1952. The Propagation of Innovation Waves. Lund Studies in Geography, B, 4: 3-19.

Hagerstrand, T. 1967. Innovation Diffusion as a Spatial Process. Chicago.

Haggett, Peter. 1994. Geographical Aspects of the Emergence of Infectious Diseases. Geografiska Annaler 76B: 91-104.

Hall, George W. 1855. An Account of the Epidemic Cholera as it Prevailed in the Town of Carthage, Illinois, in the Summer of 1851. The Boston Medical and Surgical Journal 53: 157-159. 
Hastings, Loren B. 1926. Diary of Loren B. Hastings. A Pioneer of 1847. In Transactions of the Forty-Eighth Annual Reunion of the Oregon Pioneer Association, Portland, June 21, 1923 (Portland: Chausse-Prudhomme Co., Printers) pages 12-26.

Hatch, F. W. 1855. On the Climate of the Valley of the Sacramento, California. New York Journal of Medicine 15: 9-50.

Henderson, Sarah Fisher, Nellie Edith Latourette, and Kenneth Scott Latourette. 1916. Correspondance of the Reverend Ezra Fisher Pioneer Missionary of the American Baptist Home Mission Society in Indiana, Illinois, Iowa and Oregon. Oregon Historical Society Ouarterly 17: 431-480.

Himes, George H. 1909. Diary of James Akin, Jr. In Transactions of the 36th Annual Reunion of the Oregon Pioneer Association. Portland June 11th. 1908. (Portland, OR: Chausse-Prudhomme Co.) pages 259-274.

Hirsch, August. 1883-1886. Handbook of Geographical and Historical Pathology. (3 vols.) Translated from the Second German Edition by Charles Creighton. London: The New Sydenham Society.

Holmes, Kenneth L. (ed.). Covered Wagon Women: Diaries and Letters from the Wagon Trails, 1840-1890 (11 volumes, 1983-1993). The Arthur H. Clarke Co., Glendale, CA.

Howe, G. Melvyn, (ed.). 1977. A World Geography of Human Diseases. San Francisco: Academic Press.

Hume, Edgar Erskine. 1927. Max von Pettenkoffer. New York: Paul B. Hoeber, Inc.

Huq, Anwarul, Eugene B. Small, Paul A. West, and Rita R. Colwell. 1984. The Role of Planktonic Copepods in the Survival and Multiplication of Vibrio cholerae in the Aquatic Environment. In Rita R. Colwell (ed.). Vibrios in the Environment (New York: John Wiley \& Sons) pages 521-534.

Islam, Mohammed Sirajul. 1990. Increased Toxin Production by Vibrio cholerae O1 during Survival with a Green Algae, Rhizoclonium fonatanum, in an Artifical Aquatic Environment. Microbiology and Immunology 34; 557-563. 
Islam, Mohammed Sirajul, Bohumil S. Drasar, and David J. Bradley. 1989.

Attachment of toxigenic Vibrio cholerae $\mathrm{O} 1$ to various freshwater plants and survival with a filamentous green alga, Rhizoclonium fontanum. Journal of Tropical Medicine and Hygiene 92: 396-401.

Islam, Mohammed Sirajul, B. S. Drasar, and D. J. Bradley. 1990. Survival of toxigenic Vibrie cholerae O1 with a common duckweed, Lemna minor, in artificial aquatic ecosystems. Transactions of the Royal Society of Tropical Medicine and Hygiene 84: 422-424.

Islam, Mohammed Sirajul, M. J. Alam, and P. K. B. Neogi. 1992. Seasonality and Toxigenicity of Vibrio cholerae non-O1 isolated from different components of pond ecosystems of Dhaka City, Bangladesh. World Journal of Microbiology and Biotechnology 8; 160-163.

Johnston, Alexander Keith. 1856. On the Geographical Distribution of Health and Disease, in Connexion Chiefly with Natural Phenomena. Transactions of the Epidemiological Society of London 2: 25-71.

Jones, Kelvyn, and Graham Moon. 1991. Medical Geography. Progress in Human Geography 15: 437-443.

Jusatz, H. 1977. Cholera. In A World Geography of Human Diseases. G. Melvyn Howe (ed.) (New York: Academic Press) pages 131-143.

Kane, T. C., D. C. Culver, and J. Mathieu. 1994. Biotic Fluxes and Gene Flow. In Janine Gibert, Dan L. Danielpol, and Jack A. Stanford (eds.) Groundwater Ecology (New York: Academic Press, Inc.) pages 245-270.

Kaper, James B., Alessio Fasano, and Michele Trucksis. 1994. Toxins of Vibrio cholerae. In Kaye I. Wachsmuth, Paul A. Blake, and Orjan Olsvik (eds.). Vibrio cholerae and Cholera. Molecular to Global Perspectives. (Washington, D.C.: American Society for Microbiology) pages 145-176

Kauffman, Christian. 1983. Letter from Christian Kauffman to his Parents, November 18, 1852. Oregon Genealogical Society Fall 1983, p. 35. 
Kay, Bradford A., Cheryl A. Bopp, and Joy G. Wells. 1994. Isolation and Identification of Vibrio cholerae O1 from Fecal Specimens. In Kaye I. Wachsmuth, Paul A. Blake, and Orjan Olsvik (eds.). Vibrio cholerae and Cholera. Molecular to Global Perspectives (Washington, D.C.: American Society for Microbiology) pages 3-25 in

Kaysner, Charles A., and Walter E. Hill. 1994. Toxigenic Vibrio cholerae O1 in Food and Water. In Kaye I. Wachsmuth, Paul A. Blake, and Orjan Olsvik (eds.). Vibrio cholerae and Cholera. Molecular to Global Perspectives. (Washington, D.C.: American Society for Microbiology) pages 27-39.

Kearns, Robert A. 1993. Place and Health: Toward a Reformed Medical Geography. The Professional Geographer 45: 139-147.

Kearns, Robin A., and Wilbert M. Gesler. 1998. Putting Health into Place. Landscape, Identity and Well-being. John Rennie Short, Series Editor, Space, Place and Society. Syracuse: Syracuse University Press.

Kerns, John T. 1917. Journal of Crossing the Plains to Oregon in 1852. In Transactions of the Forty-Second Annual Reunion of the Oregon Pioneer Association, Portland, June 25, 1914 (Portland: Chausse-Prudhomme Co., Printers) pages 148-193.

Knapp. M. L. 1855a. Cause, Nature, Cure and Prevention of Epidemic Cholera. Eclectic Medical Journal, Fourth Series, 1: 135-144, 223-229.

Knapp, M. L. 1855b. Medical Topography of the State of Illinois, the field of the writer's observations. New York Journal of Medicine 15: 366-389.

Koch, Robert. 1884. An Address on Cholera and its Bacillus. The British Medical Journal 2: 403-407, 453-459.

Koskinen,. S. 1988. Time Trends in Cause Specific Mortality by Occupational Class in England and Wales. In Proceedings of the IUSSP Conference held in Florence, June 1985. Florence.

Kundu, K. P. and U. P. How. 1938. Prawns as a possible vector of $V$. cholerae. Indian Medical Gazette 73: 605.

Larsell, Olof. 1946. Outline of History of Medicine in Pacific Northwest. Northwest Medicine 31: 390-396, 437-443, 483-489. 
Larsell, Olof. 1947. The Doctor in Oregon. Portland: Binfords and Mort.

Latham, Baldwin. 1877. Importance of Hydro-geological Surveys from a Sanitary Point of View. The Sanitary Record 6: 229-241.

Lea, J. 1851. Cholera: a geological theory. Western Lancet, Cincinnati 12: 89, 217.

Learmonth, Andrew. 1978. Patterns of Disease and Hunger. (Problems in Modern Geography). North Pomfret, VT: David and Charles (Ltd.) Inc.

Learmonth, Andrew. 1988. Disease Ecology. Oxford: Basil Blackwell.

Leavitt, Judith W. 1973. The Pioneer Women of the West. Freeport, NY: Books for Libraries Press.

Leavitt, Judith W. 1977. Medicine without Doctors: Home Health Care in American History. A Symposium organized by the Department of the History of Medicne, University of Wisconsin, Madison. New York: Scientific History Publications.

Leavitt, Judith W. 1999. Women and Health in America: Historical Readings. 2ed. Madison, WI: University of Wisconsin Press.

Leonard, J. P. 1850. On the Different Varieties of Diarrhoea. Boston Medical and Surgical Journal 42: 304-308; 341-346; 401-406; 425-431.

Little, James. 1874. On the Geographical Distribution of Disease. In Lectures on Public health, delivered in the Lecture-Hall of the Royal Dublin Society (Royal Dublin Society), pages 62-71.

Lockley, Fred. 1981. Conversations with Pioneer Women. Oregon County Library Series, volume 1. The Lockley Files. Eugene, OR: Rainy Day Press.

Lockwood, E. Ruth. 1938. Letters of Charles Stevens. Oregon Historical Society Quarterly 37: 137-159.

Logan, Thomas M. 1851. Letters from California,--its Climate--Prevalent Diseases-States of the Medical Profession--Introduction of Cholera, etc. The New-Orleans Medical and Surgical Joumal 7: 560-580. 
McGlashan, Neil D., and John R. Blunden (eds.). 1983. Geographical Aspects of Health Essays in Honor of Andrew Learmonth. New York: Academic Press.

McKee, Ruth Karr. 1945. Mary Richardson Walker. Her Book. Caldwell, ID: The Caxton Printers Ltd.

McKeown, T., R. G. Record, and R. D. Turner. 1975. An Interpretation of the Decline in Mortality in England and Wales during the Twentieth Century. Population Studies 29: 391-422.

McKinstry, Bruce L. 1975. The California Gold Rush Overland Diary of Byron N. McKinstry. 1850-1852. Glendale, California: Arthur H. Clark Company.

McPheeters, William M. 1850. History of Epidemic Cholera in St. Louis in 1849. The St. Louis Medical and Surgical Journal 7: 99-116.

Meade, Melinda S., John W. Florin, and Wilbert M. Gesler, 1988. Medical Geography. New York: The Guilford Press.

Meade, Melinda S. 1992. Implications of Changing Demographic Structures for Rural Health Services. In Wilbert M. Gesler and Thomas C. Ricketts (eds.). Health in Rural North America. The Geography of Care Services and Delivery (New Brunswick: Rutgers University Press) page 69-85.

Meyer, Alfred H. 1954. Circulation and Settlement Patterns of the Calumet Region of Northwest Indiana and Northeast Illinois. (The First Stage of Occupance--the Pottawatomie and the Fur Trade--1830). Annals of the American Association of Geographers 44: 245-274.

Meyer, Alfred H. 1956. Circulation and Settlement Patterns of the Calumet region of Northwest Indiana and Northeast Illinois. (The Second Stage of Occupance--Pioneer Settler and Subsistance Economy.) Annals of the American Association of Geographers 46: 312-356.

Meyer, Alfred H. 1959. The Kankakee "Marsh" of Northern Indiana and Illinois. Robert S. Platt (ed.). In Field Study in American Geography. The Development of Theory and Method Exemplified by Selections. Department of Geography, Research Paper No. 61. (Chicago: The University of Chicago) pages 202-216. 
Meyer, Alfred H., and John H. Strietelmeier. 1963. Geography in World Society. A Conceptual Approach. Philadelphia: J. B. Lippincott Company.

Milikien, Herbert C. 1996. "Dead of the Bloody Flux." Cholera Stalks the Emigrant Trail. Qverland Trail 14: 4-11.

Miller, Samuel I., Elizabeth L. Hohmann, and David A. Pegues. 1995. Salmonella (including Salmonella Typhi). In Gerard L. Mandell, John E. Bennett, and Raphael Dolin (eds.). Principles and Practice of Infectious Diseases. 4ed. (2 vols.) (New York: Churchill Livingston), pages 2013-2033.

Miller, Sila V. and M. J. Miller. 1852. Letter November 24, 1852, from Salem. Oregon Territory. Typescript from original letter owned by Phil Metscham. MSS 103, Oregon Historical Society, Portland, OR.

Mintz, Eric D., Tanja Popovic, and Paul A. Blake. 1994. Transmission of Vibrio cholerae O1. In Kaye I. Wachsmuth, Paul A. Blake, and Orjan Olsvik (eds.). Vibrio cholerae and Cholera. Molecular to Global Perspectives. (Washington, D.C.: American Society for Microbiology) pages 345-356.

Morantz, Regina Markell. 1985. The "Connecting Link": The Case for the Woman Doctor in 19th-Century America. In Judith Walzer Leavitt and Ronald L. Numbers (eds.) Sickness and Health in America (Madison: The University of Wisconsin Press) pages 161-172.

Morris, Jr., J. Glenn, and the Cholera Laboratory Task Force. 1994. Vibrie cholerae 0139 Bengal. In I. Kaye Wachsmuth, Paul A. Blake, and Orjan Olsvik (eds). Vibrio cholerae and Cholera. Molecular to Global Perspectives. (Washington, D.C.: American Society for Microbiology) pages 95-102.

Murphy, Lamar Riley. 1991. Enter the Physician. The Transformation of Domestic Medicine, 1760-1860. Tuscaloosa: The University of Alabama Press.

Nichols, Mary S. Gove. 1852. Experiences in Water Cure. New York: Fowler and Wells.

Oppenheimer, J. R., M. G. Ahmed, A. Huq, K. A. Haque, A. K. M. A. Alam, K. M. S. Aziz, S. Ali, and A. S. M. Haque. 1978. Limnological studies of three ponds in Dacca, Bangladesh. Bangladesh Joumal of Fisheries 1: 1-28. 
Pacione, Michael, (Ed.). Medical Geography: Progress and Prospect Wolfeboro, New Hampshire: Croomhelm, 1986.

Pandit, C. G., and S. L. Hora. 1951. The probable role of Hilsa fish, Hilsa ilisha (Ham) in maintaining cholera endemicity in India. Indian Journal of Medical Science 5: 343.

Parsons, Lucena. 1850. An Overland Honeymoon. In Kenneth L. Holmes (ed.) Covered Wagon Women: Diaries and Letters from the Wagen Trails. 1840-1890. (11 volumes, 1983-1993) (The Arthur H. Clarke Co., Glendale, CA) Volume 5: 237-293.

Pavlovsky, E. N. 1966. The Natural Nidality of Transmissable Disease. (Frederick K. Plous, Jr., translator, N. D. Levine, ed.) Urbana, LL: University of Illinois Press.

Pengra, Charlotte Stearns. 1853. Reprinted ca. 1959 as The Diary of Charlotte Stearns Pengra. Oregon Trail---1853. Lane County Historical Society, P.O. Box 11532, Eugene, OR, 97440.

Peplies, Robert W. 1965. Patterns of Sequent Occupance in the Southern Appalachians: A Case Study of the Asheville Basin. Annals of the American Association of Geographers 55: 638-639.

Peters, John C. 1871. On the Origin and Trade of Asiatic Cholera. New York Medical Journal: A Monthly Record of Medicine and Collateral Sciences. 14:113-141, two fold-out maps.

Peters, John C., and Ely McClellan. 1875. A History of the Travels of Asiatic Cholera. In U. S. President. Cholera Epidemic of 1873 in the United States. Reports Prepared under the Direction of the Surgeon-General of the Army. House Executive Document No. 95-III, 43d Congress, 2d Session (Washington, D.C.: Government Printing Office) [Serial Set 1646].

Pollitzer, R. 1959. Cholera. Monograph No. 43. Geneva: World Health Organization. 
Preuse, Charles. 1846. Topographical Map of the Road from Missouri, Oregon commencing at the mouth of the Kansas in the Missouri River and ending at the Mouth of the Wallah-Wallah in the Columbia. In VII Sections... From the field notes and journal of Capt. I.C. Fremont, and from the sketches and notes made on the ground with assistant Charles Preuse. Compiled by Charles Preuse in accompaniment of Captain John Charles Fremont, 1846. By Order of the Senate of the United States. Baltimore: W. Weber \& Co.

Pringle, Virgil K. 1923. Diary of Virgil Pringle. 1846. In Transactions of the Forty-Eighth Annual Reunion of the Oregon Pioneer Association, Portland, July 1, 1920. (Portland: Chausse-Prudhomme Co., Printers) pages 281-300.

Pyle, G. F. 1969. The Diffusion of Cholera in the United States in the Nineteenth Century. Geographical Analysis 1: 59-75.

Read, Martha S. 1852. A History of our Journey. In Kenneth L. Holmes (ed.) Covered Wagon Women: Diaries and Letters from the Wagon Trails, 1840-1890. (11 volumes, 1983-1993) (The Arthur H. Clarke Co., Glendale, CA) Volume 5: 207-251.

Rieck, Richard L. 1991. A Geography of Death on the Oregon-California Trail, 1840-1860. Qverland Journal 11: 13-21.

Rieck, Richard L. 1993. Geography on the Overland Trails - Part I. The Raveled Routes--Elevation, Plains and Mountains. Overland Journal 11: 12-22.

Rieck, Richard L. 1999. Geography of the Oregon Trail West of Fort Hall. A Plethora of Options. Overland Joumal 17: 9-23.

Roberts, Nell C., Henry B. Bradford, Jr., and Joan R. Barbay. 1984. Ecology of Vibrio cholerae in Louisiana Coastal Areas. In Rita R. Colwell (ed.). Vibrios in the Environment (New York: John Wiley \& Sons) pages 389-398.

Rogers, Sir Leonard. 1928. The Incidence and Spread of Cholera in India: Forecasting and Control of Epidemics. Indian Medical Research Memoirs. Memoir No. 9, March 1928. Supplemental Series to the Indian Journal of Medical Research. Calcutta: Thacker, Spink, \& Co.

Rogers, David E. and Eli Ginzberg ( eds.). 1993 Medical Care and the Health of the Poor. Cornell University Medical College, 8th Conference on Health Policy. Boulder: Westview Press. 
Ronchetti, V, 1911-1912. Case di transmissione dell'infezione colerica per mezzo dell ostriche; decorso; esame ematologico; esito. Pathologica 4: 77.

Rose, G. 1985. Sick Individuals and Sick Populations. International Joumal of Epidemiology 14: 32-38.

Rosenberg, Charles. 1962. The Cholera Years. The United States in 1832, 1849 and 1866. Chicago: The University of Chicago Press.

Rumer, Thomas A. (ed.) 1990. This Emigrating Company. The 1844 Oregon Trail Journal of Jacob Hammer. Spokane, Washington: Arthur H.Clark Company.

Russell, A. J. H., and E. R. Sundararajan. 1928. The Epidemiology of Cholera in India. Indian Research Memoirs. Memoir No. 12, October 1928.

Supplementary Series to the Indian Journal of Medical Research. Calcutta: Thacker, Spink \& Co.

Schneider, Dona, and Michael R. Greenberg. 1992. Death Rates in Rural America. 1939 - 1981. Convergence and Poverty. In Wilbert M. Gesler and Thomas C. Ricketts (eds.) Health in Rural North America. The Geography of Health Care Services and Delivery (New Brunswick: Rutgers University Press) pages 55-68.

Scott, Leslie M. 1924. History of the Oregon Country. (6 vols). Cambridge: The Riverside Press.

Scouttetten, Raoul Joseph Henri. 1832. A Medical and Topographical History of the Cholera Morbus. Including the Mode and Prevention and Treatment. With a Report Read at the Royal Academy of Medicine, at Paris, Sept. 17. 1831. Translated from the French, by A Sidney Doane. Boston: Carter and Hendee.

Seidler, Ramon J., and Thomas M. Evans. 1984. Computer-Assisted Analysis of Vibrio Field Data: Four Coastal Areas. In Rita R. Colwell (ed.). Vibrios in the Environment (New York: John Wiley \& Sons) pages 411-425.

Sherrill, Hunting. 1835. On the Pathology of Epidemic Cholera, with some Observations of the History of the Disease and the General Cause and nature of Epidemics: containing an Improved Plan of Treatment, the Means of Prevention, and Rules for Corporations and Individuals to Pursue. New York: Samuel Wood and Sons. 
Singleton, F. L., R. Attwell, S. Jangi, and R. R. Colwell. 1982. Effects of Temperature and Salinity on Vibrio cholerae growth. Applied Environmental Microbiology 44: 1047-1058.

Smith, Delazon. 1852. Letters to Oregon Weekly Times. Speech. MSS 225. Oregon Historical Society Library, Portland, Oregon.

Snow, John. 1849. On the Mode of Communication of Cholera. London Medical Gazette 44: 730-732, 745-752, 923-929.

Snow, John. 1936. Snow on Cholera. New York: The Commonweath Fund.

Spira, W. M., A. Huq, Q. S. Ahned, and Y.A. Saeed. 1981. Uptake of Vibrio cholerae biotype of el tor from contaminated water by Water Hyacinth (Eichornia crassipes). Applied Environmental Microbiology 42: 550-554.

Stamp, L. Dudley. 1964a. The Geography of Life and Death. Ithaca: Cornell University Press.

Stamp, L. Dudley. 1964b. Some Aspects of Medical Geography. New York: Oxford University Press.

Stille, Alfred. 1885. Cholera, Its Origin, History, Causation, Symptoms, Lesions, Prevention, and Treatment. Philadelphia: Lea and Brothers.

Stillman, J. D. B. 1851. Observations of the Medical Topography and Diseases (especially Diarthea) of the Sacramento Valley, California, during the years 1849-50. The New York Journal of Medicine 7: 289-307.

Stolley, Paul D., and Tamar Lasky. 1998. Investigating Disease Patterns. The Science of Epidemiology. New York: Scientific American Library.

Stout, Lewis. 1852. Diary, 1852. Descriptions of the Travels from lowa to Oregon. From the Eva Emery Dye Papers. MSS 1509, Oregon Historical Society, Portland, OR.

Swan, John. 1753. The Entire Works of Dr. Sydenham. Newly Made English from the Originals: Wherein the History of Acute and Chronic Diseases, and the Safest and Most Effectual Methods of Treating them, are Faithfully, Clearly. and Accurately Delivered. London: E. Cave at Saint John's Gate. 
Swaroop, S. 1951. Endemicity of cholera in India. Indian Journal of Medical Research 39: 141.

Swerdlow, David L., and Margaretha Isaacson. 1994. The Epidemiology of Cholera. In I. Kaye Wachsmuth, Paul A. Blake, and Orjan Olsvik (eds). Vibrio cholerae and Cholera. Molecular to Global Perspectives. (Washington, D.C.: American Society for Microbiology) pages 297-307.

Tauxe, Robert V., and Andrew T. Pavia. 1994. Salmonellosis: Nontyphoidal. In Alfred S. Evans and Philip S. Brachman (eds.) Bacterial Infections. Epidemiology and Control (New York: Plenum Medical Book Company) pages 613-630.

Tauxe, Robert A., Luis Seminario, Robert Tapia, and Marlo Libel. 1994. The Latin American Epidemic. In I. Kaye Wachsmuth, Paul A. Blake, and Orjan Olsvik (eds). Vibrio cholerae and Cholera. Molecular to Global Perspectives. (Washington, D.C.: American Society for Microbiology) pages 321-344.

Taylor, D. N., K.T. McDermott, and R. J. Little. 1983. Campylobacter enteritis associated with drinking untreated water in back-country areas in the Rocky Mountains. Annals of Internal Medicine 99: 38.

Thomas, Lewis F. 1931. The Sequence of Areal Occupance in a Section of St. Louis, Missouri. Annals of the American Association of Geographers 21: 75-90.

Thompson, Kenneth. 1971. Climatotherapy in California. California Historical Society Quarterly 50: 111-130.

Tison, D. L. and M. T. Kelly. 1984. Sea Water and Vibrio Cholera. Medical Journal of Australia 140: 564.

Todd, Edgeley Woodman (ed.). 1971. A Doctor on the California Trail. The Diary of Dr. John Hudson Wayman, 1852. Denver, CO: Old West Publishing Company.

Townley, John. 1988. The Trail-West: A Bilbiography-Index to Western American Trails, 1841 to 1869 . Reno, Nev: Jamison Station. 
Trafzar, Clifford E. 1997. Death Stalks the Yakama: Epidemiological Transitions and Mortality on the Yakima Indian Reservation, 1888-1964. East Lansing: Michigan State University Press.

Trewartha, Glenn T. 1940. A Second Epoch of Destructive Occupance in the Driftless Hill Land. (1760-1832: Period of British, Spanish and Early American Control.) Annals of the American Association of Geographers 30: 109-142.

Turner, Charles W. (ed.) 1974. AMedic Fortyniner. (Life and Letters of Dr. Reuben Knox, 1849-'51), n.1.: McClure Press.

Unruh, John D., Jr. 1993. The Plains Across. The Overland Emigrants and the Trans-Mississippi West. 1840-1860. Urbana: University of Illinois Press.

Viele, Egbert L. 1874/5. The Relations of Topography to Health in Connection with the Principles and Practice of Drainage and Sewerage. The Sanitarian (New York) 2: 449-459.

Voronov, A. G. 1967. An Analysis of the Concept of a "Natural Infection Focus." Soviet Geography: Review and Translation 8: 751-766.

Voronov, A. G. 1977. The Geographical Environment and Human Health. Soviet Geography: Review and Translation 18: 230-237.

Wachsmuth, Kaye, Orjan Olsvik, Gracia M. Evins, and Tanja Popovic. 1994. Molecular Epidemiology of Cholera. In Kaye I. Wachsmuth, Paul A. Blake, and Orjan Olsvik (eds.). Vibrio cholerae and Cholera. Molecular to Global Perspectives (Washington, D.C.: American Society for Microbiology) pages 357-370.

Waterman, S.H., G. Juarez, S. J. Carr. 1990. Salmonella arizona infections in Latinos associated with Rattlesnake medicine. American Joumal of Public Health 80: 286-289.

Webber, Bert. 1988. The Oregon Trail Diary of Rev. Evans Parrish in 1844. Medford, OR: Webb Research Group.

Webber, Bert. 1994. The Oregon Trail Diary of James Akin.Jr. in 1852. Medford, OR: Webb Research Group. 
Webber, Bert. 1997. The Oregon Trail Diary of Twin Sisters, Cecelia Adams and Parthenia Blank. Medford, OR: Webb Research Group.

Weiss, Harry B., and Howard R. Kemble. 1977. The Great American Water Cure Craze. Past Times Press: Trenton, New Jersey.

Wendt, Edmund Charles. 1885. A Treatise on Asiatic Cholera. New York: William Wood and Company.

West, Paul Andrew, and John Vincent Lee. 1984. Distribution and Growth of Vibrio cholerae in a Natural Brackish Water. In Rita R. Colwell (ed.). Vibrios in the Environment (New York: John Wiley \& Sons) pages 451-462.

West, Paul A., and Rita R. Colwell. 1984. Identification and Classification of Vibrionaceae--An Overview. In Rita R. Colwell (ed.). Vibrios in the Environment (New York: John Wiley \& Sons), pages 285-363.

White, Kris, and Mary-Catherine Cuthill. 1993. Overland Passages. A Guide to Qverland Documents in the Oregon Historical Society. Portland: Oregon Historical Society Press.

Whittlesey, Derwent. 1929. Sequent Occupance. Annals of the American Association of Geography 19: 162-165.

Wilkinson, Richard G. 1973. Poverty and Progress: an Ecological Model of Economic Development. London: Methuen.

Wilkinson, Richard G. 1986. Income and Morality. In Richard G. Wilkinson (ed.). Class and Health: Research and Longitudinal Data. London: Tavistock.

Wilkinson, Richard G. 1994. The Epidemiological Transition: from Material Scarcity to Social Disadvantage? Daedalus 123: 61-67.

Wilkinson, Richard G. 1996. Unhealthy Societies. The Afflictions of Inequality. New York: Routledge.

Young, F. G. 1900. The Oregon Trail. Oregon Historical Society Quarterly 1: 339-370. 
APPENDIX A GLOSSARY 


\section{GLOSSARY}

Abiocenotic--adjective used in reference to disease type, implying the disease is not derived from any living biological materials found within the environmental setting used to define the disease nidus (alt. spelling abiocoenotic) (Voronov 1967, 1977). (See antonym: biocenotic; compare with cenogenetic).

Achlorhydria--a condition of the stomach in which no or very little hydrochloride is secreted, resulted in fairly non-acidic and relatively alkaline gastric conditions, typically condition of genetic origin.

Anthroponosis--a disease characteristic only of man and not animals and which might otherwise lack natural foci. (from Gk. anthros $\sim$ man + Gk. nosos disease; pl. anthroponoses; adjective: anthroponotic) (Voronov 1977)

Anthroponomic--laws, actions or behaviors of man in relation to the environment (from Gk. anthropos $\sim \operatorname{man}+\mathrm{Gk}$. nomos $\sim$ laws).

Anthroponotic-axenotic diseases--diseases peculiar to man, which are communicated independent of any other living things, i.e. transmitted non-zoonotically (without animal vector involvement) in the form of droplets or dust (flu, cold, small pox), alimentary food and water (Asiatic cholera, typhoid, worms), or by direct contact with a disease victim (venereal disease) (noun: anthroponoses-axenoses) (Voronov 1977).

Anthropo-zoonotic diseases-- diseases which infect both man and animals; may demonstrate little distinction between the two, or show preference for zoonosis (animals) over anthroponosis (man). (Meade, Florin and Gesler 1988, 63).

Axenosis (noun)--a disease typical of the given natural setting, which is not transmitted by vectors (from prefix a- $\sim$ without/not $+\mathrm{Gk}$ xenos $\sim$ stranger/foreign/different; pl. axenoses; adjective: axenotic) (Voronov 1967, 1977). 
Axenotic, zoonotic disease--a disease which is directly transmitted by either the bite of an infected animal (i.e. rabies), through contact with a dead animal (i.e. anthrax, glanders), by diffusion of the disease-causing organism through water and polluted objects, or through some other animal product that is not a living vector. The broad distribution of this disease is based on the ecology of its living animal or animal carcass carrier/reservoir and their specific geography relative to human geography; a disease peculiar to both man and animal, spread without need for an intermediary host (rabies, anthrax, brucellosis, hoof and mouth disease) (Voronov 1967, 1977 757).

Biocenotic--(1) used in this presentation to make reference to diseases common to or originated from a biological component of the given pathogenic environment (from ceno- (prefix, Latin, derived from Greek koinos $\sim$ common) and bios (life) (alt. spelling biocoenotic); (2) in traditional (pre-1950) writings, related to suffix -cene, a term often used to refer to new biotic materials developing in or introduced to a given environmental setting (i.e. introduction of new plants (phytocoenotic) or animals (zoocoenotic); possibly derived from Greek kainos new). (See definition for antonym abiocenotic) (Voronov 1967, 1977; Funk \& Wagnalls 1963).

Cholera--a diarrhea-like syndrome typically with a pale, watery discharge due to Vibrio cholerae. Possible source(s) of term: chole (Greek), for bile, referring to claimed cause and/or color or appearance of stool (traditionally, "bile" is considered yellow), combined with -reo (Greek to flow); according to Hoblyn (1846), cholera was term used by the Greek to refer to a "water-trough" or gutter for rain, perhaps referring to the flow of stools (see also Dunglison 1874, 209; Wendt 1885, xii)

Disease ecology--complex factors involving both the population or community and its individuals with regard to personal and regional human ecology and disease issues. Social rather than biological laws often dictate the outcome of these maladies (Voronov 1977 230).

Effluvium--a substance that flows from another substance or object, especially due to decomposition; an emanation (Dunglison 1874, 341).

Enzootic--an endemic disease infecting animals, by which the animal may be considered a reservoir (Meade, Florin and Gesler, 1988, 63). 
Epizootic--an epidemic disease infecting animals (Meade, Florin and Gesler 1988, 63).

Fermentation Theory for disease--see Zymotic Theory

Foci/Focus--the place from which a spreading disease pattern arises, a regions where a pathogen tends to thrive and repeatedly reinfect local animals and communities.

Fomite--an object which serves as a carrier of an infectious agent, such as a contaminated blanket, money, or water (Meade, Florin and Gesler 1988, 10)

Host--"the organism infected by the disease" (Meade, Florin and Gesler 1988, 63)

intermediate hosts--assist the organism during one of its stages of development in the life cycle, i.e the asexual or larval stage primary or definitive hosts--enable the pathogen to mature and engage in reproductive activities

Hypochlorhydria--a condition of the stomach lining in which inadequate amounts of hydrochloric acid are produced, and which results in a reduced aciditiy of the stomach environment, thereby increasing the chances for successful passage of bacteria and other living, potentially pathogenic organisms into the digestive tract. Usually a condition induced by numerous causes, but often linked to socioeconomic status such as poor nutrition and malnutrition, alcoholism and drug use. Other potential causes include imbibation of alkaline waters, and ingestion or intake of alkaline mineral salts and their associated beverage as mineral remedies (i.e. sodium bicarbonate antacids).

Metaxenosis--diseases transmitted by vectors (Voronov) (from prefix Gk. meta. after, beside, with, change + Gk. xenos $\sim$ strange, foreign; pl. metaxenoses, adjective metaxenotic).

Metaxenotic (adj.)--a disease organism capable of infecting both humans and animals, and one which often transfers from animal carrier or reservoir to human victims with a particular predisposition which makes them prone to the disease.

Metaxenotic, zoonotic disease--a disease with particular ecological and physiographic features in a given area which when combined provide the 
right conditions for supporting the development of both the animals and disease hosts, expect narrow distributions based on these natural and human derived limitations; a disease of both man and animal, typically spread through an intermediary animal vector (tick-born encephalitis, African sleeping sickness, bubonic plague, tularemia, opisthorchiasis) (Voronov 1967, Voronov 1977, 758).

Miasma/Miasm--emanated matter, i.e. from sick bodies, decaying plant and animal substances in swamps (from Greek miasma a stain or contaminant). Related terms: effluvium; mal aria or "bad air" (Italian, popular beginning ca. 1720); also has some synonymity with contagion (Dunglison 1874,655 ).

Nidus--from the Latin word nidus for nest, refers to a focus of infection; a place where the disease exists and from where its diffusion originates (Pavlovsky 1966, 249).

Pedology--"the science that treats the origin, properties and classifications of soils"; for this thesis, not to be confused with the homonym refering to the study of children (Funk \& Wagnalls 1963).

Physioanthropic foci--a place for the origination of a disease pattern which did not exist until man's interference, i.e. through the introduction of the disease-causing bacterium or animalcule or the transformation of a previously natural environment (Voronov 1977).

Reservoir--an animal which serves as the host for a given disease, a term of anthropocentric nature according to Meade, Florin and Gesler $(1988,63)$.

Vector--the biological carrier of a disease organism, which undergoes a life change associated with the disease; distinguished from disease carriers or vehicles (i.e. flies) and fomites or abiotic reservoirs of disease (i.e. water-borne organic debris, air/water particulates) (Meade, Florin and Gesler 1988, 63).

Vehicle--a carrier of an infectious agent, usually a biological agent capable of transporting the substance without engaging in any internal biological processes important to the survival of the infectiousagent, i.e. an insect, fish, pet (Meade, Florin and Gesler 1988, 10).

Zoonosis--a disease transmitted by animal vector(s); "diseases communicable from animals to man under natural conditions" (from prefix zoo- animal + Gk. nosos $\sim$ disease; pl. zoonoses ; adj. zoonotic) (Voronov 1967, 750). 
Zoonotic-axenotic disease--see axenotic-zoonotic disease

Zoonotic-metaxenotic disease--see metaxenotic-zoonotic disease

Zymotic theory for disease--'[r]elating to or appertaining to fermentation ... In the classification of Dr. Wm. Farr ... comprise[s] diseases which are epidemic, endemic, communicable, inoculable, capable of propagating from existing foci, or of generation; induced by a specific material or poison, or by the want or bad quality of food. This class includes four orders: --miasmatic, enthetic [inoculated, infected], dietetic, and parasitic diseases." Popular ca. 1850-1875. (Dunglison 1874, 1131) (from Greek zyme ferment) (see also miasma). 
References for Glossary

Dunglison, Richard J. 1874. Medical Lexicon. A Dictionary of Medical Science A New Edition. Philadelphia: Henry C. Lea.

Funk \& Wagnalls Standard College Dictionary. 1963. (Marckwardt, Albert H. (Chairman)). New York: Funk \& Wagnalls.

Hoblyn, Richard D. 1846. A Dictionary of Medical Terms. Philadelphia: Lea \& Blanchard.

Markovin, A. P. 1962. Historical Sketch of the Development of Soviet Medical Geography. Soviet Geography: Review and Translation 3: 3-19.

Pavlovsky, E. N. 1966. The Natural Nidality of Transmissable Disease (N. D. Levine, ed.) Urbana, IL: Univeristy of Illinois Press.

Voronov, A. G. 1967. An Analysis of the Concept of a "Natural Infection Focus." Soviet Geography: Review and Translation 8: 751-766.

Voronov, A. G. 1977. The Geographical Environment and Human Health. Soviet Geography: Review and Translation 18: 230-237.

Wendt, Edmund Charles (ed.). 1885. A Treatise on Asiatic Cholera. New York: William Wood and Company. 


\section{APPENDIX B}

VIBRIO CHOLERAE: FOOD STUFFS AND OTHER GROWING SURFACES 
NOTE: The first two tables of this appendix deal with data compiled from

Pollitzer's Cholera (Geneva: World Health Organization, 1959). The second pair of tables is information compiled from Williams's Wagon WheelKitchens. Food on the Oregon Trail. (Lawrence: University Press of Kansas, 1993). Raw data for this appendix is in possession of author and the Oregon Historical Society.

\section{TABLES}

Longevity of Vibrio cholerae on Surfaces outside the Human Body Longevity of Vibrio on Various Foodstuffs

Popular Trail Foods

Numbers of Entries for each Food Class

\section{LONGEVITY OF VIBRIO CHOLERAE ON SURFACES OUTSIDE THE HUMAN BODY (POLLITZER 1958)}

\begin{tabular}{|l|r|r|}
\hline & LIFESPAN (DAYS) \\
\cline { 2 - 3 } GROWING CONDITION & minimum & maximum \\
\hline cloth, soaked in situ & 1 & 2 \\
\hline cloth, cholera stool on depurated cotton & 0 & 2 \\
\hline cloth, cholera stool on raw cotton and cloth & 0 & 3 \\
\hline fabric, cholera stool on leather surface & 0 & 2 \\
\hline fabric, cholera stool on rubber surface & 0 & 0.5 \\
\hline metal, brass plates & 0.25 & 0.5 \\
\hline metal, copper/silver coins & 0.25 & 0.5 \\
\hline paper, blotting-paper, books, letters, postcards & 0.5 & 2 \\
\hline moist cigars and snuff-tobacco & 0 & 1 \\
\hline moist dusts & 1 & 3 \\
\hline stools on moist earth & 14 & 16 \\
\hline stools in cesspools, manure, possibly latrines & 7 & 14 \\
\hline stools, infected & 1 & 2 \\
\hline stools, in septic tank & 0 & 1 \\
\hline rice water stools, room temperature, dark, in petri dishes & 1 & 21 \\
\hline rice water stools above ground during moist weather & 1 & 7 \\
\hline vibrio on garden earth & 2 & 3 \\
\hline
\end{tabular}


LONGEVITY OF VIBRIO ON VARIOUS FOOD STUFFS (POLLITZER 1958)

\begin{tabular}{|c|c|c|}
\hline FOOD TYPE & EXAMPLES & LENGTH OF SURVIVAL \\
\hline Baked Goods & bread, pastry, biscuit & 1 to 7 days \\
\hline Beverages & $\begin{array}{l}\text { beer, wine, coffee, cocoa, chicory, fruit } \\
\text { juice, soda }\end{array}$ & 2 hours to 7 days \\
\hline \multirow[t]{10}{*}{ Dairy } & $\begin{array}{l}\text { butter, low grade (acidic to high grade, } \\
\text { non-acidic) }\end{array}$ & $\begin{array}{l}1 \text { day to more than } 30 \\
\text { days }\end{array}$ \\
\hline & cheese (cottage \& regular) & one half day to 2 days \\
\hline & cheese (Yogurt cheese) & 2 hours \\
\hline & milk, raw & one half day to 3 days \\
\hline & milk, boiled & 9 days \\
\hline & milk, steam sterilized & 14 to $>21$ days \\
\hline & milk, curdled & 5 minutes \\
\hline & milk, sour & 1 hour \\
\hline & milk, weakly acidic whey & 2 days \\
\hline & milk, carbonated & 2 days and longer \\
\hline \multirow[t]{9}{*}{ Fish } & fresh & 2 days \\
\hline & smoked (hering) & 1 to 4 days \\
\hline & macerated (in vinegar) & one half day \\
\hline & caviar & 2 to $>6$ days \\
\hline & in vinegar with sugar & 2 to 6 hours \\
\hline & fresh, mid-summer & 2 to 3 days \\
\hline & fresh, late summer & 7 to 10 days \\
\hline & fresh, winter & 14 to 21 days \\
\hline & fresh, winter, in ice box & 28 to 50 days \\
\hline \multirow[t]{2}{*}{ Condiments } & sugar & 3 days \\
\hline & honey & 1 day \\
\hline \multirow[t]{2}{*}{ Fruit } & dates, grapes, melons & 3 hours to 14 days \\
\hline & lemons and oranges & 1 hour to ten days \\
\hline Grains/Legumes & rice and lentils & 8 hours to 2 days \\
\hline Meat & beek, ham, roast pork, & 7 to 14 days \\
\hline \multirow[t]{3}{*}{ Shellfish } & $\begin{array}{l}\text { oysters, clams, at room temperature, } \\
\text { shelled }\end{array}$ & 3 to 7 days \\
\hline & oysters, clams, in sea water & 15 to 45 days \\
\hline & in vinegar & 1 to 7 hours \\
\hline \multirow[t]{2}{*}{ Vegetables } & $\begin{array}{l}\text { greens, lentil, cucumbers, } \\
\text { garlic/onions }\end{array}$ & one half day to 3 days \\
\hline & lettuce and spinach & 22 to 29 days \\
\hline
\end{tabular}


POPULAR TRAIL FOODS (WILLIAMS, 1993)

\begin{tabular}{|c|c|}
\hline FOOD TYPE & EXAMPLES \\
\hline Baked goods & pies, pastries, fruit cakes, biscuits, bread, hardtack \\
\hline Baking goods & $\begin{array}{l}\text { baking soda, chocolate, cream of tartar, flour, } \\
\text { molasses, nuts, yeast }\end{array}$ \\
\hline Beverages & $\begin{array}{l}\text { various alcoholic beverages, coffee, lemonade, natura } \\
\text { mineral springs; excluding milk }\end{array}$ \\
\hline Dairy Products & milk (fresh and preserved), cheese, butter, whey \\
\hline Deserts & $\begin{array}{l}\text { puddings, blancmange, boudin blanc, frozen } \\
\text { sweetened milk paste ("ice cream") }\end{array}$ \\
\hline Animal Fats & lard, mutton, shortening, suet, tallow \\
\hline Fish & $\begin{array}{l}\text { Codfish, pickled herring and salmon, canned sardines } \\
\text { and trout, shellfish }\end{array}$ \\
\hline $\begin{array}{l}\text { Flavorants and } \\
\text { Condiments }\end{array}$ & $\begin{array}{l}\text { garlic/onion/chives/wild onion, bay leaves, juniper } \\
\text { berries, lemon syrup, pickles, salts, pepper, } \\
\text { peppermint essence, sugar, vinegar }\end{array}$ \\
\hline Fruit & $\begin{array}{l}\text { apples, berries, currants, figs, gooseberries, prunes, } \\
\text { pumpkin, raisins, wild buffalo berry }\end{array}$ \\
\hline Grain Foods & $\begin{array}{l}\text { unnamed cereal, Indian mush/"suppawn" pudding, } \\
\text { corn, hominy, samp, cornmeal, corn starch, } \\
\text { macaroni/pasta, rice, rice cakes, whole wheat flour }\end{array}$ \\
\hline Meats & $\begin{array}{l}\text { antelope, beef, buffalo, ham, poultry, wild mountain } \\
\text { goat, wild prairie dogs, wild rabbit, etc., in the form of } \\
\text { cured, sausage, jerky, stewed, roasted. }\end{array}$ \\
\hline Soups and Stews & $\begin{array}{l}\text { beef, fish, potable soup, soup and dumplings, } \\
\text { Borden's vegetable meat soupbread, }\end{array}$ \\
\hline Vegetables & $\begin{array}{l}\text { beans, carrots, corn, garlic, onion, mustard greens, } \\
\text { potatoes, tomatoes, turnips, wild buffalo root, wild } \\
\text { grape, wild hognut, wild onion, wild prairie pea }\end{array}$ \\
\hline
\end{tabular}


NUMBER OF ENTRIES FOR EACH FOOD CLASS (IBID, 1993)

\begin{tabular}{|l|c|}
\hline FOOD TYPE & NUMBER \\
\hline Baked goods & 25 \\
\hline Baking goods & 10 \\
\hline Beverages & 4 \\
\hline Dairy Products & 6 \\
\hline Deserts & 5 \\
\hline Animal Fats & 5 \\
\hline Fish & 7 \\
\hline Flavorants \& Condiment & 12 \\
\hline Fruit & 10 \\
\hline Grain Foods & 10 \\
\hline Meats & 18 \\
\hline Soups and Stews & 6 \\
\hline Vegetables & 17 \\
\hline
\end{tabular}


APPENDIX C

A HISTORICAL REVIEW OF CHOLERA EPIDEMIOLOGY 
Cholera Deaths in Relation to Age and Ethnicity

Historical data about cholera incidence shows that Vibrio cholerae Classical produced the greatest number of deaths in middle-aged people ranging from 21 to 40 years of age. An example of this age distribution feature is provided by a listing of fatalities published by a cholera hospital in New York in 1832 (Bradford 1900, 242).

DEATHS IN TWO HOMEOPATHIC CHOLERA HOSPITALS

IN NEW YORK IN 1832 (BRADFORD 1900, 142)

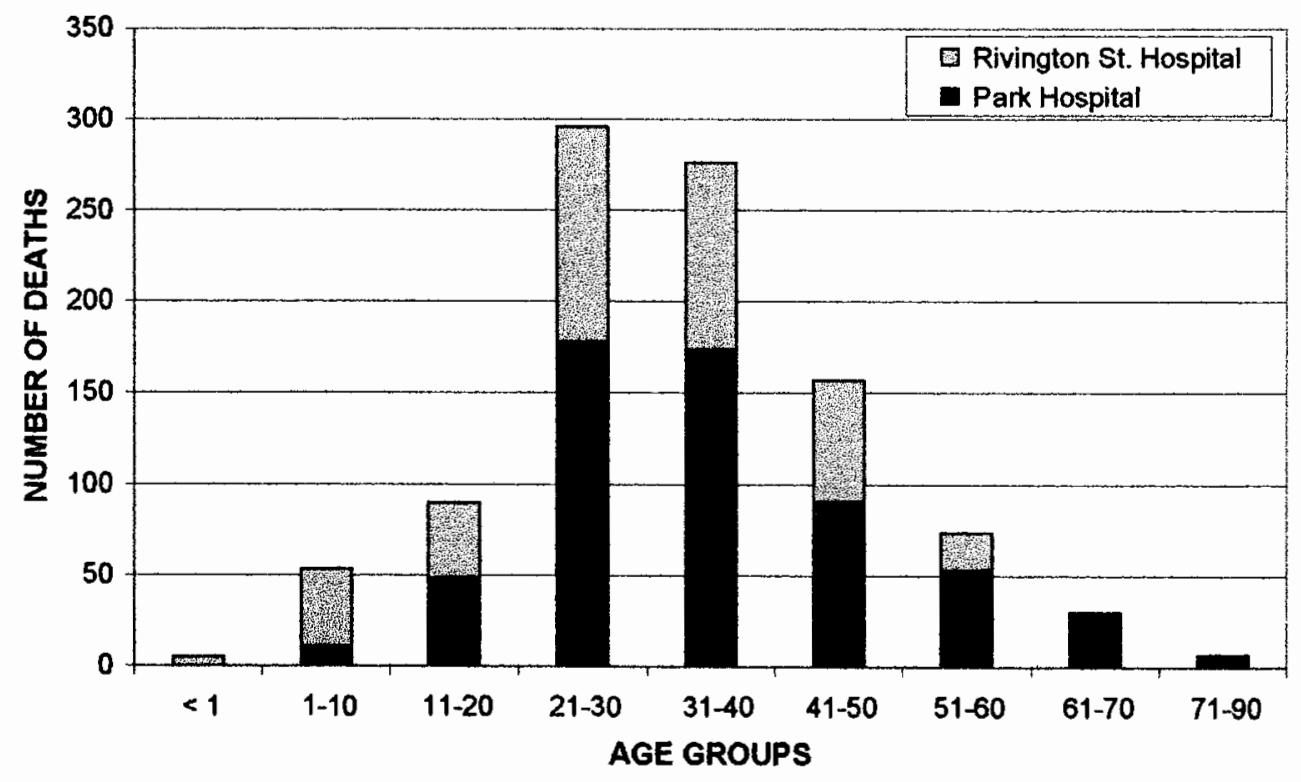


When the results of the 1832 New York cholera hospital study were combined with a similar study of the 1849 cholera deaths also provided by Bradford ( $i b i d$ ), a reduction in age groupings was carried out, followed by the production of a similar graph demonstrating that the majority of cholera deaths involved the 21 to 40 year age group.

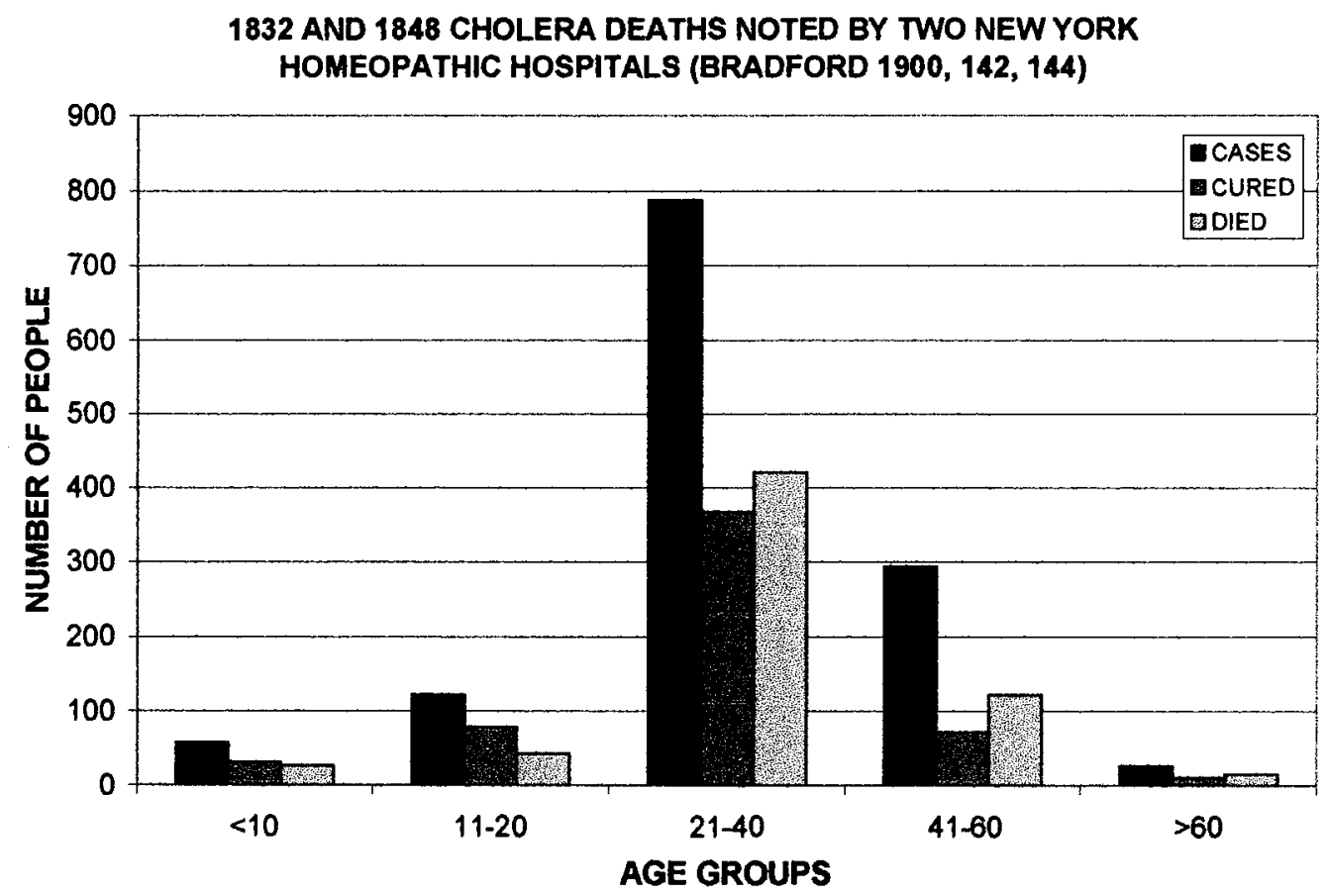


This crude death rate is comparable to the number of cholera patients who were hospitalized. The lowest percentage of deaths involved young victims between the ages of eleven and twenty years. Those who succumbed most to Asiatic cholera were the oldest patients.

PERCENT FATALITY IN TOTAL REPORTED CHOLERA CASES AT A NEW YORK CHOLERA HOSPITAL IN 1848, BY AGE GROUP

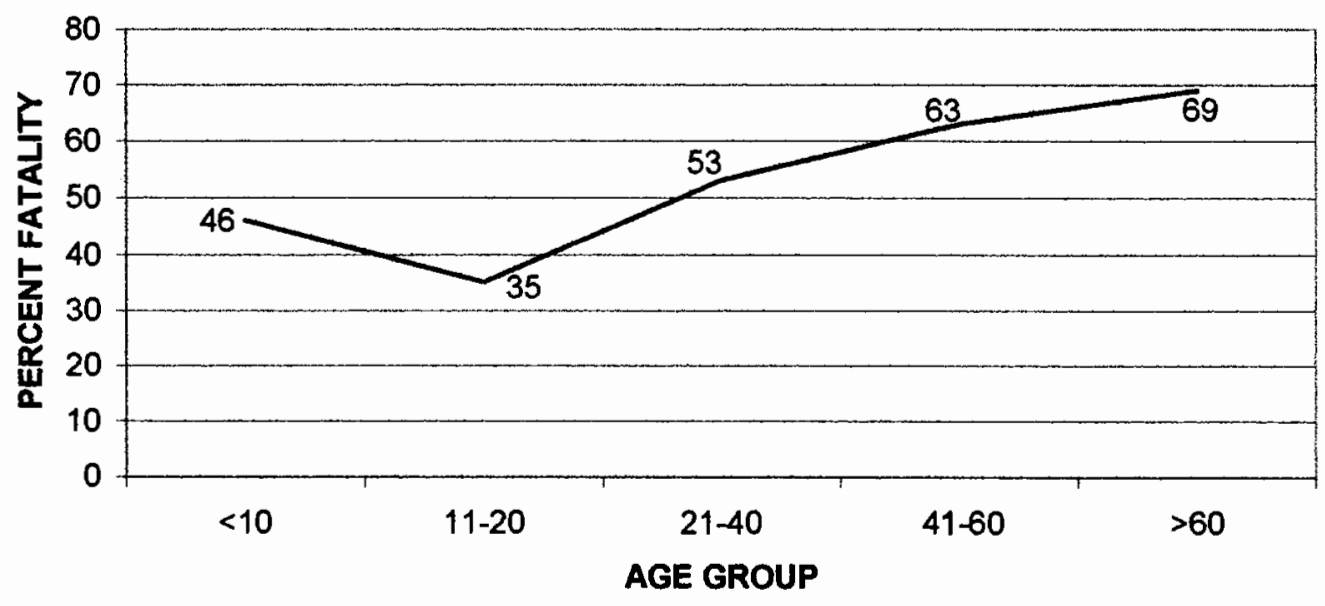

\section{AND 1848 CHOLERA DEATHS NOTED BY NEW YORK HOMOEOPATHIC CHOLERA HOSPITALS (BRADFORD 1900, 142, 144)}

\begin{tabular}{|l|c|c|c|c|c|}
\hline AGE RANGE & $<10$ & $11-20$ & $21-40$ & $41-60$ & $>60$ \\
\hline CASES & 58 & 122 & 788 & 294 & 27 \\
\hline CURED & 31 & 79 & 367 & 72 & 11 \\
\hline DIED & 27 & 43 & 421 & 122 & 16 \\
\hline PERCENT DEATH & 46 & 35 & 53 & 63 & 69 \\
\hline
\end{tabular}


Finally, the best supporting evidence for Bradford's results is the commonly cited study of the 1832 cholera epidemic in Manchester, England by Gaulter in 1833, which showed a similar outcome for percent fatality relative to age groups (Gaulter 1833,113 , in Creighton 1965, 827).

CHOLERA DEATHS IN MANCHESTER, ENGLAND, BY AGE GROUPS, BY PERCENTAGE (GAULTER 1833, 113, IN CREIGHTON 1965, 827)

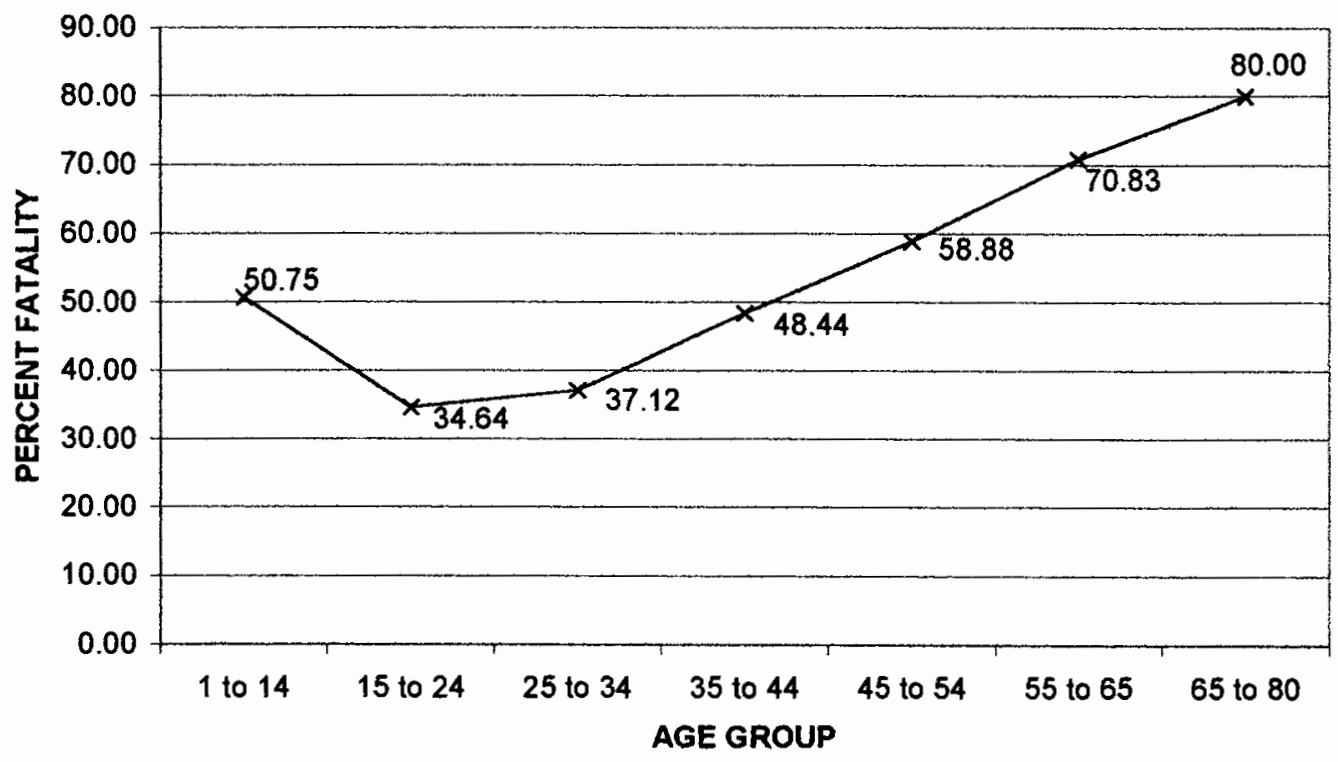


Much later, a more detailed study of Asiatic cholera on United States populations was produced for the the United States Government following the 1866 epidemic. For this epidemic, a high incidence of cholera fatality was noted in middle aged people living in Tennessee, Kentucky, the Northern Interior Valley, Louisiana and Alabama. The numbers of deaths due to cholera were highest in the 21 to 30 year old age group, followed closely by the 31 to 40 year age group. Also note the slight increase in numbers of fatalities involving two year old children of the one to five year old age group.

Due to lack of detailed population statistics at the time of this study, percent fatality for each population of a given age group could not be reviewed. Most likely, age group-related percent fatalities resembled those of the earlier studies by Bradford and Gaulter already cited in this appendix.

\section{CHOLERA DEATHS IN THE UNITED STATES, BY AGE GROUPS (MCCLELLAN 1873, 34)}

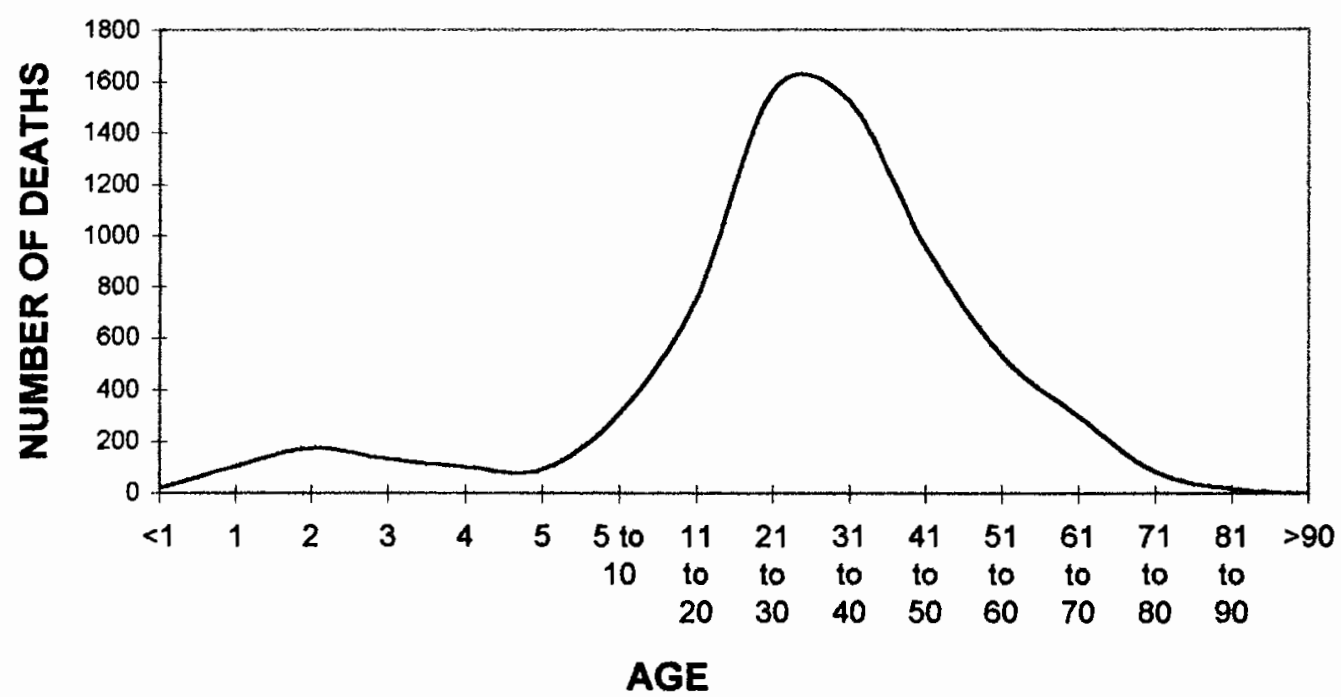




\section{SUMMARY}

The economic and political state of the United States during the mid-eighteenth century was in many ways akin to that of a modern rapidly developing country. Drastic changes in population size, type and density took place, resulting in a state of expansion in demographic terms (Taeuber and Taeuber 1968, 320). Unlike poorly-developed developing countries, this mid-nineteenth century transitional state of the United States could in part be assigned blamed for the high incidence of cholera deaths due to the rapid development of new cities, many without proper sanitation practices. The large number of fatalities in children and middle aged population clusters might also be interpreted as a direct consequence of the decision of these people to migrate. Due to the length of time at sea and the poor food stores on board, many of these immigrants, already poorly nourished in Europe, increased their susceptibility to infection by Asiatic cholera due to their physical state and living conditions soon after their arrival.

The studies of cholera fatalities in 1832,1848 , and 1873 suggest that Vibrio cholerae Classical had its greatest percent fatality on the older age groups, with the greatest numbers of taking place in middle aged individuals. This age distribution of cholera fatality in the mid-nineteenth century American urban setting distinguishes the nineteenth century United States Asiatic cholera epidemic from the more contemporary epidemics produced by Vibrio cholera $\mathrm{El}$ Tor within developing countries. In Bangladesh, a higher cholera fatality is seen in victims ranging from 2 to 9 years (Svennerholm, Jonson, and Holmgren 1994, 267). According to Szu, Gupta and Robbins $(1994,383)$, the 2 to 3 year old group alone may experience as much as $31 \%$ fatality due to El Tor cholera. Reasons for these difference in childhood fatality for Vibrio cholerae Classical in the United States are uncertain, but may be linked to hospitalization practices common to the time, i.e. the tendency for infant, toddler and childhood care to take place in a domestic setting rather than a nineteenth century hospital setting. Other reasons for the low incidence of children deaths due to cholera in the 1800 s might be related to family 
living practices such as child-parent interactions connected with toilet habits and feeding behaviors.

Another way of interpreting this age difference in cholera fatalities in the rapidly developing United States versus contemporary developing countries states is to assume that a higher incidence of deaths in middle-aged adults in the United States took place in the mid-1800s due to a variety of health-, occupation-, and social behavior-related features common for the time. The lack of adequate sanitation practices, a lack of knowledge of the bacterial cause for cholera, and the lack of public health providers probably increased the likelihood of cholera onset and perpetuation of an epidemic. The most important risk factors for cholera at this time, especially amongst immigrant populations, related to the possible history of malnutrition, possibly alcoholism, and the link of each to low stomach acidity or hypochlorhydria, a stomach and intestinal environment less threatening to vibrio and other bacteria once they are ingested (Richardson 1994, 274-275). 


\section{References}

Bradford, Thomas Lindsley. 1900. The Logic of Figure or Comparative Results of Homoeopathic and Other Treatments. Philadelphia: Boericke \& Tafel.

Creighton, Charles. 1965. A History of Epidemics in Britain. London: Frank Cass \& Company, Limited.

Gaulter, Henry. 1833. The Origin and Progress of the Malignant Cholera in Manchester, London. London.

McClellan, Ely. 1875. A History of the Travels of Asiatic Cholera. In John M. Woodworth/U. S. President. The Cholera Epidemic of 1873 in the United States. Reports Prepared under the Direction of the Surgeon-General of the Army. House Executive Document No. 95-III, 43d Congress, 2d Session (Washington, D.C.: Government Printing Office) [Serial Set 1646, Government Documents Collection, Multnomah Library, Portland OR].

Richardson, Stephen H. 1994. Host Susceptibility. In Kaye I. Wachsmuth, Paul A. Blake, and Orjan Olsvik (eds.) Vibrie cholerae and Cholera. Molecular to Global Perspectives (Washington, D.C.: American Society for Microbiology) pages 273-289.

Svennerholm, Ann-Mari, Gunhild Jonson, and Jan Holmgren. 1994. Immunity to Vibrio cholerae Infection. In I. Kaye Wachsmuth, Paul A. Blake, and Orjan Olsvik (eds). Vibrio cholerae and Cholera. Molecular to Global Perspectives (Washington, D.C.: American Society for Microbiology) pages 257-271.

Szu, Shousun C., Rajesh Gupta, and John B. Robins. 1994. Induction of Serum Vibriocidal Antibodies by O-Specific Polysaccharide-Protein Conjugate Vaccines for Prevention of Cholera. In I. Kaye Wachsmuth, Paul A. Blake, and Orjan Olsvik (eds). Vibrio cholerae and Cholera. Molecular to Global Perspectives (Washington, D.C.: American Society for Microbiology) pages 381-394.

Taeuber, Conrad, and Irene B. Taeuber. 1968. Immigration to the United States. Pages 314-331 in Charles B. Nam (ed.) Population and Society. A Textbook of Readings. Boston: Houghton Mifflin Company. 
APPENDIX D

THE GEOGRAPHY OF OTHER FORMS OF DIARRHEA 


\section{Introduction}

The geography of two of the more common organisms responsible for dysentery--shigella and amoeba--has been well documented (May 1958). According to May, little evidence exists suggesting that either of these two pathogens could have been present along the Oregon Trail. Since shigella is almost totally dependent upon human activities for its continued propagation, one may assume that since trail populations could not bring Asiatic cholera through the Rocky Mountains due to reduced population density, that similar features made it unlikely for shigella to be carried along the western portion of the trail. The same argument exists for Entamoeba histolytica, the cause for amoebic dysentery.

Both shigella and amoeba produce diarrheal epidemics, due to their tropical and sub-tropical origins, are expected to engage in some of the same climate-sensitive spatial diffusion features characteristic of Vibrio cholerae. Therefore, even if shigellic or amoebic dysentery managed to strike emigrants crossing the Great Plains, they would be expected to cease ebing an influence and unable to continue this migration westward due to reductions in trail population caused by earlier fatalities along with changes in trail climate induced by elevation change.

This section reviews shigella and amoebic dysentery along with several dysentery-like diseases possibly borne by the Trail.

\section{Entamoeba}

Entamoeba histolytica is the cause for amoebic dysentery, a pandemic disease common to underdeveloped countries (May 1958, 192-3). This amoeba thrives in slightly alkaline waters where raw sewage is dumped. It is highly sensitive to humidity and temperature changes. Unlike vibrio, amoeba may at time persist in fresh water environments.

This amoeba exists in two forms. Its motile form, referred to as a trophozoite, resides in the gut of its victim. Under stressful conditions, it may convert to cystoid form, which is tolerant of the dry conditions often following its passage through the intestinal tract. Cysts may survive outside the body as long as 
30 days in moist, cool regions and serve as a means for amoeba to be spread to new environments and victims by attaching itself to flies.
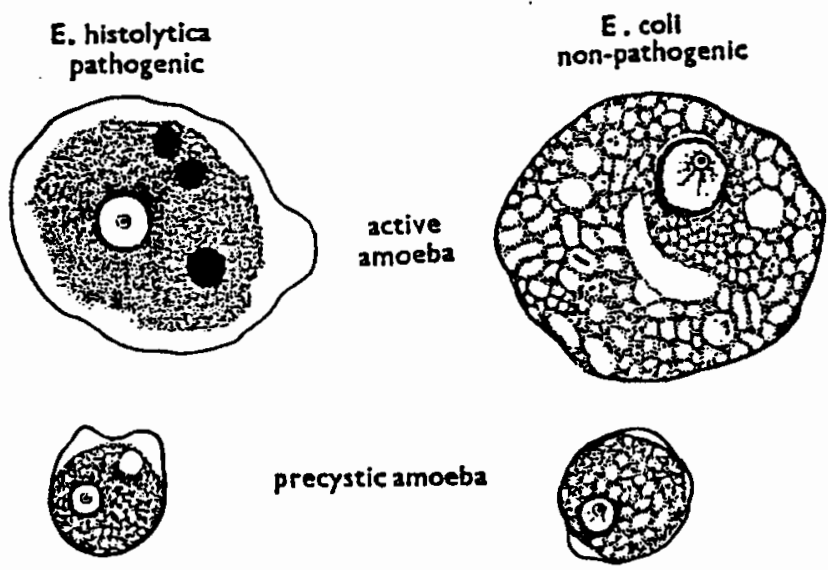

precystic amoeba

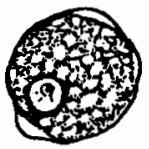

The Human Dysentery Amoeba (Entamoeba histolytica) and the harmless commensal Entamoeba coli and their cysts (LaPage 1966, 47)

Both trophozoites and cysts are intolerant of excessive drying or heating conditions. This environmental requirement makes amoebic dysentery highly unlikely to continue in extremely warm to desert-like environments. Due to its sensitivity to environmental chemicals, highly polluted waters may also be fatal to this organism. Therefore, amoeba tends to infect developing regions rather than highly developed urban regions. In epidemic form, the diarrhea it produces worsens with time as it continues to infect new victims. Therefore, populations often become more symptomatic of this disease as the epidemic progresses. According to Mays, given the right environmental conditions, the potential for catching this disease increases at high elevations increases due to the difficulties of effectively sterilizing water through boiling, a problem which allowed amoebic epidemics to develop even in high elevation places like Quinto, Ecuador (May 1958 201). 
Some food sources are capable of carrying amoeba to new victims, including raw vegetables and fruits, foods and drinks. Like with many diseases, stomach acidity prevents the passage of amoeba into the intestines. An important diagnostic symptom for this form of dysentery is the liver damage induced by its persistence in the liver long after the conclusion of its diarrheal stage.

Trail features working against the possible diffusion of amoebic dysentery west of the Great Plains include the climatic change which ensued as the Rocky Mountains of Wyoming are crossed, followed by the dry soils overlooking the Snake River valley. In addition, since Asiatic cholera greatly reduced the population density of pioneers on the Trail, an effect hastened by the branching of the Trail once Platte River valley was passed, this reduction in population density most likely reduced the likelihood that interactions between disease carriers and potential victims would continue to support a continued diffusion of the human-dependent amoebic dysentery.

\section{Shigella}

The shigella bacterium was first identified by Dr. Kioshi Shiga in 1898 and is currently referred to as Shigella dysenteriae I. Two other species of Shigella commonly responsible for dysentery in recent years are S. flexneri and S. sonnei. Shigella sonnei tends to reside in West Coast communities, especially in Alaska (Keusch and Bennish 1994, 631).

According to May, the cause for true dysentery, Shigella dysenteriae is uncommon to the United States, but its close relative Shigella sonne $i$ is distributed throughout North and Middle America. Another species, Shigella paradysenteriae, is common to the Pacific Northwest. May defined the types of regions most likely to be impacted by shigella dysentery as agricultural regions (Mays 1958).

May notes the distribution of shigella to be global, with more violent cases erupting in tropical climates. Shigellic dysentery epidemics may resemble Asiatic cholera epidemics due to their shared seasonal requirements. Hot, rainy conditions increase the severity of this epidemic. Shigella tends to be more virulent and more fatal in warmer tropical regions. Temperature, humidity and the availability of nutrients impact shigella spread. The impact of seasonal wind patterns on insect 
carriers may be important. Shigella has the ability to survive in salt water for several days, suggesting a supporting role of the saline waters along the Platte River and certain parts of the Rocky Mountains (May 1958, Keusch and Bennish 1994).

The symptoms of Shigella typically begin with fever, malaise, abdominal pain, and watery diarrhea. Watery diarrhea without blood is the most common form of this diarrheal illness, which leads to the production of bloody, mucusy stools in severe cases. In healthy victims, this disease is non-fatal and tends to last 5 to 10 days (Keusch and Bennish 1994).

Its epidemicity is mostly due to human and cultural behaviors, rather than climatic, biological and ecological cause. Shigella is typically spread by way of a person-to-person stool-hand-mouth route. Insects may serve as common carriers for shigella but are not required for it to be spread to new victims. Proper washing techniques help to reduce the likelihood of the spread of Shigella to new victims. Water used for personal hygiene in particular was an important means for shigella transmission to new people. It may also be caught by swimming in contaminated waters. Social activities and living behaviors often related to the spread of this form of dysentery stem from a life in poverty, crowding, poor sanitation, and poor water sources, each of which are commonly associated with precipitating shigella dysentery epidemics. Malnutrition adds to the probability of developing a shigellic disease by facilitating the passage of bacteria through an otherwise acidic stomach lining, increasing the severity of the disease as well. Asymptomatic carriers are noted (May 1958, Keusch and Bennish 1994).

In endemic Shigella dysentery regions, children are most heavily affected by the bacterium; in non-endemic regions, all age groups are equally affected. Unlike cholera, which requires significant population density to spread quickly from a highly susceptible person in one family to a similar susceptible person in the next, familial Shigella spread can take place rapidly with shigella. The diarrheal condition associated with Shigella infection, shigellosis, is characterized by a frank, bloody diarrhea. Compared with other dysentery-inducing organisms, Shigella is quite resistant to stomach acid, for which reason as few as ten cells may 
produce severe dysentery. Shigella produces a toxin much like the vibrio toxin which adds fluid and salts to the intestinal tract.

Unlike Vibrio cholerae, a disease heavily dependent upon warm temperate to tropical environments, shigellic dysentery is pandemic and produces epidemics in most climatic regions of the world, especially during the summer and early fall. It resembles cholera due its higher incidence in poverty-stricken communities. In the United States, the highest incidence for shigella is currently in the southwest (Keusch and Bennish 1994).

The geography underlying a severe shigellic dysentery epidemic in Uganda in 1944 resembles the Oregon trail epidemic scenario. Suffering from malnutrition, Ugandans obtained their water from wells dug in permeable volcanic soils. As a dysentery epidemic ensued, subsequent rainfall caused the pathogen to percolate through the substratum and infect nearby wells (May 1958 167). Open, non-latrine defecation increased the spread of this disease.

\section{Escherichia coli}

Escherichia coli is common to the human and animal intestinal tract and is ubiquitous or globally distributed in numerous pathogenic and non-pathogenic forms. E. coli was associated with diarrhea for the first time during the $1920 \mathrm{~s}$, and remains a frequent cause for a number of fairly common bacterial infections, including urinary tract infection and traveler's diarrhea. Like the salmonella (described in the thesis), diarrhea induced by E. coli takes one to two days to begin following its ingestion. Typical cases consist of three to four days of diarrhea and may include mild fever, vomiting and chills as additional symptoms.

Recent studies have led to the definition of five types of pathogenic Escherichia coli: enterotoxic $E$. coli $[$ ETEC], enteroadherent $E$. coli $[\mathrm{EAEC}]$, enteropathogenic $E$. coli $[\mathrm{EPEC}]$, enteroinvasive $E$. coli $[\mathrm{EIEC}]$, and enterohemorrhagic E. coli [EHEC]. ETEC and EAEC produce traveller's diarrhea, the latter being common to tourists of Africa and Mexico. EPEC primarily infects children, especially in underdeveloped countries. EIEC is a rare malady in the United States, but important to note for this study due to its resemblance to other symptoms found to be associated with the various forms of dysentery uncovered, 
including fever. A most recent cause for concern, EHEC, produces bloody stools, no fever, and is highly fatal in elderly people due to its shiga-like toxin. Of the five types of $E$. coli, ETEC and EIEC are most often associated with fevers, and EHEC most closely resembles dysentery (DuPont and Mathewson 1998).

In an historical sense, Escherichia coli may not have been associated with many of the severe dysentery-like diseases noted during the nineteenth century, although the possibility for the evolution of such a novel strain would not be unexpected. In 1982, a severely toxic form of EHEC, was discovered and classified as its own distinct form, demonstrating the possible evolution of an equally unique strain of $E$. coli along the Oregon Trail. More recent episodes of $E$. coli-induced epidemics in the Pacific Northwest further support the possibility that a unique pathogenic form of $E$. coli might have evolved in the Pacific Northwest during its earliest years of migration. However, whether or not the most recently discovered shiga-toxin bearing $E$. coli strains existed 150 years ago in Oregon pioneer history remains uncertain. In sum, the likelihood for an $E$. coli-induced diarrhea epidemic along the Oregon Trail appears unlikely due to the recent evolution of this diarrheal affect.

\section{Yersinia}

The diarrhea-like condition yersiniosis is produced by Yersinia pseudotuberculosis or $Y$. enterocolitica. Considered a very recent development in disease history, this form of diarrhea is rarely fatal, features which make it unlikely to be associated with the more fatal Oregon Trail epidemics. However, this feature alone does not exclude yersinia-induced dysentery from consideration in Oregon Trail history. Yersinia possesses unique survival advantages along the high elevation portions of the trail due to its adaptation to much colder climates, the results of which have resulted in recent epidemics induced by the consumption of refrigerated foods.

Such a survivability in cold climates provides yersinia with a geographic distribution potentially more global than others. It has a higher frequency of incidence in cold climates regions where other bacteria are scarce and in addition is more likely to be a cause for disease spread through improperly cooked meats, 
especially pork. Other causes for the spread of yersinia include physical contact with contaminated swine or untreated water.

Yersiniosis typically infects children less than five years old and older people generate an appendicitis-like symptomatology. Diarrhea is infrequent in many of these cases. Long-lasting infections result in arthritis. For this study, yersiniosis, is removed from the possible causes since it's diarrheal form is most likely a recently evolved disease pattern (Butler 1995).

Other Microorganisms Responsible for Dysentery or Severe Diarrhea

Streptococcus (Stratton 1995), Corynebacterium (MacGregor 1995) and Rhodococcus (Brown 1995) produce a dysentery-like condition due due to the lack of diarrhea as their primary symptom and/or their rarity they are considered less important to Oregon Trail history.

Although giardia (Giardia lamblia) is not a dysentery-inducing organism, it deserves mention due to its commonness in the Rocky Mountains, especially in modern day trail settings. Like amoebic dysentery, significant amounts of water are required for the initiation and spread of giardiasis, features absent along significant portions of the trail west of Fort Laramie (Hill 1995; Ravdin 1995).

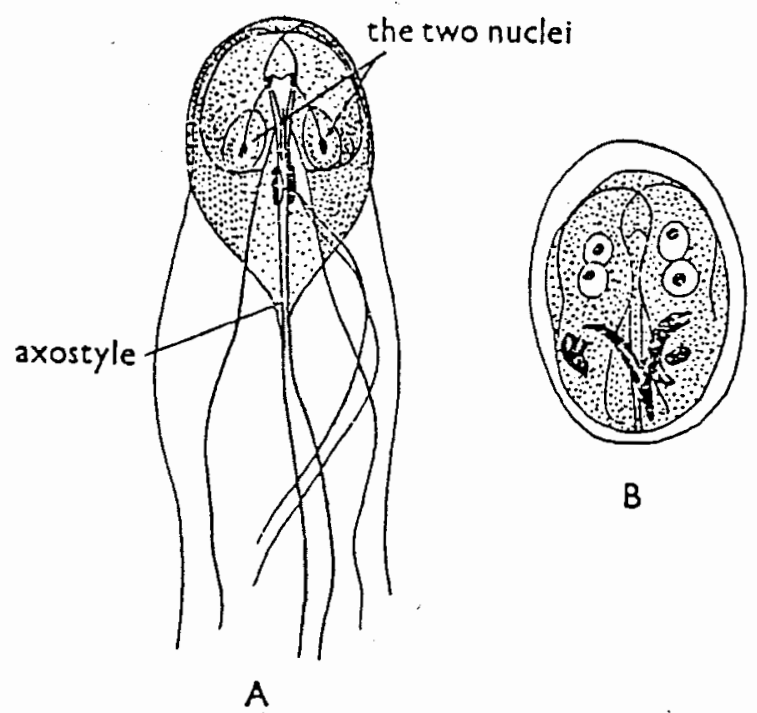

Giardia intestinalis A. trophozoite B. cyst (LaPage 1963, 207) 
Mineral Springs and other abiotic axenotic causes. Imbibing highly concentrated mineral water and salt water produces diarrhea by inducing an osmosis of water from the blood into the intestines. The likelihood for mistaken imbibition of these waters exists, for some emigrants made mention of potential medical values of these waters, in turn using this argument to defend its use as a medicinal tonic (Walker 1851). Were it not for the fear of drinking the more deadly alkali waters, this cause for diarthea would most likely be fairly prevalent along the trail. It is assumed for this study that the much clearer watery diarrhea induced by imbibing these waters, if such discharges did occur, had a distinct appearance rarely confused by pioneers with the mucusy, bloody diarrhea of dysentery. Unlike the Asiatic cholera, such a disease would typically be non-fatal.

Finally, similar conclusions can be drawn for this study about diarrheal cases induced by poor food choice, preparation and consumption, including even the consumption of wild plants for medicine or food. Several plants along the trail were possibly ingested to serve as medicines. The Croton leaf (Croton capitatus), for example, traded for by a physician (William 1993, 131), most likely served as a strong laxative much like its relative Croton tiglium, an official source for the same type of plant medicine. Likewise, many of the drugs prescribed by physicians had diarrhea as an expected or unexpected side effect (i.e. Rhubarb (Rheum spp.) and various "Wild Cucumbers"). Together, these domestic, natural and iatrogenically induced cases of diarrhea are not considered in this study of Trail diarrhea, the focus of which remains on the unexpected bacterial induced diarrhea complaints typical of Asiatic cholera and opportunistic dysentery. 


\section{References}

Brown, Arthur E. 1995. Other Corynebacteria and Rhodococcus. In Gerald C. Mandell, John E, Bennett, and Raphael Dolin (eds.) Principles and Practice of Infectious Diseases. 4ed. (New York: Churchill Livingstone) pages1872-1880.

Butler, Thomas. 1995. Yersinia species (Including Plague). In Gerald C. Mandell, John E. Bennett, and Raphael Dolin. Principles and Practice of Infectious Diseases.4ed. (New York: Churchill Livingstone) pages 2070-2078.

Dupont, Herbert L. 1995. Shigella Species (Bacillary Dysentery). In Principles and Practice of Infectious Diseases. 4ed. (2 vols.) Gerard L. Mandell, John E. Bennett, and Raphael Dolin (eds.). (New York: Churchill Livingston) pages 2033-2039.

Dupont, Herbert L., and John J. Mathewson. 1998. Escherichia coli Diarrhea. In Alfred S. Evans and Philip S. Brachman (eds.) Bacterial Infections of Humans. Epidemiology and Control. 3ed. (New York: Plenum Medical Book Company) pages 269-283.

Hill, David R. 1995. Giardia Lamblia. In Gerald C. Mandell, John E, Bennett, and Raphael Dolin (eds.) Principles and Practice of Infectious Diseases. 4ed. (New York: Churchill Livingstone) pages 2487-2493.

Kapperud, Georg, and Sally Bryna Slome. 1994. Yersinia enterocolitica Infections. In Alfred S. Evans and Philip S. Brachman (eds.) Bacterial Infections. Epidemiology and Control (New York: Plenum Medical Book Company) pages 859-873.

Keusch, Gerald T., and Michael L. Bennish. 1994. Shigellosis. In Alfred S. Evans and Philip S. Brachman (eds.) Bacterial Infections. Epidemiology and Control (New York: Plenum Medical Book Company) pages 631-656.

LaPage, Geoffrey. 1966. Animals Parastic in Man. Revised Edition. NewYork: Dover Publications, Inc.

MacGregor, Rob Roy. 1995. Corynebacterium diphtheriae. In Gerald C. Mandell, John E, Bennett, and Raphael Dolin (eds.) Principles and Practice of Infectious Diseases. 4ed. (New York: Churchill Livingstone) pages1865-1872. 
May, Jacques M. 1958. The Ecology of Disease. New York: M.D. Publications, Inc.

Ravdin, Jonathan I. 1995. Protozoal Diseases. Introduction. In Gerald C. Mandell, John E, Bennett, and Raphael Dolin (eds.) Principles and Practice of Infectious Diseases. 4ed (New York: Churchill Livingstone) pages 2393-2395.

Ravdin, Jonathan I., and William A. Petri, Jr. 1995. Entamoeba Histolytica (Amebiasis). In Gerard L. Mandell, John E. Bennett, and Raphael Dolin (eds.). Principles and Practice of Infectious Diseases. 4ed. (2 vols.) (New York: Churchill Livingston) pages 2395-2408.

Stratton, Charles W. 1995. Streptococcus intermedius Group. In Gerald C. Mandell, John E, Bennett, and Raphael Dolin (eds.) Principles and Practice of Infectious Diseases. 4ed. (New York: Churchill Livingstone) pages 1861-1864.

Walker, G. S. 1851. Hot Springs on the Overland Route to California. The Medical Examiner and Record of Science 7: 775-777.

Williams, Jacqueline. 1993. Wagon Wheel Kitchens. Food on the Oregon Trail. Lawrence: University Press of Kansas. 


\section{APPENDIX E}

\section{OREGON TRAIL DEMOGRAPHY}




\section{AN OVERVIEW OF TRAIL DEMOGRAPHY}

A number of studies were carried out by pioneers during the late nineteenth and early twentieth century (Barlow 1895, Carey 1923, Hartman 1924). A brief review of this data suggests that 1850 was an important year in livestock (including oxen) migration to Oregon and so set the stage for the dysentery epidemic along the Oregon Trail west of Fort Laramie (Figure E-1).

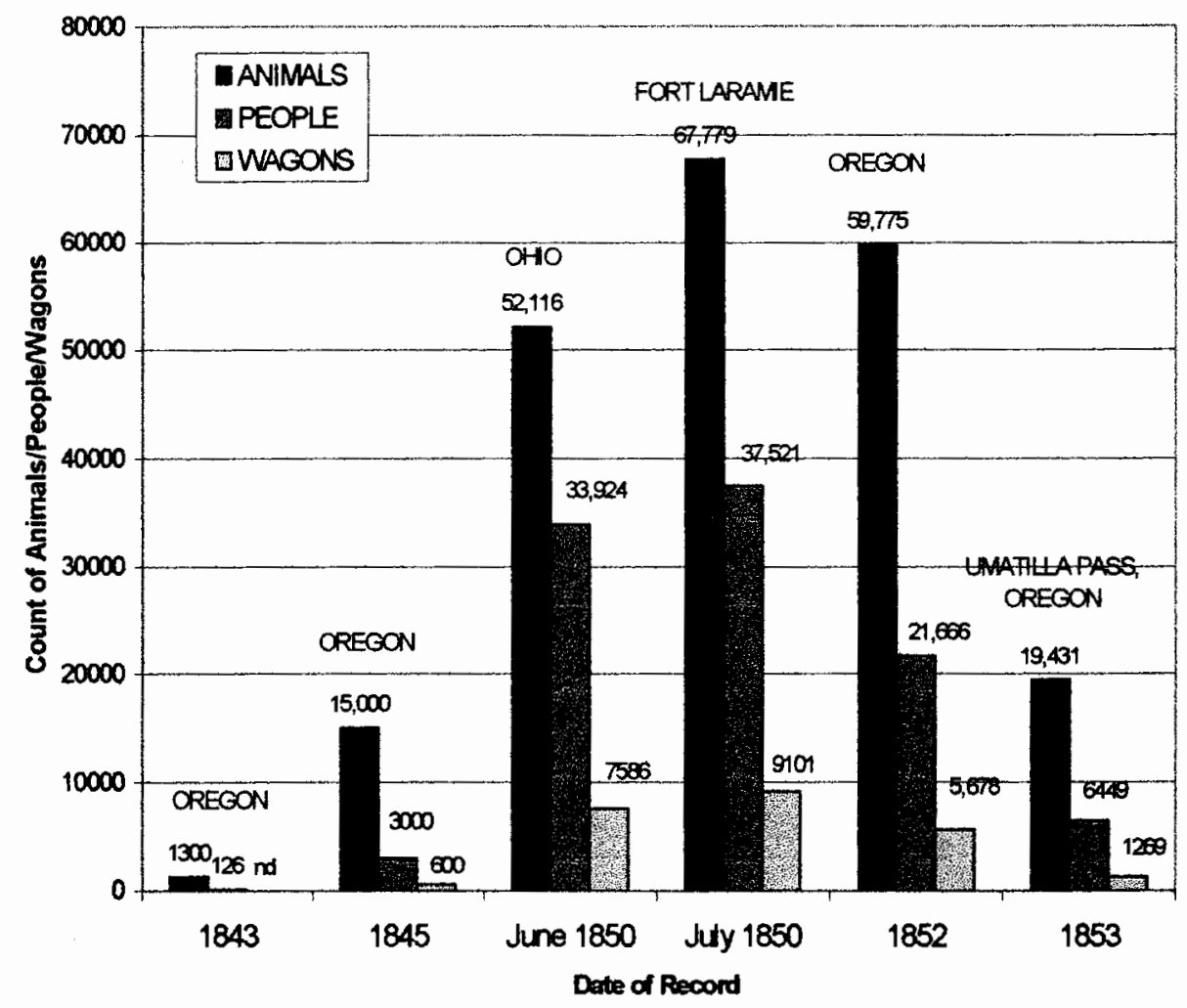

Figure E-1. Migration Statistics for Midwest, Fort Laramie, Oregon, by Years and Place (References for data listed at end of this appendix). 
As shown by the summary of this data in the tables which follow (Tables 1 and 2), the ratio of animal to people was not a significant factor in dysentery development, for if this were the case, the 50:1 animal to people ratio for 1845 should have made that an important dysentery year if this ratio was the primary determinant. Most likely, time had to pass in order for the trail to become susceptible to disease development due to the water contamination by decaying animal carcasses along with their increase in number. McKinley's dairy (1850), for example stated that the first important dysentery year was 1850 , which, according to a number of published reviews about trail populations at the time of the migration as well as much later, a 1.9:1.0 ratio of animals to people existed in 1850. (A listing of these appears on the last page before the bibliography.) This suggests that both population numbers and density were most important in determining whether or not an epidemic would ensue along the Oregon Trail. With more people passing through an infected area where the bacteria responsible for dysentery reside (i.e. on carcasses), a greater likelihood exists for the right people to be infected (i.e. the poorly nourished pioneers).

\section{TABLE 1}

PEOPLE, WAGONS AND ANIMALS ON THE OREGON TRAIL

\begin{tabular}{r|rrrrr} 
& $\mathbf{1 8 4 3}$ & $\mathbf{1 8 4 5}$ & June 1850 & July $\mathbf{1 8 5 0}$ & $\mathbf{1 8 5 2}$ \\
\hline PEOPLE & 126 & 3000 & 33,924 & 37,521 & 21,666 \\
WAGONS & & 600 & 7586 & 9101 & 5,678 \\
ANIMALS & 1300 & 15,000 & 52,116 & 67,779 & 59,775 \\
\hline
\end{tabular}

TABLE 2

ANIMAL TO PEOPLE RATIO ON THE OREGON TRAL

\begin{tabular}{|c|c|}
\hline YEAR & ANIMALS:PEOPLE RATIO \\
\hline 1843 & 10.3 \\
\hline 1845 & 50 \\
\hline 1850 & 1.9 \\
\hline 1852 & 2.8 \\
\hline
\end{tabular}


Oregon Trail Population Density. A detailed review of the size of the wagon trains and families accompanying the trains to Oregon was provided by $\mathrm{E}$. L. (Roy) Meyers (1960). According to Meyers, the number of people per wagon varied from about three to six between 1844 and 1853, the most active decade of Oregon Trail migration. Reviewing the annual statistics for this overland emigrant population 1844-1853, we find annual fluctuations in the trail population figures, with the greater number of trains reported Meyers as eight in 1847 carrying a little more that 3000 people, many trains averaging at least six people per wagon (Figure $\mathrm{E}-2)$.

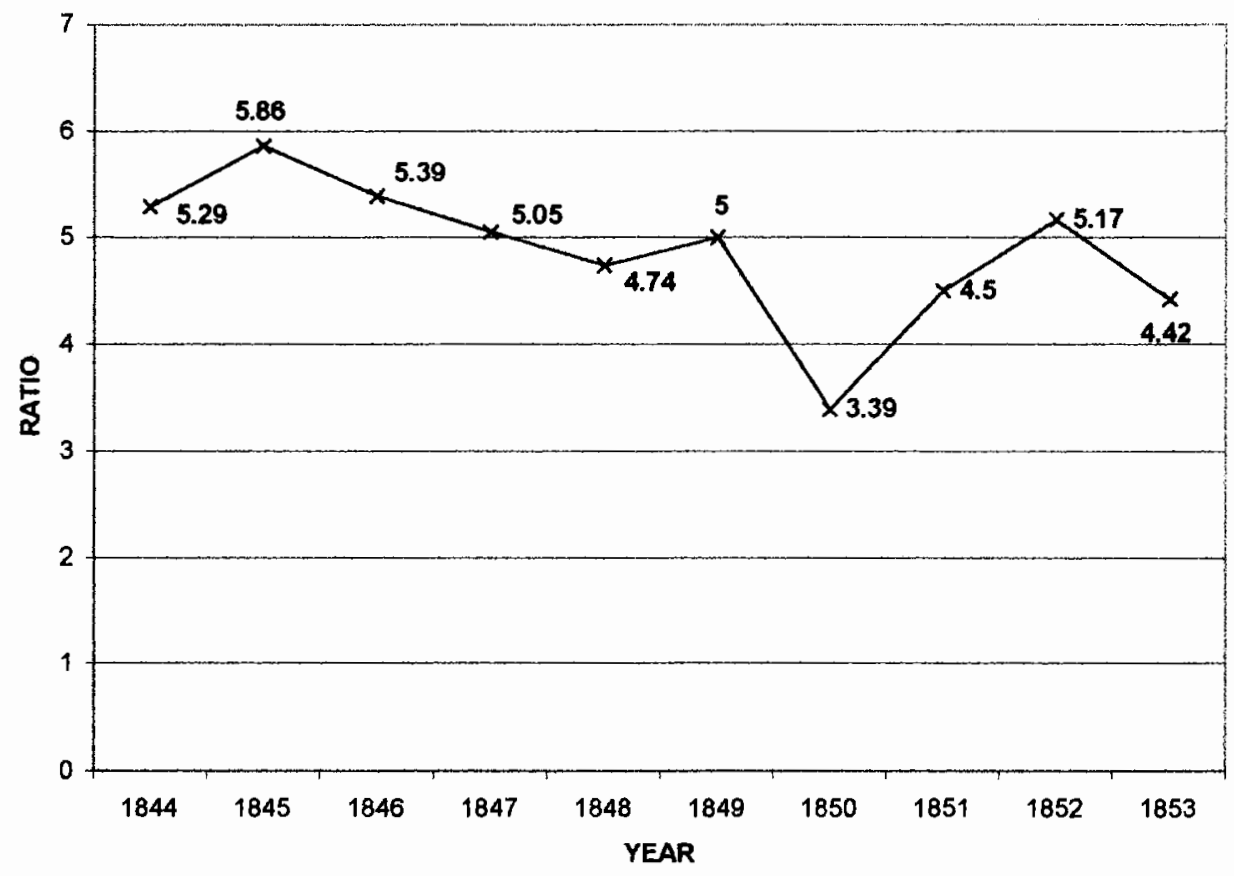

Figure E-2. Ratio of People to Wagons, by Average number of Emigrants per Wagon, based on the total annual migration figures for 1844 to 1853 (Meyers 1960) 


\section{TABLE 3}

\section{ANNUAL OREGON TRAL MIGRATION PATTERN, BY WAGON TRAINS AND PEOPLE 1844 TO 1853 \\ (MEYERS 1960, 79)}

\begin{tabular}{|r|r|r|r|r|}
\hline YEAR & WAGONS & PEOPLE & PEOPLEWAGONS & \# TRAINS \\
\hline $\mathbf{1 8 4 4}$ & $\mathbf{2 1 0}$ & 1110 & 5.29 & 3 \\
\hline $\mathbf{1 8 4 5}$ & 348 & 2040 & 5.86 & 8 \\
\hline $\mathbf{1 8 4 6}$ & 142 & 766 & 5.39 & 2 \\
\hline $\mathbf{1 8 4 7}$ & 597 & 3014 & 5.05 & 8 \\
\hline $\mathbf{1 8 4 8}$ & 246 & 1165 & 4.74 & 2 \\
\hline $\mathbf{1 8 4 9}$ & 165 & 825 & 5 & 1 \\
\hline 1850 & 180 & 610 & 3.39 & 1 \\
\hline 1851 & 410 & 1847 & 4.5 & 4 \\
\hline $\mathbf{1 8 5 2}$ & $\mathbf{4 0 1}$ & 2075 & 5.17 & 3 \\
\hline 1853 & 181 & 800 & 4.42 & 4 \\
\hline TOTAL & 2782 & 13,712 & 4.93 & 35 \\
\hline 10 YEAR MEAN & & 4.87 & \\
\hline
\end{tabular}

The average number of wagons for trains during this decade also varied greatly from about 40 to 130 wagons per train (Table 4, Figure E-3), with actual values ranging from 10 to 357 wagons per train (Figure E-4). According to these and earlier tables and figures, the overall average for the size of migrating families during this decade of Oregon Trail history was between four and five people per wagon. No ages for these people were given by Meyers, but presumably, beginning in 1847 , the number of families migrating westward steadily increased, with the first sizeable wagon trains (with well over 100 wagons per train) beginning their migration in 1852 . 
TABLE 4

AVERAGES OF WAGONS PER TRAIN AND PEOPLE PER TRAIN, BY YEAR OF OREGON TRAIL EMIGRATION (MEYERS 1960)

\begin{tabular}{|r|r|r|}
\hline & \multicolumn{2}{|c|}{ PER TRAIN AVERAGE } \\
\cline { 2 - 3 } YEAGONS/TRAIN & PEOPLE/TRAIN \\
\hline 1844 & 70 & 370 \\
\hline 1845 & 43.5 & 255 \\
\hline 1846 & 71 & 383 \\
\hline 1847 & 74.6 & 376.5 \\
\hline 1848 & 123 & 582.5 \\
\hline 1849 & 165 & 825 \\
\hline 1850 & 180 & 610 \\
\hline 1851 & 102.5 & 461.8 \\
\hline 1852 & 133.3 & 691.7 \\
\hline 1853 & 45.3 & 200 \\
\hline Decade avg & 100.82 & 475.55 \\
\hline
\end{tabular}

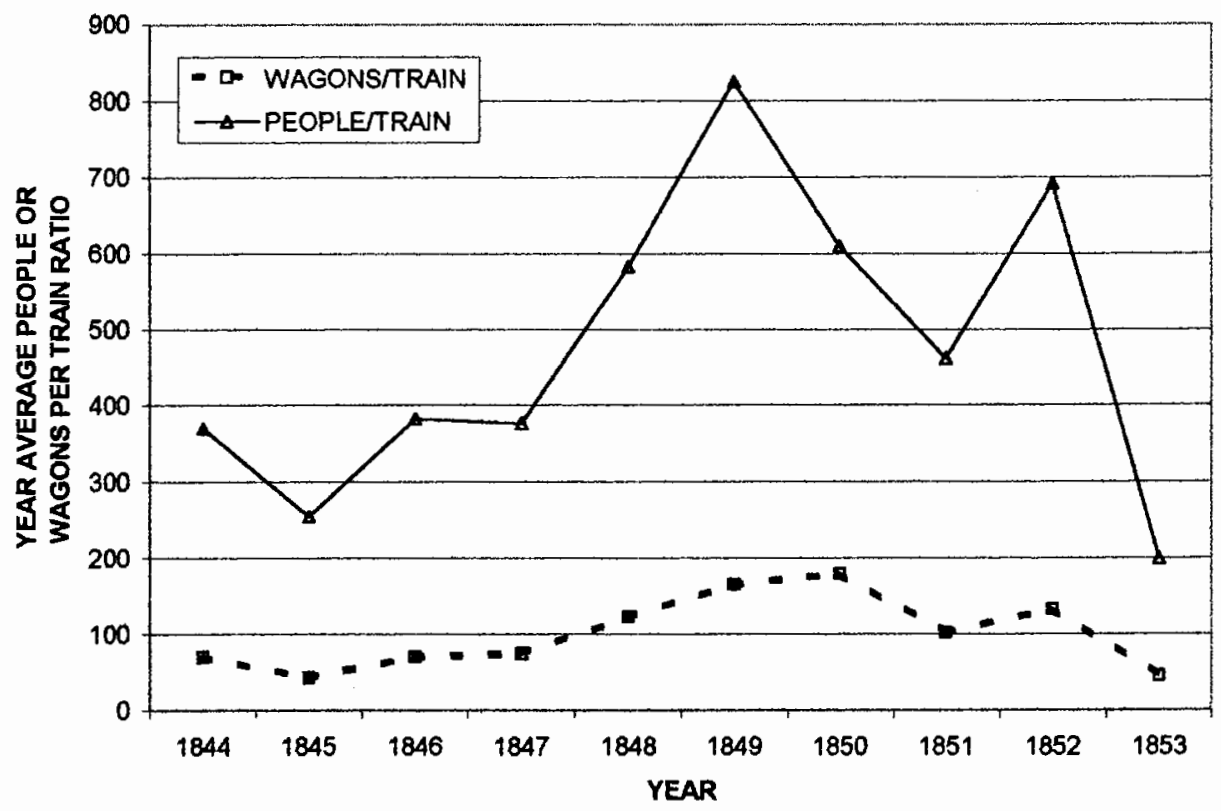

Figure E-3. Train Sizes based on average number of Wagons and People per Train in a Given Year, 1844 to 1853 (Meyers 1960) 


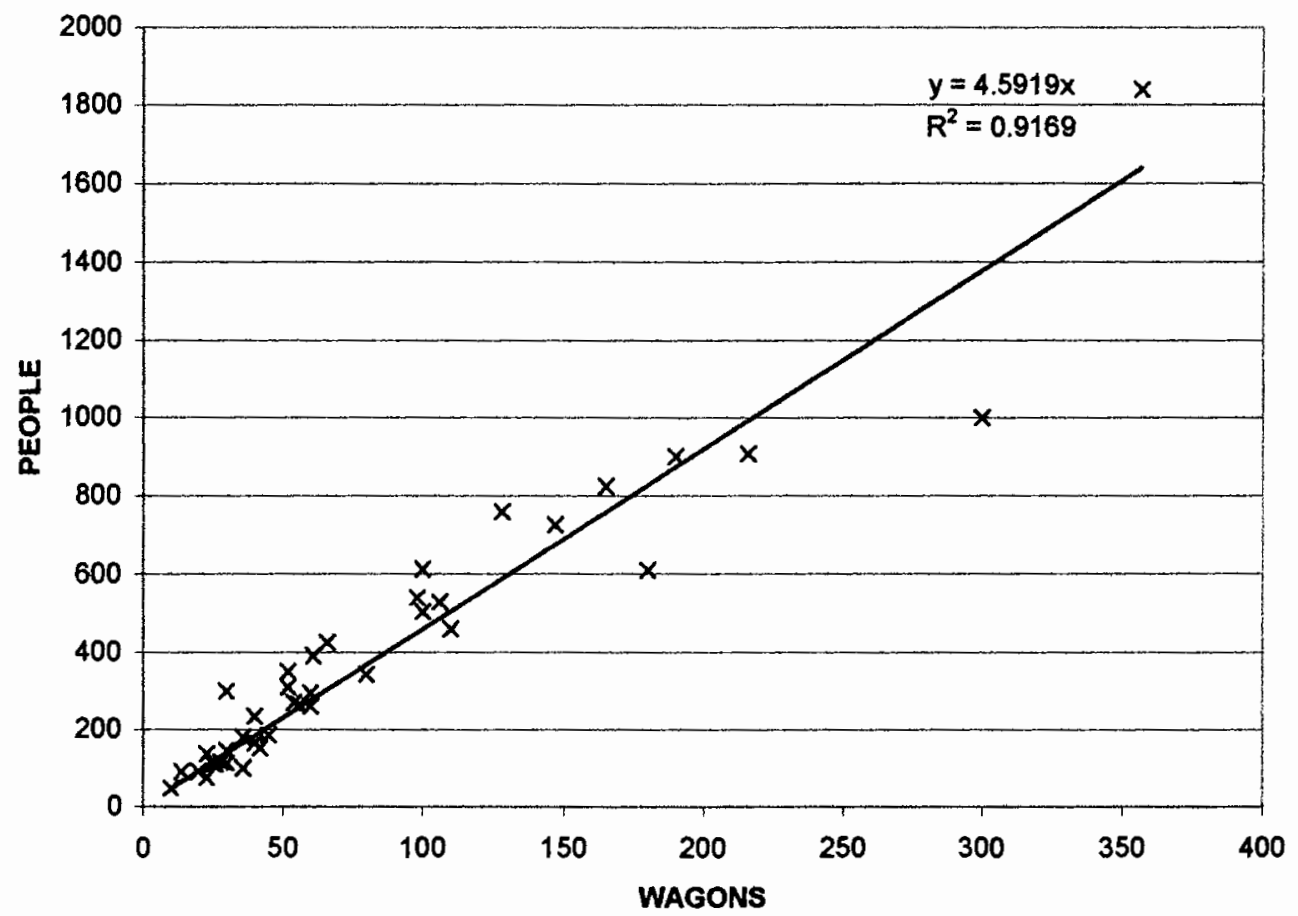

Figure E-4. Summary of People to Wagon data for the Oregon Trail, 1844-1853 (Meyers 1960) 
Umatilla Pass, 1853. Records of pioneers passing through a military post or agency established at the Far West end of the overland route in Umatilla were recorded daily. A review of the records for summer of 1853 was possible due to its regular publication several times per week in the Oregon Statesman. This data (Table 5) provides us with valuable insights into the size of these families making their way into Oregon State that summer and the time frame in which these emigrants finally made their way through Umatilla Pass; the 1853 migration demography was presumably similar to the 1852 migration.

We are also provided important information about the age grouping of the trail population with this emigrant data. Although exact ages cannot be determined, and in some cases pioneers registered as part of these core families may have not been children, this information still details how many relatives, mostly children, made their way to the Northwest, as the dysentery epidemic reached its peak during this migration. Similarly, these data provide important insights into how many middle aged parents (especially $>40$ years of age), with sizeable families including elders who might have made their way to Oregon (in populations with sizeable families, i.e. 7-10 members, for the most part). This data suggests the most likely families to migrate to the trail were fairly young and had few children (Figure E-5). The numbers of families passing through Umatilla daily varied considerably, but showed tendencies to pass through this Pass in sizeable aggregates or population clusters, thereby facilitating any sort of person-to-person disease transmission then underway (Figure E-6 and E-7).

The disadvantage to the Umatilla Agency data is that it does not take into account trail deaths which took place along the Great Plains, especially of wives and children, when interpreting family size. Furthermore, it does not differentiate children into age groups.

As the 1850 Oregon State census data discussed later indicates, the numbers of people over the age of 65 years of age--those most susceptible to both Asiatic cholera and dysentery, made up a fairly small percentage of the Oregon Trail and State populations. 
TABLE 5

REPORTS OF EMIGRANTS PASSING THROUGH UMATILLA AGENCY, 1853

\begin{tabular}{|c|c|c|c|c|c|c|c|c|c|c|c|c|c|c|}
\hline \multirow[b]{2}{*}{ DATE } & \multicolumn{14}{|c|}{ NUMBER OF CHILDREN IN FAMILY } \\
\hline & 0 & 1 & 2 & 3 & 41 & 5 & 6 & 7 & 8 & 9 & 10 & 71 & 12 & Total \\
\hline July [1?16, 1853 & 0 & 2 & 0 & 2 & 1 & 0 & 1 & 0 & 0 & 0 & 0 & 0 & 0 & 6 \\
\hline July 20,1853 & 1 & 2 & 0 & 0 & 0 & 4 & 0 & 0 & 0 & 0 & 0 & 0 & 0 & 7 \\
\hline July 23,1853 & 1 & 4 & 1 & 0 & 1 & 1 & 1 & 0 & 0 & 0 & 0 & 0 & 0 & 9 \\
\hline July 25,1853 & 6 & 6 & 1 & 5 & 5 & 1 & 3 & 1 & 0 & 0 & 0 & 0 & 0 & 28 \\
\hline July 29,1853 & 0 & 0 & 0 & 1 & 0 & 0 & 1 & 0 & 0 & 0 & 0 & 0 & 0 & 2 \\
\hline August 3,1853 & 9 & 8 & 1 & 2 & 2 & 1 & 3 & 0 & 1 & 0 & 0 & 0 & 0 & 27 \\
\hline August 7,1853 & 5 & 2 & 1 & 0 & 1 & 2 & 0 & 1 & 0 & 0 & 1 & 0 & 0 & 13 \\
\hline August 8,1853 & 4 & 1 & 3 & 0 & 1 & 3 & 1 & 1 & 0 & 0 & 0 & 0 & 0 & 14 \\
\hline August 0,1853 & 0 & 0 & 3 & 0 & 1 & 1 & 0 & 0 & 0 & 0 & 0 & 0 & 0 & 5 \\
\hline August 10, 1853 & 1 & 2 & 0 & 2 & 1 & 2 & 1 & 1 & 0 & 1 & 0 & 0 & 0 & 11 \\
\hline August 11, 1853 & 1 & 0 & 0 & 2 & 1 & 1 & 2 & 2 & 1 & 0 & 0 & 0 & 0 & 10 \\
\hline August 12,1853 & 2 & 0 & 1 & 1 & 0 & 1 & 0 & 0 & 0 & 0 & 0 & 0 & 0 & 5 \\
\hline August 13, 1853 & 0 & 1 & 0 & 0 & 0 & 0 & 0 & 0 & 0 & 0 & 0 & 0 & 0 & 1 \\
\hline August 14,1853 & 5 & 0 & 2 & 0 & 1 & 1 & 1 & 1 & 0 & 0 & 0 & 0 & 0 & 11 \\
\hline August 15,1853 & 5 & 3 & 1 & 3 & 2 & 1 & 0 & 2 & 1 & 1 & 0 & 0 & 0 & 19 \\
\hline August 17,1853 & 1 & 6 & 3 & 1 & 3 & 3 & 1 & 0 & 0 & 0 & 0 & 0 & 0 & 18 \\
\hline August 18,1853 & 4 & 4 & 3 & 3 & 1 & 7 & 3 & 0 & 0 & 0 & 0 & 0 & 0 & 25 \\
\hline August 19, 1853 & 2 & 6 & 2 & 3 & 1 & 4 & 3 & 1 & 0 & 1 & 1 & 0 & 0 & 24 \\
\hline August 20,1853 & 3 & 9 & 8 & 6 & 4 & 4 & 2 & 1 & 1 & 2 & 0 & 0 & 0 & 40 \\
\hline August 21, 1853 & 7 & 2 & 7 & 7 & 4 & 5 & 0 & 0 & 2 & 1 & 0 & 0 & 0 & 35 \\
\hline August 23,1853 & 3 & 1 & 4 & 4 & 4 & 5 & 2 & 0 & 0 & 1 & 0 & 0 & 0 & 24 \\
\hline August 24,1853 & 4 & 2 & 1 & 1 & 3 & 3 & 2 & 2 & 0 & 0 & 0 & 0 & 0 & 18 \\
\hline August 25,1853 & 0 & 2 & 2 & 0 & 0 & 0 & 0 & 0 & 0 & 0 & 0 & 0 & 0 & 4 \\
\hline August 26, 1853 & 0 & 2 & 2 & 1 & 1 & 0 & 0 & 0 & 1 & 0 & 0 & 0 & 0 & 7 \\
\hline August 27, 1853 & 5 & 2 & 10 & 1 & 0 & 5 & 1 & 2 & 1 & 0 & 0 & 0 & 0 & 27 \\
\hline August 28, 1853 & 3 & 8 & 1 & 4 & 5 & 0 & 2 & 2 & 0 & 1 & 0 & 0 & 0 & 26 \\
\hline August 29, 1853 & 1 & 0 & 0 & 0 & 0 & 0 & 0 & 0 & 0 & 0 & 0 & 0 & 0 & 1 \\
\hline August 30,1853 & 7 & 1 & 6 & 2 & 2 & 0 & 5 & 2 & 3 & 1 & 0 & 0 & 0 & 29 \\
\hline September 1,1853 & 6 & 9 & 4 & 0 & 2 & 1 & 1 & 1 & 1 & 0 & 0 & 0 & 0 & 25 \\
\hline September 2, 1853 & 7 & 3 & 3 & 3 & 6 & 3 & 0 & 3 & 3 & 1 & 0 & 0 & 0 & 32 \\
\hline September 5, 1853 & 8 & 7 & 7 & 7 & 10 & 1 & 4 & 1 & 0 & 2 & 0 & 0 & 0 & 47 \\
\hline September 10,1853 & 8 & 7 & 10 & 5 & 8 & 6 & 1 & 1 & 2 & 0 & 0 & 0 & 0 & 48 \\
\hline September 12, 1863 & 4 & 4 & 6 & 1 & 2 & 2 & 1 & 1 & 0 & 1 & 1 & 0 & 0 & 23 \\
\hline September 13,1853 & 2 & 4 & 3 & 5 & 1 & 1 & 0 & 0 & 0 & 0 & 0 & 0 & 0 & 16 \\
\hline September 14,1853 & 3 & 2 & 5 & 3 & 3 & 2 & 2 & 0 & 1 & 1 & 0 & 0 & 0 & 22 \\
\hline September 16,1853 & 4 & 3 & 0 & 1 & 3 & 0 & 2 & 3 & 0 & 0 & 0 & 0 & 0 & 16 \\
\hline September 17,1853 & 0 & 3 & 2 & 2 & 2 & 0 & 1 & 1 & 0 & 0 & 0 & 0 & 0 & 11 \\
\hline September 18,1853 & 4 & 4 & 5 & 5 & 5 & 2 & 2 & 0 & 0 & 0 & 0 & 0 & 0 & 27 \\
\hline September 20,1853 & 1 & 1 & 0 & 0 & 0 & 0 & 0 & 1 & 0 & 0 & 0 & 0 & 0 & 3 \\
\hline September 21, 1853 & 2 & 5 & 5 & 3 & 6 & 5 & 2 & 5 & 2 & 0 & 0 & 1 & 0 & 36 \\
\hline September 22, 1853 & 2 & 2 & 1 & 2 & 4 & 0 & 1 & 0 & 0 & 0 & 0 & 0 & 0 & 12 \\
\hline September 24, 1853 & 2 & 2 & 1 & 2 & 3 & 2 & 1 & 0 & 0 & 1 & 0 & 0 & 1 & 15 \\
\hline September 25,1853 & 4 & 1 & 3 & 0 & 0 & 1 & 0 & 1 & 0 & 1 & 0 & 0 & 0 & 11 \\
\hline September 27,1853 & 0 & 0 & 0 & 0 & 1 & 0 & 0 & 0 & 0 & 0 & 0 & 0 & 0 & 1 \\
\hline TOTAL & 137 & 133 & 118 & 90 & 101 & 81 & 53 & 37 & 20 & 16 & 3 & 1 & 1 & 791 \\
\hline
\end{tabular}




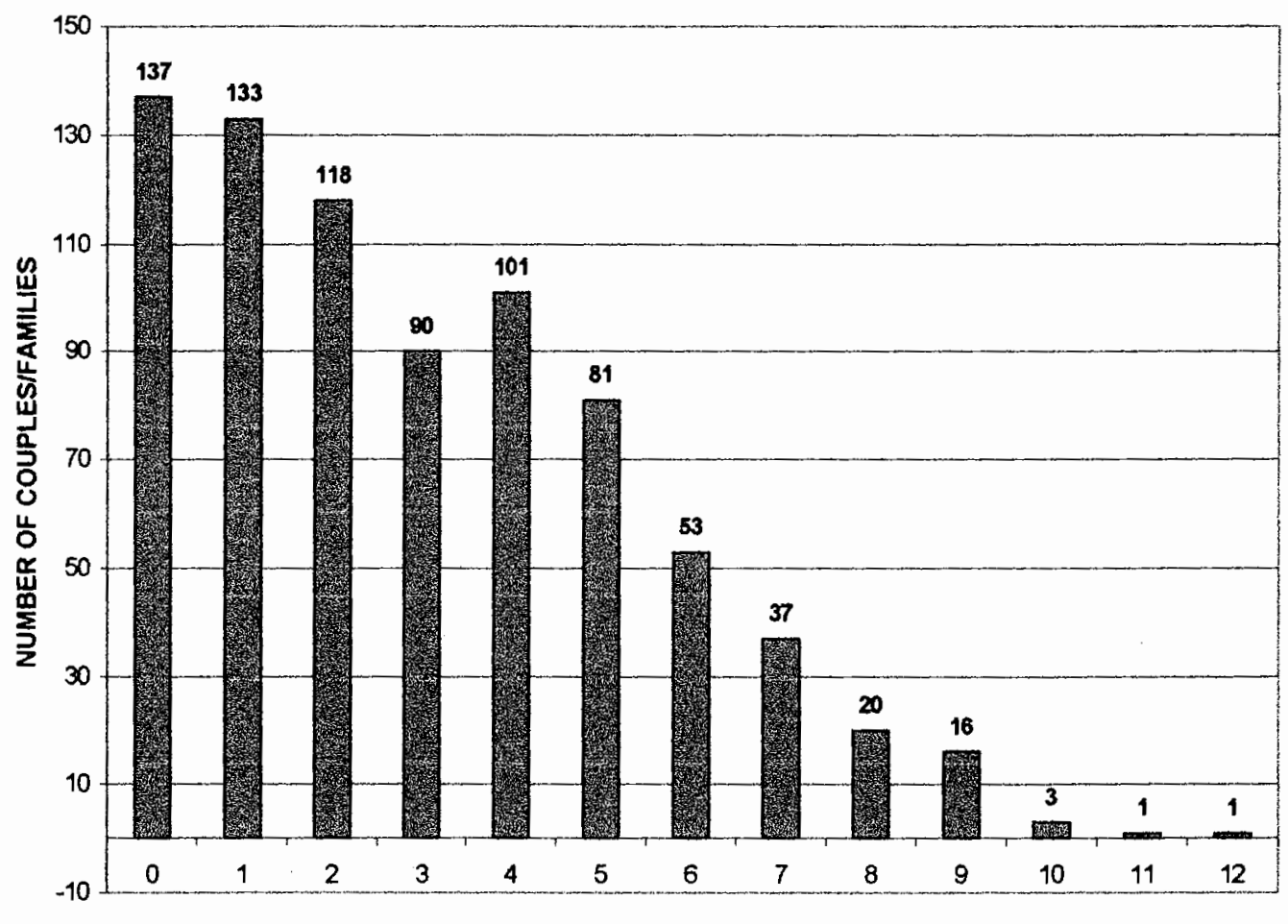

NUMBER OF CHILDREN PER FAMILY

Figure E-5. Family Size of Oregon trail Emigrants Reporting at Umatilla Agency, 1853 (from listings published in the Oregon Statesman) 


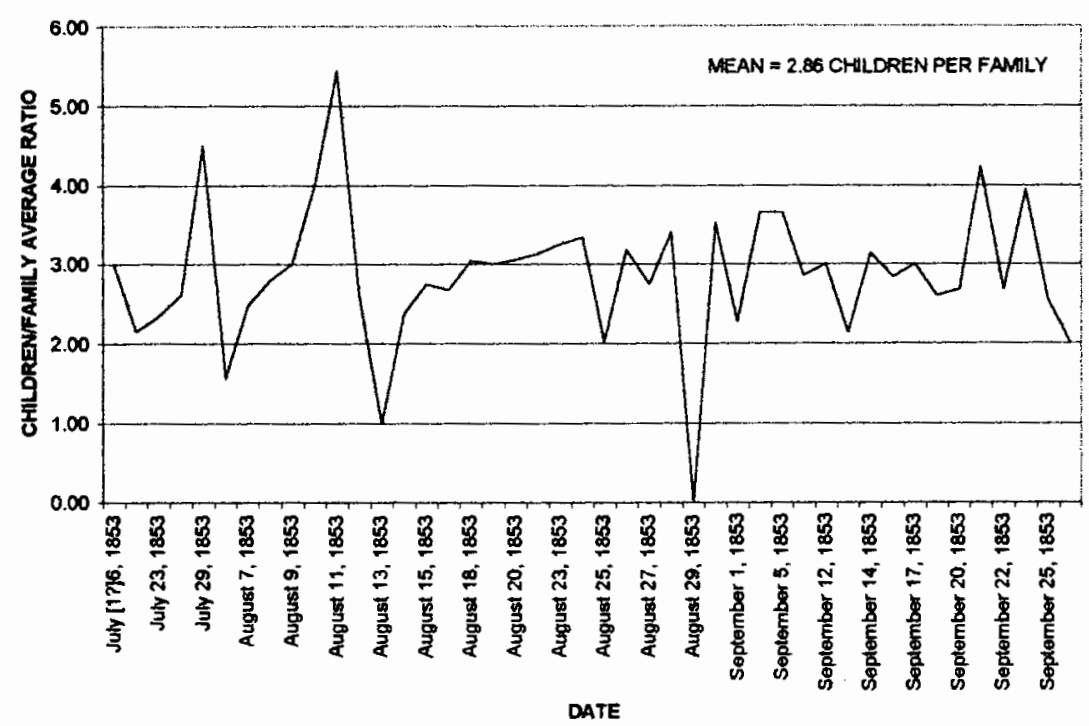

Figure E-6. Mean number of Children per Family passing through Umatilla Pass each Day in Summer of 1853 (Oregon Statesman, various dates)

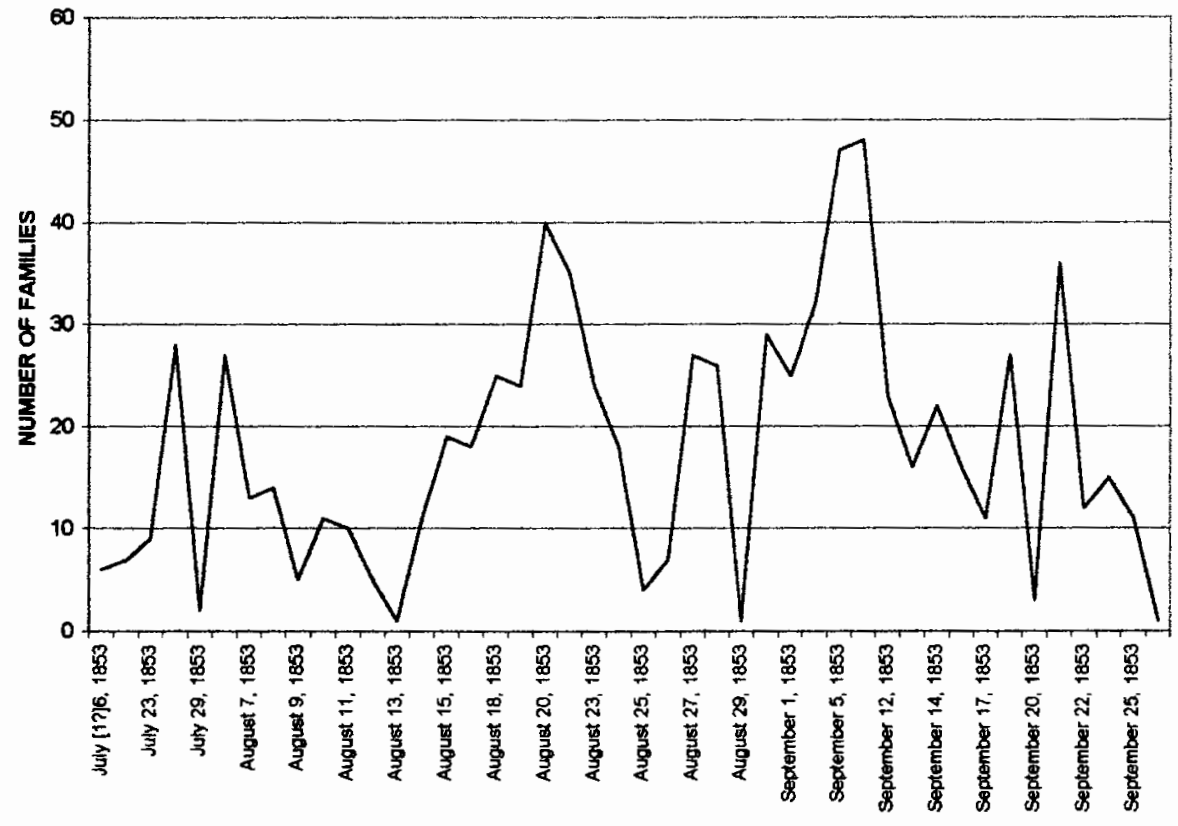

Figure E-7. Number of Families passing through Umatilla, per day, 1853 
Oregon Territory and State Demography. Between 1843 and 1846, the number of pioneers making their way to Oregon increased only slightly from prior years. In some cases, these newcomers were the main family unit of a pioneer who previously came Oregon to establish a land claim in accordance with the government's requirements for Oregon Territory (i.e. a family had five years to stake their claim and develop the land for permanent occupancy). A sizeable wagon train (eight wagons) made its way westward in 1847 according to Meyers. The largest migrations of 1848 and later were typically related to land claim issues. Between 1848 and 1851, such claims were formidable. Each man could obtain as much as 320 acres, each husband and wife team as much as 640 acres. In 1852, the size of the land one could acquire was reduced, and had to be settled and resided upon by 1855 .

Most of the settlements for these claims took place before 1857, the year in which some of the last of the land claims could be secured by pioneers to avoid relinquishing control of their land to the government.

A review of the Oregon population during these earliest settlement years was produced by Oregon Trail pioneer and state historian Evans (1886) (Table 6).

\section{TABLE 6}

EARLY OREGON POPULATION DATA (EVANS 1886)

\begin{tabular}{|c|c|c|c|}
\hline Year & New People & Total & Notes \\
\hline 1841 & 400 & & 1650 with "British subjects of all classes" \\
\hline 1842 & 137 & 537 & \\
\hline 1843 & 875 & 1412 & \\
\hline 1844 & 475 & 1887 & \\
\hline 1845 & 3000 & 4887 & \\
\hline 1846 & 1350 & 6237 & 7887 if British is included \\
\hline
\end{tabular}

Based on this data and 1860 census data, population growth in Oregon was steady throughout its early years of Territory and State history (see Figures 16 and 17 , main text). 
The Oregon " 1849 Census". More population information is contained in a review of an "1849 census" of Oregonians published in the local newspaper Oregon Statesman in 1852 , (possibly a version of the 1850 Census taken by the United States government) (Anonymous 1852c) (Table 7, Figure E-8).

\section{TABLE 7}

POPULATION OF OREGON IN 1849 (ANONYMOUS 1852c)

\begin{tabular}{|l|r|r|r|}
\hline COUNTY & MALES <21 & MALES > 21 & FEMALES \\
\hline Benton & 271 & 229 & 370 \\
\hline Marion & 470 & 552 & 660 \\
\hline Clackamas & 401 & 401 & 590 \\
\hline Clatsop & 49 & 103 & 75 \\
\hline Lewis & 40 & 64 & 71 \\
\hline Linn & 295 & 269 & 359 \\
\hline Polk & 337 & 328 & 520 \\
\hline Washington & 350 & 316 & 476 \\
\hline Clarke & 6 & 61 & 32 \\
\hline Yamhill & 397 & 410 & 571 \\
\hline Total & 1875 & 2505 & 3424 \\
\hline
\end{tabular}

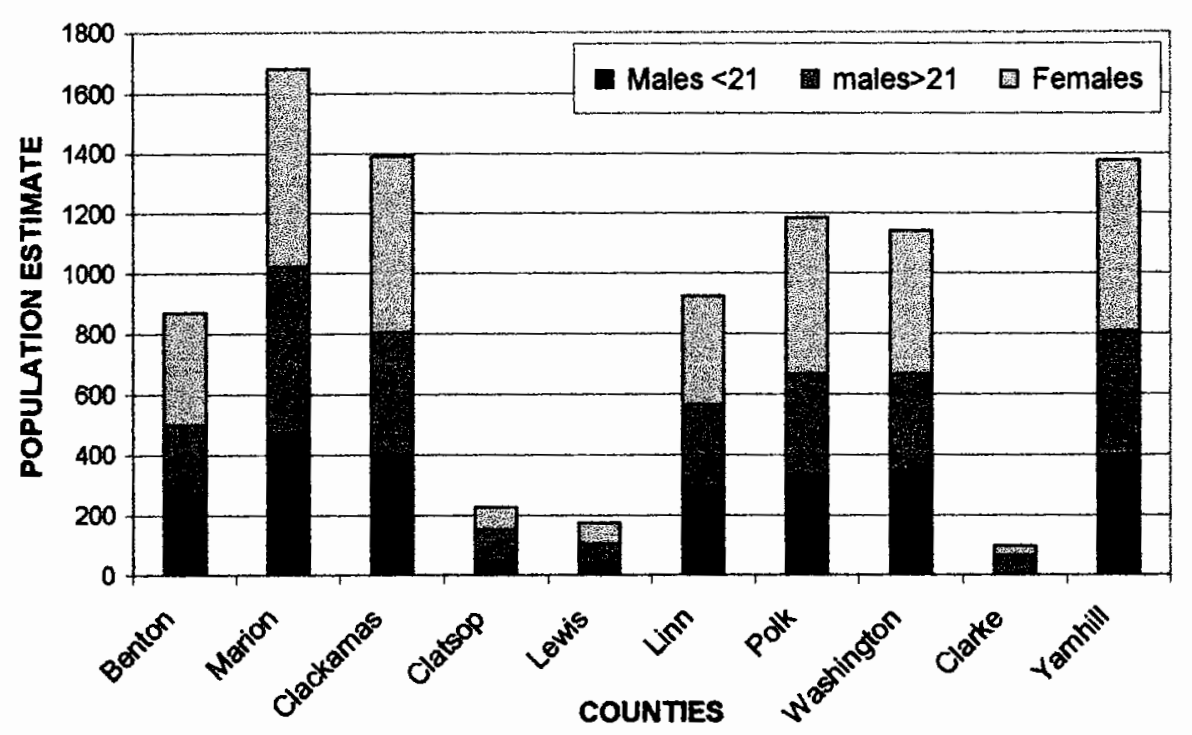

Figure E-8. 1849 Oregon Census (Anonymous 1852c) 
The Oregon State 1850 Census. Oregon Territory became an official State in 1850 , leading to the first official census to be taken of this region along with the rest of the United States during this official census year (DeBow 1853). This census for Oregon State also included demographic data for local residents residing in Washington Territory. It detailed the region's population by age and sex, and by "White" (White American) and "Black" (African American). (Figures E-9 and E-10). It is important to note that for this census year Oregon's County boundaries were quite different than the contemporary boundaries, a map of which appears in most United States historical atlases.

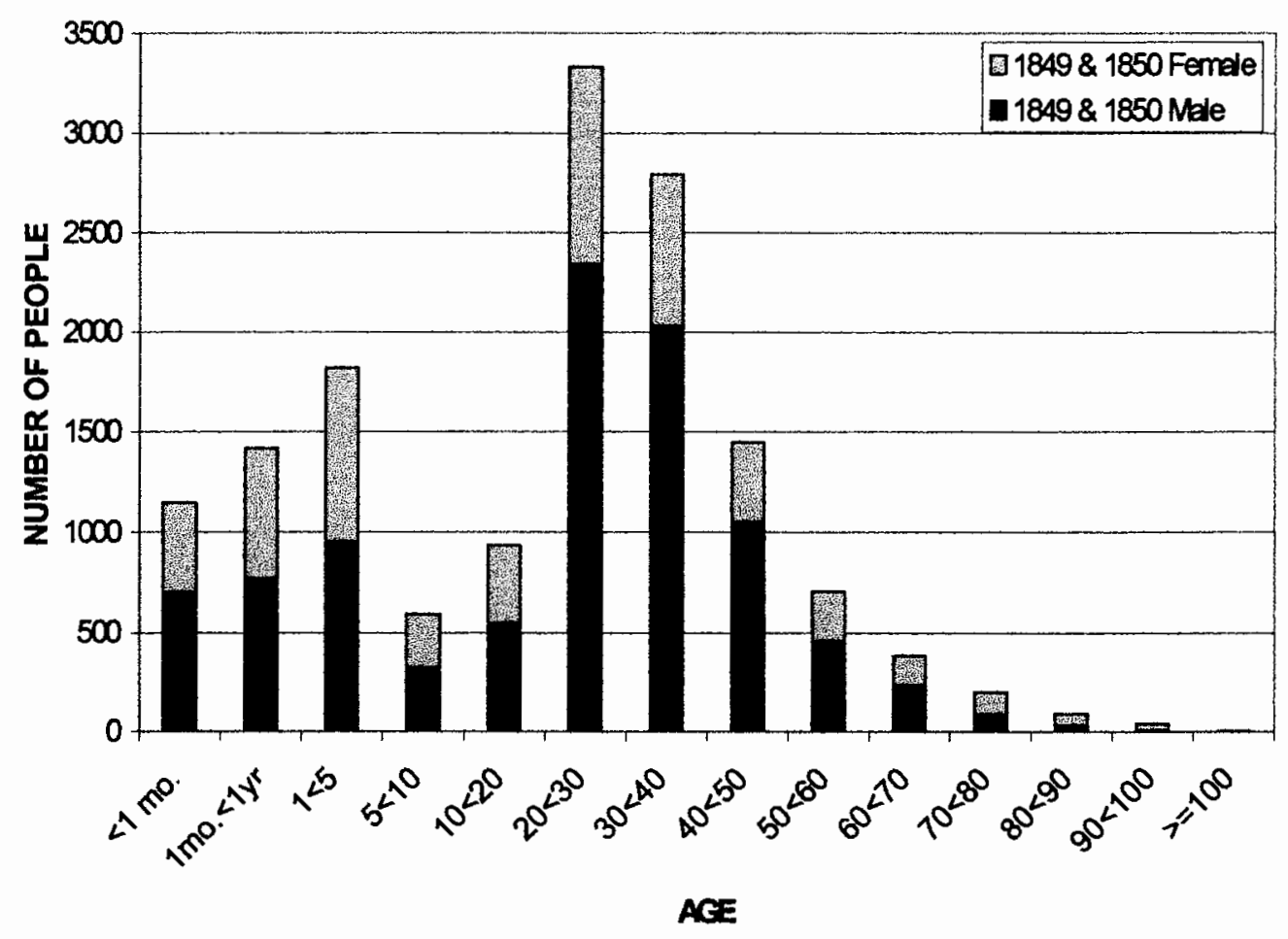

Figure E-9. 1849 and 1850 Oregon Population Counts, By Age and Sex (DeBow 1853) 


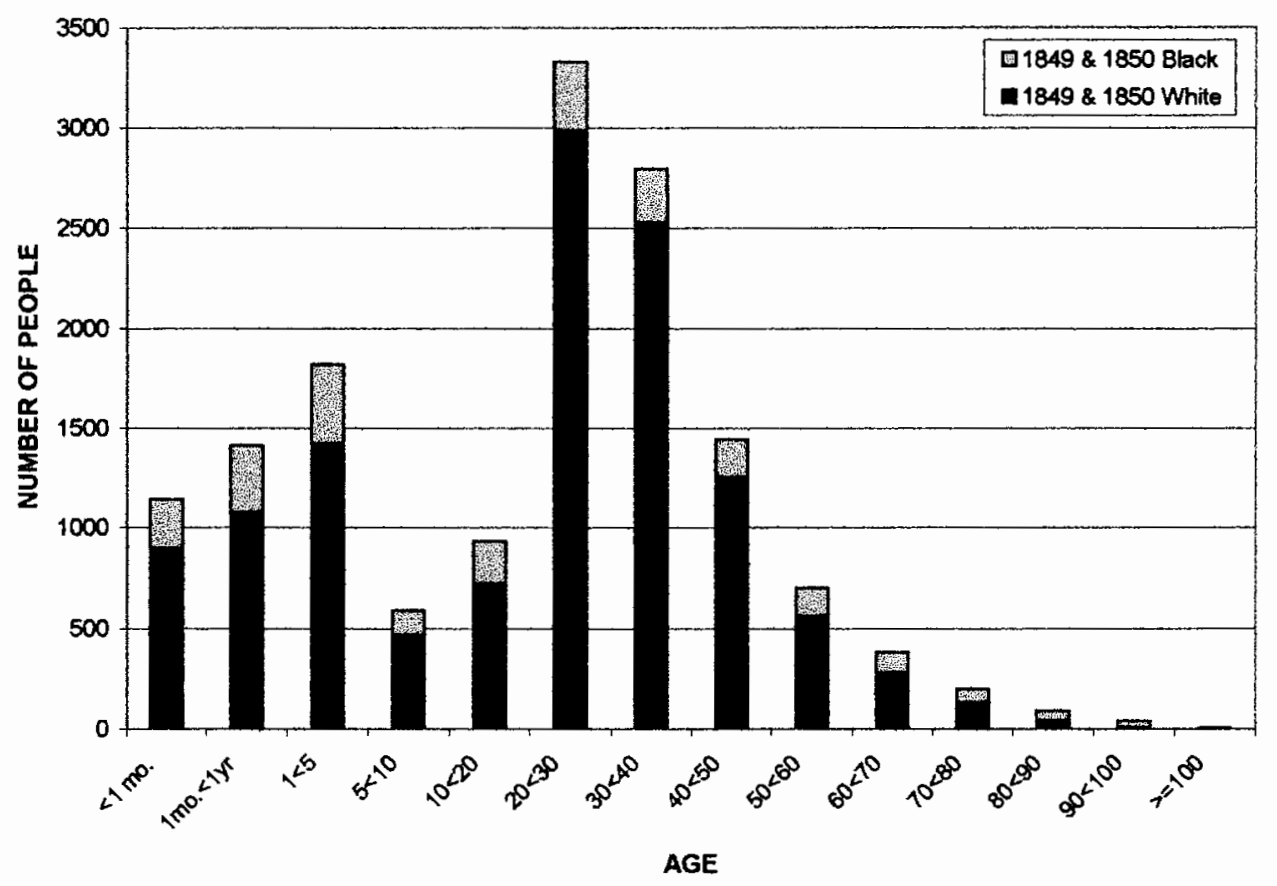

Figure E-10. Oregon 1850 Population Count, by Age and Skin Color (DeBow 1853)

The Oregon Census data for 1850 is particularly important to the elimination of the likelihood for a diffusion of Asiatic cholera into Oregon due to what it reveals about the local population. The overall population count was fairly low for Oregon. Although several semi-urban regions may have developed, they lacked significant population density. Aside from the military barracks population, the densest population aggregates within Oregon's county settings were minimal, as noted by the listings of how many people resided in a single location, places where disease could in theory spread from person to person more easily (Table 8). 


\section{TABLE 8}

POPULATION AGGREGATES IN OREGON (1850 OREGON CENSUS)

\begin{tabular}{|c|c|c|}
\hline COUNTY & NUMBER & DESCRIPTION \\
\hline \multirow[t]{2}{*}{$\overline{\text { CLARK }}$} & 236 & Soldiers of the Columbia Barracks \\
\hline & 24 & $\begin{array}{l}\text { Madame Superior, from Belgium, set up a place } \\
\text { in Oregon City; most living here were } 2 \text { to } 18 \\
\text { years of age. }\end{array}$ \\
\hline \multirow[t]{3}{*}{ CLATSOP } & 21 & hotel (p. 81) \\
\hline & 16 & lumberyard, (p. 90, 91) \\
\hline & 14 & lumberyard \\
\hline LEWIS & 54 & Soldiers from Ireland and Germany \\
\hline \multirow[t]{2}{*}{ MARION } & 27 & $\begin{array}{l}\text { a Belgian group ranging in age from four to fifty } \\
\text { years of age, with children born in Oregon } \\
\text { Territory between the ages of } 2 \text { and } 12 \text { (pp. 185- } \\
\text { 186) }\end{array}$ \\
\hline & 13 & $\begin{array}{l}\text { residents: incl a painter, carpenter, blacksmith, } \\
\text { physician }\end{array}$ \\
\hline \multirow[t]{8}{*}{ WASHINGTON } & 33 & boarding house with sailors and laborers \\
\hline & 30 & $\begin{array}{l}\text { hotel; including captains, sailors, steward and } \\
\text { cook. }\end{array}$ \\
\hline & 27 & carpenters, laborers, all over 15 years of age \\
\hline & 23 & Merchant Calum Reed's Place, with laborers \\
\hline & 21 & boarding house with sailors and laborers \\
\hline & 18 & unidentified location (inn?), with laborers \\
\hline & 16 & inn \\
\hline & 16 & $\begin{array}{l}\text { hotel; also including captains, sailors, steward } \\
\text { and cook. }\end{array}$ \\
\hline
\end{tabular}

The Oregon and California Censuses. This above mentioned Oregon Population data documented by the 1850 census can be compared with the California census data (Figures E-11 and E-12). 


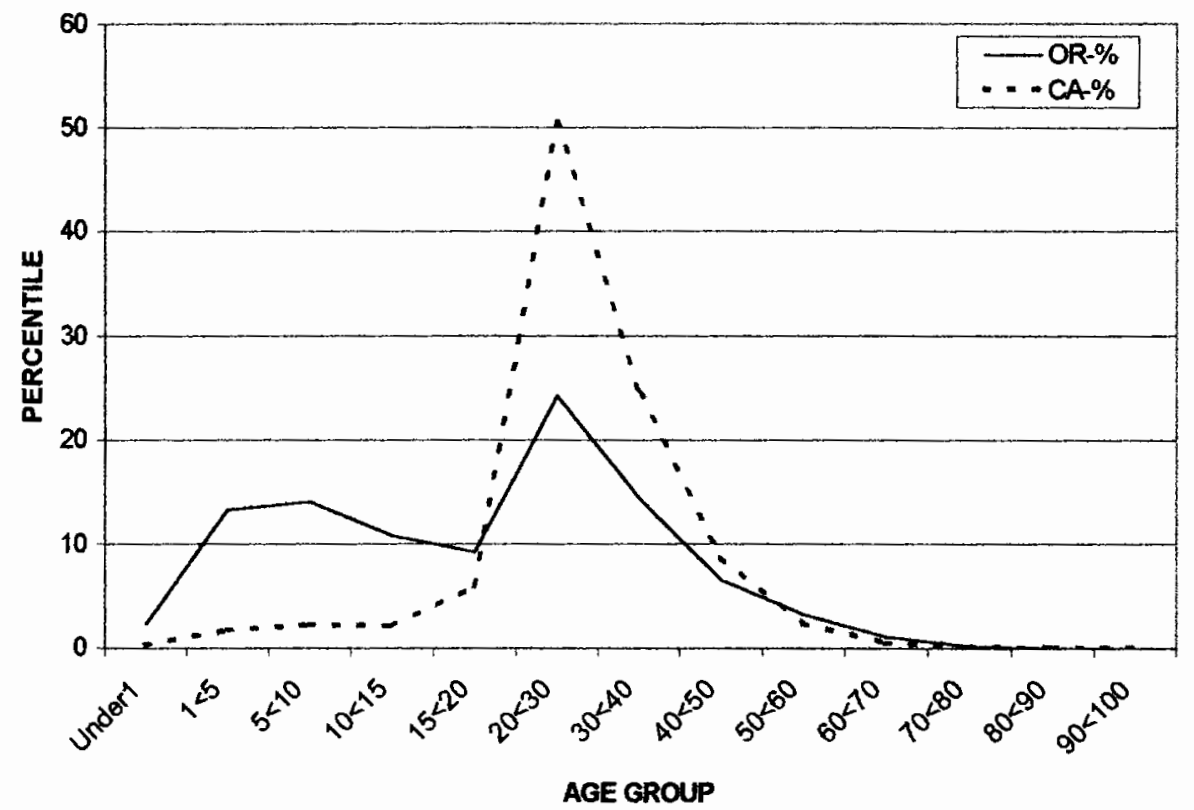

Figure E-11. Oregon and California Populations, by Age Group Percentages, 1850 (DeBow 1854)

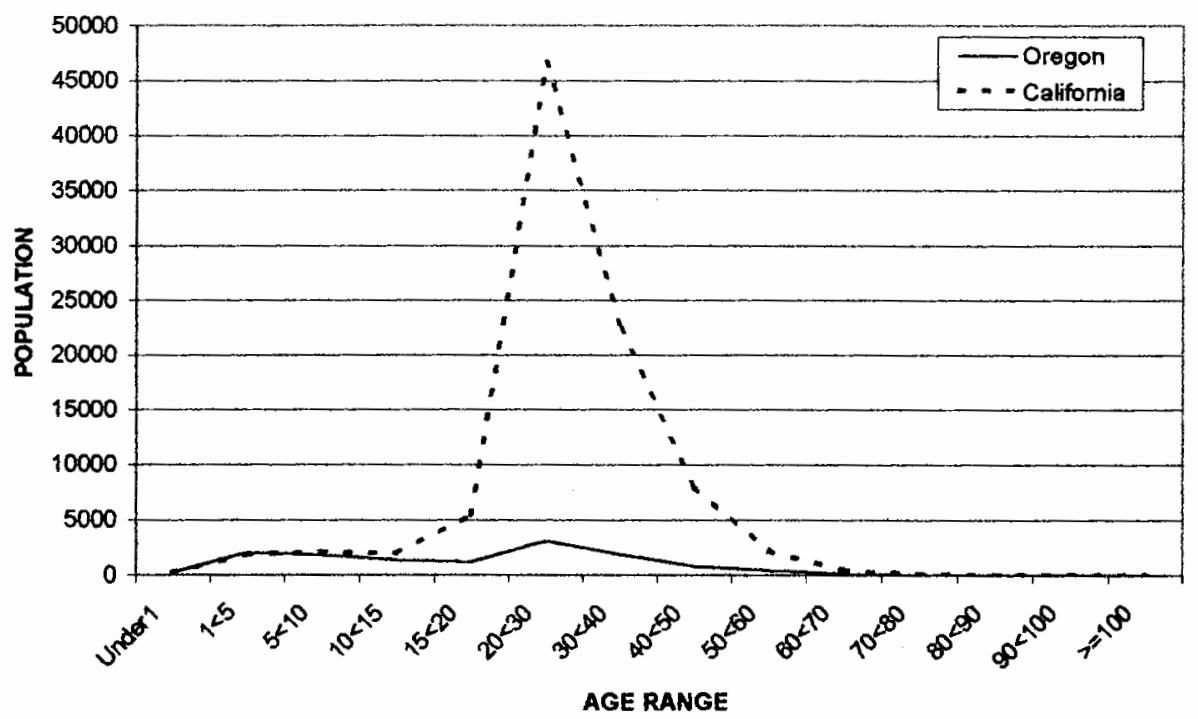

Figure E-12. Oregon and California Populations, By Age Group, 1850 (DeBow 1854) 
Trail Death Statistics. Finally, the two reviews of Oregon Trail fatalities published by Oregon newspapers were evaluated for this study:

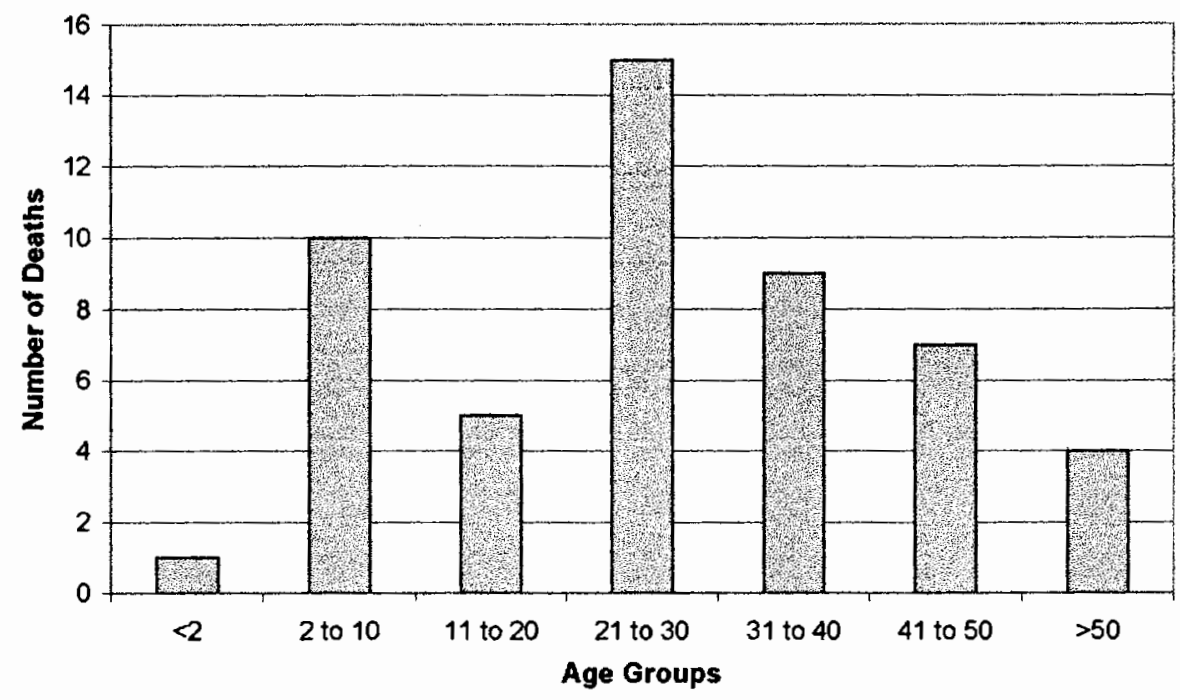

Figure E-13. Trail Deaths on Platte River and Near Chimney Rock, by Age Groups, 1852 (Anonymous 1852a)

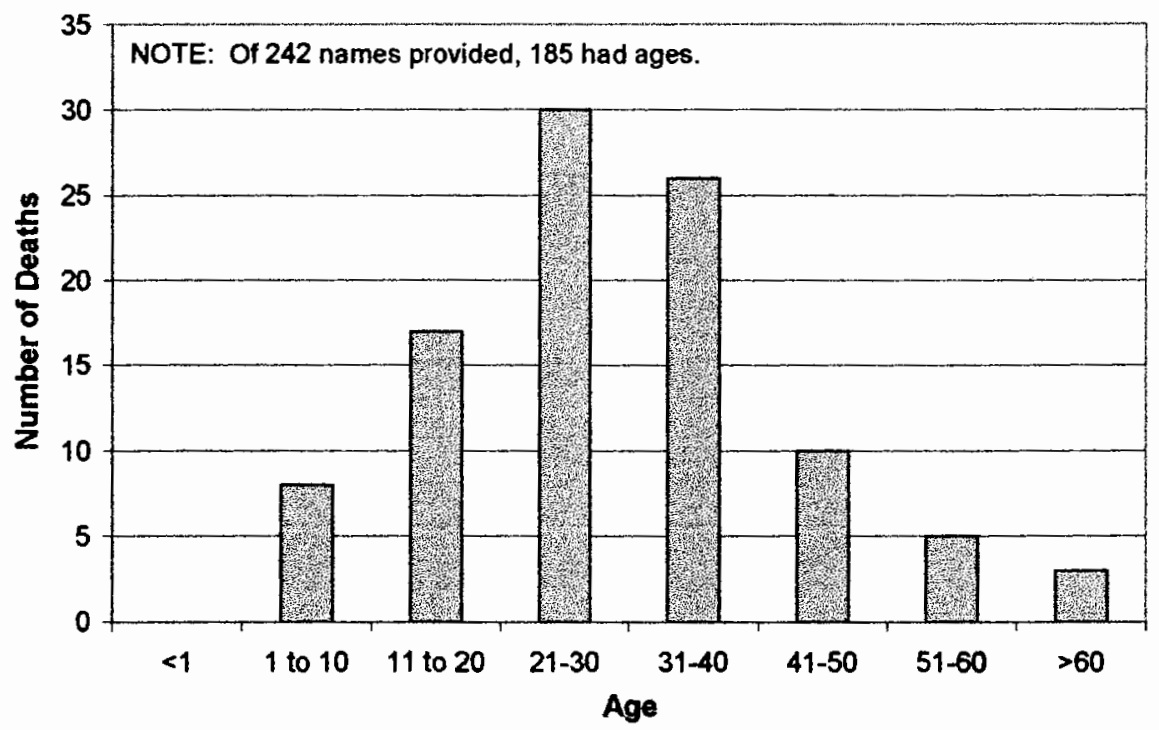

Figure E-14. Trail Deaths reported in a California Newspaper, 1852 , by age groups (Anonymous $1852 \mathrm{~b}$ ) 


\section{SUMMARY}

These findings strengthen the argument for a human geographic reason why Asiatic cholera failed to strike Oregon. According to the hierarchical diffusion model proposed for Asiatic cholera by this study, the higher population count in California, especially in and around it heavily populated urban regions like San Francisco and Sacramento, would have discluded Oregon from being the first place for Asiatic cholera to hit, even though Oregon had steady commerce underway by 1850 involving numerous countries along the entire Pacific Rim (see the various Shipping Records in the Oregon Statesman and Sandwich Island News).

As noted in the thesis, Asiatic cholera did in fact strike the California towns, and perhaps many other other heavily populated rural parts of California by late 1851, with various local physical geographic and climatic features supporting its diffusion deeper into the sourthern States by way of both overland and the combined overland-oceanic routes through the Texas, Mexico and Central America to California.

However, for identical physical geographic reasons, we can disclude the possible diffusion of Asiatic cholera diffusion to Oregon along the Pacific Rim between 1850 and 1853, even though mention of this is made in other Oregon history writings as well. One writing detailing the history of the Pacific coastal life in Oregon and California suggested that "cholera" came to Oregon by way of a California-Oregon ocean transport route, noting that Calvin Tibbetts, during his return from the Gold Rush of 1849 died from such a disease, i.e. "and upon returning [he] was stricken with cholera and died on board ship, August, 1849" (Overmeyer 1937, 101). This cholera death took place more than one year before California actually suffered Asiatic cholera.

Another possible means for Asiatic cholera penetration of Oregon would have been along heavily travelled military transportation transoceanic routes or overland routes. As suggested by the study of the Asiatic cholera which managed to pass through the Ural Mountains of Russia in 1831, it is also possible that one of Oregon's military entourages could have carried Asiatic cholera from a southern sea port back to the Pacific Northwest. Historical evidence for such an event involved Lt.-Col. B. L. E. Bonneville's military travels through Panama in 1852. 
During their stay in Panama, a cholera epidemic killed 150 of his soldiers. Yet in spite of its fatality in Panama, this epidemic never managed to make its way to Fort Vancouver in 1852, and no further incidence of "cholera" has been noted by these fort historians (Crandall 1930, 387; Carlton 1937, 31).

The final reviews of "cholera" and dysentery in Oregon history by Larsell also reveal little to no incidence that Asiatic cholera struck Oregon. Several interesting medical climatology interpretations of "cholera" relative to dysentery do appear however in Olof Larsell's review of Oregon Territory and State medical history (Larsell 1947, 487). Most of Dr. William Barclay's notes taken at the Fort were destroyed, but his review of Dysentery and Measles epidemics remained and was entitled "Memorandum of Medical facts from Dr. Barclay's Case Book, Medical Officer to the Hon. H. Bay Co. since 1839, up to 1850". In this memorandum, Barclay noted that Dysentery first arrived in Oregon on the Columbia in August 1844. He likened it to "Tropical Dysentery [a form of diarhea] traced to the shipping, and aggravated by the climate, a great many cases approaching to cholera, vomiting, purging, cramp, spasm, soldness, and tossing of the body forcibly in every direction attended with Lock Jaw--loss of pulse Clammy sweats terminates in death." Of the numerous diarrhea epidemics taking place in the United States in 1849 , barclay also wrote "The Dysentery has now become an endemic of the Country far and and near extending beyond West of the Rocky Mountains but of a milder nature than when it first appeared -- like all epidemics of this Country have been hitherto very severe on the first appearance." Barclay later noted: "at this moment the only Endemics of the Country of any importance are Dysentery and Intermittent Fevers--occasionally the Hooping Cough and Influenza ..." Barclay's notes tell us that some form of dysentery was already prevalent in Oregon along with fevers, most likely an opportunistic form of diarrhea brought on by the development of unsanitary town settings, hamlets and the like all along the increasingly populated water routes.

Evidence for another form of "cholera," perhaps linked to Typhus Fever, may also be noted in early Oregon history. On October 18, 1845, Members of the Meek party were possibly taken ill by Typhoid Fever: "Many of them are sick; quite a number have died; a disease prevails among them resembling the old camp 
distemper in the Revolutionary war" (Carey 1923, 272-273). Similarly, in 1852 Rev. Mr. Thomas Stevens, his wife, and three children experienced "a severe attack of the camp fever," taking the life of their 17 year old daughter, and leading him to write "There has been an unusual amount of suffering on the way by cholera, in a mitigated form, and camp fever." (Henderson, Latourette, and Latourette 1916, 470).

This suggests that even though Oregon's population was minimal when compared with California and the much more established Eastern United States, it remained vulnerable to dysentery as a "pioneer" town which meets the requirements for existing in an intermediate stage of development as noted in Whittlesey's sequent occupance model. Since it was in its early stage of development, Oregon Territory/State remained highly vulnerable to other forms of diarrhea, but due to its youth, never experienced the brunt of the most severe diarrhea epidemic to strike the United States during the mid and late nineteenth century--Asiatic cholera. 


\section{Figure E-1 References by Year}

1843

Barlow, Mrs. M. S. 1895. Reminiscences of Oregon Pioneers. In Transactions of the 23rd Annual Reunion of the Oregon Pioneer Association for 1895. (Portland, Oregon: Geo. H. Himes \& Co.) pages 69-86. See p. 75.

\section{4}

No Data.

1845

Carey, Charles Henry. 1923. Diary of Reverend George Gray-III. Oregon Historical Society Quarterly 24: 269-333.

$\underline{1850}$

Hartman, Ames William. 1924. The California and Oregon Trail. 1849-1860. Oregon Historical Society Quarterly 25: 1-35

"From the Plains". Statistics quoted from the Qhio Statesman about emigrants through Fort Laramie region, on July 8,1850 , as they appeared in the registry. In Oregon Spectator, 3 October $18502: 1 \quad 5(4)$.

1851

No Data

1852

"Death on the Plains." Qregon Statesman September 25, 1852. p. 2. [Grave information noted in May while passing through Fort Kearney, published in "Mortality on the Plains" from The Eldorado News.]

1853

Oregonian, Oct. 29, 1853, p. 1, col. 2-4. Umatilla Pass, Oregon. 


\section{References}

1850 Federal Census, Oregon Territory. Transcribed by Elsie J. Browning. nd. Oregon Historical Society Typescript. Oregon Historical Society, Portland, Oregon.

Anonymous. 1852a. "Death on the Plains." Oregon Statesman September 25, 1852. p. 2. [Grave information noted in May while passing through Fort Kearney, published in "Mortality on the Plains" from The Eldorado News.]

Anonymous. 1852b. List of the Deaths on the Plains this Season. Oregon Weekly Times, $3: 1$, November 20,1852, p. 2 . Copied from The Sacramento Union.

Anonymous. 1852c. Population of Oregon in 1849. Oregon Statesman, 3, 24. August 30, 1852 .

Barlow, Mrs. M. S. 1895. Reminiscences of Oregon Pioneers. In Transactions of the 23rd Annual Reunion of the Oregon Pioneer Association for 1895. (Portland, Oregon: Geo. H. Himes \& Co.) pages 69-86. See p. 75.

Carey, Charles Henry. 1923. Diary of Reverend George Gray-III. Qregon Historical Society Quarterly 24: 269-333.

DeBow, J. D. B. 1853. The Seventh Census of the United States: 1850 Washington: Robert Armstrong, Public Printer.

DeBow, J. D. B. 1854. Statistical View of the United States. Washington, D.C.: Superintendent of the United States. Republished in 1970 as a part of Demographic Monographs, No. 5. New York: Gordon and Breach Science Publishers.

Evans, Elwood. 1886. The Annual Address. In Transactions of the Fifth Annual Re-union of the Oregon Pioneer Association for 1882, pp. 13-37. Salem, OR: E. M. Waite. Statistics given, beginning with those in the Howitzer Report of 1843 (p. 26).

Henderson, Sarah Fisher, Nellie Edith Latourette, and Kenneth Scott Latourette. 1916. Correspondance of the Reverend Ezra Fisher Pioneer Missionary of the American Baptist Home Mission Society in Indiana, Illinois, Iowa and Oregon. Oregon Historical Society Quarterly 17: 431-480.

Meyers, E. L. (Roy). 1960. Covered Wagons. 1844-1853. Newsletter, Genealogical Forum of Portland. Oregon. 9: 71, 79.

Overmeyer, Philip Henry. 1937. Members of the First Wyeth Expedition. Qregon Historical Society Quarterly 36: 94-101.

Young, F. G. 1900. The Oregon Trail. Oregon Historical Society Quarterly 1: 339-370. 
APPENDIX F

ROCKY MOUNTAIN SPOTTED FEVER 


\section{Rocky Mountain Spotted Fever}

Throughout American history, numerous "spotted fevers" have been documented in regions aside from the Rocky Mountains. During the late eighteenth and early nineteenth century, the large swamplands of the Atlantic states were often associated with "Petechial or Spotted Fever" (Strong 1810, Colden 1814, Hosack 1814).

Early mention of "Mountain Fever" appears in a medical journal article (Waggoner 1850). During the early nineteenth century, this disease was often associated with numerous other febrile illnesses experienced by mountaineers, trappers, novice explorers and pioneers. According to Larsell, cases were probably sporadic at best along the Oregon Trail (Larsell 1947, 613).

Possibly one of the earliest documented transmissions of this disease to Oregon was in November 1847 , when it was "brought overland by the annual express of the H. Bay Company and the Mountain Trappers" according to historical documents (Larsell 1932, 1947, 28). Unable to remain in Oregon, this epidemic ceased in 1848 after infecting local natives and others in and around the fort.

During the mid to late nineteenth century, this form of febrile disease was found to be specific to high altitude regions throughout the Rocky Mountains and Sierras. In 1878, "Mountain Fever" was defined as:
"Fever belonging to mountainous regions, A form of fever, said to be peculiar to the elevated regions of the Rocky Mountains, and seen only at an altitude of 7000 feet and upwards." (Dunglison 1874, 419).

In 1875, medical climatologist, hydrologist and sanitarian Charles Smart associated it with a combination of topographic and hydrologic features (Smart 1875). This differentiation of "mountain fever" as a disease specific to miasmic malarial regions contrasts with Dunglison's statement about its specificity to mountain regions (op cit. 417-9), suggesting Smart's mountain fever may have pertained to one or more fevers induced by either mosquitoes (true malaria, or yellow fever) or water contamination from axenotic animal-born bacteria (the opportunistic bacterial causes noted in this thesis). 
Oregon medical historian Olof Larsell suggested Mountain Fever was most likely present in the Pacific Northwest as early as the first settlement years of Oregon Territory, if not earlier. Human migration and pioneer activities would have been a chief cause for its diffusion away from its focus or ecological origin in the heart of the Rocky Mountains, places where both the tick and the host (various deer) reside. Most likely the heavy settlement of eastern Oregon during the late nineteenth and early twentieth centuries caused this disease to diffuse westward and therefore increase its incidence in the state (Larsell 1947, 471, 613).

Although apparently prevalent in the 1880 s and 1890 s in Oregon and Idaho under the names of "blue disease" and "black fever," it wasn't until 1899 that specific clinical differences between this disease and other fevers became clear as it increased in incidence. In June 1899, Idaho physician Dr. E. E. Maxey discussed its uniqueness and geographically-definable behaviors in a paper presented to the Oregon State Medical Society. This provided one of the first definitive descriptions of this disease as:

"an acute, endemic, non-contagious, but probably
infectious disease characterized clinically by a
continuous high fever, arthritic and muscular pains
and a petechial or purpuric eruption in the skin, first
appearing in the ankles, wrists and forehead, but
rapidly spreading to all parts of the body" (Maxey
1899,433 , in Larsell 1947, 613).

During the very early 1900 s, several Idaho physicians began to link the deaths due to this "spotted fever" to bites from ticks residing on ground squirrels (Wilson and Chowning 1904). The vector cause for Rocky Mountain Spotted Fever finally became clear in 1906, when Idaho physician Dr. Howard Taylor Ricketts associated the bacteria responsible for this disease, Rickettsia rickettsia, with its vector the wood tick (Dermacentor andersoni) (Ricketts 1906, 1907, Garrison 1913, 706). The following year, McCalla documented its combined metaxenotic, anthropo-zoonotic and purely anthroponotic epidemiological nature 
(McCalla 1908), and over the next decade, much of its remaining epidemiological behavior was well documented and summarized by Simeon Burt Wolbach (1919).

In Oregon Trail diaries, the true Rocky Mountain Spotted Fever was probably the "Typhus" fevers of the Rocky Mountains. Although its chief characteristic is red spots on the skin, this symptom is shared by numerous other maladies and may even bear these names in error, i.e. "reddening of the skin" due to "scurvy." Along Snake River, this disease was known as "black measles" by Idaho physicians as early as 1873 (Woodward and Dumler 1998). Mention of painful joints or muscles help distinguish this disease from the opportunistic bacterial caused fevers, although some deviations from this rule exist. It also helps to note that the symptoms of Rocky Mountain Spotted Fever tend to start from the area of the tick-bite, thus the mention of their tendency to spread from ankles, wrists and forehead by Dunglison. Due to a combination of ecological and climatic reasons, the Rocky Mountain Spotted Fever tends to be more prevalent in the spring, and so was less likely to infect late arrivals of the Oregon trail migration (Woodward and Dumler 1998).

Geographically, this disease is restricted mostly to Colorado, Montana, Wyoming, Idaho and Oregon (see Figure F-1). Its mesofocus or permanent region of natural endemicity has been defined as extending "from the eastern limits of the Rocky Mountain System in northern Colorado and southern Wyoming westward to include the Sierras of California" (Dr. R. R. Parker, Spotted Fever Laboratory, Hamilton, Montana, in Larsell 1947, 612). Both historically, as well as during recent decades, this disease has for various reasons extended well beyond its original focus in the Rocky Mountains (Dumler 1991; Pinkerton and Maxcy 1931; Harrell 1949; Hattwick, O’Brien and Hanson 1976; Pederson, Jr. 1977; Woodward and Dumler 1998). 


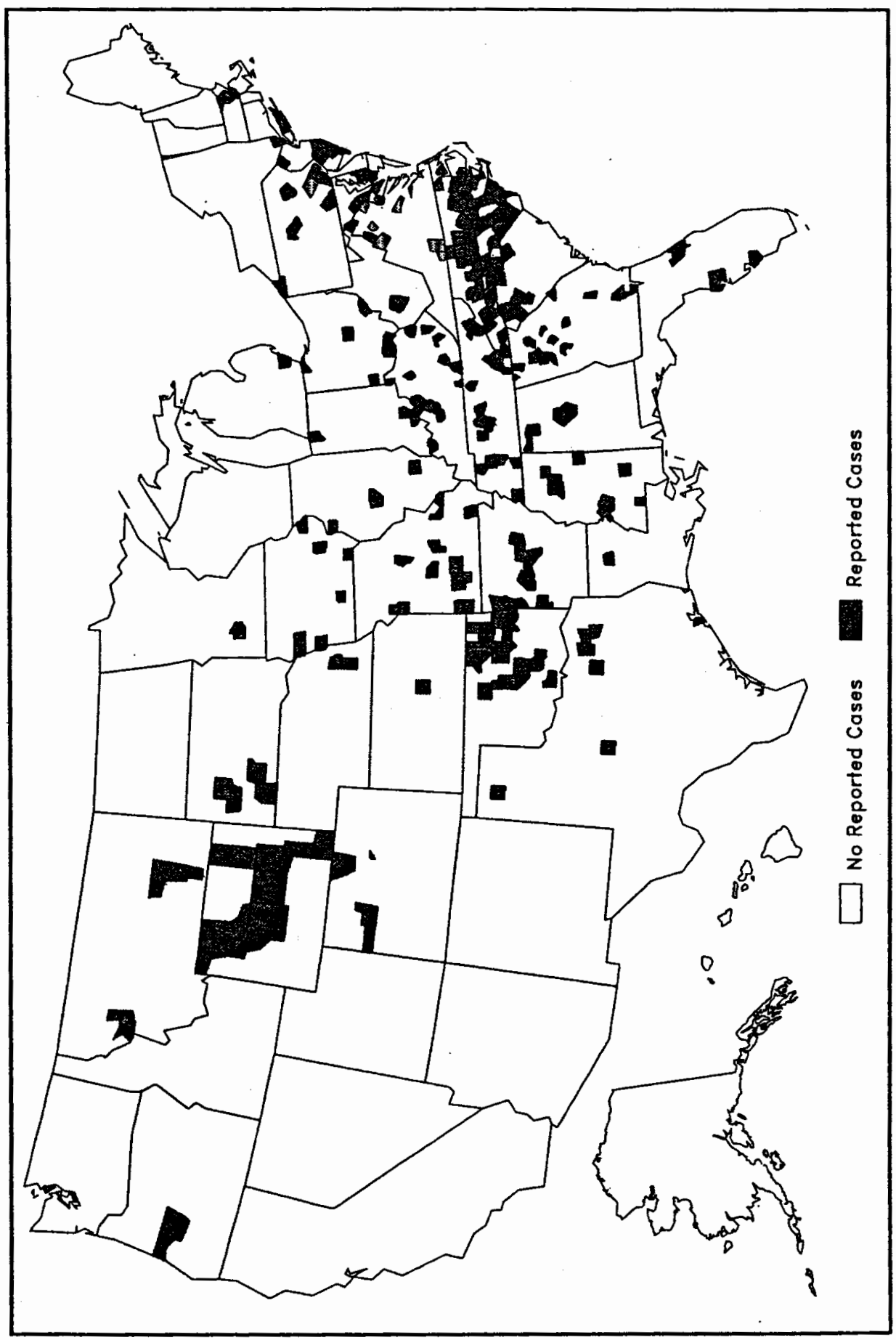

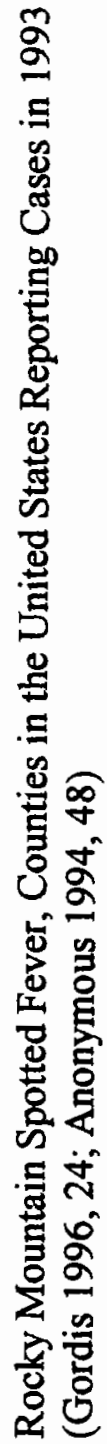




\section{References}

Anonymous (Center for Disease Control and Prevention). 1994. Summary of Notifiable Diseases, United States: 1993. MMWR 42:48.

Colden. Cadwallader. 1814. Observations on the Fever which Prevailed in the City of New-York in 1741 and 2, written in 1743, by the late Hon. Cadwallader Colden. Communicated to Dr. David Hosack by C. D. Colden, Esq. The American Medical and Philosophical Register 1: 310-330.

Dumler, J. S. 1991. Fatal Rocky Mountain Spotted Fever in Maryland--1901. JAMA 265: 718.

Garrison, Fielding H. 1913. An Introduction to the History of Medicine 4ed. Philadelphia: W. B. Saunders.

Gordis, Leon. 1996. Epidemiology. Philadelphia: W. B. Saunders.

Harrell, G. T. 1949. Rocky Mountain Spotted Fever. Medicine 28: 333-370.

Hattwick, M. A., R. J. O'Brien, and B. F. Hanson. 1976. Rocky Mountain Spotted Fever: Epidemiology of an Increasing Problem. Annals of Internal Medicine 84: 732-739.

Hosack, David. 1814. Observations on the Spotted Fever, as it appeared in Orange County, State of New-York, in 1808 and 1809. Communicated in a Letter from Doctor David R. Arnell, of Goshen, to Dr. David Hosack, Professor of Botany and Materia Medica, in Columbia College, New-York. The American Medical and Philosophical Register 1: 12-16.

Larsell, Olof, 1932. An Outline of the History of Medicine in the Pacific Northwest. Northwest Medicine 31.

Larsell, Olof. 1947. The Doctor in Oregon. Portland: Binfords and Mort.

Maxey, E. E. 1899. Some Observations on the So-Called Spotted Fever of Idaho. Medical Sentinel 7: 433.

McCalla, L. P. 1908. Direct Transmission from man to man of the Rocky Mountain Spotted Tick Fever. Medical Sentinel 16: 87. 
Pederson, C. E., Jr.. 1977. Rocky Mountain Spotted Fever: A Disease that must be Recognized. Journal of American Medical Technology 39: 190-198.

Pincoffs, M. C., and C. C. Shaw. 1933. The Eastern Type of Rocky Mountain Spotted Fever. Report of a Case with Demonstration of Rickettsia. Medical Clinics of North America 16: 1097-1113.

Pinkerton, H., and K. F. Maxcy. 1931. Pathological Study of a Case of Endemic Typhus in Virginia with Demonstration of Rickettsia. American Journal of Pathology 7: 95-103.

Ricketts, H. T. 1906. The Study of "Rocky Mountain Spotted Fever" (tick fever) by means of animal inoculations. JAMA 47: 1-10.

Ricketts, H. T. 1907. The role of the Wood Tick (Dermacentor occidentalis) in Rocky Mountain Spotted Fever, and the Susceptibility of Local Animals to this Disease. JAMA 49:24.

Smart, C. 1878. On Mountain Fever and Malarious Waters. American Journal of Medical Science, Philadelphia 75: 17-43.

Strong, Nathan. 1810. An Inaugural Dissertation on the Disease termed Petechial or Spotted Fever. Submitted to the Examining Committee of the Medical Society of Connecticut for the County of Hartford. Hartford: Gleason. (see also Review, published in 1814 by The American Medical and Philosophical Register 1: 87-92.

Waggoner, F. R. 1850. On the Mountain or Continued Miasmatic Fever of Colorado Territory. American Journal of Medical Science, Philadelphia 1: 50-55.

Wilson, L. B. and W. M. Chowning. 1904. Studies in Pyroplasmosis Hominus ("Spotted Fever" or "Tick Fever" of the Rocky Mountains). Journal of Infectious Diseases 1: 31-36.

Wolbach, S. B. 1919. Studies on the Rocky Mountain Spotted Fever. Journal of Medical Research 41: 1-97.

Woodward, Theodore E. and J. Stephen Dumler. 1998. Rocky Mountain Spotted Fever. In Alfred S. Evans and Philip S. Brachman (eds.) Bacterial Infections of Humans. Epidemiology and Control. 3ed. (New York: Plenum Medical Book Company) pages 597-612. 
APPENDIX G

OREGON TRAIL MAPS 


\section{Map Descriptions}

The following maps are provided to assist the reader in locating Oregon Trail locations mentioned in the thesis.

Kansas \& Missouri

Nebraska

Wyoming

Idaho

Oregon

These were copied come from a single untitled document (six pages, stapled, each page bears a heading/title) currently in possession of the Oregon Historical Society, Portland, Oregon and stored in a Vertical File referred to as "Overland Journeys//Oregon Trail//Maps and routes." According to Oregon Historical Society Maps Librarian Elizabeth Winroth, this document was probably produced by the United States Department of the Interior, National Park Service, and served as a handout to participants attending a gathering designed to initiate the Comprehensive Management and Land Use programs and/or develop certain sections of the Oregon Trail into National, State and local parks (ca. 1980?).

For more information on Trail geography and history, consult any of the books cited in the attached bibliography. For detailed descriptions of trail topography and geography, review any of the articles by geographer Rieck published in the Qverland Joumal beginning 1991. 


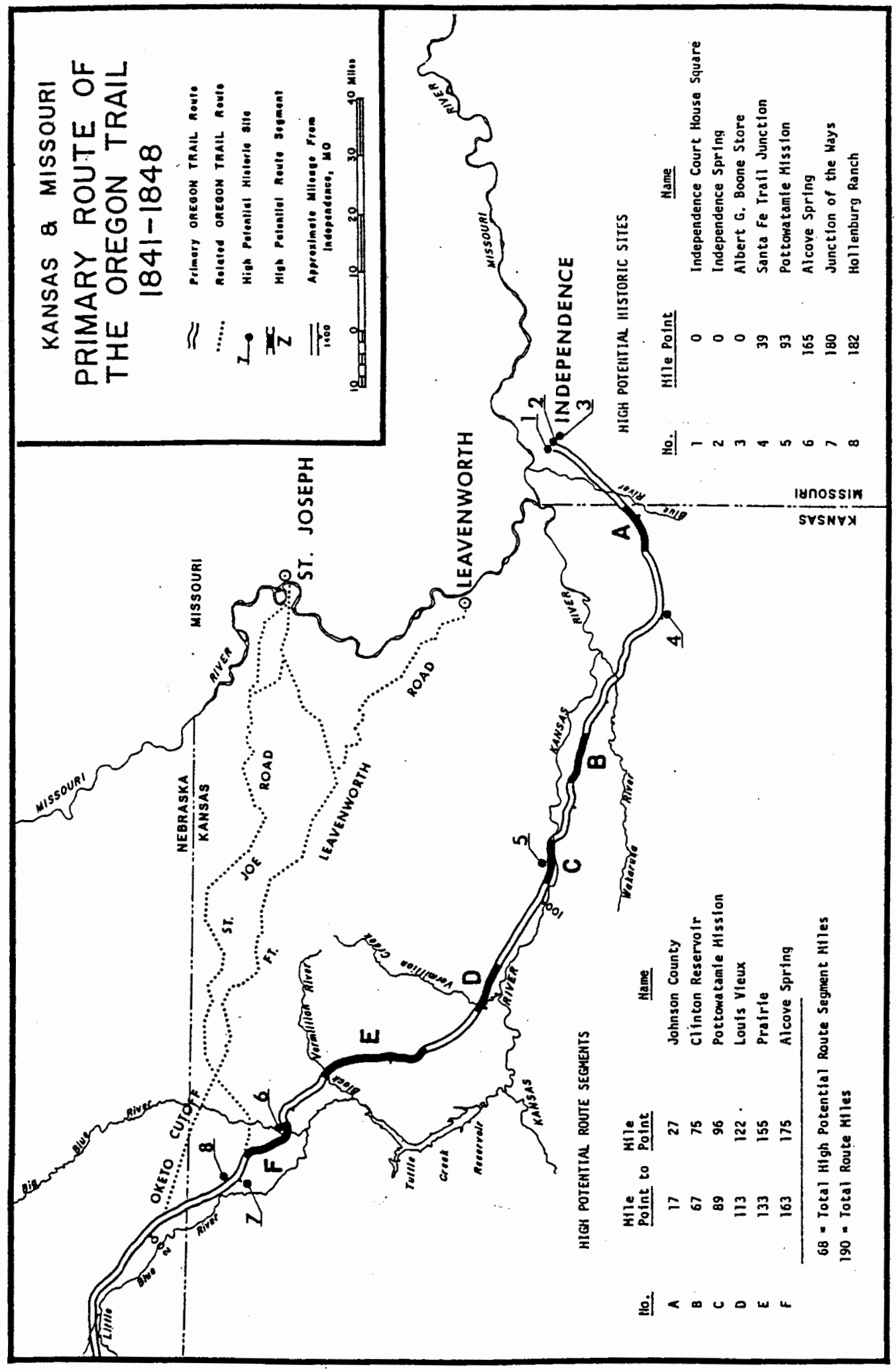




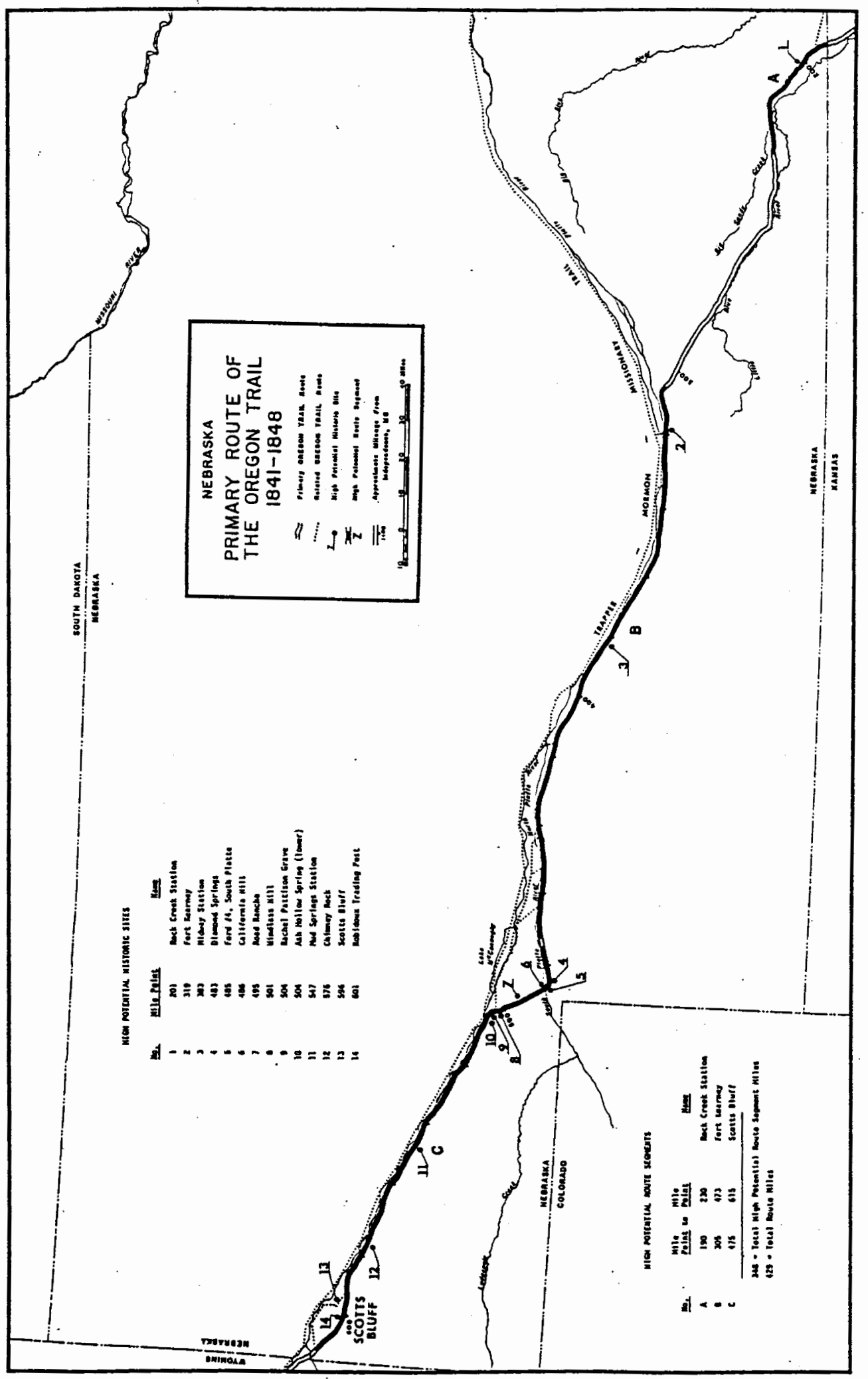




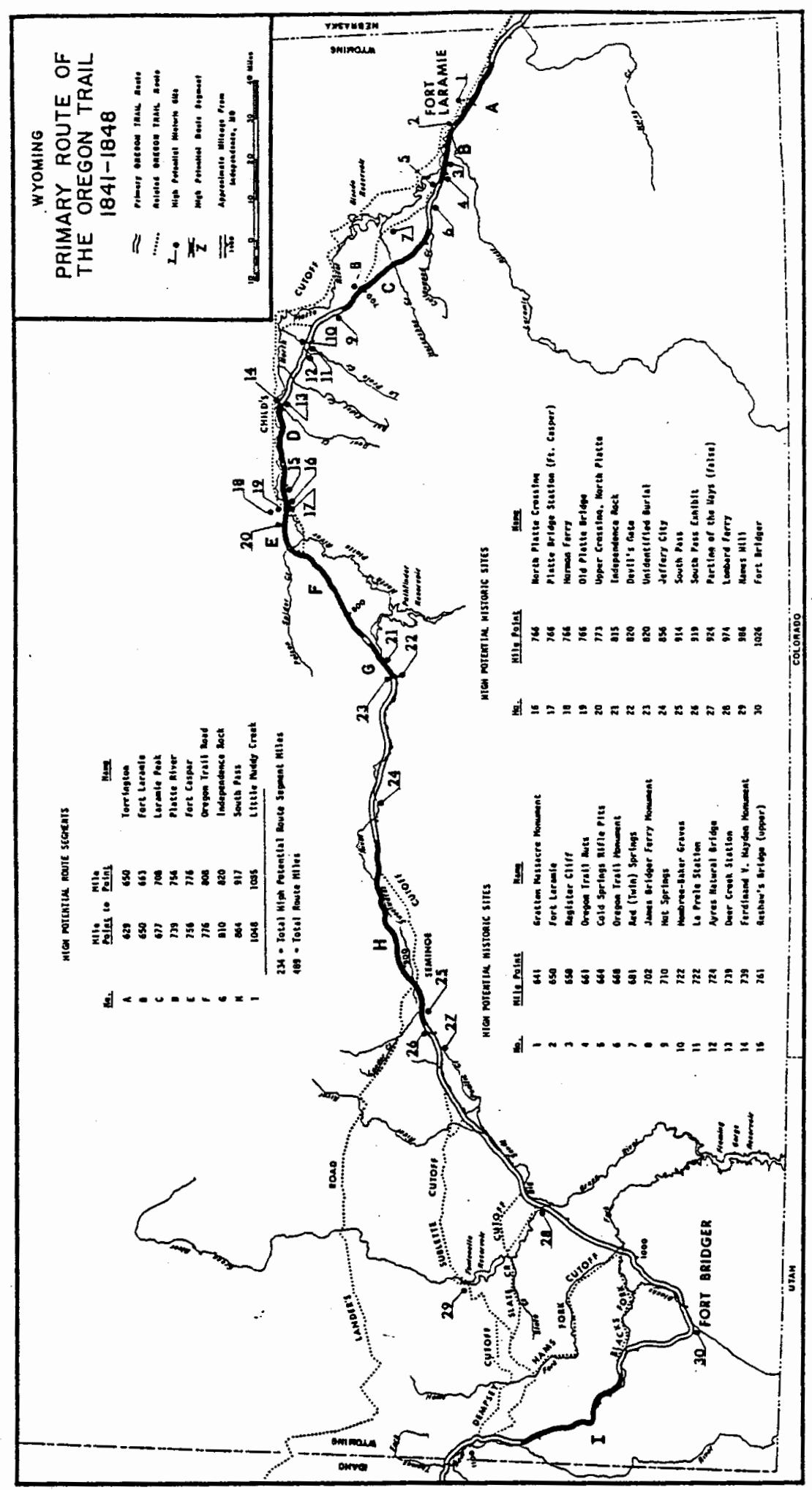




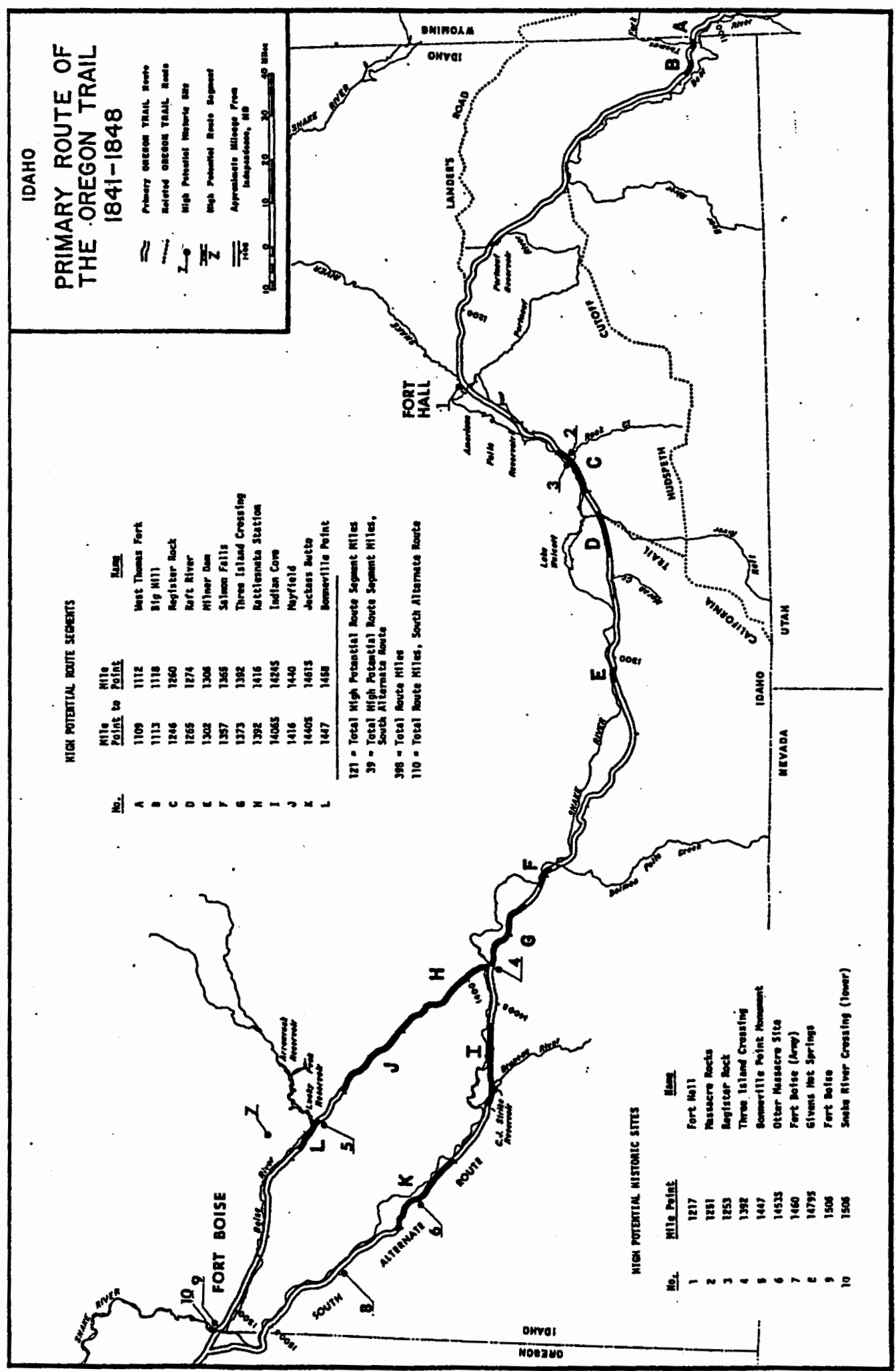




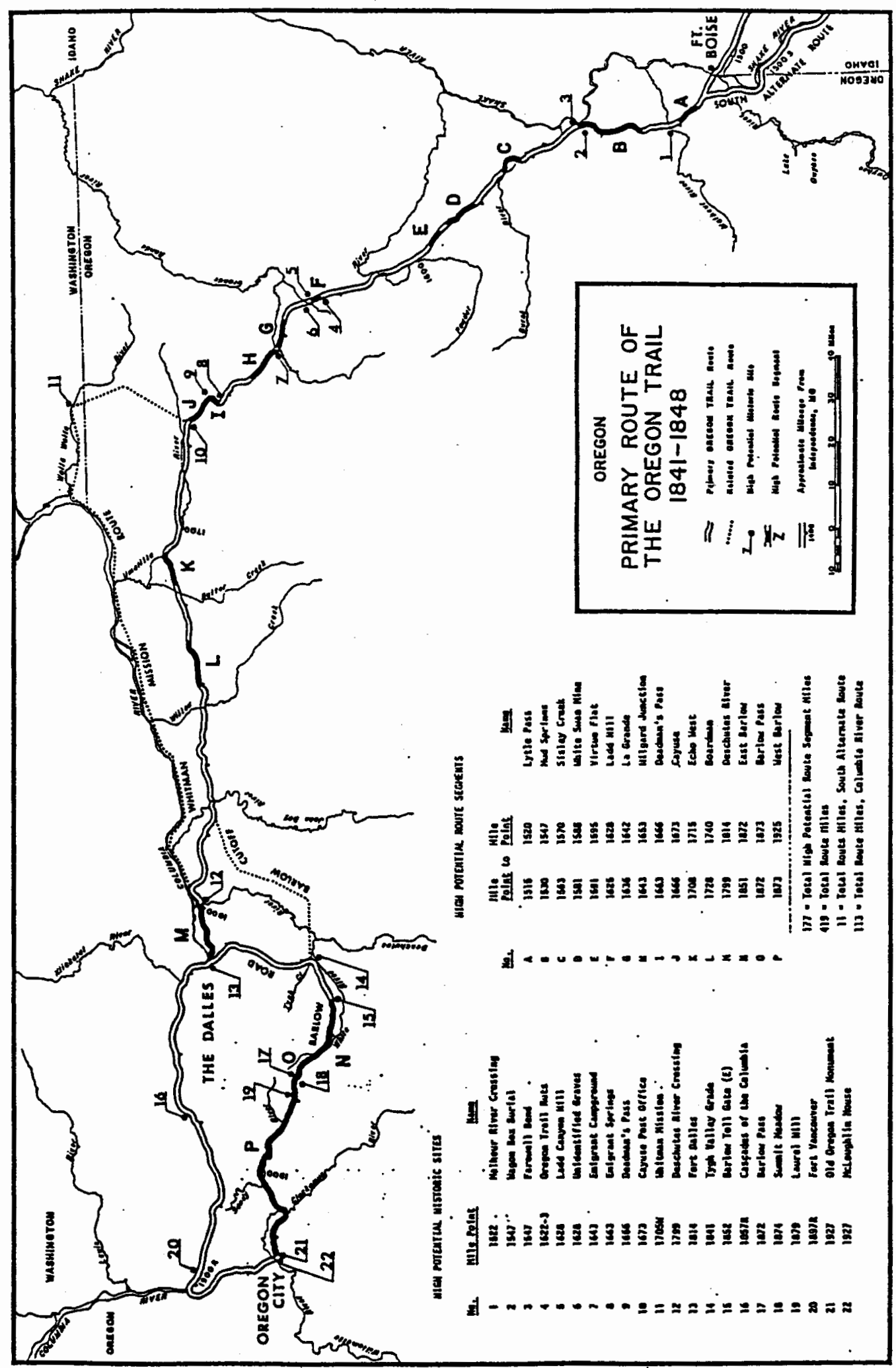




\section{REFERENCES}

Coffman, Lloyd W. 1993. Blazing a Wagon Trail to Oregon. Springfield, OR: Echo Books.

Fanselow, Julie. 1992. Travelling the Oregon Trail. Helena, Montana: Falcon.

Franzwa, Gregory M. 1990. Maps of the Oregon Trail. St. Louis, MO: The Patrice Press.

Franzwa, Gregory M. 1988. The Oregon Trail Revisited. 4ed. Tucson, AZ: The Patrice Press.

Hill, William E. 1992. The Oregon Trail. Yesterday and Today A Brief History and Pictorial Journey Along the Wagon Tracks of Pioneers. Caldwell, $\mathrm{OH}$ : The Caxton Printers, Ltd.

Rieck, Richard L. 1991. A Geography of Death on the Oregon-California Trail, 1840-1860. Overland Journal 11: 13-21.

Rieck, Richard L. 1993. Geography on the Overland Trails -- Part I. The Raveled Routes--Elevation, Plains and Mountains. Overland Journal 11: 12-22.

Rieck, Richard L. 1999. Geography of the Oregon Trail West of Fort Hall. A Plethora of Options. Overland Journal 17: 9-23.

United States Department of the Interior. 1981. Comprehensive Management and Use Plan. Oregon National Historic Trail. Appendix II Primary Route. Qregon National Historic Trail. United States Department of the Interior. National Park Service. August 1981. 